\title{
The Noncanonical Pathway for In Vivo Nitric Oxide Generation: The Nitrate-Nitrite-Nitric Oxide Pathway
}

\author{
V. Kapil, R. S. Khambata, D. A. Jones, K. Rathod, C. Primus, G. Massimo, J. M. Fukuto, and A. Ahluwalia
}

William Harvey Research Institute, Barts and The London School of Medicine and Dentistry, Queen Mary University London, London, United Kingdom (V.K., R.S.K., D.A.J., K.R., C.P., G.M., A.A.) and Department of Chemistry, Sonoma State University, Rohnert Park, California (J.M.F.)

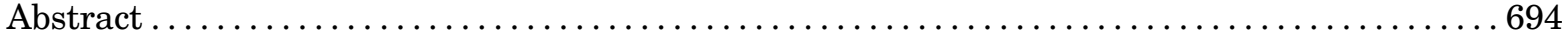

Significance Statement.................................................. 694

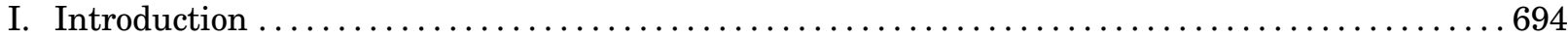

A. Chemistry of $\cdot \mathrm{NO}$ and Its Metabolism to Nitrite and Nitrate $\ldots \ldots \ldots \ldots \ldots \ldots \ldots \ldots \ldots 6 . \ldots \ldots 6$

II. Inorganic Nitrite and Nitrate ........................................ 697

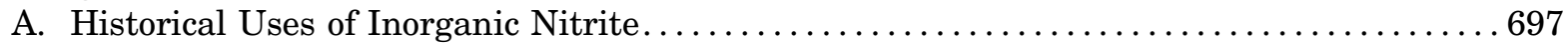

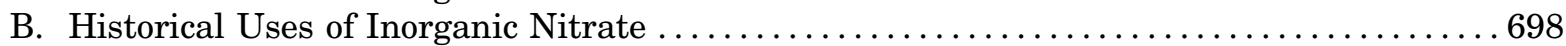

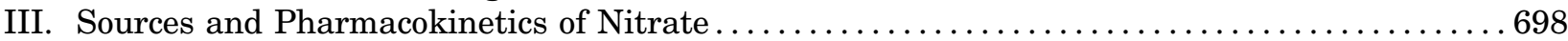

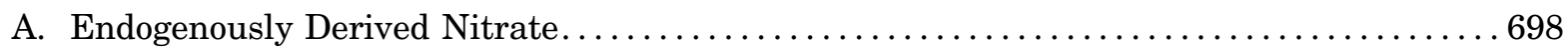

B. Exogenous Sources of Nitrate . . . . . . . . . . . . . . . . . . . . . . . . . . . . 699

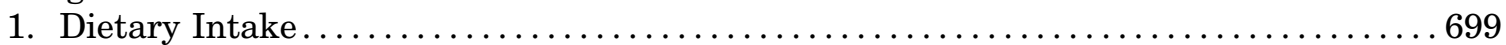

2. Water Supplies ................................................. 699

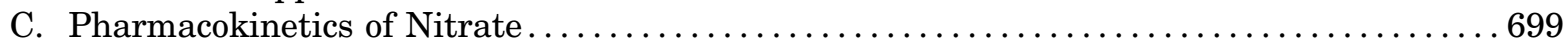

D. Enterosalivary Circulation and Oral Reduction of Nitrate . . . . . . . . . . . . . . . 700

E. Nitrate Reductases.................................................... 702

1. Prokaryotic Nitrate Reductases .......................................... 702

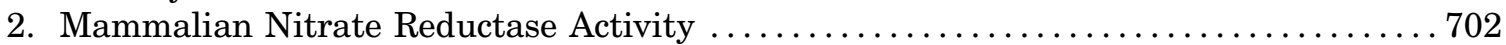

IV. Sources and Pharmacokinetics of Nitrite .................................. 703

A. Endogenously Derived Nitrite from the Enterosalivary Circuit $\ldots \ldots \ldots \ldots \ldots \ldots \ldots \ldots \ldots 703$

B. Endogenously Derived Nitrite from NOS Activity . . . . . . . . . . . . . . . . . . 704

C. Exogenous Sources of Nitrite . . . . . . . . . . . . . . . . . . . . . . . . . . . . . . . 704

D. Systemic Nitrite Absorption ........................................ 705

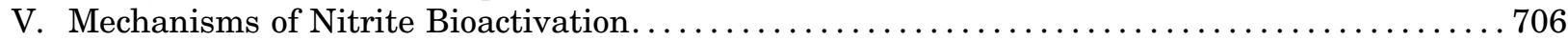

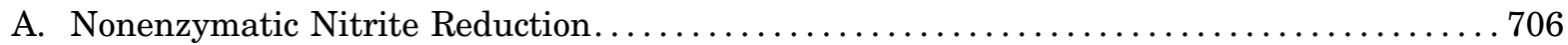

B. Mammalian Nitrite Reductases.................................... 706

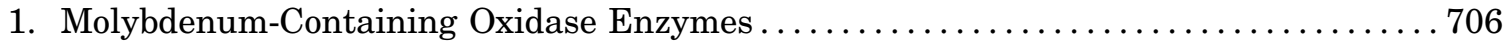

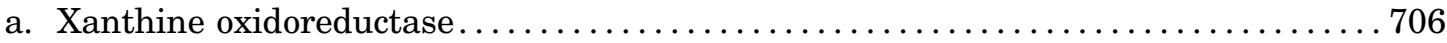

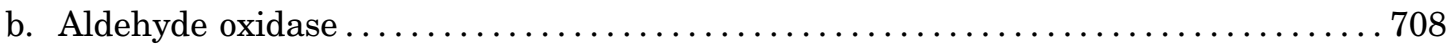

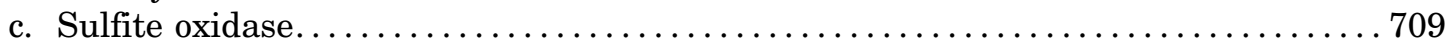

d. Mitochondrial amidoxime reducing component $\ldots \ldots \ldots \ldots \ldots \ldots \ldots \ldots \ldots \ldots$

2. Mitochondrial Respiratory Chain Enzymes ............................. 709

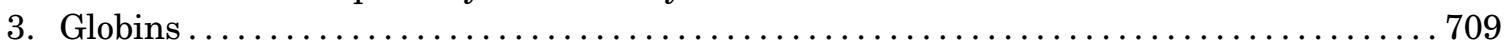

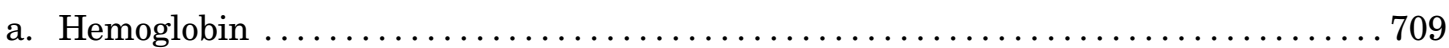

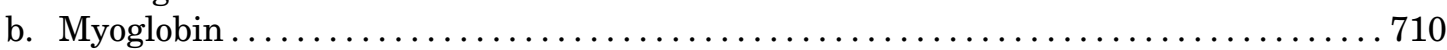

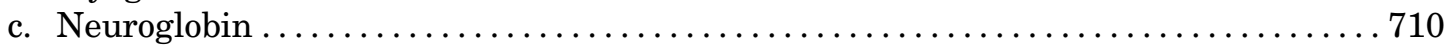

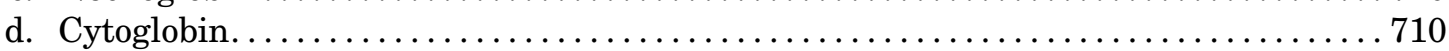

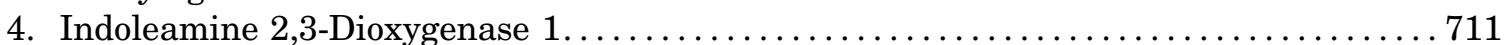

Address correspondence to: A. Ahluwalia, Centre for Cardiac Medicines and Device Innovation, William Harvey Research Institute, Charterhouse Square, London EC1M 6BQ, UK. E-mail: a.ahluwalia@qmul.ac.uk

V.K. and D.A.J. were supported by a Barts Charity Programme grant, C.P. by a Derek Willoughby clinical research training fellowship, and K.R. by a National Institute for Health Academic Clinical Lectureship award.

https://doi.org/10.1124/pr.120.019240. 


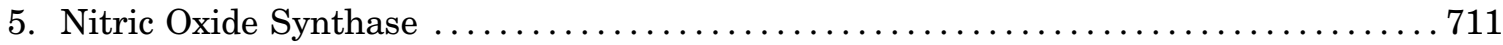

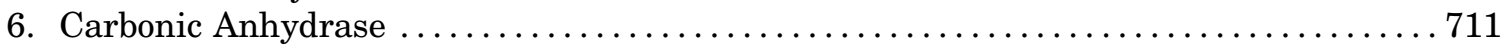

VI. Functional Effects of the Noncanonical 'NO Pathway and Clinical Translation ........... 712

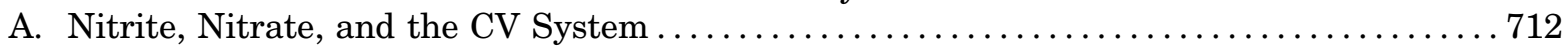

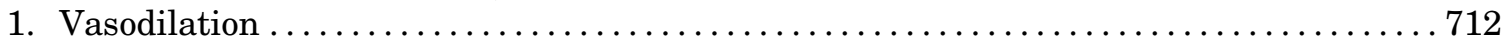

2. Blood Pressure ..................................................... 714

3. Enterosalivary Generation of Nitrite Regulates Basal BP ....................... 719

4. Endothelial Dysfunction ............................................ 720

5. Arterial Stiffness ............................................... 720

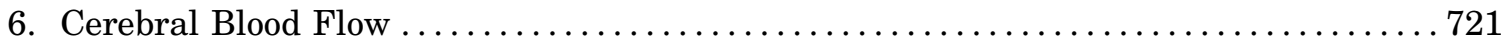

B. Nitrite and Nitrate in Exercise and Muscle Biology ......................... 721

1. Nitrate and Exercise Performance on Moderately Trained Athletes .............. 722

a. Mechanisms for enhanced exercise performance after nitrate supplementation . . . 723

2. Nitrate and Exercise Performance in Patient Populations.................... 724

3. Cardiac Muscle Function and Heart Failure ............................. 725

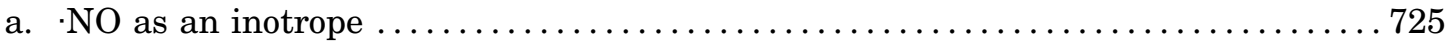

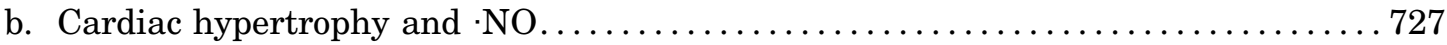

c. Positive inotropic and antihypertrophic effects of nitrite and nitrate $\ldots \ldots \ldots \ldots . \ldots 727$

d. Preclinical studies: cardiac dysfunction, nitrite, and nitrate $\ldots \ldots \ldots \ldots \ldots \ldots \ldots 727$

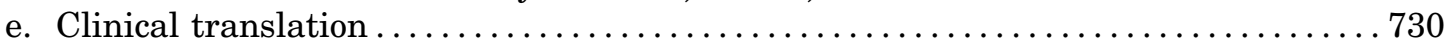

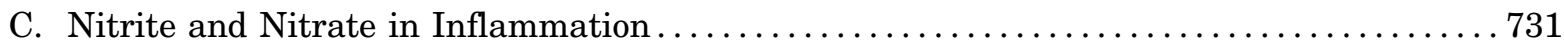

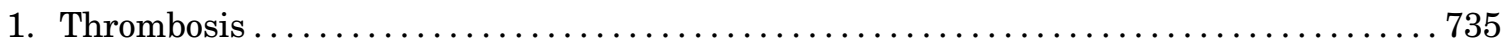

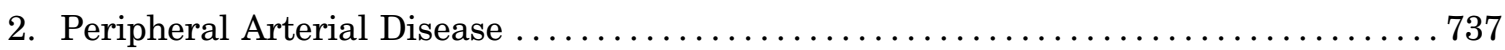

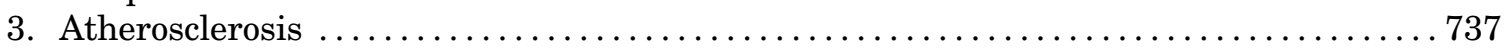

D. Nitrite and Nitrate in the Respiratory System $\ldots \ldots \ldots \ldots \ldots \ldots \ldots \ldots \ldots \ldots \ldots \ldots \ldots \ldots$

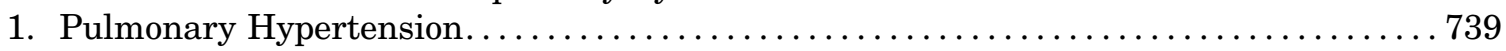

2. Chronic Obstructive Pulmonary Disease .......................... 740

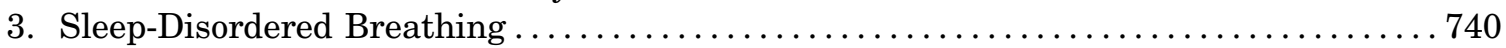

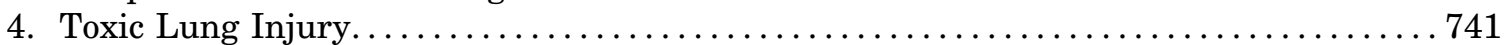

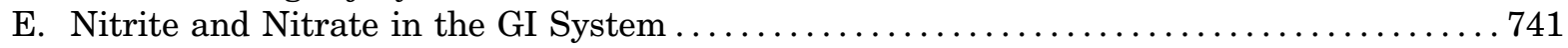

F. Nitrite and Nitrate in Metabolic Diseases. . . . . . . . . . . . . . . . . . . . . . . 742

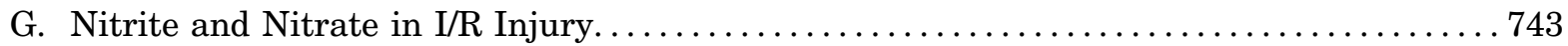

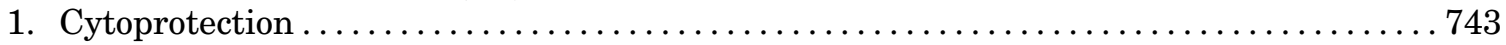

2. Potential Mechanisms for Nitrite-Induced Reduction in I/R Injury . . . . . . . . . 743

3. Potential Mechanisms for Nitrite-Induced Cytoprotection in I/R Injury ............ 744

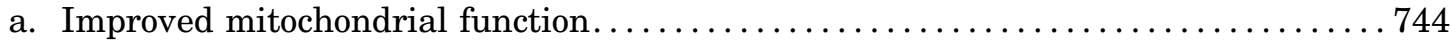

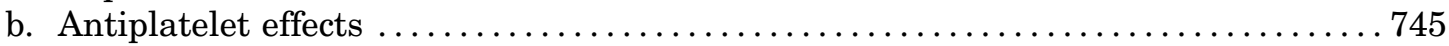

\begin{abstract}
ABBREVIATIONS: ABP, ambulatory blood pressure; ADI, acceptable daily intake; AMI, acute myocardial infarction; AMPK, AMPactivated protein kinase; AO, aldehyde oxidase; ApoE, apolipoprotein E; BNP, brain natriuretic peptide; BP, blood pressure; CABG, coronary artery bypass grafting; CCL2, chemokine (C-C motif) ligand 2; cGMP, cyclic GMP; COPD, chronic obstructive pulmonary disease; C-PTIO, 2(4-carboxyphenyl)-4,4,5,5-tetramethylimidazoline-1-oxyl-3-oxide; CV, cardiovascular; CVD, cardiovascular disease; CXCL2, chemokine (C-X-C motif) ligand 2; DASH, Dietary Approaches to Stop Hypertension; DBP, diastolic blood pressure; deoxyHb, deoxyhemoglobin; deoxyMb, deoxymyoglobin; dP/dt, rate of change of pressure; DOCA, deoxycorticosterone acetate; EDRF, endothelium-derived relaxing factor; eNOS, endothelial nitric oxide synthase; Fe(II), ferrous; Fe(III), ferric; FMD, flow-mediated dilation; GAG, glycosaminoglycan; GC-1, soluble guanylyl cyclase; GI, gastrointestinal; GTN, glyceryl trinitrate; HF, heart failure; HFpEF, heart failure with preserved ejection fraction; HFrEF, heart failure with reduced ejection fraction; ICAM-1, intercellular adhesion molecule-1; IDO1, indoleamine 2,3-dioxygenase 1; IL, interleukin; iNO, inhaled-NO; iNOS, inducible nitric oxide synthase; I/R, ischemia/reperfusion; $\mathrm{K}_{\mathrm{ATP}}$, ATP-sensitive $\mathrm{K}^{+}$; KO, knockout; L-NAME, $N(\gamma)-$-nitro-Larginine methyl ester; LV, left ventricular; LVEF, left ventricular ejection fraction; MAP, mean arterial pressure; mARC, mitochondrial amidoxime reductase; $\mathrm{Mb}$, myoglobin; MI, myocardial infarction; MRI, magnetic resonance imaging; -NO, nitric oxide; NOS, nitric oxide synthase; NOx, nitrate and nitrite; NSAID, nonsteroidal anti-inflammatory drug; NT-proBNP, N-terminal portion of BNP; NYHA, New York Heart Association of Heart Failure; ODQ, 1H-[1,2,4]oxadiazolo[4,3-a]quinoxalin-1-one; OSA, obstructive sleep apnea syndrome; oxyHb, oxyhemoglobin; oxyMb, oxymyoglobin; $p_{50}$, partial pressure to achieve $50 \%$ saturation; PAD, peripheral arterial disease; PAH, pulmonary arterial hypertension; PAP, pulmonary arterial pressure; PCI, percutaneous coronary intervention; PCr, phosphocreatine; PDE, phosphodiesterase; Pi, inorganic phosphate; PKG, protein kinase G; PVR, pulmonary vascular resistance; PWV, pulse wave velocity; rIPC, remote ischemic preconditioning; ROS, reactive oxygen species; R-state, relaxed state; SAH, subarachnoid hemorrhage; SBP, systolic blood pressure; SHR, spontaneously hypertensive rat; SO, sulfite oxidase; SR, strain rate; TAC, thoracic aortic constriction; TIMI, thrombosis in myocardial infarction; $\mathrm{TNF} \alpha$, tumor necrosis factor alpha; TUNEL, terminal deoxynucleotidyl transferase-mediated digoxigenindeoxyuridine triphosphate nick-end labeling; T-state, tense state; $\mathrm{VO}_{2}$, oxygen uptake; VASP, vasodilator-stimulated phosphoprotein; $\mathrm{VO}_{2 \max }$, maximal oxygen consumption; WHO, World Health Organization; WT, wild type; XOR, xanthine oxidoreductase.
\end{abstract}




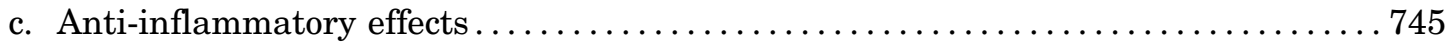

4. Nitrite as a Mediator of Remote Ischemic Preconditioning ................... 746

5. Translational Aspects ............................................ 746

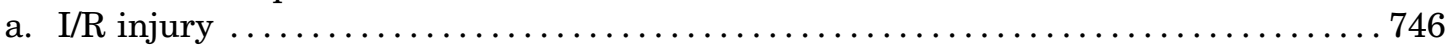

b. Humans models of I/R injury: transient endothelial dysfunction $\ldots \ldots \ldots \ldots \ldots \ldots 74$

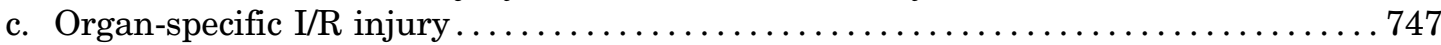

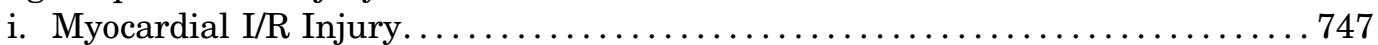

ii. Cardiopulmonary Surgery ..................................... 748

iii. Skeletal Muscle I/R Injury (Crush Syndrome) ........................ 749

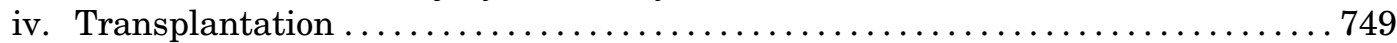

v. Global Ischemia (Cardiac Arrest) ................................. 749

VII. Concerns Regarding Nitrite- and Nitrate-Based Therapeutics . . . . . . . . . . . . . . . . 750

A. Epidemiologic Links to Possible Benefits of Dietary Nitrate . . . . . . . . . . . . . . 750

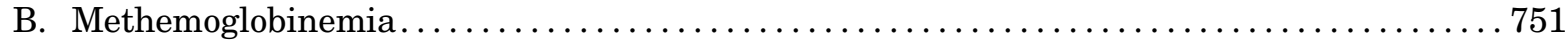

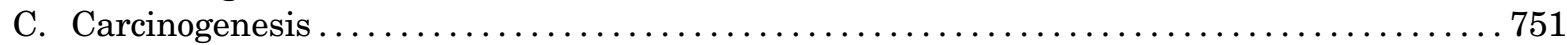

D. Pharmacokinetic Considerations considering Nitrite and Nitrate as $\cdot$ NO-Therapeutics _..752

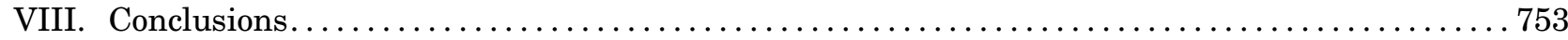

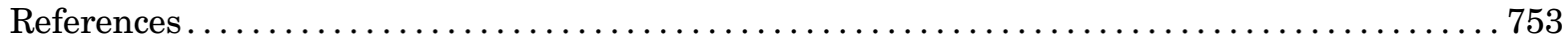

Abstract-In contrast to nitric oxide, which has well established and important roles in the regulation of blood flow and thrombosis, neurotransmission, the normal functioning of the genitourinary system, and the inflammation response and host defense, its oxidized metabolites nitrite and nitrate have, until recently, been considered to be relatively inactive. However, this view has been radically revised over the past decade and more. Much evidence has now accumulated demonstrating that nitrite serves as a storage form of nitric oxide, releasing nitric oxide preferentially under acidic and/or hypoxic conditions but also occurring under physiologic conditions: a phenomenon that is catalyzed by a number of distinct mammalian nitrite reductases. Importantly, preclinical studies demonstrate that reduction of nitrite to nitric oxide results in a number of beneficial effects, including vasodilatation of blood vessels and lowering of blood pressure, as well as cytoprotective effects that limit the extent of damage caused by an ischemia/ reperfusion insult, with this latter issue having been translated more recently to the clinical setting. In addition, research has demonstrated that the other main metabolite of the oxidation of nitric oxide (i.e., nitrate) can also be sequentially reduced through processing

\section{Introduction}

Nitric oxide $(\cdot \mathrm{NO})$ was discovered by the British chemist Joseph Priestley simultaneous with his discovery of oxygen in 1776 . For the next 200 years, -NO was largely thought of as an unwanted, atmospheric pollutant (Spicer, 1977). However, the discovery of mammalian NO production and its protean effects on biologic systems profoundly changed this view. The magnitude of the importance of this shift in view is reflected by the award of the Nobel Prize in Physiology or Medicine in 1998 to Furchgott, Ignarro, and Murad, which is shared for their seminal roles in the discovery "concerning NO as a signaling molecule in the cardiovascular system" (https://www.nobelprize.org/prizes/medicine/1998/ in vivo to nitrite and then nitrite to nitric oxide to exert a range of beneficial effects-most notably lowering of blood pressure, a phenomenon that has also been confirmed recently to be an effective method for blood pressure lowering in patients with hypertension. This review will provide a detailed description of the pathways involved in the bioactivation of both nitrate and nitrite in vivo, their functional effects in preclinical models, and their mechanisms of action, as well as a discussion of translational exploration of this pathway in diverse disease states characterized by deficiencies in bioavailable nitric oxide.

Significance Statement-The past 15 years has seen a major revision in our understanding of the pathways for nitric oxide synthesis in the body with the discovery of the noncanonical pathway for nitric oxide generation known as the nitrate-nitrite-nitric oxide pathway. This review describes the molecular components of this pathway, its role in physiology, potential therapeutics of targeting this pathway, and their impact in experimental models, as well as the clinical translation (past and future) and potential side effects. summary). A PubMed search of the term -NO identifies one publication in 1816, which describes the unfortunate event of poisoning with $\mathrm{NO}$ of quicksilver, rising to a colossal 6670 publications in 2017, with the highest number to date occurring in 2015 , with 7277 . These numbers clearly demonstrate that interest in this molecule and its biologic function really started to heat up after the seminal 1980 paper describing "The obligatory role of the endothelium..." and increasing exponentially after the Nobel Prize award. But perhaps more pertinently for this review, by the early 2000 s, interest in $\cdot \mathrm{NO}$, although still high, had plateaued until the more recent $5-10$ years, in which it is clear that there has been a sudden boost in interest. We suggest that this reignited interest comes in part from discoveries demonstrating 

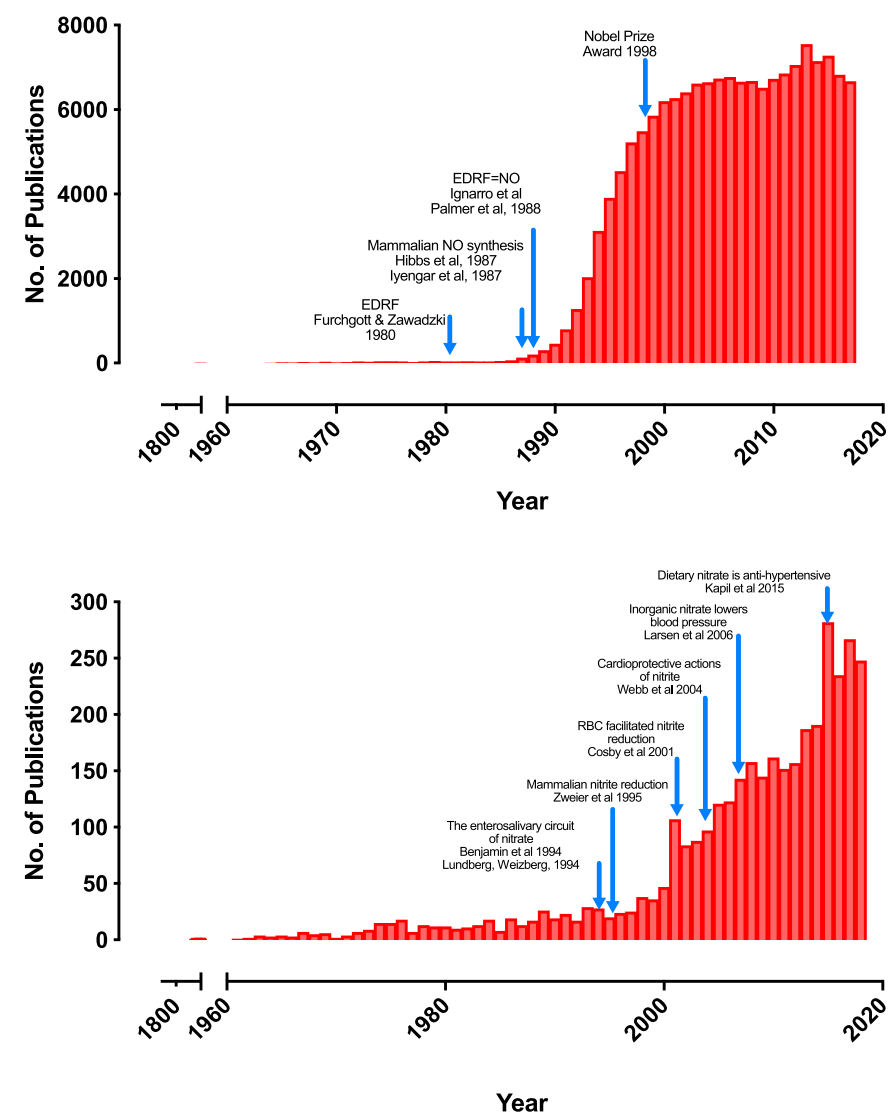

Fig. 1. Number of publications per year for (upper) -NO and (lower) nitrate and nitrite. Figures highlight only some of the key observations in the fields, and this is not an exhaustive list. Please see the text for greater detail. EDRF, endothelium derived relaxing factor.

the significant biologic activity of the nitrate-nitrite-NO pathway, which we now describe as the noncanonical pathway for in vivo $\mathrm{NO}$ generation. Moreover, it seems to us that interest in $\mathrm{NO}$, by virtue of these discoveries, is not going to abate any time soon (Fig. 1).

\section{A. Chemistry of $\cdot N O$ and Its Metabolism to Nitrite and Nitrate}

-NO is a small, diatomic, amphipathic, free-radical molecule that is freely diffusible and membranepermeable. Although one of the simplest biologic molecules, NO has relevant functions in almost every human physiologic system, including critical roles in neurotransmission, gastrointestinal (GI) physiology, genitourinary function, innate immunity, and the cardiovascular (CV) system (Moncada and Higgs, 1993).

There are three core properties of $\cdot \mathrm{NO}$ that determine its physical and chemical interactions and enable generation of a range of $\mathrm{NO}$ and other nitrogen species (Fig. 2): it is electrically neutral, it is small, and it has an unpaired electron in a nonbonding molecular orbital. The fundamental chemistry of $\cdot \mathrm{NO}$ is unique among all other small-molecule signaling agents. Since -NO possesses an unpaired electron (i.e., it is paramagnetic), it readily reacts with many other species that are also paramagnetic. For example, $\cdot \mathrm{NO}$ reacts with dioxygen $\left(\mathrm{O}_{2}\right)$, superoxide $\left(\cdot \mathrm{O}_{2}^{-}\right)$, and nitrogen dioxide $\left(\mathrm{NO}_{2}\right)$, as well as oxidizing carbon/nitrogen-centered radicals that would otherwise oxidize biologic molecules, potentially causing an "oxidative stress" (vide infra). Indeed, the ability of $\mathrm{NO}$ to react with and quench oxidizing radical species is the basis of its antioxidant properties.

-NO also reacts with transition metals and, therefore, in biologic systems, has numerous possible targets, i.e., molecules containing an iron heme moiety. The coordination chemistry of $\cdot \mathrm{NO}$ is unique compared with other small, diatomic molecules (e.g., $\mathrm{O}_{2}, \mathrm{CO}$ ) in that it can react with both ferric [Fe(III)] and ferrous [Fe(II)] heme proteins (that contain an open coordination site). Reaction with $\mathrm{Fe}$ (III)-hemes often results in reduction to $\mathrm{Fe}(\mathrm{II})$-hemes, with consequent generation of nitrite (Fukuto et al., 2000). The coordination of $\cdot \mathrm{NO}$ with $\mathrm{Fe}(\mathrm{II})$-heme typically leads to the formation of a relatively stable Fe(II)-NO complex. The primary biologic target for $\cdot \mathrm{NO}$ is, indeed, the $\mathrm{Fe}$ (II)-heme protein soluble guanylyl cyclase (Hobbs and Stasch, 2010) (GC-1, or more commonly known as sGC [Alexander et al., 2019]). Coordination of $\cdot \mathrm{NO}$ to the $\mathrm{Fe}(\mathrm{II})$-heme of GC-1 results in activation of the enzyme triggering generation of cyclic GMP (cGMP). Importantly, the coordination chemistry of $\cdot \mathrm{NO}$ with $\mathrm{Fe}$ (II)-hemes is unique among all small diatomics; thus, only $\cdot \mathrm{NO}$ is capable of significantly activating $\mathrm{GC}-1$ via heme coordination. $\mathrm{NO}$ can also react with $\mathrm{O}_{2}$ bound to $\mathrm{Fe}(\mathrm{II})$-heme [Fe(II)-hemeO $\mathrm{O}_{2}$, such as that found in oxyhemoglobin [oxyHb, $\mathrm{Fe}(\mathrm{II}) \mathrm{HbO}_{2}$ ] or oxymyoglobin [oxyMb, $\mathrm{Fe}(\mathrm{II}) \mathrm{MbO}_{2}$ ], to give ferric $\mathrm{Hb}$ or ferric myoglobin $(\mathrm{Mb})$ [ $\mathrm{Fe}(\mathrm{III}) \mathrm{Hb}, \mathrm{Fe}(\mathrm{III}) \mathrm{Mb}$, respectively] and nitrate, a reaction described first by Hermann (1865), cited in Gladwin et al. (2005) (eq. 1.1). Oxidative termination of $\mathrm{NO}$ activity with $\mathrm{Hb}$ is as follows:

\section{oxyHb nitric oxide metHb nitrate

$$
\mathrm{Fe}(\mathrm{II}) \mathrm{HbO}_{2}+\mathrm{NO} \Rightarrow \mathrm{Fe}(\mathrm{III}) \mathrm{Hb}+\mathrm{NO}_{3^{-}} .
$$

It is now understood that the reaction of $\cdot \mathrm{NO}$ with $\mathrm{Fe}$ (II) $\mathrm{HbO}_{2}$ is relatively fast and provides a sink $\left(6-8 \times 10^{7}\right.$

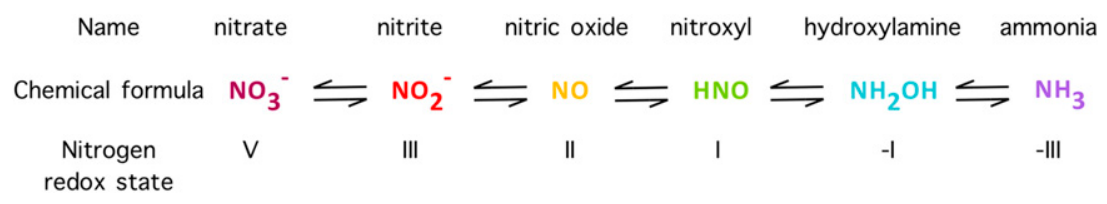

Fig. 2. Redox relationship of NO and other nitrogen species. 
$\mathrm{M}^{-1} \mathrm{~s}^{-1}$ ) for $\cdot \mathrm{NO}$ (Feelisch and Noack, 1987; Eich et al., 1996; Herold et al., 2001). Since this reaction is so fast, there were originally concerns that there was little chance of $\mathrm{NO}$ expressing functional activity in vivo (Lancaster, 1994); however, the discovery of a cell-free layer of blood flowing adjacent to the endothelium (Liao et al., 1999) and the recognition that the encapsulation of $\mathrm{Hb}$ within the erythrocyte limits the speed of the reaction because of the need for diffusion through the erythrocyte membrane (Liu et al., 1998; Vaughn et al., 1998, 2000; Han et al., 2002) have allayed these concerns, for the most part.

Like all biologic molecules, 'NO moves only insomuch that the probability of random diffusion is greater for movement into a compartment with a lower concentration, resulting in net movement along a concentration gradient. Hence, $\cdot \mathrm{NO}$ molecules move away from a specific point of generation. Since $\mathrm{NO}$ is electrically neutral, it has a high diffusion coefficient $\left[10^{-7} \mathrm{~cm}^{2} \mathrm{~s}^{-1}\right.$ (Vanderkooi et al., 1994)] (Malinski et al., 1993) and may travel far $(100-200 \mu \mathrm{m})$ in a short time frame (Lancaster, 1994, 1997); however, because of its numerous interactions with a number of diverse molecules (i.e., something to which it can chemically react), this can greatly reduce its sphere of biologic action (Lancaster, 1997).

-NO does not dimerize in gas or in solution and is poorly soluble in water $\left(1.57 \mathrm{mmol} \mathrm{dm}^{-3}\right.$ at $\left.35^{\circ} \mathrm{C}\right)$ (Hughes, 2008) and does not react with water (i.e., -NO is not electrophilic). $\mathrm{NO}$ is lipophilic, which allows it to freely enter and accumulate in cell membranes. Although 'NO has been characterized as a "highly reactive" molecule, it is inherently stable in the pure form. However, it can react readily with specific species, such as those that also possess an unpaired electron. As discussed previously, the unpaired electron of $\cdot \mathrm{NO}$ makes it reactive with other paramagnetic species, including $\mathrm{O}_{2}, \mathrm{NO}_{2}$ (Bonner and Hughes, 1988; Ignarro et al., 1993), superoxide (Blough and Zafiriou, 1985), of $\mathrm{NO}$ with $\mathrm{O}_{2}$ initially leads to the formation of $\mathrm{NO}_{2}$, which is also a radical that is a relatively strong oxidant and, like $\cdot \mathrm{NO}$, will also react with other radicals such as $\cdot \mathrm{NO}$. The reaction of $\mathrm{NO}$ and $\mathrm{NO}_{2}$ results in the formation of $\mathrm{N}_{2} \mathrm{O}_{3}$ (a nonradical species). In a purely aqueous system, $\mathrm{N}_{2} \mathrm{O}_{3}$ can react with water to give nitrite. This series of chemical reactions is shown below (eq. 1.2). Oxidation of NO in aqueous solutions is as follows:

\section{dioxygen nitric oxide nitrogen dioxide $\mathrm{O}_{2}+2 \mathrm{NO} \quad \Rightarrow \quad \mathbf{2} \mathbf{N O}_{2}$}
nitrogen dioxide nitric oxide dinitrogen trioxide $\begin{array}{llll}\mathrm{NO}_{2} & +\mathrm{NO} & \Rightarrow & \mathbf{N}_{2} \mathrm{O}_{3}\end{array}$

$\begin{array}{lll}\text { dinitrogen trioxide } & \text { water } & \text { nitrite } \\ \mathrm{N}_{2} \mathrm{O}_{3} & +\mathbf{H}_{2} \mathrm{O} \Rightarrow \mathbf{N O}_{2^{-}}+2 \mathbf{H}^{+}\end{array}$

At biologically relevant levels of $\cdot \mathrm{NO}$, this process is very slow, as the overall reaction kinetics are second order with respect to $\mathrm{NO}$, making the $\mathrm{O}_{2}$-dependent oxidation of $\cdot \mathrm{NO}$ to nitrite of limited importance ( $\mathrm{Li}$ and Lancaster, 2012). In pure aqueous solutions, $\mathrm{NO}$ is slowly converted to nitrite, although there is evidence in humans of a nitrite synthase function of the multifunction copper-containing protein caeruloplasmin facilitating this reaction (Shiva et al., 2006). The importance of this reaction in vivo for termination of $\mathrm{NO}$ activity and regulating basal $\cdot \mathrm{NO}$ levels is currently unclear. The same reactivity of $\cdot \mathrm{NO}$ for transition metals has spurred interest in developing transition metal-based scavengers of $\cdot \mathrm{NO}$, such as ruthenium complexes that are being developed for use in situations in which large amounts of inducible $\mathrm{NO}$ synthase (iNOS)-derived $\mathrm{NO}$ may be detrimental, such as in tumor growth (Flitney et al., 2011).

In addition, and of particular relevance to this review, is the potential for reduction of nitrite by deoxyHb

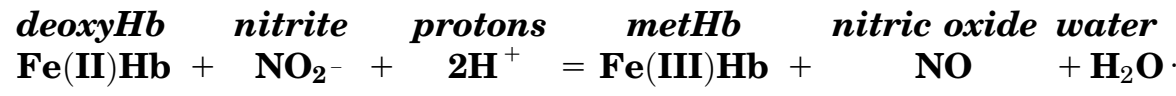

and other "radicals," such as those involved in deleterious oxidative events (Rubbo et al., 1996). In spite of the fact that $\cdot \mathrm{NO}$ possesses an unpaired electron (and is considered to be a "radical" species), it is important to note that it is not an oxidizing radical (i.e., it does not readily take electrons or abstract $\mathrm{H}$-atoms) and, therefore, is distinct from other known radical oxidants, such as $\mathrm{NO}_{2}$ or hydroxyl radical (HO-). Indeed, besides coordination to metals, $\mathrm{NO}$ tends to react only with other radicals that already exist or have been preformed in solution (e.g., $\mathrm{O}_{2}$, superoxide, $\mathrm{NO}_{2}$, etc.). The reaction
[Fe(II)Hb] to give $\cdot \mathrm{NO}$ (Cosby et al., 2003; Huang et al., 2005b; Grubina et al., 2007), described below (eq. 1.3). The reaction of $\mathrm{NO}_{2-}$ with deoxyHb is as follows:

However, how -NO derived from nitrite reduction within the erythrocyte in the presence of an excess of oxyHb (even in relative hypoxia), a rapid $\mathrm{NO}$ scavenger, escapes the erythrocyte is not clear. Some have suggested that NO bioactivity is exported from erythrocytes as dinitrogen trioxide after a nitrite anhydrase reaction involving $\mathrm{Hb}$ (eqs. 1.4-1.6) and that, once 
outside, the erythrocyte can dissociate to $\mathrm{NO}$ and nitrogen dioxide (Basu et al., 2007; Hopmann et al., 2011). It should be noted that $\mathrm{NO}$ made via these reactions represents a disproportionation (one species is oxidized, whereas the other is reduced) and not an overall reduction reaction. $\mathrm{NO}_{2-}$ acidification to form $\mathrm{HNO}_{2}$ is as follows:

$$
\begin{gathered}
\text { nitrite } \\
\mathrm{NO}_{2}
\end{gathered}+\begin{gathered}
\text { proton } \\
\mathbf{H}^{+}
\end{gathered} \Leftrightarrow \begin{gathered}
\text { nitrous acid } \\
\mathrm{HNO}_{2}
\end{gathered} .
$$

Dehydration of $\mathrm{HNO}_{2}$ is

$$
\begin{gathered}
\text { nitrous acid } \\
2 \mathrm{HNO}_{2}
\end{gathered} \Leftrightarrow \mathrm{H}_{2} \mathbf{O}+\underset{\mathbf{N}_{2} \mathbf{O}_{3}}{\text { wateride }}
$$

$\mathrm{N}_{2} \mathrm{O}_{3}$ dissociation to $\mathrm{NO}$ is

$$
\begin{array}{cccc}
\text { dinitrogen trioxide nitric oxide nitrogen dioxide } \\
\qquad \mathbf{N}_{2} \mathbf{O}_{3} & \Leftrightarrow & \mathrm{NO} & +
\end{array} \mathrm{NO}_{2} .
$$

Since the early proposals that $\mathrm{Hb}$ may be a site for nitrite reduction, a number of other nitrite reductases have been identified, and these and the chemistry involved are discussed in more detail in this review.

It is worthwhile to briefly discuss the potential for nitrite to be generated via the reactions of $\cdot \mathrm{NO}$ with $\mathrm{O}_{2}$-derived species such as superoxide. Although it was previously thought that the reaction of $\cdot \mathrm{NO}$ with superoxide was of toxicological/pathophysiological concern, since the product, peroxynitrite $\left(\mathrm{ONOO}^{-}\right)$, is a potential oxidant, this idea has not been well supported. The generation of peroxynitrite from this reaction may simply serve to limit the signaling associated with $\cdot \mathrm{NO}$ and/or superoxide. However, it is also worth considering that the $\cdot \mathrm{NO} /$ superoxide reaction can serve as a source of nitrite since peroxynitrite in the presence of excess $\mathrm{NO}$ or superoxide will lead to the formation of nitrite (Jourd'heuil et al., 2001).

Thus, unless $\mathrm{NO}$ and superoxide were generated at the same time, same flux, and in the same place in a cell (a highly unlikely scenario), nitrite generation will be the primary fate of this reaction. This also indicates that the spatial and temporal aspects of nitrite generation (via the $\cdot \mathrm{NO} /$ superoxide reaction) can be governed by the place and time of reactive oxygen species (ROS) [superoxide via xanthine oxidoreductase (XOR), for example] and 'NO generation. Moreover, it has been reported that $\mathrm{NO}$ can be metabolized by cells to give nitrite (Thomas et al., 2001) (although the chemical reactions responsible for the cellular conversion of -NO to nitrite have not been established). Finally, just as the formation of nitrite from $\mathrm{NO}$ can be dependent on the timely and localized generation of ROS, the reverse process (formation of $\cdot \mathrm{NO}$ from nitrite) can also be dependent on $\mathrm{O}_{2}$ and $\mathrm{O}_{2}$-derived species as well (Wink, 2003).

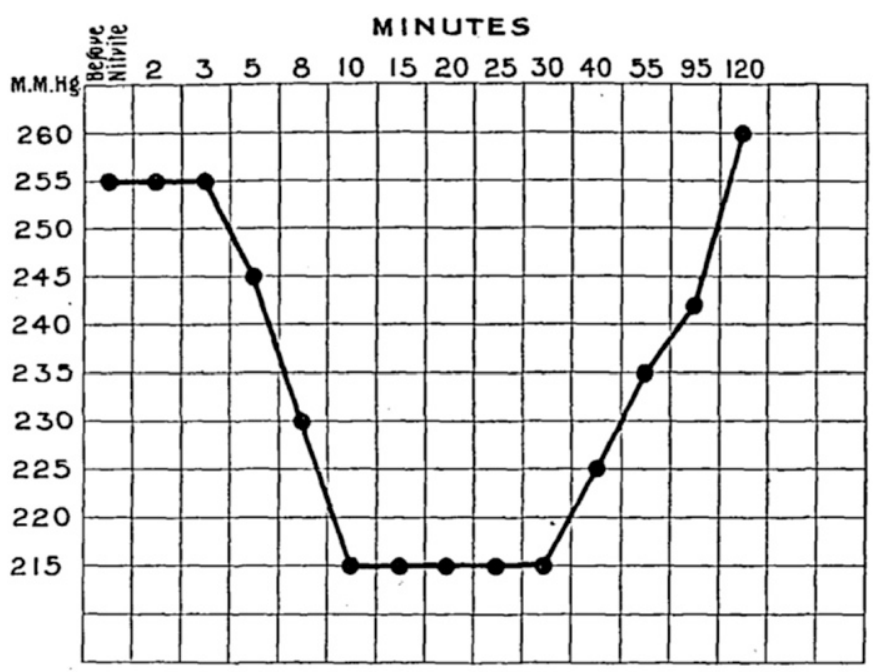

2 GRAINS SODIUM NITRITE

Fig. 3. Oral inorganic nitrite and acute BP response (Matthew, 1909).

\section{Inorganic Nitrite and Nitrate}

\section{A. Historical Uses of Inorganic Nitrite}

The use of nitrovasodilators by Lauder Brunton and Murrell led to the exploration of related chemicals that included salts of inorganic nitrite. Below are the words that Reichert used to start his detailed monograph on the actions of potassium nitrite to explain why he was using a related substance to amyl nitrite (Reichert and Mitchell, 1880):

"The very great value of amyl nitrite in warding off impending paroxysms of epileptic convulsions, angina pectoris, and asthma, has been so generally recognized by the profession, that the discovery of a new salt whose physiological action is identical with... that of amyl nitrite, but whose effects would be more permanent and therefore suitable for maintaining a continuous systemic influence, we would have an addition to our materia medica which would fill a very apparent therapeutic void."

The experiments that Reichert was describing in this work demonstrated that, in dogs and cats, potassium nitrite caused profound hypotension, leading to death, and perhaps more importantly, that in humans potassium nitrite had a synonymous effect to the organic amyl nitrite (Reichert and Mitchell, 1880). These observations were followed by a detailed comparative analysis of the effects of sodium nitrite and organic nitrites, including amyl nitrite and glyceryl trinitrate (GTN). In normotensive subjects, the blood pressure (BP)-lowering effects of organic nitrites and nitrates were observed for up to 30 minutes postadministration, but a similar level of $\mathrm{BP}$ reduction was maintained for up to 60 minutes after inorganic nitrite dosing, indicating some differences in biologic activity between the two compound classes. The effects of sodium nitrite were much larger in patients with significant hypertension (see Fig. 3), with maximal systolic $\mathrm{BP}(\mathrm{SBP})$ reductions up to $50 \mathrm{~mm} \mathrm{Hg}$ 
(Matthew, 1909; Wallace and Ringer, 1909). It was after this, in the early part of the 20th century, that inorganic nitrite was used for the treatment of BP appearing in materiae medicae and being produced by several pharmaceutical suppliers for the treatment of patients with hypertension (Butler and Feelisch, 2008). This occurred despite an absence of a clear understanding of the mechanisms involved. However, the use of nitrite salts for BP management never really took off, and this relates to concerns regarding the reactions between nitrite and oxyHb generating metHB (eq. 1.3). If metHB levels rise $>10 \%$, the fraction of bound oxygen to $\mathrm{Hb}$ becomes insufficient for metabolic demand, thus provoking symptomatic hypoxemia despite adequate oxygenation (Skold et al., 2011). Indeed, concerns relating to this continue to be raised in relation to the use of both organic and inorganic nitrites in clinical practice (Pierce and Nielsen, 1989; Finan et al., 1998; Modarai et al., 2002).

\section{B. Historical Uses of Inorganic Nitrate}

Inorganic nitrate has been used in traditional Chinese medicine to treat cardiovascular disease (CVD) for over a millennium. The following passage is a translation from an 8th century CE manuscript discovered in the Mogao caves in Gansu Province, China (Butler and Moffett, 2005):

"Putting under the tongue to cause heart qi to flow freely for treating symptoms such as struck by evil, acute heart pains and cold in the hands and feet which can kill a patient in an instant. Look at the patient's fingers and those with greenish-black nails are such cases. Take saltpeter [xiaoshi, potassium nitrate] (five measures of a bi spoon) and realgar [xiongshi, arsenic sulphide] (one measure of a bi spoon) and combine the two into a fine powder. Lift the patient's tongue and sprinkle one measure of a bi spoon under the tongue. If saliva is produced, have the patient swallow it. This is a certain cure."

Interestingly, the comment regarding the production of saliva and the importance of swallowing appears to relate to knowledge of the bioactivation of inorganic nitrate by the oral microbiota (see below). Although it is difficult to tell whether there was widespread use of inorganic nitrate in traditional Chinese medicine over the proceeding centuries, it was much later, in the early 20th century, that Western physicians explored the utility of the same chemicals. Edward Stieglitz produced a body of work in Chicago with bismuth subnitrate [chemical formula: $\mathrm{Bi}_{5} \mathrm{O}(\mathrm{OH})_{9}\left(\mathrm{NO}_{3}\right)_{4}$ ]. At that time, bismuth subnitrate was being used as an established and recommended treatment of peptic ulcer disease and diarrhea, with the caveat and caution against prolonged use because of the risk of hypotension (Frick, 1924). Stieglitz was aware of evidence from bacteriologists that enteric bacteria could convert nitrate to nitrite (Salen, 1925; Zobell, 1932). He thus proposed the following (Stieglitz, 1927):
"The idea to use bismuth subnitrate as an auxiliary to break the vicious circle of vascular fatigue arose from the observation of three cases of nitrate poisoning resulting from the liberal use of bismuth subnitrate in severe diarrhoeas... Therefore, theoretically, small frequent doses should lead to the liberation of small amounts of nitrite, uniformly and continuously absorbed. The effect of this is quite different from the violent, very transient vasodilatory effect of other forms of nitrite, such as nitroglycerol, amyl nitrite and sodium nitrite. The action to be expected is a gradually increasing vascular relaxation, with localized physiological rest to the arteriolar musculature."

He reported, in almost 1000 patients, sustained hypotensive effects of bismuth subnitrate (Stieglitz, 1927, 1928, 1930, 1932). Furthermore, he determined that, although the basal level of nitrite in blood was 110$220 \mathrm{nmol} / \mathrm{l}$, this was increased after an inorganic nitrate load and that, although nitrite was not a normal constituent of fresh urine, it could be detected after an oral inorganic nitrate load (Stieglitz and Palmer, 1934, 1936, 1937). Lastly, he expended much effort exploring the nitrate-reducing activity of bacteria in vitro, resulting with his hypothesis that bacterial nitrate reduction might be responsible for significant physiologic effects in vivo (Stieglitz and Palmer, 1936). There was not widespread uptake of this therapy, in part because of concerns regarding methemoglobinemia (Comly, 1945; Walton, 1951) and the prevailing view that nitrate was an inert end product of oxidative $\cdot$ NO metabolism (Bonner and Hughes, 1988; Ignarro et al., 1993). However, of course, all of this changed in the late 2000s with the realization that nitrate via the noncanonical pathway offers an alternative approach to -NO delivery and potential BP lowering.

\section{Sources and Pharmacokinetics of Nitrate}

There are two major sources of nitrate in humans, i.e., through the oxidation of ' $\mathrm{NO}$ and directly from exogenously derived (environment and diet) sources.

\section{A. Endogenously Derived Nitrate}

Assessments of the contribution of endogenously derived nitrate to daily bodily exposure has suggested that $\sim 25 \%$ of bodily nitrate comes from endogenous sources (Green et al., 1981). Plasma nitrate levels in healthy, fasted persons have been shown to be in the order of 20 $40 \mu \mathrm{mol} / \mathrm{l}$ (Gladwin et al., 2000; Lundberg and Govoni, 2004; Webb et al., 2008b). In long-term nitrogen balance studies lasting 3 months, in healthy participants given $<180 \mu \mathrm{mol}$ nitrate daily, endogenous nitrate biosynthesis estimated from 24-hour urine collection was between 0.5 and $1 \mathrm{mmol}$ daily (Green et al., 1981), although with the contribution of iNOS in inflammatory states, this can be much higher (Stichtenoth et al., 1994). 


\section{B. Exogenous Sources of Nitrate}

Humans are exposed to exogenously derived nitrate on a daily basis. There are two primary sources: drinking water and diet.

1. Dietary Intake. The predominant dietary source of nitrate comes from vegetable intake. Using the World Health Organization (WHO) recommended intake of mixed vegetables of $400 \mathrm{~g}$ daily as a guide would lead to a total daily nitrate intake of $\sim 2.5 \mathrm{mmol}$, although in reality, most people consume less than this, with estimates at 1.5-2 mmol (or 93-124 mg) nitrate daily (World Cancer Research Fund/American Institute for Cancer Research, 2007; European Food Safety Authority, 2008). However, in vegetable-rich diets, such as the proposed diet based upon the Dietary Approaches to Stop Hypertension (DASH) study, estimates suggest that intake levels can easily be increased to somewhere in the region of 6-20 mmol daily (Hord et al., 2009). Other dietary patterns, such as the traditional Japanese diet, may also have significantly higher nitrate intakes (Sobko et al., 2010) compared with European or United States diets. This variation in intake is driven by the differences in nitrate levels found in vegetables. In general, large green leafy vegetables contain the largest amounts of nitrate per gram (European Food Safety Authority, 2008), and this source is thought to be responsible for the elevated amounts consumed within the traditional Japanese diet. Importantly, because of concerns associated with toxicity (see later), the WHO has set an acceptable daily intake (ADI) recommendation for dietary nitrate at $3.7 \mathrm{mg} / \mathrm{kg}$ daily, which equates to $\sim 4 \mathrm{mmol}$ nitrate daily for an average $70-\mathrm{kg}$ person (European Food Safety Authority, 2008).

2. Water Supplies. Because of historical concerns regarding toxicity from nitrate in drinking water supplies, mostly concerning the risk of infantile methemoglobinemia (see later), there exists regulatory control of the nitrate level in water at $<50 \mathrm{mg} / \mathrm{l}$ (U.S. Public Health Service, 1962). The levels of nitrate in drinking water derived from surface water do not exceed $10 \mathrm{mg} / \mathrm{l}$ in most countries. In such conditions, the contribution of drinking water to nitrate intake is usually less than 14\% (World Health Organization, 2011), and therefore, vegetables are the main source of nitrate intake (Chilvers et al., 1984; European Centre for Ecotoxicology and Toxicology of Chemicals, 1988).

In some particularly agricultural areas, however, concentrations of nitrate in drinking water are higher because of runoff and the discharge of sewage effluent and certain industrial wastes. In 15 European countries, evidence was shown indicating that the percentage of the population exposed to nitrate levels in drinking water above $50 \mathrm{mg} / \mathrm{l}$ ranged from $0.5 \%$ to $10 \%$ (European Centre for Ecotoxicology and Toxicology of Chemicals, 1988). Individual wells in agricultural areas throughout the world often contain drinking water with nitrate levels exceeding $50 \mathrm{mg} / \mathrm{l}$ (World Health Organization, 2011), and in such circumstances, drinking water will be the major source of total nitrate intake, especially for bottle-fed infants (World Health Organization, 2011).

\section{Pharmacokinetics of Nitrate}

After the oral ingestion of nitrate, it is rapidly absorbed across the upper GI tract (Hawksworth and Hill, 1971; Witter et al., 1979; Miyoshi et al., 2003) and does not undergo transformation with firstpass metabolism, thereby having almost $100 \%$ bioavailability (van Velzen et al., 2008). It is not clear how nitrate is able to cross the upper GI tract, and no putative mechanism or transporter has been identified to date.

After ingestion of a single inorganic nitrate load as a salt or in dietary form (i.e., vegetable), significant elevation in circulating plasma nitrate levels can be detected within 15 minutes, with peak levels achieved by 30-60 minutes postdose (McKnight et al., 1997; Lundberg and Govoni, 2004; van Velzen et al., 2008; Webb et al., 2008b). The effective half-life for nitrate in the plasma after consumption of different vegetable sources is $\sim 6$ hours (van Velzen et al., 2008), with a slow reduction over time and significant elevation in circulating plasma nitrate levels even 24 hours postsingle-dose administration (Webb et al., 2008b; Kapil et al., 2010).

The fate of nitrate in the plasma is 2-fold. Studies with radiolabeled $\left[{ }^{15} \mathrm{~N}\right]$ nitrate reveal that two-thirds is excreted in the urine. Peak excretion of nitrate occurs $\sim 6$ hours after supplementation with small amounts and has been accounted for in sweat (up to $10 \%)$ or feces $(<1 \%)$ (Green et al., 1981; Wagner et al., 1983, 1984; Bartholomew and Hill, 1984; Packer et al., 1989; Pannala et al., 2003). Nitrate is freely filtered at the glomerulus, and clearance from the plasma has been estimated as $\sim 20 \mathrm{ml} / \mathrm{min}$ in healthy subjects (Wennmalm et al., 1993). This relatively low rate of clearance (taking into consideration that a normal glomerular filtration rate is between 100 and $125 \mathrm{ml} / \mathrm{min}$ ) suggests that much of the filtered nitrate is reabsorbed and explains its relatively long half-life (Kahn et al., 1975; Rahma et al., 2001).

As such, renal reabsorption of nitrate increases with increasing filtered nitrate level, with no clear transport limit (Godfrey and Majid, 1998). In clearance experiments, both mannitol and furosemide inhibited tubular reabsorption of nitrate, suggesting that nitrate reabsorption occurs across the whole tubule. Further stopflow experiments also suggest that nitrate is avidly reabsorbed at the same location as sodium in the distal tubule, suggesting cotransport (Rahma et al., 2001), although the transporters for such action have not been identified, and this remains one of the major unknowns in the field. 


\section{Enterosalivary Circulation and Oral Reduction of Nitrate}

The remaining $(\sim 25 \%)$ of nitrate that is not excreted by the kidneys is selectively taken up by the salivary glands (Spiegelhalder et al., 1976; Tannenbaum et al., 1976; Kortboyer et al., 1994) via the two-nitrate/oneproton electrogenic cotransporter sialin (Qin et al., 2012). This reuptake of nitrate is often described as the enterosalivary circulation of nitrate (Duncan et al., 1995). Salivary nitrate levels at baseline are $>10$-fold higher than circulating plasma nitrate levels (Spiegelhalder et al., 1976; Lundberg and Govoni, 2004), indicating a concentration of nitrate within the oral cavity. This circuit of nitrate is a relatively quick process; within 20-60 minutes post-inorganic nitrate load, an elevation in salivary nitrate levels is detectable (Harada et al., 1974; Ishiwata, 1976b; McKnight et al., 1997).

These early studies demonstrated that in addition to these rises in salivary nitrate with oral nitrate dosing, rises in the chemically related but distinct anion nitrite occur hand in hand. It is noteworthy that the primary aim of these investigations was to determine whether nitrate ingestion might result in sufficient nitrite generation to lead to formation of $N$-nitroso compounds linked to carcinogenesis (Harada et al., 1974; Tannenbaum et al., 1974, 1976; Eisenbrand et al., 1980). Studies have shown that there is no nitrite in saliva taken directly from salivary gland ducts, as opposed to mixed saliva in the oral cavity, indicating that conversion of nitrate to nitrite within the oral cavity, and not within the salivary glands, was responsible for salivary nitrite levels. It was in 1975 that it was first suggested that the appearance of nitrite within the saliva may be due to the activity of nitrate-reducing bacteria within the oral cavity (Ishiwata et al., 1975d). It was known at that time that bacteria existing in the lower GI tract (Salen, 1925; Zobell, 1932; Stieglitz and Palmer, 1936) could use nitrate as a terminal electron donor in respiration instead of oxygen and, thereby, reduce nitrate to nitrite (MorenoVivián et al., 1999; Lundberg et al., 2004). In addition, consumption of nitrate and corresponding formation of nitrite in human saliva in vitro at $37^{\circ} \mathrm{C}$ had been shown to be prevented by heating the saliva to $100^{\circ} \mathrm{C}$ or by passing the saliva first through a filter (Goaz and Biswell, 1961; Ishiwata et al., 1975a). If the filter residue was returned to the saliva filtrate, the changes in salivary nitrate and nitrite levels were restored, suggesting a denaturable, biologic element in the residue fraction that was necessary for nitrate reduction (Goaz and Biswell, 1961; Ishiwata et al., 1975a). Further studies using commercially available antibacterial mouthwash or systemic antibiotics resulted in up to $90 \%$ reduction in salivary nitrite levels after an inorganic dietary load, supporting the view that bacterial conversion of nitrate was responsible for salivary nitrite (Tannenbaum et al., 1976; Dougall et al., 1995; Duncan et al., 1995).
Sasaki and Matano (1979) used a filter-paper technique to identify particular areas of the oral cavity that were responsible for nitrate reduction. They impregnated small $1.5-\mathrm{cm}^{2}$ pieces of filter paper with potassium nitrate and placed them on particular areas of the oral cavity for 90 seconds. On removal, they agitated the paper squares with distilled water and determined nitrite accumulation colorimetrically. Their investigations revealed that significant nitrate reduction was localized to only the posterior, dorsal aspect of the tongue, an observation that has since been confirmed in rodents (Duncan et al., 1995). Incubation of rat tongue sections with nitrate solution ex vivo revealed abundant nitrate reduction completely attenuated by prior boiling (Duncan et al., 1995; Li et al., 1997). In addition, oral nitratereduction activity was found to be completely absent in any part of the oral cavity of rats raised in a germ-free environment (Duncan et al., 1995). Histologic examinations of these sections demonstrated the presence of abundant bacteria in the deep, interpapillary sulci (crypts) in the posterior third of the tongue and relatively less elsewhere, which coincided with the distribution of nitrate reductase activity across the tongue (Fig. 4) (Sasaki and Matano, 1979; Sasaki et al., 1981; Duncan et al., 1995; Li et al., 1997).

The first bacterial species identified capable of facilitating oral nitrate reduction, Bacillus coagulans, was found by incubating saliva samples on nitrate-containing blood agar under anaerobic conditions (Maruyuma et al., 1976). Studies with samples of rat tongue or human saliva, using standard culture and colony isolation, coupled predominantly with species identification by biochemical means, have implicated Veillonella, Lactobacillus, Micrococcus, Corynebacterium, Propionibacterium, Neisseria, Actinomyces, commensal Staphylococcus, and Rothia spp. as playing significant roles in oral nitrate reduction (Murumatsu et al., 1979; Doel et al., 2005). Importantly, these observations have been limited to only those bacteria that can be cultured. More recent use of biofilm modeling has revealed two additional species with nitrate reductase activity (Hyde et al., 2014); however, even this model only supported culture of $\sim 100$ different species-level taxa. Importantly, nonculturable organisms, detected using cultureindependent molecular analyses, make up a significant proportion of the total oral microbiome (Dewhirst et al., 2010). The human microbiome project, utilizing nextgeneration sequencing methods, has shown that cultureindependent analyses of the bacterial genome targeting the 16S rRNA gene identify 700 bacterial species resident in the human oral cavity, with a predicted total species richness of $\sim 1000$ (Dewhirst et al., 2010). With the advent of these next-generation sequencing techniques and the human oral microbiome project, further novel nitrate reductase-containing species are being identified, although the relative importance of any of these to overall oral nitrate reduction has been difficult 

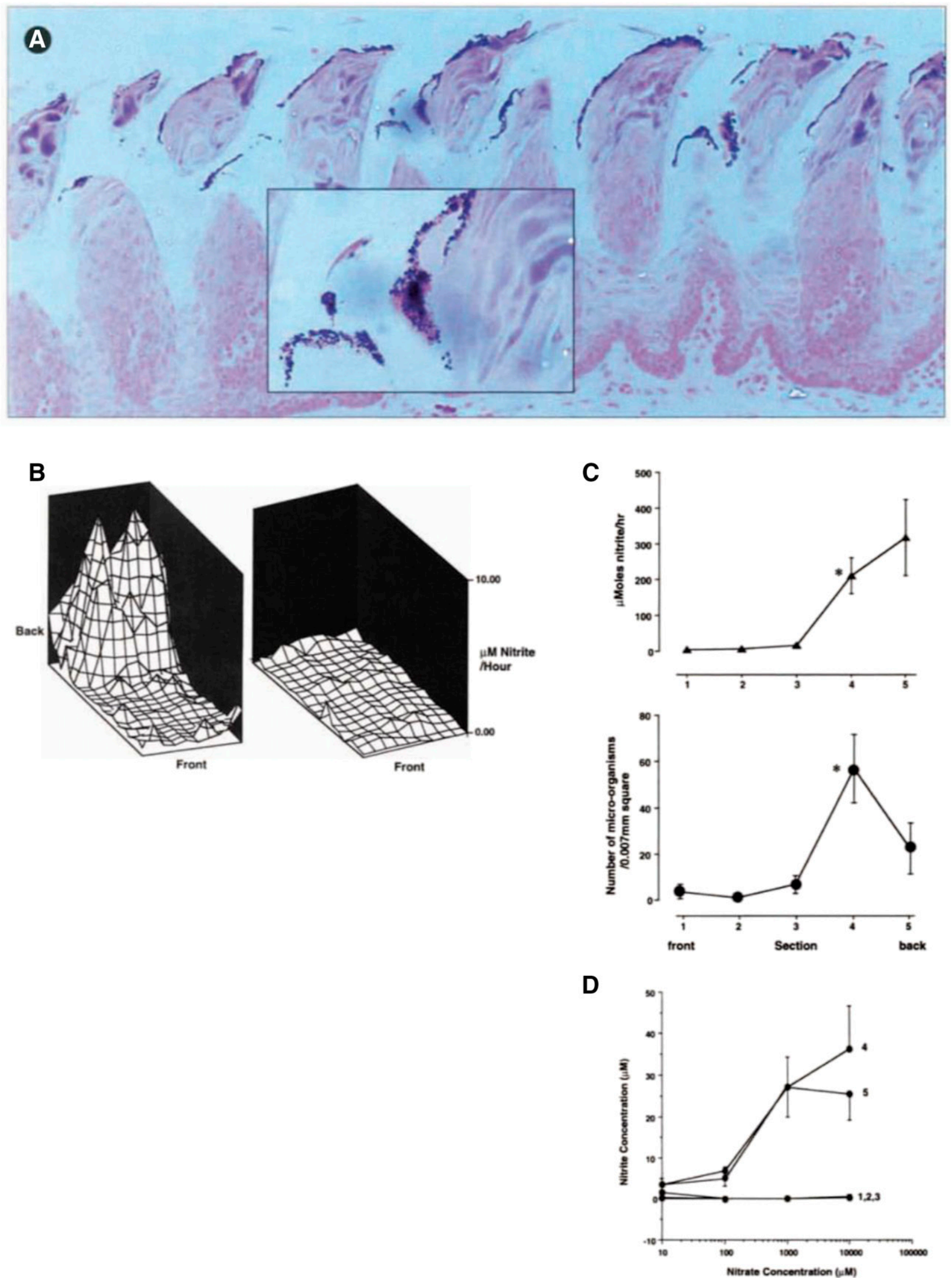

Fig. 4. Oral microbiome and nitrate reduction. Reprinted by permission from Springer: (Nature), Nature Medicine, Chemical generation of nitric oxide in the mouth from the enterosalivary circulation of dietary nitrate Duncan et al. (1995). (A) Micrograph showing the dorsal epithelial surface of the posterior third of the rat tongue. A convoluted surface with deep interpapillary clefts is seen and large numbers of microorganisms are present (dark areas). (B) Three-dimensional plot of nitrate reduction on the surface of (left) conventional $(n=7)$ and (right) germ-free $(n=2)$ rat tongues. Nitrate reduction (measured as micromoles nitrite per hour) is mainly confined to the posterior third of the tongue in conventional rats but is absent in those raised in a germ-free environment. (C and D) Sections 1 to 3 correspond to the anterior two-thirds of the tongue and 4 to 5 to the posterior third. Comparison between nitrate reduction and the microbial population over the surface of the rat tongue $(n=5)$. The distribution of nitrate reduction (micromoles nitrite per hour) relates to the distribution of microorganisms. 
to determine given the interdependency of microbial ecology (Hajishengallis et al., 2012).

Observations have also suggested that within the oral cavity, nitrate reduction is not, as previously thought, restricted to the anaerobic crypt environment at the dorsal surface of the tongue. Recent demonstrations show that bacteria residing on the teeth, on the cheek surface, and even in human dental plaque are capable of nitrate reduction (Schreiber et al., 2010). However, again, the relative contribution from this site versus the others is uncertain. In addition, there is some evidence that long-term dietary nitrate supplementation actually changes oral microbial ecology and may lead to further improvement in the processing of nitrate to nitrite (Hyde et al., 2014; Velmurugan et al., 2016; Vanhatalo et al., 2018; Burleigh et al., 2019). Feeding healthy pigs nitrate led to a change in the diversity of the oral microbiota (Trevisi et al., 2011), decreasing the Shannon index (a measure of the number of different types of bacteria and their relative abundance), suggesting that persistent (2-week) dietary nitrate treatment causes either a reduction in the richness of the community or triggers numbers of certain species to rise, thus reducing evenness. This effect was associated with acute increases in oral nitrate reduction followed by decreases with high doses of nitrate, although the identity of the species involved was not determined. In addition, in patients with hypercholesterolemia randomized to dietary nitrate for 6 weeks or control, there was a significant shift in 78 oral microbial taxa only after nitrate treatment, with Rothia and Neiserria spp. representing the greatest change (Velmurugan et al., 2016). Further studies have confirmed these increases in Rothia and Neiserria spp. in a healthy volunteer cohort after dietary nitrate supplementation for 10 days and have also noted reductions in Prevotella spp. and Veillonella spp. (Vanhatalo et al., 2018). However, whether these changes in oral microbiome in response to inorganic nitrate supplementation lead to further beneficial functional changes is not clear, as there is conflicting evidence of whether abundance of nitratereducing bacteria in the oral microbiome correlates to baseline plasma nitrite (Burleigh et al., 2018; Vanhatalo et al., 2018). Additionally, vascular responses to an acute dietary nitrate load were not different in healthy volunteers with increased nitrate-reducing bacteria identified in their oral microbiome (Burleigh et al., 2019).

Interestingly, there appear to be sex differences in the nitrate-nitrite-NO pathway, at least in part relating to oral microbial conversion of salivary nitrate to nitrite. The first hint of such an effect was demonstrated in a post hoc analysis of one of our first nitrate supplementation studies in healthy volunteers. Healthy women, in comparison with healthy men, had higher baseline plasma nitrite levels despite similar plasma nitrate levels and also greaterfold increases in plasma nitrite after a fixed dose of inorganic nitrate (Kapil et al., 2010).
Prospective evaluation confirms these baseline differences in plasma nitrite levels despite similar plasma nitrate levels and that this is represented in other biologic matrices additionally, namely in saliva and urine (Kapil et al., 2018). In addition, investigation of the enterosalivary pathway reveals that women have greater capacity for oral nitrate reduction compared with men. That is, for a fixed concentration of nitrate in the oral cavity, there is greater molar conversion to nitrite (Kapil et al., 2018). Despite these robust differences, there were no clear differences in oral microbial community diversity or structure (by 16s RNA profiling) overall or when restricted to taxa known to contain nitrate reductase genes (Kapil et al., 2018). A possible explanation is that bacterial nitrate reductase expression is influenced by sex hormones, although this has not been evaluated to date. Importantly, these differences in processing of nitrate to nitrite do not lead to divergence in response to inorganic nitrate supplementation, at least in $\mathrm{CV}$ responses such as BP and endothelial function (Kapil et al., 2018).

\section{E. Nitrate Reductases}

1. Prokaryotic Nitrate Reductases. The nitrogen cycle details the chemical transformations that recycle nitrogen between the atmosphere, biosphere, and hydrosphere. The most reduced form of nitrogen is ammonia, the oxidized form of nitrogen, whereas the most oxidized form is nitrate. Microbes drive the nitrogen cycle, as they use an assortment of redox reactions to metabolize nitrogen for energy transduction, detoxification, or assimilation (Stein and Klotz, 2016). These microbial reactions are essential to most Terran life, as they are essential to maintain bioavailability of nitrogen.

Many bacteria readily reduce nitrate to nitrite via nitrate reductases. All prokaryotic nitrate reductases are molybdenum-dependent enzymes. They are traditionally separated into three major groups: membrane-bound periplasmic nitrate reductase (Nap), membrane-bound respiratory nitrate reductase (Nar), and the cytoplasmic, assimilatory nitrate reductase (Nas) (Sparacino-Watkins et al., 2014). Nitrate is retained in soils, sediments, and water, providing a biologically useful pool for many bacteria. Enzymatic reduction to nitrite generates enormous energy (Moreno-Vivián et al., 1999), which the organisms use to maintain homeostatic processes and life.

2. Mammalian Nitrate Reductase Activity. Despite the fact that it is accepted that mammals, in the main, lack the enzymes capable of undertaking nitrate reduction to nitrite and are therefore reliant on functioning oral microflora, there is some evidence that mammalian nitrate reductases may have a role. Although antibacterial mouthwash treatment in humans totally abrogated ex vivo nitrate reduction in saliva incubated with $1 \mathrm{mmol} / \mathrm{l}$ nitrate solution and prevented any increase in saliva nitrite levels in vivo, there was still a small increase in plasma nitrite level after an inorganic 


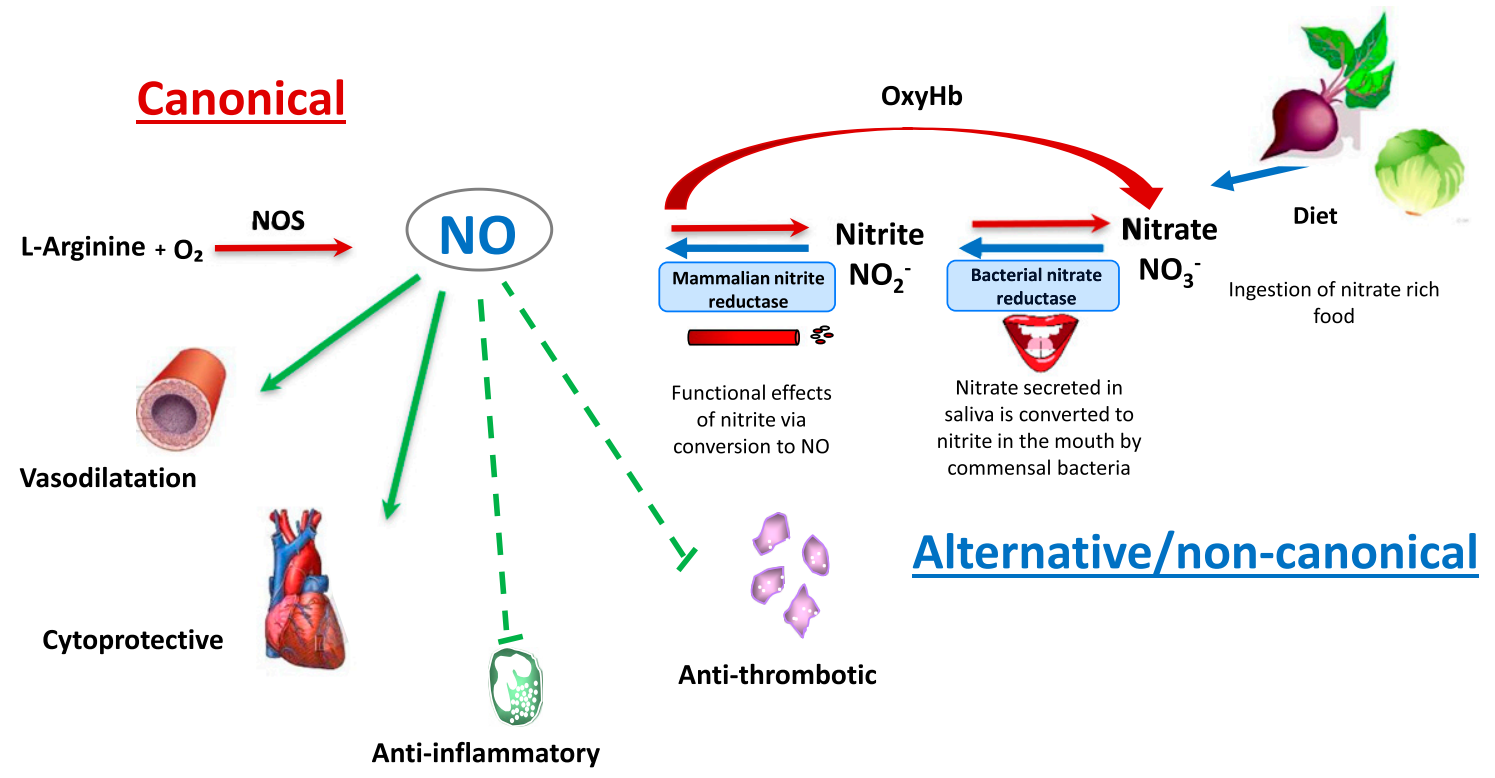

Fig. 5. NO cycle in humans. Colored arrows indicate oxidation and reduction.

nitrate load (Govoni et al., 2008). Although there could be nitrate reduction from lower GI commensals, an alternative explanation of mammalian nitrate reduction has also been postulated that is particularly focused on XOR.

XOR demonstrates nitrate-reduction activity in vitro under anoxic conditions that can be abrogated by XOR inhibition ( $\mathrm{Li}$ et al., 2003). Furthermore, in normoxic wild-type rats, increases in plasma nitrite are partially abrogated after nitrate supplementation by XOR inhibition (Jansson et al., 2008). Similar results were demonstrated in endothelial $\cdot \mathrm{NO}$ synthase (eNOS)-deficient and germ-free mice, thereby excluding bacterial nitrate reduction and vascular $\cdot \mathrm{NO}$ synthase (NOS) activation as the source of nitrite (Jansson et al., 2008). Germ-free mice exhibited greater tissue levels of XOR, suggesting that this may represent a functional compensatory response to uphold nitrate production in the absence of a commensal microflora (Huang et al., 2010). These studies seem to confirm much earlier studies on ex vivo mammalian liver/muscle homogenates suggesting that XOR may exhibit nitrate-reducing capability (Bernheim and Dixon, 1928; Ward et al., 1985, 1986). In contrast, very recently, Moretti et al. (2019) have published findings suggesting a lack of mammalian nitrate reductase activity in germ-free mice in a separate study, indicating some heterogeneity in studies with animals rendered "germ-free." Irrespective, the presence and importance of putative nitrate reductases in human physiology is yet to be firmly established.

\section{Sources and Pharmacokinetics of Nitrite}

Plasma nitrite levels in the circulation are much lower than nitrate, with measurements from several different research groups falling in the $0.2-0.5 \mu \mathrm{mol} / \mathrm{h}$ range under basal, fasting conditions (Grau et al., 2007). Nitrite also has a much shorter half-life than nitrate, estimated to be between $\sim 15$ and 45 minutes in the circulation (Dejam et al., 2007; Hunault et al., 2009). In addition, nitrite levels measured in the plasma are likely to reflect multiple different sources. Nitrite that is generated from the metabolism of $\cdot \mathrm{NO}$, in the oral cavity or from dietary sources, undergoes absorption and both enzymatic and nonenzymatic conversion to $\cdot \mathrm{NO}$ (Fig. 5).

\section{A. Endogenously Derived Nitrite from the Enterosalivary Circuit}

Elevation of systemic nitrite levels after ingestion of inorganic nitrate has been demonstrated to occur across a range of species as well as in humans. For example, provision of $1 \mathrm{~g} / \mathrm{l}(16.2 \mathrm{mmol} / \mathrm{l})$ inorganic nitrate in the drinking water to C57BL6 mice increases steady-state plasma nitrite levels by $\sim 50 \%$ (from $\sim 0.8$ to $1.2 \mu \mathrm{mol} / \mathrm{l}$ ) and increases tissue levels (for example, heart tissue) by $500 \%$ (from $\sim 3$ to $18 \mu \mathrm{mol} / \mathrm{l}$ ), highlighting that plasma nitrite levels may not be indicative of tissue-specific levels or changes in levels (Bryan et al., 2007). Interestingly, supplementation of drinking water in SpragueDawley rats with much lower amounts of nitrate (to provide total daily nitrate intake of 0.1 and $1 \mathrm{mmol} / \mathrm{kg}$ ) for 7 days increased plasma nitrite levels from 0.4 to 0.6 and $2.6 \mu \mathrm{mol} / \mathrm{l}$, respectively (Jansson et al., 2007). The differences reflected in these two studies reveal that the pharmacokinetics and handling of nitrate may be species-dependent.

Thus, studies in humans have been important to determine the impact of nitrate supplementation on systemic nitrite levels. In these studies, systemic nitrite levels have largely been examined in saliva, plasma, and urine only because, understandably, it is difficult to get tissue samples in healthy-subject studies. Although Stieglitz had shown more than 70 years ago that inorganic nitrate supplementation acutely (within 1 hour) 
and chronically (up to 14 days) elevated blood nitrite levels (Stieglitz and Palmer, 1936), it is only more recently that researchers have studied systemic nitrite elevations after inorganic nitrate supplementation in depth, trying to elucidate whether sufficient nitratederived nitrite from the oral cavity reaches the circulation in humans. One of the first explorations of this phenomenon was conducted in healthy subjects who were supplemented with $\sim 120 \mu \mathrm{mol} / \mathrm{kg} \mathrm{NaNO}$ (equivalent to $\sim 8 \mathrm{mmol} \mathrm{NaNO}_{3}$ and $496 \mathrm{mg}$ of nitrate for a 70-kg person) in a single dose (Lundberg and Govoni, 2004). Salivary, plasma, and urinary NOx levels were assayed for up to 3 hours postingestion. In contrast to the very rapid appearance of nitrate in the plasma (within 15 minutes, as previously discussed above) and early plateau phase (within 1 hour), plasma nitrite levels were only significantly detected above basal values after 30 minutes and were still rising at 90 minutes. In this experiment, some subjects were asked to refrain from swallowing their saliva (by spitting all saliva out) to interrupt the enterosalivary circulation. In these subjects, although there was no difference in plasma nitrate levels compared with control (swallowing saliva), plasma nitrite levels did not rise. However, following resumption of swallowing saliva after 1 hour, plasma nitrite levels started to rise again (Lundberg and Govoni, 2004).

In 2006, Weitzberg and Lundberg also demonstrated that plasma nitrite levels were significantly higher $(219 \pm 105 \mathrm{nmol} / \mathrm{l})$ after 3 days of supplementation with $0.1 \mathrm{mmol} / \mathrm{kg} \mathrm{NaNO}{ }_{3}(\sim 7 \mathrm{mmol}$ and $434 \mathrm{mg}$ nitrate) compared with after 3 days of matched placebo $(0.1 \mathrm{mmol} / \mathrm{kg}$ sodium chloride, $\mathrm{NaCl})$ supplementation $(138 \pm 38 \mathrm{nmol} / \mathrm{l})$ (Larsen et al., 2006). The $\sim 1.5$-fold increases in plasma nitrite levels from baseline after supplementation with $0.1 \mathrm{mmol} / \mathrm{kg}$ in humans was similar to that observed in rats described above (Jansson et al., 2007). Similarly, we have demonstrated dose-dependent effects after the ingestion of nitrate in both inorganic salt and the dietary form of beetroot juice (Webb et al., 2008b; Kapil et al., 2010). Although beetroot is purple-red, it is a green leafy vegetable and contains significant nitrate levels (Santamaria, 2006). Ingestion of $500 \mathrm{ml}$ of beetroot juice [mean $($ nitrate $)=45.0 \mathrm{mmol} / \mathrm{l}]$ provided $\sim 22.5 \mathrm{mmol}$ ( $\sim 1395 \mathrm{mg}$ nitrate) and was associated with an elevation of plasma nitrite levels from 0.4 to $0.6 \mu \mathrm{mol} / \mathrm{l}$. Plasma nitrite levels were slower to rise than plasma nitrate levels, with peak plasma nitrite levels apparent 3 hours after ingestion, compared with peak plasma nitrate levels at 60-90 minutes (Webb et al., 2008b). There were similar effects when a matched dose of nitrate salts $(24 \mathrm{mmol}$ potassium nitrate) was used (Kapil et al., 2010). In addition, interruption of the enterosalivary circulation by avoidance of swallowing saliva prevented the rises in plasma nitrite but not plasma nitrate levels, confirming the critical importance of oral nitrate reduction in modulating systemic nitrite levels after inorganic nitrate ingestion (Webb et al., 2008b).
Further evidence for the importance of the oral microflora in facilitating this process is taken from studies that have sought to suppress the bacteria responsible for nitrate reduction. Prior treatment with a chlorhexidine antiseptic mouthwash in animals and humans has been shown to prevent the increases in plasma nitrite levels associated with nitrate ingestion (Govoni et al., 2008; Petersson et al., 2009; Jädert et al., 2012).

In summary, $\sim 1$ hour after an inorganic nitrate load, plasma nitrite levels rise in a slow and sustained manner in humans, peaking in the circulation after 2.5-3 hours, reflecting the ingestion and enterosalivary processing of inorganic nitrate (Lundberg and Govoni, 2004; Webb et al., 2008b; Kapil et al., 2010).

\section{B. Endogenously Derived Nitrite from NOS Activity}

Nitrite is formed by oxidation of $\cdot \mathrm{NO}$ as previously described above and has been suggested to be the most sensitive reflection of acute eNOS activity. In the human forearm circulation, stimulation of eNOS with acetylcholine or inhibition of NOS activity with NG-monomethylL-arginine acetate rapidly altered venous plasma nitrite levels up or down, respectively, but without changes in plasma nitrate levels (Lauer et al., 2001).

Furthermore, basal plasma nitrite levels in several species were found to be similar, suggesting similar levels of constitutive NOS activity, and application of several different NOS inhibitors demonstrated crossspecies increases in vascular resistance that correlated to decreases in plasma nitrite levels but not plasma nitrate levels (Kleinbongard et al., 2003). Transgenic mice with genetic deficiency in eNOS have $70 \%$ lower plasma nitrite levels than wild-type C57BL6 littermate controls, which was similar to the levels measured in wild-type mice treated with an NOS inhibitor (Kleinbongard et al., 2003). These observations suggest that $70 \%$ of plasma nitrite is likely derived from eNOS. Similarly, in humans with CVD risk factors, it has been shown that plasma nitrite concentration inversely correlates to increasing number of $\mathrm{CV}$ risk factors and correlates directly to brachial artery flow-mediated dilation (FMD), suggesting that plasma nitrite levels could be used as a surrogate for endothelial function in those with CVD risk factors (Kleinbongard et al., 2006).

\section{Exogenous Sources of Nitrite}

Plasma nitrite levels are also determined by dietary nitrite and nitrate consumption. Dietary nitrite intake levels in humans are not as substantial as dietary nitrate, with minimal intake occurring from drinking water. Nitrite levels in drinking water are usually below $0.1 \mathrm{mg} / \mathrm{l}$ (World Health Organization, 2011). Daily nitrite intake is similar across Europe and North America, with estimates suggesting ingestion of $0.3-$ $0.9 \mathrm{mg} /$ day, which equates to $6-20 \mu \mathrm{mol}$ nitrite ingested per day (Schuddeboom, 1993). The primary sources of dietary nitrite consumption are cured, processed meats. 
Nitrite is added to meat as a preservative, as it prevents oxidation of fatty acids, preventing rancidity and controlling Clostridium botulinum (Hustad et al., 1973; Honikel, 2008). Meat products contain up to $6.4 \mathrm{mg}$ of nitrite per kilogram (European Centre for Ecotoxicology and Toxicology of Chemicals, 1988), whereas vegetables contain very little nitrite (Hord et al., 2009).

In many studies exploring nitrite bioactivity, nitrite salts have been used, with the most commonly used being the sodium salt. The $\sim 30$-minute half-life mentioned above comes from work using $\mathrm{NaNO}_{2}$ in healthy volunteers. In patients with diabetes, similar findings have been observed. Kevil and colleagues demonstrated that peak levels of circulating nitrite were achieved within 30 minutes after ingestion of an $80-\mathrm{mg}$ dose of $\mathrm{NaNO}_{2}$, returning back to baseline within the 6-hour measurement period (Greenway et al., 2012). This group also assessed the impact of enteric coating upon circulating levels of nitrite in the same patient group. They showed that a statistically significant rise in circulating levels was not achieved with the entericcoated $\mathrm{NaNO}_{2}$ over the 6 hours; however, there was a trend for a rise that began to appear at around 1.5 hours after ingestion, peaking at 2.5 hours and maintained until 4.5 hours postingestion. Although, as noted, this rise was not statistically different from baseline (Greenway et al., 2012), the authors suggested that with doses higher than $80 \mathrm{mg}$, it may be possible to provide longer-lasting elevations of circulating nitrite that might prove useful in therapeutics.

However, mean salivary volume swallowed is estimated to be $\sim 1.5$ 1/day (Dawes, 1972; Lagerlöf and Dawes, 1984), and mean basal salivary nitrite levels are $\sim 100-300 \mu \mathrm{mol} / \mathrm{l}$ (Lundberg and Govoni, 2004; Govoni et al., 2008; Bahra et al., 2012). Thus, swallowing of saliva could be responsible for total amounts of intragastric nitrite in the order of 150-300 $\mu$ mol daily. Mean plasma nitrite levels are $0.2-0.5 \mu \mathrm{mol} / \mathrm{l}$, suggesting total circulatory nitrite levels at any one point of 1$2.5 \mu \mathrm{mol}$. Thus, the same total amount of nitrite would enter the stomach every 30 minutes. Although not all of swallowed nitrite survives to appear in the circulation, even if a fraction entered the circulation, it would make an important contribution to plasma nitrite levels under basal conditions. Some evidence suggests that salivary nitrite might account for the $30 \%$ of plasma nitrite concentration that cannot be accounted for by eNOS activity. Under basal conditions, chronic use of antibacterial mouthwash, which totally attenuated oral nitrate reduction, reduced salivary nitrite concentration by $90 \%$ and plasma nitrite levels by $25 \%$ (Kapil et al., 2013).

\section{Systemic Nitrite Absorption}

The nitrite that is formed in the oral cavity after bacterial conversion from nitrate is swallowed and may be directly acidified to increase levels of $\cdot \mathrm{NO}$ in the stomach (Benjamin et al., 1994; Lundberg et al., 1994). However, a significant proportion of swallowed nitrite appears to survive passage into the stomach and, after transfer across the gut wall, enters the systemic circulation. The disappearance of nitrite from the stomach is a rapid process, with decline of nitrite levels by half within 10 minutes, as a consequence of absorption rather than chemical reactions of nitrite or gastric emptying (Licht et al., 1986).

Similar to the lack of knowledge relating to nitrate absorption in the GI tract, exactly how nitrite enters the circulation is uncertain. As a charged anion, an active uptake mechanism is likely to be involved, but this is yet to be proven. Although little work has been published describing active uptake mechanisms in gastric environs specifically, there have been some studies attempting to discern uptake mechanisms. In erythrocyte ghosts, nitrite exchange with bicarbonate $\left(\mathrm{HCO}_{3}-\right)$ is inhibited by the nonspecific anion-exchange inhibitor diisothiocyanatostilbene disulfonate, suggesting that at least for erythrocytes, there may be a role for the anion-exchange transporter- 1 for the movement of nitrite across the membrane (Shingles et al., 1997; Vitturi et al., 2009; Jensen and Rohde, 2010). A similar anion-exchange transporter-1 dependence for nitrite transport has been demonstrated in pancreatic acini (Zhao et al., 1994). However, other researchers have failed to demonstrate the same effect of diisothiocyanatostilbene disulfonate (Zavodnik et al., 1999; May et al., 2000; Jensen, 2005). Additionally, May et al. (2000) demonstrated that nitrite uptake was dependent upon sodium and phosphate levels and therefore suggested that the sodium-dependent phosphate transporter was important.

However, in the gastric lumen, $\mathrm{pH}$ is between 1.0 and 2.5. The $p K_{\mathrm{a}}$ of nitrous acid $\left(\mathrm{HNO}_{2}\right)$ in aqueous solutions is 3.3-3.4 (Butler and Ridd, 2004), and therefore, most of the nitrite will be in the neutral, lipophilic $\mathrm{HNO}_{2}$ form. It has been hypothesized that the passive movement of $\mathrm{HNO}_{2}$ from the acidic gastric environment into the neutral circulation may underlie the apparent transport of nitrite across the gastric wall (eq. 1.4), a possibility demonstrated to occur across the erythrocyte membrane (Samouilov et al., 2007; Webb and Ahluwalia, 2010). Arguing against the above proposal are studies in rats assessing the importance of gastric $\mathrm{pH}$ in circulating nitrite concentrations (Pinheiro et al., 2012). Treatment of rats with large doses $(30 \mathrm{mg} / \mathrm{kg}$, equivalent to 150 times the usual clinical dose) of the proton pump inhibitor omeprazole (clinical daily doses are usually $10-20 \mathrm{mg} /$ day) followed by 15 or $45 \mathrm{mg} / \mathrm{kg}$ $\mathrm{NaNO}_{2}$ orally, although increasing gastric $\mathrm{pH}$ from 4 to 6 , did not impact upon circulating nitrite levels. Similar observations have been seen in healthy volunteers (Montenegro et al., 2017) in which treatment with $40 \mathrm{mg}$ of esomeprazole did not lower circulating nitrite 
levels after an oral dose of $0.3 \mathrm{mg} / \mathrm{kg}(\sim 0.3 \mathrm{mmol})$ of nitrite. The exact contribution of passive diffusion of $\mathrm{HNO}_{2}$ and/or active uptake of nitrite is still to be fully determined and quantified. However, what is apparent is that ingestion of inorganic nitrate, via the enterosalivary circulation and bacterial nitrate reduction, eventually leads to increases in plasma and tissue nitrite levels. Interestingly, it is now apparent that tissue levels of nitrite can be widely different and that plasma nitrite levels are, in general, the lowest in vivo, with potentially most of the "blood" nitrite carried inside the erythrocyte and much higher nitrite levels in certain tissues of the body, particularly the blood vessel wall (Bryan et al., 2005; Dejam et al., 2005).

\section{Mechanisms of Nitrite Bioactivation}

It is recognized that there are two distinct pathways for nitrite bioactivation: either nitrite can be reduced to -NO through acidification, as in the gut, or it can be reduced via a host of mammalian enzymes, which we describe below.

\section{A. Nonenzymatic Nitrite Reduction}

The acidic environment of the stomach lends itself to the bioactivation of nitrite via the chemical reactions outlined above and shown in eqs. 1.4-1.6 (Benjamin et al., 1994). Firstly, nitrite is protonated, leading to the formation of nitrous acid, and at low $\mathrm{pH}, \mathrm{HNO}_{2}$ decomposes to form $\mathrm{N}_{2} \mathrm{O}_{3}$, which in turn can dissociate to $\mathrm{NO}$ and $\mathrm{NO}_{2}$. It was proposed that this acidification of nitrite to generate $\cdot \mathrm{NO}$ acts as a defense mechanism against swallowed pathogenic microorganisms (Benjamin et al., 1994) and that this effect was responsible for the increases in $\mathrm{NO}$ measured in response to dietary nitrate supplementation (Benjamin et al., 1994; Lundberg et al., 1994). Whereas Benjamin and colleagues used potassium nitrate to elevate stomach nitrite levels, Lundberg and colleagues demonstrated that ingestion of $50 \mathrm{~g}$ of iceberg lettuce $(1.3 \mathrm{mg} / \mathrm{kg}$ nitrate content) led to a 4 -fold elevation in exhaled NO 5 minutes after ingestion. This response was abolished by pretreatment with $240 \mathrm{mg}$ of omeprazole over a 24-hour period before lettuce ingestion (Lundberg et al., 1994). A year later, it was demonstrated using EPR spectroscopy and -NO spin traps that in rat hearts, negligible ${ }^{15} \cdot \mathrm{NO}$ is observed despite being treated with $1 \mathrm{mmol} / \mathrm{l}{ }^{15} \mathrm{~N}$-nitrite; however, in the ischemic rat heart, a 10-fold increase in the EPR signal was observed (Zweier et al., 1995). The authors suggested that the ischemia-induced acidosis provides the protons required for the acidic disproportionation of nitrite to $\cdot \mathrm{NO}$ without the need of a catalyst/enzyme. However, although the chemistry is correct, it is now clear that the reaction is facilitated by mammalian enzymatic activity within tissues and that this catalytic activity enables nitrite reduction under physiologic as

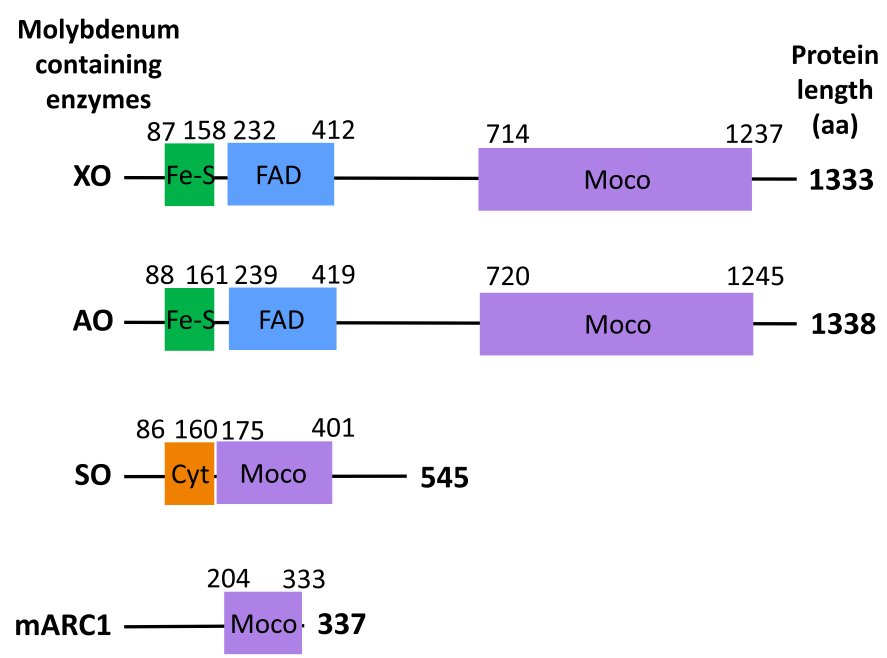

Fig. 6. The primary sequence structure of the four known mammalian molybdenum-containing enzymes. Numbers denote the first and last residues of the domains highlighted (data obtained from NCBI/Protein). aa, amino acid; Cyt, cytochrome $b_{5}$; FE-S, iron-sulfur; Moco, molybdenum cofactor; NCBI, National Center for Biotechnology Information; XO, xanthine oxidase.

well as pathologic conditions, but the lower the $\mathrm{O}_{2}$ tension and $\mathrm{pH}$, the greater the nitrite reduction. Below, we summarize the evidence supporting the key mammalian nitrite reductases that have been identified.

\section{B. Mammalian Nitrite Reductases}

1. Molybdenum-Containing Oxidase Enzymes. In mammals, there are four known molybdenumcontaining enzymes: XOR, sulfite oxidase (SO), aldehyde oxidase (AO), and mitochondrial amidoxime reductase (mARC) (Fig. 6). Although all have been shown to function as a nitrite reductase to various degrees, XOR has been identified as perhaps the major mammalian nitrite reductase and certainly is the most prominent molybdenum-containing enzyme responsible for nitrite bioactivation.

a. Xanthine oxidoreductase. XOR is widely distributed throughout the body, with the highest levels of expression in the liver (Linder et al., 1999). XOR is synthesized primarily in the liver and the lung, reflecting the high expression found within these tissues, with much lower levels of XOR expressed in most organs, including the brain, gut, heart, and in blood vessels (Abadeh et al., 1992, 1993). XOR has been localized within the cytoplasm of numerous cell types (Jarasch et al., 1981, 1986; Moriwaki et al., 1993; Radi et al., 1997; Houston et al., 1999) but has also been localized bound to the outer surface of cells through binding to heparin sulfate glycosaminoglycans (GAGs). This expression on the cell surface via GAGs has been suggested to account for substantial XOR expression identified on the endothelial surface in patients with coronary artery disease (Spiekermann et al., 2003) and that observed in erythrocytes from individuals undergoing coronary artery bypass grafting (CABG) (Webb 
et al., 2008a), hypertensive rats, and patients with hypertension (Ghosh et al., 2013). More recently, we also identified XOR activity in erythrocyte preparations of apolipoprotein $\mathrm{E}$ (ApoE) knockout (KO) mice (Khambata et al., 2017), an atherosclerotic-prone mouse model in which an upregulation of XOR activity versus wild-type (WT) C57BL6 littermates was observed.

XOR has a FAD domain, two iron-sulfur domains, and a molybdenum-binding domain, the latter being the site for purine catabolism. The classically accepted function of XOR is the oxidation of hypoxanthine to xanthine and xanthine to uric acid, which occurs at the molybdenum site (eq. 1.7a), and the reduction of $\mathrm{O}_{2}$, occurring at the $\mathrm{FAD}$ site. However, in addition to these, it has been known for $\sim 20$ years that nitrite is reduced to $\cdot \mathrm{NO}$ at the molybdenum site (Millar et al., 1998; Zhang et al., 1998). The mechanism by which this reaction was proposed to occur was through $\mathrm{NADH}$ acting as a under anaerobic conditions, i.e., $<1 \%$ oxygen, XOR catalyzed this reaction. In this study, the authors confirmed that XOR drove nitrite reduction at the molybdenum-binding site with $\mathrm{NADH}$ as the reducing substrate, since both allopurinol and diphenyleneiodinium, the molybdenum and FAD-directed inhibitors, respectively, blocked this reaction. Further studies by Zweier's group demonstrated that XOR could also catalyze nitrite reduction to $\mathrm{NO}$ in both aerobic and anaerobic conditions ( $\mathrm{Li}$ et al., 2004). Using substrates of xanthine or aldehyde, which act at the molybdenum site as electron donors, it was shown that $\mathrm{O}_{2}$ functions as a competitive inhibitor of nitrite reduction, whereas using $\mathrm{NADH}$ as the electron donor at the FAD site, nitrite reduction still occurs even in the presence of oxygen at $\sim 70 \%$ of the level observed in anoxia.

These observations have led us to suggest that a potentially useful approach for therapeutics may be to

$$
\text { a. Hypoxanthine } \underset{\mathrm{H}_{2} \mathrm{O}+\mathrm{O}_{2}}{\longrightarrow} \text { Xanthine }+\underset{\left.\mathbf{M o}^{\mathbf{v I}}\right)}{\longrightarrow} \underset{\mathrm{H}_{2} \mathrm{O}+\mathrm{O}_{2}}{\longrightarrow} \text { Uric acid } \stackrel{\left(\mathbf{M o}^{\mathbf{I V}}\right)}{\longrightarrow}+1 \mathrm{e}-
$$

reducing substrate, donating electrons to the $\mathrm{FAD}$ site to form $\mathrm{FADH}_{2}$ (eq. 1.7b); these electrons were then proposed to be shuttled from the FAD site to the molybdenum site via the iron-sulfur clusters (eq. 1.7c). The authors suggested that Mo (VI) is reduced to Mo (IV), and the $\mathrm{O}^{-}$that is donated from nitrite results in $\mathrm{Mo}(\mathrm{V})$ and the release of $\cdot \mathrm{NO}$ (eq. 1.7d). At the end of the reaction, for each reducing substrate oxidized, two molecules of $\cdot \mathrm{NO}$ were proposed to be formed in a oneelectron-reducing process resulting in Mo (VI). Equation 1.7 shows reactions of XOR.

Reaction at the molybdenum-binding site is as follows:

Reaction at the FAD site is as follows:

$$
\text { b. } \left.\mathrm{NADH}+2 \mathrm{H}^{+} \leftrightarrow \mathrm{NAD}^{+}+\mathrm{FADH}_{2}\right)
$$

Internal electron shuttling is as follows:

$$
\text { c. } \mathrm{Mo}^{\mathrm{IV}} / \mathrm{Mo}^{\mathrm{VI}} \stackrel{\mathbf{F e}-\mathbf{S}(\mathbf{I}) / \mathbf{F e}-\mathbf{S}(\mathbf{I I})}{\longrightarrow} \mathrm{FADH}_{2} / \mathrm{FAD}^{+}
$$

Nitrite reduction at the Mo-Co site is as follows:

$$
\begin{gathered}
\left(\mathbf{M o}^{\mathbf{I v}}\right) \\
\text { d. } \left.2 \mathrm{NO}_{2^{-}}+4 \mathrm{H}^{+}+2 \mathrm{e}\right) \\
-2 \cdot \mathrm{NO}+2 \mathrm{H}_{2} \mathrm{O}
\end{gathered}
$$

Millar et al. (1998) demonstrated that in the presence of $\mathrm{O}_{2}$, purified bovine XOR was unable to catalyze the reduction of nitrite $(1-30 \mathrm{mmol} / \mathrm{l})$ to $\mathrm{NO}$; however, take advantage of this balance of reactions. We have suggested that under optimal nitrite-reducing conditions, XOR may be "switched" from a detrimental ROS-generating enzyme to a protective one through preferential generation of $\cdot \mathrm{NO}$. We propose that in conditions of excess nitrite and in the presence of the reducing substrate $\mathrm{NADH}$, electrons will be shuttled from the FAD site to the molybdenum site via ironsulfur domains, resulting in a decrease in the availability of the electrons needed for $\mathrm{O}_{2}$ reduction. This would result in generation of $\cdot \mathrm{NO}$ and a concomitant reduction of superoxide and $\mathrm{H}_{2} \mathrm{O}_{2}$, which are thought to be major contributors to the oxidative stress that characterizes many chronic disease states, in particular CVD (Sugamura and Keaney, 2011), and to which XOR contributes (Berry and Hare, 2004).

This latter point is particularly important in disease, since both XOR expression and activity are substantially enhanced, and this possibly offers an opportunity for enhanced nitrite reduction too. An important observation, particularly relevant when discussing the potential utilization of XOR-mediated nitrite reduction in therapeutics, is that XOR activity is enhanced in scenarios of hypoxia and acidosis, conditions that are both prevalent in the setting of ischemia/reperfusion (I/R) injury. Using purified XOR under aerobic conditions, nitrite reduction was enhanced with acidic $\mathrm{pH}$, with $\cdot \mathrm{NO}$ generation 3 times greater at $\mathrm{pH} 6$ compared with $\mathrm{pH} 7.4$ and a further 3 times greater from $\mathrm{pH} 6.4$ to $\mathrm{pH} 5.5$ when incubated with $1 \mathrm{mmol} / \mathrm{l}$ sodium nitrite 
(Li et al., 2004). In isolated rat heart preparations, $\mathrm{pH}$ plummeted from 7.4 to 5.5 within 20 minutes of ischemia (Zweier et al., 1999), providing the ideal environment for XOR-dependent nitrite reduction. Our own observations have supported these findings. Using homogenates of rat and human heart, we demonstrated an elevation of nitrite-derived $\cdot \mathrm{NO}$ production not only with increasing concentrations of $\mathrm{NaNO}_{2}$ but, importantly, also with decreasing $\mathrm{pH}(6.0-5.0)$ (Webb et al., 2004). Additionally, Zweier and colleagues demonstrated that rat heart homogenates incubated with $10 \mu \mathrm{mol} / / \mathrm{NaNO}_{2}$ gassed with $2 \% \mathrm{O}_{2}$ demonstrated $50 \%$ greater nitrite reduction than when under $5 \% \mathrm{O}_{2}$, an effect that was substantially inhibited by the XOR inhibitor oxypurinol (Li et al., 2004). These observations suggest that XOR-mediated nitrite reduction is perhaps a phenomenon particularly relevant under ischemia, as opposed to normal physiologic conditions of $\mathrm{pH} 7.4$ and normoxia. Although it is worth noting that under physiologic conditions, $\mathrm{O}_{2}$ tension within organs can vary enormously, with partial pressure of oxygen $\left(\mathrm{PaO}_{2}\right)$ of $90-100 \mathrm{~mm} \mathrm{Hg}$ in arterial blood, $40 \mathrm{~mm} \mathrm{Hg}$ in the venous return, and $35 \mathrm{~mm} \mathrm{Hg}$ in the heart and brain, thus raising the possibility that, although within the arterial side of the circulation in normoxia, XOR may play little role as a nitrite reductase, this may not be the case in regions that normally exist at lower $\mathrm{O}_{2}$ tensions.

Accordingly, evidence for a role for XOR in mediating nitrite reduction under physiologic conditions (i.e., normoxia and $\mathrm{pH}$ 7.4) has grown in the last few years. We reported that bolus doses of $\mathrm{NaNO}_{2}(1-10,000 \mathrm{nmol} / \mathrm{kg})$ reduce mean arterial pressure (MAP) in the spontaneously hypertensive rat (SHR) model, effects abolished by allopurinol (50 mg/kg) (Ghosh et al., 2013). We also demonstrated enhanced XOR levels of erythrocytes (measured using Western blotting) in the SHR model compared with the normotensive Wistar Kyoto strain control associated with elevated allopurinol-sensitive nitrite reductase activity, measured by gas-phase chemiluminescence. There was a very similar profile of activity in purified erythrocytes collected from normotensive and hypertensive humans. However, a recent study assessing erythrocytic nitrite reduction of blood collected from both normotensive and hypertensive volunteers demonstrated no effect of allopurinol upon nitrite reductase activity, measured using EPR detection of nitrosyl $\mathrm{Hb}$ (Liu et al., 2015). The authors highlighted a number of possible reasons for the differences between the two studies, including: concentrations of nitrite used (Ghosh et al., 10-100 $\mu \mathrm{mol} / \mathrm{l}$; Liu et al., $10 \mathrm{mmol} / \mathrm{l}$ ); differences in the buffer that may have led to differing levels of XOR; potentially xanthine dehydrogenase expression versus xanthine oxidase expression; and that erythrocytes were collected from drug-naïve hypertensives in the previous study (Ghosh et al., 2013) as opposed to treated hypertensives. However, another likely explanation is that in the study by Kim-Shapiro and colleagues, blood was collected with heparin as the anticoagulant, and heparin will cleave any XOR bound via GAGs on the erythrocytes (Adachi et al., 1993; Spiekermann et al., 2003). This fact underlies why in all studies in our laboratory, when assessing the nitrite reductase activity of blood elements, sodium citrate is used as the anticoagulant. In contrast to the above, Rosenbaek et al. (2018) pretreated healthy individuals with placebo or allopurinol, infused $\mathrm{NaNO}_{2}$ at $3.5 \mu \mathrm{mol} / \mathrm{kg}$ per hour, and found no differences in brachial BP. However, the dose of $\mathrm{NaNO}_{2}$ used did not cause substantial BP lowering itself. Furthermore, allopurinol may cause opposing effects in reducing $\mathrm{NO}$ production but also potentially reducing superoxide production, thereby mitigating measurable vascular effects.

There is some evidence that nitrate and nitrite interfere with each other with respect to XOR activity. Damacena-Angelis et al. (2017), using high concentrations of purified XOR (concentrations unlikely to occur in vivo even in the most extreme of conditions), demonstrated that $30 \mathrm{mmol} / \mathrm{NaNO} \mathrm{Na}_{3}$ attenuated $\mathrm{NaNO}_{2}$ $(1 \mathrm{mmol} / \mathrm{l})$ reduction to $\mathrm{NO}$ by $\sim 60 \%$. Although these findings initially suggest that there is competition between the two anions, the use of such high concentrations to evidence these effects creates uncertainty regarding potential physiologic relevance.

b. Aldehyde oxidase. Similar to XOR, AO consists of an FAD binding site, iron-sulfur domains, and a molybdenum-binding center and is highly expressed in the liver, but it is also found in other tissues, such as blood vessels, heart, lung, and kidney (Moriwaki et al., 1998, 2001). AO has multiple functions, including catalyzing the oxidation of aldehydes and heterocyclic compounds to produce carboxylic acid. The first demonstration of the nitrite reductase capacity of AO came from studies led by Jay Zweier. Using $\mathrm{NaNO}_{2}$ $(100 \mu \mathrm{mol} / \mathrm{l})$ and raloxifene $(50 \mathrm{nmol} / \mathrm{l})$, an AO inhibitor, -NO production was reduced by $\sim 40 \%$ in $1 \mathrm{~g}$ of rat liver or heart homogenate ( $\mathrm{Li}$ et al., 2008). Subsequent studies by Zweier's group demonstrated that the mechanism by which $\mathrm{AO}$ reduces nitrite is similar to that of $\mathrm{XOR}$ in that nitrite reduction is enhanced in hypoxic conditions and occurs at the molybdenum site ( $\mathrm{Li}$ et al., 2009). Similar to XOR, NADH acts as a reducing substrate, donating electrons to the $\mathrm{FAD}$ site, an effect inhibited by diphenyleneiodinium. Aldehydes can also act as the electron donor at the molybdenum site of $\mathrm{AO}$ to facilitate nitrite reduction ( $\mathrm{Li}$ et al., 2009). Again, similar to XOR, there is enhanced nitrite reduction under acidic $\mathrm{pH}$, with the greatest activity occurring at pH 6 and decreasing at lower pHs (Li et al., 2009). In contrast, however, recent testing of raloxifene in healthy volunteers demonstrated that, if anything, the activity of $\mathrm{NaNO}_{2}$ was enhanced with treatment, intimating that pathways other than $\mathrm{AO}$ were involved in the effects seen (Omar et al., 2015). Thus, at present, the 
physiologic significance of the nitrite reductase activity of $\mathrm{AO}$ is uncertain.

c. Sulfite oxidase. SO is located within the intermembrane space of mitochondria and exists as a homodimer, with each monomer containing a molybdenumbinding, an $\mathrm{N}$-terminal cytochrome $b_{5}$-type heme, and a C-terminal domain. The physiological function of $\mathrm{SO}$ is to oxidize sulfite $\left(\mathrm{SO}_{3}^{2-}\right)$ to sulfate $\left(\mathrm{SO}_{4}^{2-}\right)$, which concomitantly reduces molybdenum from +6 to +4 . It has recently been demonstrated that $\mathrm{SO}$ is also capable of reducing nitrite to $\mathrm{NO}$ under anaerobic conditions (Wang et al., 2010), a process enhanced under acidic conditions (Wang et al., 2015). Similar to XOR and AO, reduction of nitrite to $\mathrm{NO}$ occurs at the molybdenum domain; however, SO does this by the one-electron oxidation of $\mathrm{Mo}+6$ to $\mathrm{Mo}+5$, which was demonstrated using sulfite, a two-electron donor, and phenosafranine, a one- or two-electron donor in which nitrite reduction did not occur in the presence of the former (Wang et al., 2015). The authors also demonstrated that human fibroblasts collected from molybdenum cofactordeficient and SO-deficient individuals have significantly reduced cGMP levels with the addition of $50 \mu \mathrm{mol} / \mathrm{l}$ nitrite in $1 \%$ and $20 \%$ oxygen, in comparison with WT controls, demonstrating the importance of SO-dependent nitrite reduction in vivo (Wang et al., 2015).

d. Mitochondrial amidoxime reducing component. Although mARC, a molybdenum-containing enzyme, was described over a decade ago, its physiologic role is unknown (Havemayer et al., 2006). Humans possess two genes that encode for mARC-1 and -2 , both of which have been shown to reduce nitrite to $\cdot \mathrm{NO}$, albeit with suprapharmacological levels $\left(\mathrm{NaNO}_{2} 1 \mathrm{mmol} / \mathrm{l}\right)$ (Sparacino-Watkins et al., 2014). The authors demonstrated that for nitrite reduction to occur, cytochrome $b_{5}$ and cytochrome $b_{5}$ reductase need to be present to facilitate electron transport from the FAD site to the molybdenum site within mARC, so $\mathrm{NADH}$ is also required (Sparacino-Watkins et al., 2014). Using sitedirected mutagenesis to switch the cysteine of the active molybdenum site to alanine (C273A), nitrite reduction to $\cdot \mathrm{NO}$ was completely abolished. Similar to other molybdenum-containing enzymes, the rate of nitrite reduction is enhanced under acidic (3-fold, from $\mathrm{pH} 7.5$ to $\mathrm{pH}$ 6.5) and hypoxic conditions (Sparacino-Watkins et al., 2014). The physiologic role of mARC facilitating nitrite to $\mathrm{NO}$ reduction remains uncertain.

2. Mitochondrial Respiratory Chain Enzymes. mARC is not the only mitochondrial component capable of reducing nitrite to $\mathrm{NO}$. Experiments with rat liver homogenates demonstrate that inhibition of complex I or II leads to an attenuation of nitrite-derived $\cdot \mathrm{NO}$ $\left(\mathrm{NaNO}_{2} 50 \mu \mathrm{mol} / \mathrm{l}\right)$ at $\mathrm{pH} \quad 7.25$ and under anoxic conditions (Kozlov et al., 1999). It was suggested that inhibition of complex I or II will prevent electron flow to complex III, which has been implicated as the site of mitochondrial nitrite reduction. As such, inhibition of complex III (also known as cytochrome $b_{1}$ complex/ cytochrome c reductase) completely abolished nitrite reduction (Kozlov et al., 1999; Nohl et al., 2000). There is also evidence to suggest that complex IV (cytochrome c oxidase) may reduce nitrite to $\mathrm{NO}$. Treatment of rat liver homogenate with either antimycin A or myxothiazol (both complex III inhibitors) in the presence of the electron donor $N, N, N^{\prime}, N^{\prime}$-tetramethyl-p-phenylenediamine dihydrochloride, which feeds electrons downstream of complex III of the respiratory chain, did not block nitrite reduction (Castello et al., 2006). Furthermore, carbon monoxide, a complex IV inhibitor, inhibited nitrite reduction (Castello et al., 2006). However, $\mathrm{NaNO}_{2}(1 \mathrm{mmol} / \mathrm{l})$ reduction in this in vitro setting was only evident when experiments were conducted at $\mathrm{O}_{2}$ concentrations below $2 \%$ being maximal under anoxic conditions (Castello et al., 2006). The physiologic relevance of this phenomenon likely pertains only to the ischemic setting, and further investigation assessing the impact of this pathway upon biologic function is needed to better understand significance.

3. Globins. The globins are a family of globular heme-containing proteins that are involved in the transport of $\mathrm{O}_{2}$; however, an abundance of literature supports a role for these proteins in facilitating nitrite reduction. In particular, we summarize below the evidence for $\mathrm{Hb}, \mathrm{Mb}$, neuroglobin, and cytoglobin as nitrite reductases.

a. Hemoglobin. It was first discovered in the $1930 \mathrm{~s}$ by Brooks and further elucidated by Doyle and colleagues in the 1980s that deoxyHb $\left(\mathrm{HbFe}^{2+}\right)$ in the presence of nitrite has the ability to produce $\mathrm{NO}$, metHB $\left(\mathrm{HbFe}^{3+}\right)$, and hydroxide (Brooks, 1937; Doyle et al., 1981) (see eq. 1.2). Despite these observations from many years ago, it was not until 2003 that Gladwin and colleagues proposed the biologic significance of this reaction in terms of vasodilation. Gladwin's studies indicated that in the presence of deoxyHb, nitrite generates $\mathrm{NO}$, a phenomenon much reduced in the presence of oxyHb (Cosby et al., 2003), the latter being as one would suspect due to the rapid $\mathrm{NO}$ scavenging characteristics of oxyHb. This opposing activity of different $\mathrm{Hb}$ states has led to inevitable uncertainty regarding the functional significance of $\mathrm{Hb}$ as a nitrite reductase.

Further studies by Gladwin and colleagues investigating the kinetics of these reactions has led to the proposal that the extent of nitrite reduction and the rate of reaction is dependent upon the state of the $\mathrm{Hb}$ tetramer. $\mathrm{Hb}$ can exist in two states, the tense state (T-state), in which $\mathrm{Hb}$ lacks oxygen, termed deoxyHb, and the relaxed state ( $\mathrm{R}$-state), in which $\mathrm{Hb}$ is oxygenated, termed oxyHb. It has been demonstrated that the $\mathrm{R}$-state reacts with nitrite $\sim 100$-fold faster than the T-state (Huang et al., 2005a,b). This results in the peak rate of $\mathrm{NO}$ production occurring when $\mathrm{Hb}$ is $50 \%$ 
saturated $\left(p_{50}\right)$ with oxygen. The physiologic relevance of these observations has been demonstrated using organ bath pharmacology. Precontracted rat aortic rings subject to increasing concentrations of $\mathrm{NaNO}_{2}$ $(10 \mathrm{nmol} / \mathrm{l}$ to $300 \mu \mathrm{mol} / \mathrm{l})$ under decreasing $\mathrm{O}_{2}$ tensions $(60,25,15 \mathrm{~mm} \mathrm{Hg})$ relaxed the greatest under low $\mathrm{O}_{2}$ tension, with significant relaxant activity evident at concentrations of $200 \mathrm{nmol} / / \mathrm{NaNO}_{2}$ (Crawford et al., 2006), i.e., concentrations well within the physiologic range of plasma nitrite concentration.

However, the issue still remains, considering the nitrite chemistry proposed above, how can the $\cdot \mathrm{NO}$ produced from nitrite reduction by $\mathrm{Hb}$ escape scavenging by oxyHb, particularly since maximal nitrite reduction occurs at $p_{50}$, so considerable and sufficient $\mathrm{oxyHb}$ is present. There have been various hypotheses explaining how this might happen, including those mentioned earlier relating to the cell-free layer at the blood vessel wall created by flowing blood. However, there is also some chemistry that has been proposed to explain how this might occur. It has been suggested that the reaction of nitrite and deoxyHb forms an intermediate, such as $\mathrm{N}_{2} \mathrm{O}_{3}$, which is less reactive than $\mathrm{NO}$ and so is able to escape the erythrocyte and, once outside, can dissociate to release $\mathrm{NO}$ (Robinson and Lancaster, 2005; Basu et al., 2007; Hopmann et al., 2011). Similarly, a second hypothesis is that $S$-nitrosohemoglobin is generated, which allows escape from the erythrocyte and subsequent dissociation to release $\mathrm{NO}$ (Stamler et al., 1997; Pawloski et al., 2001; Nagababu et al., 2006; Salgado et al., 2009). Although it is clear that $\mathrm{Hb}$ does express nitrite reductase capacity, the continued uncertainty regarding the issues highlighted above make it difficult to be certain of the exact role of $\mathrm{Hb}$ in mediating the functional effects that have been attributed to nitrite in vivo.

b. Myoglobin. Deoxy Mb (deoxyMb) was first demonstrated to act as a nitrite reductase by Gladwin and colleagues, who discovered that nitrite bioactivation is $\sim 36$ times faster with deoxyMb compared with deox$\mathrm{yHb}$ : an effect that was attributed to its lower heme redox potential (Shiva et al., 2007a). The physiologic relevance of $\mathrm{Mb}$-mediated nitrite reduction has been demonstrated in hearts excised from $\mathrm{Mb} \mathrm{KO}$ mice, in which there was $\sim 50 \%$ reduction in $\mathrm{NaNO}_{2}(100 \mu \mathrm{mol} / \mathrm{l})$ derived $\mathrm{NO}$, compared with hearts of WT mice production after 30 minutes at $\mathrm{pH} 7.4$ (Hendgen-Cotta et al., 2008). These transgenics have also helped to confirm the biologic importance of this chemistry: WT mice subjected to left anterior coronary artery occlusion and treated with $48 \mathrm{nmol} / 1 \mathrm{NaNO}_{2}$ had $61 \%$ smaller infarcts compared with those with no treatment, whereas there was no difference between $\mathrm{NaNO}_{2}$-treated and untreated $\mathrm{Mb} \mathrm{KO}$ mice (Hendgen-Cotta et al., 2008). It has also been suggested that this chemistry of $\mathrm{Mb}$ is not simply restricted to the heart, since $\mathrm{Mb}$ is also present in vascular smooth muscle. Studies with mice and under systemic hypoxia, induced by ventilation with $10 \% \mathrm{O}_{2} / 90 \% \mathrm{~N}_{2}$, facilitated $\mathrm{NaNO}_{2}(10 \mu \mathrm{mol} / \mathrm{l})$ reduction that was associated with an $\sim 3$-fold and 2 -fold elevation in plasma and aortic cGMP, respectively (Totzeck et al., 2012).

c. Neuroglobin. Neuroglobin is found in the brain of humans and mice and shares $21 \%$ and $25 \%$ homology with $\mathrm{Mb}$ and $\mathrm{Hb}$, respectively (Burmester et al., 2000). Neuroglobin has been shown to express cytoprotective effects in vivo (Sun et al., 2003; Khan et al., 2006), although whether this relates to its ability to reduce nitrite to $\mathrm{NO}$ is unclear. The mechanism of nitrite reduction proposed is similar to that of the other globins; however, neuroglobin contains a hexa-coordinate heme atom, whereas $\mathrm{Mb}$ and $\mathrm{Hb}$ contain penta-coordinate heme atoms (Tiso et al., 2011). Recombinant murine and human neuroglobin elicit nitrite reductase activity when in the ferrous form under hypoxic conditions at $\mathrm{pH}$ 7.4 (Petersen et al., 2008; Tiso et al., 2011); however, the rate is $\sim 2000 \times$ faster in the penta-coordinate state as opposed to the hexa-coordinate state (Jayaraman et al., 2011; Tiso et al., 2011). One of the key differences between neuroglobin and the penta-coordinate globins, such as $\mathrm{Mb}$, is that a distal histidine residue is bound to the heme, whether in the ferrous or ferric form, and for the heme to react with nitrite, the histidine must dissociate from the heme. This issue is particularly relevant because mutations in the histidine of neuroglobin profoundly influence rates of nitrite reduction, i.e., removal of His64 (E7) in neuroglobin results in a $2500 \times$ increased rate of nitrite reduction compared with the WT (Tiso et al., 2011). Further studies exploring the nitrite reductase activity of neuroglobin more closely, by expressing the zebrafish protein (which has high homology with the human protein) in Escherichia coli, indicate that subtle alterations in the distal heme binding pocket can result in a profound change in nitrite reductase capacity, hinting at possibilities of engineering proteins with improved nitrite reductase activity (Tejero et al., 2015).

d. Cytoglobin. Cytoglobin, although originally thought to be predominantly a liver protein, is now known to be widely expressed (Burmester et al., 2000) across species and has been found in human, mouse, and zebrafish, sharing $\sim 30 \%$ homology with $\mathrm{Mb}$ and $\mathrm{Hb}$ (Burmester et al., 2000). Similar to neuroglobin, the heme atom is in a hexa-coordinate state, and a pentacoordinate state is required for nitrite reduction. Under hypoxic conditions, which favor nitrite reduction, cytoglobin expression is elevated (Fordel et al., 2004). However, initially it was suggested that recombinant mouse ferrous cytoglobin had no nitrite reductase activity at $\mathrm{pH} 7.4$, with $7.4 \mu \mathrm{mol} / \mathrm{l}$ nitrite (Petersen et al., 2008). In contrast, a subsequent study has shown that although oxygenated cytoglobin, similarly to $\mathrm{Hb}$, will react with $\mathrm{NO}$ to form nitrate and so act to scavenge $\cdot \mathrm{NO}$, under anaerobic conditions and at $\mathrm{pH}$ 
7.4 or 8 , ferrous cytoglobin reduces $\mathrm{NaNO}_{2}(100 \mu \mathrm{mol} / \mathrm{l})$ to form 'NO as measured by EPR (Li et al., 2012a). In addition to this reaction occurring under physiologic $\mathrm{pH}$, nitrite reduction by cytoglobin was found to increase with decreasing $\mathrm{pH}$ ( $\mathrm{Li}$ et al., 2012a). The discrepancy between the two studies may be due to the differing concentrations of nitrite used.

That the nitrite reductase activity is catalytic and thus potentially important in vivo (because of the widespread expression of cytoglobin in tissues) was recently elegantly demonstrated in experiments with both human and fish cytoglobin. Gladwin and colleagues demonstrated that cytochrome $b_{5}$ and cytochrome $b_{5}$ reductase reduce cytoglobin at rates that are up to $250 \times$ faster than for either $\mathrm{Hb}$ or $\mathrm{Mb}$. The authors suggest that this enhanced rate of activity with physiologic levels of the reactants intimates that cytoglobin is the primary substrate for these reductants in vivo and that, because of its relatively ubiquitous expression in tissues, cytoglobin may be a critical mechanism for $\cdot \mathrm{NO}$ generation from nitrite in physiology (Amdahl et al., 2017).

4. Indoleamine 2,3-Dioxygenase 1. Very recently, it has been demonstrated that indoleamine 2,3-dioxygenase 1 (IDO1), a cytosolic heme enzyme involved in the initial and rate-limiting step of L-tryptophan metabolism in the kynurenine pathway, is capable of reducing nitrite to $\mathrm{NO}$ under anaerobic conditions (Lim et al., 2019). Similar to $\mathrm{Mb}$ and $\mathrm{Hb}$, the heme in IDO1 is in a pentacoordinate state, which may account for the increased rates, as discussed above. A contrasting feature, in comparison with other heme-containing nitrite reductases, is that the nitrite reductase activity of IDO1 is enhanced in alkaline conditions ( $\mathrm{pH}$ 8), which Lim and colleagues speculate may be due to the close proximity of histidine residues potentially capable of donating a proton (Lim et al., 2019). These initial observations have been made in recombinant human IDO1, and further studies are required to assess the in vivo relevance of these findings.

5. Nitric Oxide Synthase. Under anoxic conditions, it has been demonstrated that endothelial NOS can function as a nitrite reductase (Gautier et al., 2006; Vanin et al., 2007). Recombinant eNOS in the presence of anoxia, with NADPH $(100 \mu \mathrm{mol} / \mathrm{l})$ and $\mathrm{NaNO}_{2}$ $(500 \mu \mathrm{mol} / \mathrm{l})$ at $\mathrm{pH} 7.6$, resulted in ferrous-nitrosyl eNOS formation and then, consequently, 'NO generation (Gautier et al., 2006). This proposal was supported by studies using ${ }^{15} \mathrm{~N}$-labeled $\mathrm{NaNO}_{2}$ with EPR measurements of $^{15}$.NO (Gautier et al., 2006). Subsequently, studies with recombinant iNOS and neuronal NOS have suggested that this activity is unique to the eNOS isoform, since neither isoform generated $\cdot \mathrm{NO}$ from relatively high concentrations of $\mathrm{NaNO}_{2}(500 \mu \mathrm{mol} / \mathrm{l})$ under anoxic conditions generated with argon (Mikula et al., 2009). In addition, we have shown that erythrocytes, collected from healthy individuals, when incubated with physiologic concentrations of $\mathrm{NaNO}_{2}$
(10-100 $\mu \mathrm{mol} / \mathrm{l})$ under hypoxic conditions, generate -NO; a response that is attenuated by the eNOS inhibitors $N(\gamma)$-nitro-L-arginine methyl ester (L-NAME) and NG-monomethyl-L-arginine acetate $(300 \mu \mathrm{mol} / \mathrm{l})(\mathrm{Webb}$ et al., 2008a). The identification of eNOS as a nitrite reductase under hypoxia and anoxia is an interesting finding and suggests that this enzyme, utilizing distinct substrates dependent upon the environmental conditions, may be equipped to produce $\cdot \mathrm{NO}$ under the full spectrum of oxygen tension that is experienced in vivo.

6. Carbonic Anhydrase. More recently it has been suggested that carbonic anhydrase, a key component involved in acid-base regulation in the body through the hydration of $\mathrm{CO}_{2}$ to produce protons and thus $\mathrm{H}_{2} \mathrm{O}$ and bicarbonate $\left(\mathrm{HCO}_{3}^{-}\right)$(eq. 1.8), also acts as a nitrite reductase, particularly in metabolically active tissue. Hydration of $\mathrm{CO}_{2}$ is as follows:

$\begin{gathered}\text { Carbon dioxide } \\ \mathrm{CO}_{2}+\end{gathered} \begin{gathered}\text { water } \\ \mathrm{H}_{2} \mathrm{O}\end{gathered} \Leftrightarrow \begin{gathered}\text { carbonic acid } \\ \mathrm{H}_{2} \mathrm{CO}_{3}\end{gathered} \Leftrightarrow \quad \begin{gathered}\text { bicarbonate } \\ \mathrm{HCO}_{3}^{-}\end{gathered}+\stackrel{\text { proton }}{\mathrm{H}^{+}}$

In 2004 work from Innocenti et al. (2004) demonstrated that anions, including nitrite, could bind to the active site of carbonic anhydrase and, in this way, inhibit $\mathrm{CO}_{2}$ hydration (Innocenti et al., 2004). However, it was not until 2009 that the possibility that this interaction of nitrite with the enzyme might actually yield $\cdot \mathrm{NO}$ too was considered. Addition of $\mathrm{NaNO}_{2}(100 \mu \mathrm{mol} / \mathrm{l})$ to purified carbonic anhydrase at $\mathrm{pH} 7.2$ resulted in $\cdot \mathrm{NO}$ generation, an effect that was potentiated at $\mathrm{pH} 5.9$ (Aamand et al., 2009). Addition of dorzolamide $(250 \mu \mathrm{mol} / \mathrm{l})$, an inhibitor of the hydration of $\mathrm{CO}_{2}$, resulted in a significant elevation of $\mathrm{NO}$ generation (Aamand et al., 2009). The explanation for the inhibitory activity for $\mathrm{CO}_{2}$ hydration but not nitrite reduction was suggested by the authors to imply that distinct binding sites for the two exist, with the inhibitors only binding to the active $\mathrm{Zn}^{2+}$ binding site for $\mathrm{CO}_{2}$. The reactions proposed to underlie this are shown previously (eqs. 1.4-1.6) with a theoretical $\mathrm{N}_{2} \mathrm{O}_{3}$ intermediate formed (the levels of which are increased with reducing $\mathrm{pH}$ ) that rapidly dissociates to give $\mathrm{NO}$ (along with an equivalent of $\mathrm{NO}_{2}$ ).

This nitrite-reducing activity of carbonic anhydrase was tested for functional importance using rat aorta segments treated with $\mathrm{NaNO}_{2}(10 \mu \mathrm{mol} / \mathrm{l})$ with and without dorzolamide. The studies showed, as with the purified enzyme, an increase $(\sim 50 \%)$ in the functional relaxation response to $\mathrm{NaNO}_{2}$ (Aamand et al., 2009). However, using EPR and measurement of nitrosyl $\mathrm{Hb}$ as a readout, inhibition of carbonic anhydrase using dorzolamide did not affect erythrocyte nitrite reduction (Liu et al., 2015). Recently, it has also been shown that human platelets treated with $\mathrm{NaNO}_{2}(100 \mu \mathrm{mol} / \mathrm{l})$ showed no change in cGMP or phospho-vasodilatorstimulated phosphoprotein (phospho-VASP) ${ }^{\mathrm{S} 239}$, a marker 
of protein kinase $\mathrm{G}$ activity; however, with the addition of recombinant bovine carbonic anhydrase, there was a significant elevation in both markers (Hanff et al., 2016). In healthy volunteers, treatment with dorzolamide enhanced $\mathrm{NaNO}_{2}$-induced vasodilation of the radial artery (Omar et al., 2015) and a similar BP-lowering effect was seen in healthy volunteers treated with acetazolamide and $\mathrm{NaNO}_{2}$ (Rosenbaek et al., 2018). In contrast, more recently, a re-evaluation of the nitrite reductase activity of carbonic anhydrase has suggested little activity. Incubation of purified bovine carbonic anhydrase at $\mathrm{pH} 5.9$ with $100 \mu \mathrm{mol} / \mathrm{l}$ $\mathrm{NaNO}_{2}$ demonstrated neither $\mathrm{N}_{2} \mathrm{O}_{3}$ nor $\cdot \mathrm{NO}$ generation (Andring et al., 2018).

Although it is clear that there are numerous mammalian nitrite reductases that have been identified in cell-free and cellular preparations, in WT and transgenic animals, and in humans, the importance of these discoveries lies within the translational potential for enhanced -NO delivery into real benefits in health and disease. Below we discuss the major therapeutic areas in which targeting and translation of the noncanonical pathway for NO in humans and patients has been investigated.

\section{Functional Effects of the Noncanonical NO Pathway and Clinical Translation}

Nitrite has been used as a cyanide antidote for more than 75 years (Butler and Feelisch, 2008) and is used in food preservation to prevent oxidation of fatty acids and to prevent rancidity and malodor formation, as well as critically controlling $C$. botulinum growth and toxin production (Hustad et al., 1973; Honikel, 2008). In addition, inorganic nitrite and nitrate have been used as therapeutics in the CV system for over 85 years (Reichert and Mitchell, 1880; Stieglitz, 1927), but it is only through the relatively recent renewed interest in these anions that potential translational opportunities more broadly have been assessed.

The overwhelming evidence supporting the existence and functional efficacy of this noncanonical pathway for -NO generation has raised interest, particularly to "rescue" levels of $\mathrm{NO}$ in diseases in which reduced bioavailability plays a prominent role in pathogenesis. This is of interest particularly in CVD, in which a deficiency of bioavailable $\mathrm{NO}$ driven by decreased L-arginine-derived ' $\mathrm{NO}$ generation is thought to contribute to pathology.

Although there is limited data on the beneficial effects of nitrite elevation directly or via oral conversion of inorganic nitrate in a miscellany of unrelated conditions, such as periodontitis (Jockel-Schneider et al., 2016) and urea cycle disorders (Erez et al., 2011; Nagamani et al., 2012), there is a wealth of published preclinical and clinical studies demonstrating efficacy in disease areas in which known $\cdot \mathrm{NO}$ deficiency contributes to, or $\cdot \mathrm{NO}$ supplementation slows, disease progression.

\section{A. Nitrite, Nitrate, and the CV System}

Because of the classic role of eNOS-derived $\cdot \mathrm{NO}$, and lack thereof, in CV health and disease (Moncada and Higgs, 2006), nitrite and nitrate as therapeutics are most advanced in the realm of CVD.

1. Vasodilation. Although it had been long since demonstrated that once-acidified supraphysiologic concentrations of inorganic nitrite exerted significant vasodilator responses (Furchgott and Bhadrakom, 1953), it was only more recently in 2001 that the view that nitrite was inert at physiologic levels within the CV system was finally eroded. In rat aortic rings, application of low micromoles per liter $\mathrm{NaNO}_{2}(2.5 \mu \mathrm{mol} / \mathrm{l})$, although inactive under physiologic $\mathrm{pH}$, was shown to cause significant relaxation of precontracted rat aorta under acidic ( $\mathrm{pH}$ 6.6) conditions (Modin et al., 2001). The importance of this observation was finally appreciated with demonstration by Gladwin and colleagues that infusion of $\mathrm{NaNO}_{2}$ into the forearm of healthy volunteers causes vasodilatation with concomitant increased forearm blood flow, a phenomenon augmented when the volunteers were asked to exercise by conducting handgrips (Cosby et al., 2003). The authors proposed that this effect of exercise to increase nitrite-induced vasodilation related to the fact that conversion of nitrite to $\cdot \mathrm{NO}$ is enhanced under reduced $\mathrm{O}_{2}$ conditions. This observation simply and elegantly indicated that nitrite exerts significant biologic effects in the relative hypoxia created by conditions relevant to the normal and typical ranges in $\mathrm{O}_{2}$ tension that occur in day-to-day activity. These findings intimated a potentially important role of this anion in sustaining/regulating normal vasodilator tone in the healthy individual, particularly since, in the normal passage of blood through the circulation, $\mathrm{O}_{2}$ tension will drop from $100 \mathrm{~mm} \mathrm{Hg}$ as it exits the heart to $40 \mathrm{~mm} \mathrm{Hg}$ when it returns via the venous circulation.

The thesis that $\mathrm{O}_{2}$ tension determines the contribution that nitrite plays in regulating vascular tone was further developed by studies conducted by Frenneaux and colleagues, who used radiolabeled, autologous blood together with standard forearm plethysmographic techniques, thus enabling the separate determination of arterial and venous vasodilation. Vascular reactivity was measured over a 20 -minute infusion period. Under normoxic conditions, intra-arterial delivery of increasing doses of $\mathrm{NaNO}_{2}(314 \mathrm{nmol} / \mathrm{min}$ to $7.84 \mu \mathrm{mol} / \mathrm{min})$ decreased venous tone in a dose-dependent manner by up to 20\%-35\% (Maher et al., 2008). However, in contrast to Gladwin and colleagues' earlier works (Cosby et al., 2003), low-dose $\mathrm{NaNO}_{2}$ infusions (314 nmol/min), associated with $\sim 30 \%$ increases in forearm blood flow, did not dilate the arterial side of the circulation (Maher et al., 2008). Indeed, arterial dilation was only apparent (increasing forearm blood flow by $60 \%-80 \%$ ) at much higher 
doses (3.14-7.84 $\mu \mathrm{mol} / \mathrm{min}$ ) (Maher et al., 2008). These findings replicate much earlier work that used detailed tilt-table testing to elucidate the role of dilation of the venous circulation (and not arterial circulation) as the cause of nitrite-induced CV collapse (Weiss et al., 1937; Wilkins et al., 1937). However, to make the arterial side of the circulation "hypoxic," subjects were put through the protocol again, but only after arterial oxygen saturations were maintained at $83 \%-88 \%$ by breathing $12 \%$ $\mathrm{O}_{2}$. In this situation, although there was no change in the magnitude or duration of the effects on the venous side of the circulation, infusion of $314 \mathrm{nmol} / \mathrm{min} \mathrm{NaNO}_{2}$ (which had no effect in normoxic conditions) increased forearm blood flow by $\sim 40 \%$ (Maher et al., 2008). Such a finding is consistent with the concept that the vasodilator potential of nitrite is not solely limited to anoxia or extreme ischemia but is proportional to the extent of "hypoxia" in the tissues and blood as it deoxygenates from arterial to venous sides.

More recently, the effect of nitrite on muscular, conduit blood vessels has been shown. Infusion of a single dose of $\mathrm{NaNO}_{2}(8.7 \mu \mathrm{mol} / \mathrm{min})$ for 60 minutes into the brachial artery caused an $\sim 30 \%$ increase in radial artery diameter (Omar et al., 2015). Comparison of the dose-response relationship of $\mathrm{NaNO}_{2}$ to GTN demonstrated comparable effects. For example, with an infusion of $\mathrm{NaNO}_{2}$ of $26 \mu \mathrm{mol} / \mathrm{min}(1.8 \mathrm{mg} / \mathrm{min})$ for 20 minutes, a statistically significant $\sim 30 \%$ increase in diameter was evident, a magnitude of response similar to that produced in the same healthy volunteers by GTN $1.3 \mathrm{nmol} / \mathrm{min}$, which is equivalent to $0.3 \mu \mathrm{g} / \mathrm{min}$ (Omar et al., 2015). Furthermore, similar effects have been seen in the coronary circulation (O'Gallagher et al., 2018). Paradoxically the effect in the peripheral circulation was most pronounced in normoxia and inhibited by hypoxia or hyperoxia (Omar et al., 2015), an observation that conflicts with the findings previously discussed. Exactly why this is the case is uncertain.

Physiologically, the role of nitrite as an endocrine storage form of $\mathrm{NO}$ that is released after a decrease in $\mathrm{O}_{2}$ tension and is thus responsible for hypoxic vasodilatation has been investigated. Hypoxic vasodilation is responsible for matching $\mathrm{O}_{2}$ demand from respiring tissues to $\mathrm{O}_{2}$ delivery; thus, when metabolic demand rises, $\mathrm{O}_{2}$ consumption increases, and with this, a mild hypoxia develops that then triggers vasodilation to increase $\mathrm{O}_{2}$ availability to the organ. Erythrocytes have been identified as a key hypoxic sensor acting as a source of 'NO delivery that underlies the biologic effect (Segal and Duling, 1986; Stamler et al., 1997). However, two competing theories for the form of $\mathrm{NO}$ that is transported and stored ready to deliver $\mathrm{NO}$ on demand have been proposed: nitrite and $S$-nitrosothiols. Arterial-venous gradients of nitrite (Gladwin et al., 2000) and nitrosothiols (Stamler et al., 1992), and the formation of iron-nitrosylHb or S-nitroso-Hb as markers of consumption and $\mathrm{NO}$ delivery have been measured in the peripheral and cerebral circulation, with exercise and under hypoxia. These studies demonstrate clear evidence of arterial-venous gradients for nitrite and formation of iron-nitrosylHb only, suggesting a role for nitrite as an endocrine reservoir of $\mathrm{NO}$ activity (Gladwin et al., 2000; Bailey et al., 2017).

It is likely that nitrite-induced vasodilatation is dependent upon activation of the canonical $\mathrm{NO}$-dependent GC-1 pathway, since the GC-1 inhibitor $1 \mathrm{H}-[1,2,4]-$ oxadiazolo[4,3-a]quinoxalin-1-one (ODQ) attenuates responses to nitrite in blood vessels of rodents and pigs (Botden et al., 2012; Ghosh et al., 2013). It is noteworthy that these observations recapitulate much earlier studies using drugs such as methylene blue to block GC-1 activity (Mittal et al., 1978; Ignarro and Gruetter, 1980; Gruetter et al., 1981); however, such observations have not been observed in all vascular beds tested. Recent studies in the renal microvasculature of the mouse demonstrate nitrite is two orders of magnitude more potent than in other vascular beds (Gao et al., 2015). Interestingly, 'NO scavenging abolished nitrite-induced vasodilatation, but treatment with ODQ did not, indicating a GC-1independent effect. In the same study, inorganic nitrate supplementation reduced NADPH oxidase activity, a prime source of oxidative stress, and the actions of NADPH oxidase inhibition were synonymous and not additive. These results suggest that NADPH oxidase, at least in the renal microvasculature, could be a mechanistic target for nitrite-derived $\cdot \mathrm{NO}$ and associated $\mathrm{BP}$ lowering through reduction in oxidative stress (Gao et al., 2015).

Furthermore, there may be additional effects on vascular tone that are affected by nitrite-derived $\cdot \mathrm{NO}$ that are centrally driven. Elevation of systemic nitrite levels reduces renal sympathetic nerve signaling in rats under L-NAME or angiotensin II-driven hypertension. This treatment also reduces muscle sympathetic nerve activity in humans, a gold-standard measure of efferent sympathetic signaling (Notay et al., 2017; Guimarães et al., 2019). The precise mechanism of nitrite-derived -NO sympatholysis is not known but may relate to alterations in expression of angiotensin II receptors in the rostral ventral lateral medulla, the brainstem sympathetic control center (Guimarães et al., 2019), or to changes in peripheral chemoreflex activity. The peripheral chemoreflex is primarily responsible for augmenting ventilation in response to hypoxia but is known to be augmented in human hypertension in the absence of hypoxia and responsible for elevated BP through efferent central sympathetic signaling (Marshall, 1994), and this mechanism is attenuated after inorganic nitrate supplementation in older adult humans (Bock et al., 2018b).

Irrespective of the precise mechanism, these reported effects of nitrite on vascular tone raise the possibility that systemic nitrite administration or dietary nitrate 
supplementation, as a means to elevate circulating levels of nitrite, may be useful in the treatment of hypertension.

2. Blood Pressure. These demonstrations of the vasodilator potential of nitrite are also concordant with the effects of nitrite supplementation in normotensive animals, as well as in animal models of hypertension. In anesthetized rats, administration of $\mathrm{NaNO}_{2}$ (10-1000 $\mu \mathrm{mol} / \mathrm{kg}$, i.v.) was associated with dosedependent reductions in MAP for up to 30 minutes (Vleeming et al., 1997), observations we ourselves have reproduced in conscious tethered rats (Ghosh et al., 2013). In free-moving rats, supplementation of drinking water with extremely high concentrations of $\mathrm{NaNO}_{2}$ ( $36 \mathrm{mmol} / \mathrm{l}$ equivalent to $2.48 \mathrm{~g} / \mathrm{l}$ ) reduced $\mathrm{BP}$ measured by telemetry (Vleeming et al., 1997). If we consider that a typical Sprague-Dawley or Wistar averaged-sized adult rat $(\sim 250 \mathrm{~g})$ will drink $30-50 \mathrm{ml}$ of water daily, this would give a maximum daily dose of $\mathrm{NaNO}_{2}$ of $124 \mathrm{mg}$, which in turn, would approximate to $500 \mathrm{mg} / \mathrm{kg}$, a level exceeding the ADI by 135 times. Nevertheless, these early studies clearly demonstrate BP-lowering potential.

Similarly, in spontaneously hypertensive rats, acute bolus doses of $\mathrm{KNO}_{2}(1-30,000 \mathrm{nmol} / \mathrm{kg}$, equivalent to $\sim 10 \mathrm{nmol}$ to $0.3 \mathrm{mmol} / \mathrm{l}$ circulating concentrations) (Ghosh et al., 2013), as well as prolonged oral administration (up to 1 year) of extremely high concentrations of $\mathrm{NaNO}_{2}$ (50-100 mmol/l equating to $3.5-6.9 \mathrm{~g} / \mathrm{l}$ in drinking water), were associated with dose-dependent reductions in BP (Beier et al., 1995; Haas et al., 1999). These observations indicate two important issues: firstly, that the efficacy of nitrite was still evident in the setting of raised BP [indeed, our studies indicated a substantially enhanced potency of nitrite in this setting (Ghosh et al., 2013)], and secondly, that significant BP lowering was evident even after 1 year of ingestion. This latter observation hints at a key characteristic of nitrite, and potentially nitrate, that might endow these anions with a superior potential for therapeutics over the organic nitrates, i.e., no development of tolerance, which is the key limiting factor in the use of organic nitrates clinically (Münzel et al., 2005). This was tested more formally by Dejam et al. (2007), in which $\mathrm{NaNO}_{2}(12.5 \mu \mathrm{g} / \mathrm{kg}$ per minute) was infused in primates continuously over a 2 -week period and was also followed by a daily bolus of $\mathrm{NaNO}_{2}$ at a dose of $12,000 \mu \mathrm{g} / \mathrm{kg}$ per minute. This bolus dose lowered MAP by $18 \mathrm{~mm} \mathrm{Hg}$, with no diminution of effect over time, indicating lack of tolerance. The utility of nitrite as an antihypertensive either by acute or chronic daily oral gavage or supplementation in water has been confirmed in other models of hypertension, such as the deoxycorticosterone acetate (DOCA)-salt, two-kidney/one-clip, and L-NAME-induced hypertension (Tsuchiya et al., 2005; Montenegro et al., 2011, 2012; Amaral et al., 2015).
There is also evidence that nitrite lowers BP in humans. Infusion of $\mathrm{NaNO}_{2}$ into the brachial artery was associated with local nitrite concentrations of $\sim 200 \mu \mathrm{mol} / \mathrm{l}$ and systemic elevation of nitrite to $16 \mu \mathrm{mol} / \mathrm{l}$ and was associated with a reduction in MAP of $7 \mathrm{~mm} \mathrm{Hg}$ (Cosby et al., 2003). Further studies from the same group using stepped brachial infusions of $\mathrm{NaNO}_{2}$ achieving local venous plasma nitrite concentrations of $30 \mu \mathrm{mol} / \mathrm{l}$ were associated with a drop in MAP of $10 \mathrm{~mm} \mathrm{Hg}$, an effect that persisted for up to 3 hours (Dejam et al., 2007). Studies assessing the feasibility of long-term infusion of $\mathrm{NaNO}_{2}$ in humans has been assessed in healthy volunteers. Pluta et al. (2011) examined the duration of action of increasing doses of $\mathrm{NaNO}_{2}(4.2-445.7 \mu \mathrm{g} / \mathrm{kg}$ per hour $)$ in healthy volunteers, measuring circulating levels of nitrite, together with assessment of metHB levels and BP. This approach was taken because nitrite has a short half-life ( $\sim 30$ minutes), and the authors wished to identify whether continuous infusion might provide a mechanism to exert persistent effects upon blood flow, particularly focusing upon the potential in conditions such as cerebral vasospasm. In this study, they showed that the BP-lowering effects of $\mathrm{NaNO}_{2}$ were maintained over 48 hours and were dose-dependent but that ceasing of infusion resulted in a prompt restoration of $\mathrm{BP}$ to baseline levels in association with circulating levels of nitrite (Pluta et al., 2011).

The authors of some of the earlier animal studies assessing responses to $\mathrm{NaNO}_{2}$ hypothesized that elevation of systemic nitrite levels from nitrate via bacterial reduction would reduce $\mathrm{BP}$, although they did not explicitly test this (Classen et al., 1990; Vleeming et al., 1997). However, there is now a substantial body of evidence in both animal models and humans to support this proposal.

In rats supplemented with $10 \mathrm{mmol} / / \mathrm{NaNO}_{3}$ in drinking water over a week, $\mathrm{BP}$ was reduced when measured by cannulation under anesthesia or in freemoving animals using telemetric methods compared with matched control. This effect of $\mathrm{NaNO}_{3}$ was abolished by use of antibacterial mouthwash twice daily. Notably, this oral treatment did not affect BP lowering in response to $\mathrm{NaNO}_{2}$ supplementation (Petersson et al., 2009). In uninephrectomized rats fed a high-salt diet as a model of hypertension, supplementation with $\mathrm{NaNO}_{3}$ (0.1-1 mmol/kg per day) lowered BP and ameliorated cardiac and renal fibrosis, suggesting beneficial effects beyond BP lowering (Carlström et al., 2011).

A key feature in human hypertension and CVD is that eNOS is dysfunctional, resulting in a generalized $\mathrm{NO}$ deficiency. Several research groups have sought to explore the potential utility of nitrite and/or nitrate ${ }^{-}$ to restore $\mathrm{NO}$ homeostasis and lower BP in hypertensive animal models driven by reduced eNOS activity. Using the eNOS inhibitor L-NAME to induce hypertension, administration of $\mathrm{NaNO}_{2}$ in drinking water 
(20-200 $\mu \mathrm{mol} / \mathrm{l})$ or by oral gavage $(0.2 \mathrm{mmol} / \mathrm{kg}$ per day) for 3 to 4 weeks prevented the development of hypertension (Tsuchiya et al., 2005; Montenegro et al., 2014). Similarly, oral gavage with $0.1 \mathrm{mmol} / \mathrm{kg}$ per day $\mathrm{NaNO}_{3}$ reduced BP in both eNOS KO mice and L-NAME-treated rats (Carlström et al., 2010, 2015). These results suggest that elevating systemic nitrite levels, whether directly or via dietary nitrate supplementation, can compensate for diminished eNOSderived $\cdot \mathrm{NO}$, whether it is provided as a pretreatment or used to reverse pre-existing hypertension driven by reduced $\cdot \mathrm{NO}$ levels.

The above studies and concepts have been translated into a range of clinical studies. Although much of the preclinical data suggests that inorganic nitrite and nitrate are efficacious approaches to lower BP, whatever the cause of the hypertension, in the clinical setting, the majority of the studies to date have tested dietary nitrate rather than nitrite, and this relates to a number of reasons that include issues related to half-life and potential toxicity (discussed later).

Given the pharmacokinetic disadvantages of nitrite as a long-term therapy, only one major human study has explored inorganic nitrite therapy and BP control specifically. In this study, individual adults aged 5079 , who were free of all cardiometabolic disease and were normotensive at the start of the study (but with diminished endothelial function at baseline), were randomized in three parallel groups to receive either $40 \mathrm{mg}(0.6 \mathrm{mmol})$ or $80 \mathrm{mg}(1.2 \mathrm{mmol}) \mathrm{NaNO}_{2}$ or placebo, all twice daily for 10 weeks $(n=10-11)$. Trough plasma nitrite levels were significantly elevated $(\sim 2-$ fold) in both intervention groups after 10 weeks, but this was not associated with any change in BP (DeVan et al., 2016). The lack of any BP lowering in subjects with optimal/normal BP is not surprising and may be considered ideal, identifying an approach that does not lead to symptomatic hypotension and/or hypotension-related syncope. The lack of any BP effect likely reflects the accepted dogma that the magnitude of $\mathrm{BP}$ reduction expected from any single dose of antihypertensive agent is proportional to basal BP level (Law et al., 2003). However, this result is at odds with the majority of studies that demonstrate BP lowering in normotensive persons after systemic nitrite elevation after inorganic nitrate supplementation (Table 1) (Larsen et al., 2006; Webb et al., 2008b; Bailey et al., 2009, 2010; Kapil et al., 2010; Sobko et al., 2010; Vanhatalo et al., 2010; Lansley et al., 2011a,b; Bahra et al., 2012; Bondonno et al., 2012, 2014b; Cermak et al., 2012a; Coles and Clifton, 2012; Bond et al., 2013, 2014; Joris and Mensink, 2013; Kelly et al., 2013; Liu et al., 2013; Wylie et al., 2013; Jajja et al., 2014; Rammos et al., 2014; Ashor et al., 2015; Ashworth et al., 2015; Bourdillon et al., 2015; Jovanovski et al., 2015; Lee et al., 2015; Choi et al., 2016; Flueck et al., 2016; Jonvik et al., 2016; Raubenheimer et al., 2017; Jones et al., 2019). The first contemporary demonstration of BP-lowering effect of inorganic nitrate via conversion to nitrite used $\mathrm{NaNO}_{3}[0.1 \mathrm{mmol} / \mathrm{kg}(6.2 \mathrm{mg} / \mathrm{kg})]$ daily for 3 days compared with matched $\mathrm{NaCl}$ control in 17 healthy subjects. Plasma nitrite levels increased $\sim 1.5$-fold after nitrate supplementation only, together with a significant reduction in diastolic BP (DBP; $\Delta 3.7 \mathrm{~mm} \mathrm{Hg}$ ) (Larsen et al., 2006).

Nitrate is also available in dietary form from vegetables, so the equivalency of providing nitrate in salt form (as $\mathrm{KNO}_{3}$ ) and dietary form (as beetroot juice) was established by us in 2008 . Acute, single administration of $22.5 \mathrm{mmol}$ ( $1395 \mathrm{mg}$ ) dietary nitrate as beetroot juice (compared with water control) and an approximate equivalent of $\mathrm{KNO}_{3}$ (24 mmol; $1488 \mathrm{mg}$ nitrate) compared with matched $\mathrm{KCl}$ control in separate cohorts of healthy subjects demonstrated similar time courses of systemic nitrite elevation and BP reduction over 24 hours. Peak nitrite levels were contemporaneous to peak BP reduction at 2.5-3 hours post-inorganic nitrate supplementation. Additionally, peak BP reduction from baseline was similar for both forms of inorganic nitrate supplementation $(\sim 10 / 7 \mathrm{~mm} \mathrm{Hg})$, with no changes in either placebo group (Webb et al., 2008b; Kapil et al., 2010) (Fig. 7A). Furthermore, change in SBP was significantly inversely correlated to changes in plasma nitrite and the determining effect on $\mathrm{BP}$ (Webb et al., 2008b; Kapil et al., 2010). These studies additionally demonstrated a dose-dependent effect of inorganic nitrate supplementation on BP reduction and provided the first evidence of bioactive $\cdot \mathrm{NO}$ production after nitrate supplementation by determining significant elevation of circulating cGMP concentrations (Kapil et al., 2010); cGMP is a sensitive marker that confirms bioactive $\mathrm{NO}$ generation (Batchelor et al., 2010). An unintended but positive outcome of our work has been the introduction of beetroot juice, with known and measurable amounts of nitrate, as a mechanism to explore the biologic efficacy of the enterosalivary circuit of nitrate. The impact of this is shown in a PubMed search demonstrating the uptake of this approach after the 2008 publication (Fig. 8).

The importance of enterosalivary generation of nitrite was confirmed in our studies by asking subjects to refrain from swallowing saliva post-nitrate ingestion, thereby interrupting oral nitrate reduction but not interfering with nitrate absorption itself (Webb et al., 2008b). Elevation of circulating nitrate levels were unaffected by this intervention, but it did prevent the rise in circulating plasma nitrite level as had been demonstrated by others previously (Lundberg and Govoni, 2004). However, in addition to this, we demonstrated that this effect was associated with an absence of the BP reduction effect, thus confirming nitrite as the bioactive moiety after nitrate supplementation (Webb et al., 2008b).

Although the acute (i.e., $<24$ hour) effects of inorganic and dietary nitrate supplementation on BP are 
TABLE 1

Randomized, controlled studies evaluating nitrate supplementation on blood pressure in healthy volunteers

\begin{tabular}{|c|c|c|c|c|c|c|}
\hline Reference & Cohort & Design & Intervention & $\begin{array}{l}\text { Treatment } \\
\text { Duration }\end{array}$ & Baseline BP (mm Hg) & $\operatorname{Max} \Delta \mathrm{BP}(\mathrm{mm} \mathrm{Hg})$ \\
\hline Larsen et al., 2006 & $\begin{array}{c}\mathrm{HV} \\
\text { Age }=24\end{array}$ & $\begin{array}{l}\text { Crossover } \\
n=17\end{array}$ & $\begin{array}{l}\mathrm{NaNO}_{3}, 0.1 \mathrm{mmol} / \mathrm{kg} \text { per day } \\
\mathrm{NaCl}, 0.1 \mathrm{mmol} / \mathrm{kg} \text { per day placebo }\end{array}$ & 3 days & Clinic BP not stated & N.S./-3.7 \\
\hline Webb et al., 2008b & $\begin{array}{c}\mathrm{HV} \\
\text { Age }=26\end{array}$ & $\begin{array}{l}\text { Crossover } \\
n=14\end{array}$ & $\begin{array}{l}\text { Beetroot juice }(500 \mathrm{ml}), 22.5 \mathrm{mmol} \text { nitrate } \\
\text { Matched-volume water control }\end{array}$ & 1 day & Clinic 108/70 & $-10.4 /-8.0$ \\
\hline Bailey et al., 2009 & $\begin{array}{c}\text { HV } \\
\text { Age }=26\end{array}$ & $\begin{array}{l}\text { Crossover } \\
n=8\end{array}$ & $\begin{array}{l}\text { Beetroot juice, } 11.2 \text { mmol nitrate } \\
\text { Matched-volume black currant juice control }\end{array}$ & 6 days & Clinic BP not stated & -6/ N.S. \\
\hline Kapil et al., 2010 & $\begin{array}{c}\mathrm{HV} \\
\text { Age }=23\end{array}$ & $\begin{array}{l}\text { Crossover } \\
n=20\end{array}$ & $\begin{array}{l}\mathrm{KNO}_{3}, 24 \mathrm{mmol} \\
\mathrm{KCl}, 24 \mathrm{mmol} \text { placebo }\end{array}$ & 1 day & Clinic 110/70 & $-9.4 /-6.0$ \\
\hline Kapil et al., 2010 & $\begin{array}{c}\mathrm{HV} \\
\text { Age }=25\end{array}$ & $\begin{array}{l}\text { Crossover } \\
n=9\end{array}$ & $\begin{array}{l}\text { Beetroot juice }(250 \mathrm{ml}), 5.6 \mathrm{mmol} \text { nitrate } \\
\text { Matched-volume water control }\end{array}$ & $3 \mathrm{~h}$ & Clinic 121/71 & $-5.4 /$ N.S. \\
\hline Bailey et al., 2010 & $\begin{array}{c}\text { HV } \\
\text { Age }=28\end{array}$ & $\begin{array}{l}\text { Crossover } \\
n=7\end{array}$ & $\begin{array}{l}\text { Beetroot juice, } 5.1 \mathrm{mmol} \text { nitrate } \\
\text { Matched-volume black currant juice control }\end{array}$ & 6 days & Clinic 125/73 & $-5 /-2$ \\
\hline $\begin{array}{l}\text { Vanhatalo et al., } \\
2010\end{array}$ & $\begin{array}{c}\mathrm{HV} \\
\text { Age }=29\end{array}$ & $\begin{array}{l}\text { Crossover } \\
n=8\end{array}$ & $\begin{array}{l}\text { Beetroot juice, } 5.2 \text { mmol nitrate } \\
\text { Matched-volume black currant juice control }\end{array}$ & 15 days & Clinic $127 / 72$ & $-7 /$ N.S. \\
\hline Sobko et al., 2010 & $\begin{array}{c}\mathrm{HV} \\
\text { Age }=36\end{array}$ & $\begin{array}{l}\text { Crossover } \\
n=25\end{array}$ & $\begin{array}{l}\text { Japanese diet, } 0.3 \mathrm{mmol} / \mathrm{kg} \text { per day nitrate } \\
\text { Low-nitrate diet (nitrate content not stated) }\end{array}$ & 10 days & Clinic BP not stated & N.S./ -4.5 \\
\hline Lansley et al., 2011b & $\begin{array}{c}\mathrm{HV} \\
\text { Age }=22\end{array}$ & $\begin{array}{l}\text { Crossover } \\
n=9\end{array}$ & $\begin{array}{l}\text { Beetroot juice, } 6.2 \mathrm{mmol} \text { nitrate } \\
\text { Nitrate-deplete beetroot juice placebo }\end{array}$ & 6 days & Clinic 129/66 & $-5 /$ N.S. \\
\hline Lansley et al., 2011a & $\begin{array}{c}\mathrm{HV} \\
\text { Age }=21\end{array}$ & $\begin{array}{l}\text { Crossover } \\
n=9\end{array}$ & $\begin{array}{l}\text { Beetroot juice, } 6.2 \mathrm{mmol} \text { nitrate } \\
\text { Nitrate-deplete beetroot juice placebo }\end{array}$ & $2.5 \mathrm{~h}$ & Clinic 131/72 & $-6 /$ N.S. \\
\hline Cermak et al., 2012a & $\begin{array}{c}\text { HV } \\
\text { Age }=31\end{array}$ & $\begin{array}{l}\text { Crossover } \\
n=12\end{array}$ & $\begin{array}{l}\text { Beetroot juice, } 8 \mathrm{mmol} \text { nitrate } \\
\text { Nitrate-deplete beetroot juice placebo }\end{array}$ & 6 days & Clinic 119/74 & N.S. \\
\hline $\begin{array}{l}\text { Coles and Clifton } \\
2012\end{array}$ & $\begin{array}{l}\mathrm{HV} \\
\text { Age }=43\end{array}$ & $\begin{array}{c}\text { Crossover } \\
n=30\end{array}$ & $\begin{array}{l}\text { Beetroot juice, } 7.5 \text { mmol nitrate } \\
\text { Matched-volume apple juice (colored) }\end{array}$ & 1 day & $\begin{array}{l}\text { Clinic } 132 / 81 \\
24 \text { h ABP not stated }\end{array}$ & $\begin{array}{l}\text { N.S. } \\
\text { N.S. }\end{array}$ \\
\hline Bahra et al., 2012 & $\begin{array}{c}\mathrm{HV} \\
\text { Age }=28\end{array}$ & $\begin{array}{l}\text { Crossover } \\
n=14\end{array}$ & $\begin{array}{l}8 \mathrm{mmol} \mathrm{KNO} \\
8 \mathrm{mmol} \mathrm{KCl} \text { placebo }\end{array}$ & $3 \mathrm{~h}$ & $116 / 67$ & $-4.9 /$ N.S. \\
\hline $\begin{array}{l}\text { Bondonno et al., } \\
2012\end{array}$ & $\begin{array}{c}\mathrm{HV} \\
\text { Age }=47\end{array}$ & $\begin{array}{c}\text { Crossover } \\
n=30\end{array}$ & $\begin{array}{l}\text { High-nitrate meal (spinach), } 2.9 \mathrm{mmol} \\
\text { nitrate } \\
\text { Low-nitrate meal (apple) or drink (rice } \\
\text { milk), each }<0.1 \mathrm{mmol}\end{array}$ & $3.3 \mathrm{~h}$ & Clinic 112/68 & $-2.7 /$ N.S. \\
\hline Kelly et al., 2013 & $\begin{array}{c}\mathrm{HV} \\
\text { Age }=64\end{array}$ & $\begin{array}{c}\text { Crossover } \\
n=12\end{array}$ & $\begin{array}{l}\text { Beetroot juice, } 9.6 \mathrm{mmol} \text { nitrate } \\
\text { Nitrate-deplete beetroot juice placebo }\end{array}$ & 3 days & Clinic 125/74 & $-5 /-3$ \\
\hline Liu et al., 2013 & $\begin{array}{l}\text { HV } \\
\text { Age }=59\end{array}$ & $\begin{array}{c}\text { Crossover } \\
n=26\end{array}$ & $\begin{array}{l}\text { High-nitrate meal (spinach), } 3.5 \mathrm{mmol} \\
\text { nitrate } \\
\text { Low-nitrate meal + rice milk (nitrate } \\
\text { content not stated) }\end{array}$ & $3.5 \mathrm{~h}$ & Clinic 119/71 & $\begin{array}{l}-7.5 / \mathrm{N} . \mathrm{S} . \\
(\text { peak } 2 \mathrm{~h})\end{array}$ \\
\hline $\begin{array}{l}\text { Joris and Mensink, } \\
2013\end{array}$ & $\begin{array}{c}\mathrm{HV} \\
\text { Age }=61\end{array}$ & $\begin{array}{l}\text { Crossover } \\
n=20\end{array}$ & $\begin{array}{l}\text { Beetroot juice, } 8.0 \text { mmol nitrate } \\
\text { Control drink (not specified) }\end{array}$ & $4 \mathrm{~h}$ & Clinic 135/93 & N.S./-4 \\
\hline Wylie et al., 2013 & $\begin{array}{l}\text { HV } \\
\text { Age }=23\end{array}$ & $\begin{array}{c}\text { Crossover } \\
\text { (four limbs) } \\
n=10\end{array}$ & $\begin{array}{l}\text { Beetroot juice, } 4.2,8.4 \text {, and } 16.8 \mathrm{mmol} \\
\text { nitrate } \\
140 \mathrm{ml} \text { water control }\end{array}$ & 1 day & Clinic 119/68 & $\begin{array}{l}16.8 \mathrm{mmol}:-9 /-4 \text {; } \\
8.4 \mathrm{mmol}:-10 /-3 \text {; } \\
4.2 \mathrm{mmol}:-5 / \mathrm{N} . \mathrm{S} \text {. }\end{array}$ \\
\hline $\begin{array}{l}\text { Bond et al., } 2013 \\
\text { Bond et al., } 2014\end{array}$ & $\begin{array}{c}\mathrm{HV} \\
\text { Age }=21\end{array}$ & $\begin{array}{l}\text { Crossover } \\
n=12\end{array}$ & $\begin{array}{l}\text { Beetroot juice, } 12.1 \mathrm{mmol} \text { nitrate } \\
\text { Matched-volume orange juice }\end{array}$ & $2 \mathrm{~h}$ & Clinic BP not stated & $-5 /$ N.S. \\
\hline $\begin{array}{l}\text { Bondonno et al., } \\
2014 \mathrm{~b}\end{array}$ & $\begin{array}{c}\text { HV } \\
\text { Age }=47\end{array}$ & $\begin{array}{l}\text { Crossover } \\
n=38\end{array}$ & $\begin{array}{l}\text { High-nitrate diet, estimated }>4.8 \mathrm{mmol} \\
\text { nitrate daily } \\
\text { Low-nitrate diet, estimated }<1.6 \mathrm{mmol} \\
\text { nitrate daily }\end{array}$ & 7 days & Clinic 130/76 & N.S. \\
\hline \multirow[t]{2}{*}{ Rammos et al., 2014} & $\begin{array}{l}\mathrm{HV} \\
\text { moderate } \\
\mathrm{CV} \text { risk }\end{array}$ & $\begin{array}{l}\text { Parallel } \\
\text { (two-arm) }\end{array}$ & $\mathrm{NaNO}_{3}, 0.15 \mu \mathrm{mol} / \mathrm{kg}$ per day & 28 days & Clinic 137/80 & $-8 /$ N.S. \\
\hline & Age $=63$ & $\begin{array}{l}n=10 \\
\text { to } 11\end{array}$ & Matched-molar weight $\mathrm{NaCl}$ placebo & & & \\
\hline Jajja et al., 2014 & $\begin{array}{c}\text { HV, } \\
\text { overweight }\end{array}$ & $\begin{array}{l}\text { Parallel } \\
\text { (two-arm) }\end{array}$ & Beetroot juice, $2.6-6.5 \mathrm{mmol}$ nitrate daily & 21 days & Home 130/77 & $\begin{array}{l}\text { Home: }-7.2 / \text { N.S.; } \\
\text { clinic: N.S.; } 24 \text { h }\end{array}$ \\
\hline Ashor et al., 2015 & Age $=62$ & $\begin{array}{l}n=10 \\
\text { to } 11\end{array}$ & $\begin{array}{l}\text { Matched-volume black currant juice control } \\
\text { ABP } 126 / 81\end{array}$ & & Clinic 135/77 $24 \mathrm{~h}$ & ABP: N.S. \\
\hline $\begin{array}{l}\text { Jovanovski et al., } \\
2015\end{array}$ & $\begin{array}{c}\mathrm{HV} \\
\text { Age }=25\end{array}$ & $\begin{array}{l}\text { Crossover } \\
n=27\end{array}$ & $\begin{array}{l}\text { High-nitrate soup (spinach), } 13.6 \mathrm{mmol} \\
\text { nitrate daily } \\
\text { Low-nitrate soup, } 0.01 \mathrm{mmol} \text { daily control }\end{array}$ & 7 days & Clinic 116/69 & $-4.1 /-4.4$ \\
\hline $\begin{array}{l}\text { Ashworth et al., } \\
2015\end{array}$ & $\begin{array}{c}\mathrm{HV} \\
\text { Age }=20\end{array}$ & $\begin{array}{c}\text { crossover } \\
n=19\end{array}$ & $\begin{array}{l}\text { High-nitrate food, estimated } 5.5 \mathrm{mmol} \\
\text { nitrate daily } \\
\text { Low-nitrate food, estimated } 0.13 \mathrm{mmol} \\
\text { nitrate daily }\end{array}$ & 7 days & Clinic 107/63 & $-4.0 /$ N.S. \\
\hline $\begin{array}{l}\text { Bourdillon et al., } \\
2015\end{array}$ & $\begin{array}{c}\text { HV } \\
\text { Age }=31\end{array}$ & $\begin{array}{l}\text { Crossover } \\
n=12\end{array}$ & $\begin{array}{l}\mathrm{NaNO}_{3}, 0.1 \mathrm{mmol} / \mathrm{kg} \text { per day } \\
\mathrm{NaCl}, 0.1 \mathrm{mmol} / \mathrm{kg} \text { per day placebo }\end{array}$ & 3 days & $\begin{array}{l}\text { Plethysmographic } \\
\text { finger BP } 125 / 75\end{array}$ & N.S. \\
\hline Lee et al., 2015 & $\begin{array}{c}\text { HV } \\
\text { Age }=22\end{array}$ & $\begin{array}{l}\text { Crossover } \\
n=14\end{array}$ & $\begin{array}{l}\text { Beetroot juice, } 6.4 \mathrm{mmol} \text { nitrate } \\
\text { Nitrate-deplete beetroot juice placebo }\end{array}$ & 15 days & Clinic 116/77 & $-4 /-4$ \\
\hline Jonvik et al., 2016 & $\begin{array}{c}\text { HV } \\
\text { Age }=28\end{array}$ & $\begin{array}{c}\text { Crossover } \\
\text { (four-limb) } \\
n=18\end{array}$ & $\begin{array}{l}\mathrm{NaNO}_{3}, 12.9 \mathrm{mmol} \\
\text { Rocket, beetroot, and spinach juice, all } \\
12.9 \mathrm{mmol} \text { nitrate }\end{array}$ & $5 \mathrm{~h}$ & Clinic BP not stated & $\begin{array}{l}\mathrm{NaNO}_{3}: \mathrm{N} . \mathrm{S} . /-4 \\
\text { rocket: }-6 /-6 \\
\text { Beet: }-5 /-7.5 \\
\text { spinach: }-7 /-5\end{array}$ \\
\hline
\end{tabular}


TABLE 1-Continued

\begin{tabular}{|c|c|c|c|c|c|c|}
\hline Reference & Cohort & Design & Intervention & $\begin{array}{l}\text { Treatment } \\
\text { Duration }\end{array}$ & Baseline BP (mm Hg) & $\operatorname{Max} \Delta \mathrm{BP}(\mathrm{mm} \mathrm{Hg})$ \\
\hline Choi et al., 2016 & $\begin{array}{c}\mathrm{HV} \\
\text { Age }=23\end{array}$ & $\begin{array}{l}\text { Crossover } \\
\text { (two-limb) } \\
n=12\end{array}$ & $\begin{array}{l}\text { Beetroot juice, } 5.6 \mathrm{mmol} \text { nitrate } \\
\text { Colored water control }\end{array}$ & 15 days & $132 / 86$ & $\begin{array}{l}\text { Both } \mathrm{SBP} \text { and } \\
\text { DBP reduced }\end{array}$ \\
\hline $\begin{array}{l}\text { Raubenheimer et al., } \\
2017\end{array}$ & $\begin{array}{c}\mathrm{HV} \\
\text { Age }=64\end{array}$ & $\begin{array}{l}\text { Crossover } \\
\text { (two-limb) } \\
n=12\end{array}$ & $\begin{array}{l}\text { Beetroot juice, } 12.9 \mathrm{mmol} \text { nitrate } \\
\text { Nitrate-deplete beetroot juice placebo }\end{array}$ & $3 \mathrm{~h}$ & $133 / 89$ & $-7.9 /-5.7$ \\
\hline Jones et al., 2019 & $\begin{array}{c}\mathrm{HV} \\
\text { Age }=63\end{array}$ & $\begin{array}{l}\text { Parallel } \\
\text { (two-arm) } \\
n=7-11\end{array}$ & $\begin{array}{l}\text { Beetroot juice, } 6.5 \mathrm{mmol} \text { nitrate } \\
\text { Prune juice control }\end{array}$ & $4 \mathrm{wk}$ & $129 / 75$ & N.S. \\
\hline
\end{tabular}

HV, healthy volunteers.

important, for translation to patients with hypertension, interventions need to provide sustained BP reduction in the long term. Therefore, studies over prolonged time periods ( $>7$ days) in healthy subjects were required. This was first tested in humans indirectly by making a comparison of the effects of a traditional, nitrate-rich Japanese diet $[0.3 \mathrm{mmol} / \mathrm{kg}$ (18.6 $\mathrm{mg} / \mathrm{kg}$ ) nitrate daily], with a low-nitratecontaining control diet in a crossover study $(n=25$, 10 days per dietary intervention). In this study, the high-nitrate diet was associated with significantly lower BP (DBP - $4.5 \mathrm{~mm} \mathrm{Hg}$ ) (Sobko et al., 2010). Since this observation, several studies have tested dietary nitrate supplementation over longer periods. Using beetroot juice to deliver dietary nitrate $[5.2(322 \mathrm{mg})$ or $6.4(397 \mathrm{mg}) \mathrm{mmol} /$ day nitrate] compared with lownitrate control juice $(n=8-14$ for 15 days per intervention), sustained lowering of DBP $(\sim 5-6.5 \mathrm{~mm} \mathrm{Hg})$ was evident in healthy volunteers (Vanhatalo et al., 2010; Lee et al., 2015). In healthy older persons with prehypertension (baseline $\mathrm{BP} 137 / 80 \mathrm{~mm} \mathrm{Hg}, n=10$ to $11), 4$ weeks of daily $150 \mu \mathrm{mol} / \mathrm{kg}(9.3 \mathrm{mg}$ nitrate $/ \mathrm{kg})$ $\mathrm{NaNO}_{3}(\sim 10 \mathrm{mmol}$ nitrate for a $70-\mathrm{kg}$ subject) lowered SBP by $8 \mathrm{~mm} \mathrm{Hg}$ compared with a matched $\mathrm{NaCl}$ control (Rammos et al., 2014).

The first study in patients with hypertension followed a single dose over 24 hours and used water as a control in a crossover design. In all, 15 drug-naïve patients with hypertension (baseline daytime ambulatory $\mathrm{BP}$; $\mathrm{ABP}$ $142 / 85 \mathrm{~mm} \mathrm{Hg}$ ) were given a single dose of dietary nitrate [3.3 mmol (205 $\mathrm{mg})$ as beetroot juice]. Plasma nitrate and nitrite profiles were similar to responses seen in normotensive persons, confirming that the enterosalivary circulation was intact in hypertension. Additionally, a peak BP reduction of $\sim 11 / 10 \mathrm{~mm} \mathrm{Hg}$ (Ghosh et al., 2013) was observed, similar to the peak reduction in healthy volunteers given $22.5 \mathrm{mmol}$ despite having a fraction of the nitrate dose (Webb et al., 2008b; Kapil et al., 2010). Importantly, in healthy persons given a comparable $4 \mathrm{mmol}(248 \mathrm{mg})$ nitrate dose, BP reduction was not significant (Kapil et al., 2010). The enhanced BP response in subjects with hypertension after nitrate supplementation could simply reflect higher baseline BP evident in the hypertensive cohort, as $\mathrm{BP}$ lowering is proportional to pretreatment $\mathrm{BP}$ (Law et al., 2003). However, it could also reflect increased potency of nitrate/nitrite. In Wistar Kyoto rats treated with phenylephrine to titrate BP to match the levels evident in the strain-matched SHR, there is a diminished $\mathrm{BP}$ response to acute bolus doses of $\mathrm{KNO}_{2}$, suggesting pretreatment $\mathrm{BP}$ is not solely responsible for the augmented response seen in hypertension (Ghosh et al., 2013). There is some evidence to suggest that, in the scenario of reduced $\mathrm{NO}$ levels, the downstream signaling target GC-1 or the components of the pathway further downstream from GC-1 become sensitized to $\mathrm{NO}$. This has been demonstrated best with respect to vasoactivity, in which an enhanced vasorelaxant response to $\mathrm{NO}$ donors was shown in mice treated with NOS inhibitors (Moncada et al., 1991) and in eNOS KO mice (Brandes et al., 2000). However, whether this is similar in human hypertension, a situation in which eNOS activity is similarly reduced (Linder et al., 1990; Panza et al., 1993), is not known.

In our single dietary dosing study in patients with hypertension (Ghosh et al., 2013), SBP was reduced 24 hours postsupplementation by $\sim 8 \mathrm{~mm} \mathrm{Hg}$, which is at a level comparable to the expected BP-lowering effect of antihypertensive medicines when used at standard dose in mild hypertension $(\sim 9.1 \mathrm{~mm} \mathrm{Hg}$ ) (Law et al., 2009). This dose also represented a peak-to-trough ratio of $60 \%$ for dietary nitrate in this study and is a profile of activity consistent with an effect size suitable $(>50 \%)$ to consider as a once-daily dosage for an antihypertensive medication (Lipicky, 1994; Meredith, 1994). This initial study was been taken forward into a prolonged study assessing whether the acute effects are sustained in the longer term (Kapil et al., 2015). In this double blind, randomized, placebo-controlled, parallel study ( $n=32$ in each limb) of drug-naïve and treated patients with hypertension and uncontrolled BP, 4 weeks of daily dietary nitrate [6.4 mmol $(397 \mathrm{mg})$ as beetroot juice] was compared with a nitrate-free beetroot juice [originally developed to provide a suitable placebo (Gilchrist et al., 2014)] as a control intervention to maintain patient and investigator blindness to achieve optimal study design. BP, measured by three separate 
A

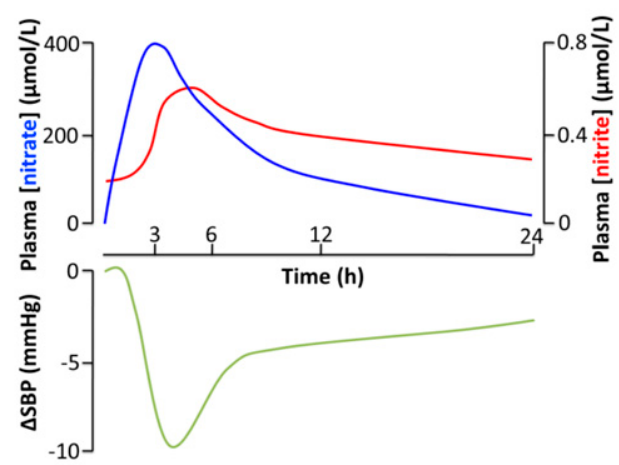

B

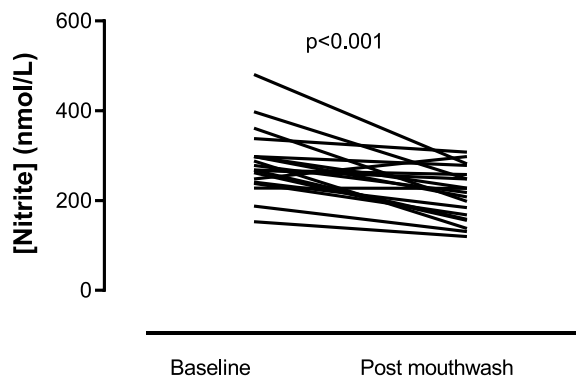

C

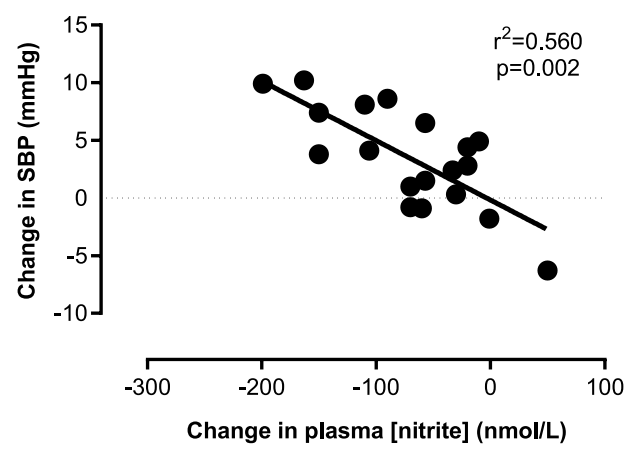

D

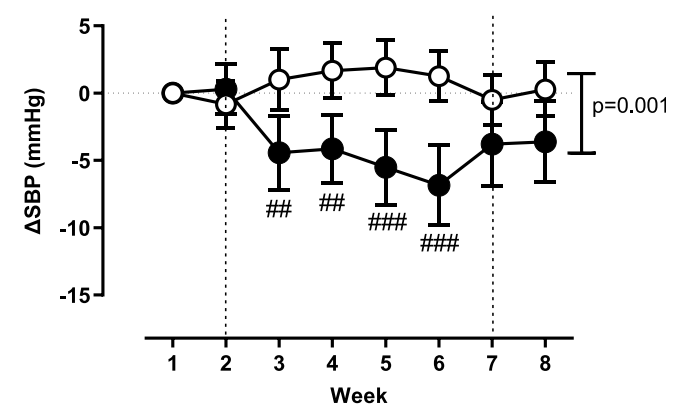

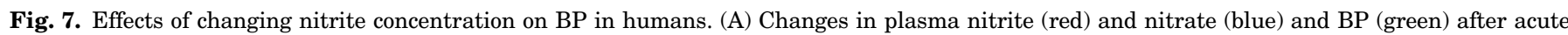

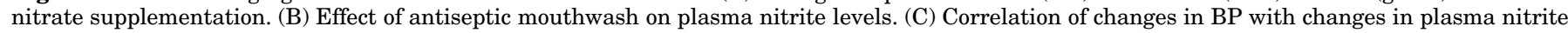

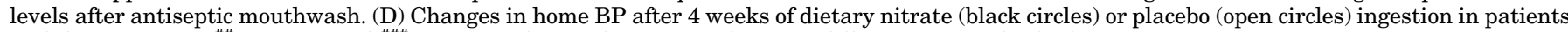
with hypertension. ${ }^{\# \#} P 0.01$ and ${ }^{\# \# \#} P<0.001$ for Bonferroni post hoc test, following 2 -way ANOVA.

methods, was significantly reduced over 4 weeks in the active intervention limb only: clinic $(-8 / 2 \mathrm{~mm} \mathrm{Hg})$, home $(-8 / 4 \mathrm{~mm} \mathrm{Hg})$, and 24-hour ABP $(-8 / 5 \mathrm{~mm} \mathrm{Hg})$, with no pharmacodynamic tolerance demonstrated by weekly home BP (Fig. 7D) (Kapil et al., 2015).

There are now several studies that have assessed the effects of dietary nitrate in patients with hypertension. The individuals in these studies in general have baseline BPs above 130/70 $\mathrm{mm} \mathrm{Hg}$ (as some have controlled BP on medication) and on balance indicate a lowering of $\mathrm{BP}$ with dietary nitrate in patients with uncontrolled BP at baseline (see Table 2) (Ghosh et al., 2013; Kapil et al., 2015; Kerley et al., 2018; Broxterman et al., 2019; Zafeiridis et al., 2019). Conversely, there are studies that show BP-lowering benefits in treated, controlled patients on medication. As an example, in a smaller, shorter duration $(n=27,1$ week) in treated, controlled patients with hypertensions (baseline BP 133/76 mm Hg), $7 \mathrm{mmol}$ (434 mg) dietary nitrate daily as beetroot juice compared with control demonstrated no effect on home or ambulatory BP, with means in low- versus high-nitrate groups being 127-128/73-74 (Bondonno et al., 2015b). In a similar study to the Kapil et al. (2015) study, in a mixed population of both patients with prehypertension and untreated hypertension, $2.5 \mathrm{mmol} /$ day nitrate compared with $<0.5 \mathrm{mmol} /$ day nitrate, both as blended vegetable juice ( 4 weeks, $n=30$ ), in a crossover study showed no difference in ABP (Blekkenhorst et al., 2018). The reasons for these differing data are uncertain; however, it is possible that these studies were underpowered $(n=27-30)$ and, also, that at least some of the volunteers had BP in the normotensive range and certainly substantially lower than the screening BPs; this fact may underlie the neutral effects. In addition, biochemical analyses suggest that at baseline, this group of participants had unusual and very high circulating levels of nitrite of $2 \mu \mathrm{mol} / \mathrm{l}$ (Bondonno et al., 2015b; Blekkenhorst et al., 2018). Although the authors suggested that this was

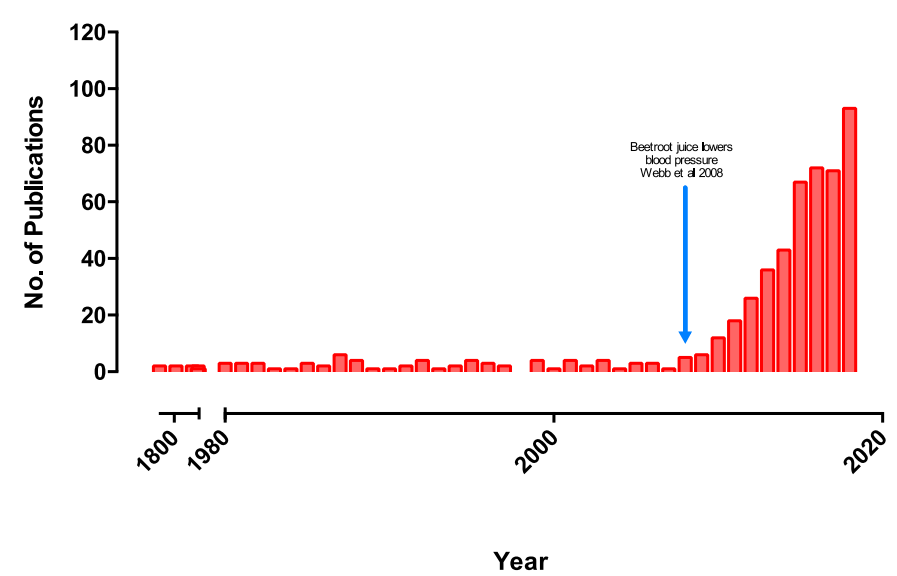

Fig. 8. Number of publications using beetroot juice. 
TABLE 2

Randomized, controlled studies evaluating nitrate supplementation on blood pressure in hypertensive patients

\begin{tabular}{|c|c|c|c|c|c|c|}
\hline Reference & Cohort & Design & Intervention & $\begin{array}{l}\text { Treatment } \\
\text { Duration }\end{array}$ & $\begin{array}{l}\text { Baseline BP } \\
\text { (mm Hg) }\end{array}$ & $\begin{array}{l}\operatorname{Max} \Delta \mathrm{BP} \\
(\mathrm{mm} \mathrm{Hg})\end{array}$ \\
\hline Ghosh et al., 2013 & $\begin{array}{l}\text { Uncontrolled HTN } \\
\text { Age }=53\end{array}$ & $\begin{array}{c}\text { Crossover } \\
n=15\end{array}$ & $\begin{array}{c}\text { Beetroot juice, } 3.3 \text { mmol nitrate } \\
\text { Matched-volume water control }\end{array}$ & 1 day & $140 / 86$ & $-8.5 / \mathrm{N} . \mathrm{S}$. \\
\hline Kapil et al., 2015 & $\begin{array}{l}\text { Uncontrolled HTN } \\
\quad \text { Age }=57\end{array}$ & $\begin{array}{c}\text { Parallel } \\
n=64\end{array}$ & $\begin{array}{l}\text { Beetroot juice, } 6.4 \mathrm{mmol} \text { nitrate } \\
\text { Nitrate-deplete beetroot juice placebo }\end{array}$ & $4 \mathrm{wk}$ & $\begin{array}{c}\text { Clinic } 138 / 84 \\
\text { Home } 139 / 82 \\
\text { ABP } 139 / 82\end{array}$ & $\begin{array}{c}\text { Clinic }-8 /-2 \\
\text { Home }-8 /-4 \\
\text { Abp }-8 /-5\end{array}$ \\
\hline Bondonno et al., 2015b & $\begin{array}{c}\text { Controlled HTN } \\
\text { Age }=63\end{array}$ & $\begin{array}{c}\text { Crossover } \\
n=30\end{array}$ & $\begin{array}{c}\text { Beetroot juice, } 7 \mathrm{mmol} \text { nitrate } \\
\text { Nitrate-deplete beetroot juice placebo }\end{array}$ & $1 \mathrm{wk}$ & $133 / 76$ & N.S. \\
\hline Kerley et al., 2018 & $\begin{array}{l}\text { Uncontrolled HTN } \\
\text { Age }=63\end{array}$ & $\begin{array}{c}\text { Crossover } \\
n=20\end{array}$ & $\begin{array}{l}\text { Beetroot juice, } 12.9 \mathrm{mmol} \text { nitrate } \\
\text { Nitrate-deplete beetroot juice placebo }\end{array}$ & $1 \mathrm{wk}$ & ABP $137 / 80$ & $-8 /-4$ \\
\hline Broxterman et al., 2019 & $\begin{array}{l}\text { Controlled HTN } \\
\text { Age }=53\end{array}$ & $\begin{array}{c}\text { Crossover } \\
n=13\end{array}$ & $\begin{array}{l}\text { Beetroot juice, } 6.2 \mathrm{mmol} \text { nitrate } \\
\text { Nitrate-deplete beetroot juice placebo }\end{array}$ & 3 days & $132 / 78$ & N.S. \\
\hline Broxterman et al., 2019 & $\begin{array}{l}\text { Uncontrolled HTN } \\
\text { Age }=49\end{array}$ & $\begin{array}{c}\text { Crossover } \\
n=14\end{array}$ & $\begin{array}{l}\text { Beetroot juice, } 6.2 \mathrm{mmol} \text { nitrate } \\
\text { Nitrate-deplete beetroot juice placebo }\end{array}$ & 3 days & $141 / 88$ & $-5 /-4$ \\
\hline Zafeiridis et al., 2019 & $\begin{array}{l}\text { Uncontrolled HTN } \\
\text { Age }=44\end{array}$ & $\begin{array}{l}\text { Crossover } \\
n=18\end{array}$ & $\begin{array}{l}\text { Beetroot juice, } 8.1 \mathrm{mmol} \text { nitrate } \\
\text { Nitrate-deplete beetroot juice placebo }\end{array}$ & $2.5 \mathrm{~h}$ & $144 / 95$ & $-6 /-2$ \\
\hline
\end{tabular}

HTN, hypertensive patients.

likely due to contamination of samples through the analytical procedures (although no measure of this was made), it is also possible that these levels relate to dietary intake. Dietary habits were recorded in this study; however, they were not reported, and thus it is not possible to assess this. Finally, $63 \%$ of the recruited patients in the first study were women (Bondonno et al., 2015b). Recent evidence from our laboratory has shown that although women appear to have greater baseline oral nitrate reductase activity and thus greater circulating nitrite levels, this seems to result in a reduced response to additional dietary nitrate loading, possibly due to the fact that the pathway is already being maximally activated (Kapil et al., 2018). It is possible that the high number of women in this cohort have therefore skewed the effect.

Although all these studies measured peripheral BP, recent evidence suggests that elevation of systemic nitrite levels may have a greater effect on central hemodynamics. Systemic intravenous $\mathrm{NaNO}_{2}$ nitrite $(8.7 \mu \mathrm{mol} / \mathrm{min})$ in healthy volunteers selectively reduced central BP rather than peripheral BP (Omar et al., 2015), and 6 months of dietary nitrate in patients with or at risk of diabetes had no effect on peripheral BP compared with placebo but did have a small, yet significant, effect on central BP (Mills et al., 2017). The explanation for the lack of peripheral BP reductions in these studies in contrast to the large body of evidence above is not clear, but it is worthy of further exploration. Certainly, previous studies have failed to demonstrate BP lowering in type 2 diabetes after increases in systemic nitrite levels (Gilchrist et al., 2013; Mohler et al., 2014; Shepherd et al., 2015a).

Overall, two recent independent meta-analyses of BP-lowering studies suggest a meaningful pooled effect size of $\sim 5 / 2 \mathrm{~mm} \mathrm{Hg}$ reduction on resting clinic BP (Ashor et al., 2017; Jackson et al., 2018), although the studies included ranges in duration from a few hours to a few weeks, as indicated in Tables 1 and 2. For a
BP-lowering intervention to be adopted clinically, support for sustained efficacy over several months is clearly needed. Further studies are underway, including a randomized, double blind, placebo-controlled evaluation of 4 months of dietary nitrate in patients with hypertensive target organ damage to assess possible reversal (clinicaltrials.gov: NCT03088514).

3. Enterosalivary Generation of Nitrite Regulates Basal BP. Nitrite is bioactive in the circulation, leading to vasodilatation and BP lowering (Cosby et al., 2003; Dejam et al., 2007), and further, the inverse correlation between baseline plasma nitrite levels and BP in healthy subjects (Kapil et al., 2010) intimates that basal plasma nitrite levels (arising from endogenous sources, i.e., eNOS) regulate BP of healthy subjects. It was thus hypothesized that interruption of the enterosalivary circulation of nitrate to nitrite under basal conditions would lower basal plasma nitrite levels and increase BP. To test this hypothesis, oral microbiomerelated nitrate reduction (i.e., nitrite synthesis) was disrupted using a validated antiseptic mouthwash protocol (Govoni et al., 2008). In a 2-week crossover study $(n=19)$, twice daily use of antiseptic mouthwash for 7 days nearly abolished oral nitrate reduction to nitrite. More importantly, this effect was accompanied by a decrease in plasma nitrite levels by $\sim 25 \%$ (Fig. 7B), similar to that predicted by studies using eNOS inhibition in humans (Lauer et al., 2001; Kleinbongard et al., 2003). These studies indicate that, when one excludes the influence of diet, $25 \%$ of circulating nitrite levels arise from the enterosalivary circuit of nitrate derived from the oxidative metabolism of endogenously generated $\cdot \mathrm{NO}$. In addition, this effect was associated with a concomitant increase in $\mathrm{BP}(2-3.5 \mathrm{~mm} \mathrm{Hg})$ that was measured by three distinct methods: clinic, home, and ambulatory BP (Kapil et al., 2013). Evaluation of home BP in this study revealed that the BP effect was apparent within 1 day of mouthwash use, with no evidence of tachyphylaxis over the week-long period of intervention (Kapil et al., 2013). This effect of increasing 
$\mathrm{BP}$ with disruption of the enterosalivary circulation has been confirmed in further studies, including in healthy volunteers ( $n=27)$ with confirmed disease-free oral health status at baseline using chlorhexidine twice daily for 7 days (Tribble et al., 2019). Importantly, this effect is also seen in patients with CVD. In treated, controlled patients with hypertension $(n=15$, baseline home $\mathrm{BP} \sim 134 / 79 \mathrm{~mm} \mathrm{Hg}$ ) randomized to receive antiseptic mouthwash as above or water control, mouthwash use led to significant increase in home SBP $(2.3 \mathrm{~mm} \mathrm{Hg}$ ) compared with control (Bondonno et al., 2015a). More recently, however, in 17 healthy females randomized to 3 days of antiseptic mouthwash or nonantibacterial placebo mouthwash, despite abrogation during the intervention period of both oral nitrate reduction and salivary nitrite levels, there was no change in plasma nitrite levels, and thus, ambulatory BP was not different (Sundqvist et al., 2016).

Further studies have shown that other oral hygiene treatments, in addition to chlorhexidine mouthwashes, impact nitrate reduction and that this effect is dependent upon the severity of the impact on oral microbiome function (McDonagh et al., 2015; Woessner et al., 2016). Support for the hypothesis that the changes in $\mathrm{BP}$ were related to lesser nitrite generated from the oral microbiome comes from robust correlation of changes in plasma nitrite concentration and changes in BP after 7 days of antiseptic mouthwash intervention (Fig. 7C) (Kapil et al., 2013). It is unlikely that these effects relate to other mechanisms, such as increased stress due to instillation of mouthwash, since the effects on SBP were evident in the averaged nighttime BP mean as well (Kapil et al., 2013). Although these increases in $\mathrm{BP}$ were small $(\sim \Delta \mathrm{SBP}$ $2-3.5 \mathrm{~mm} \mathrm{Hg}$ ), such effects at a population level are known to lead to a significantly increased risk of stroke and ischemic heart disease over a life course (Lewington et al., 2002). Importantly, it appears that recovery from acute use of antibacterial mouthwash (twice daily for 1 week) is apparent both in microbiological ecology and in vascular responses within 3-7 days (Tribble et al., 2019).

4. Endothelial Dysfunction. Endothelial dysfunction is synonymous with reduced bioavailable $\mathrm{NO}$, is an early marker common to all CVD risk factors, and is predictive of future CVD events (Brunner et al., 2005). Long-term dietary nitrite and nitrate deficiency worsens ex vivo-assessed endothelial function in C57BL6 mice and was associated with CV death (Kina-Tanada et al., 2017). Additionally, nitrite supplementation improves ex vivo endothelial function in several different models associated with cardiometabolic disease (Sindler et al., 2015; Ling et al., 2016), whereas dietary nitrate has been shown to improve endothelial function in models of atherosclerosis (Bakker et al., 2016) as well as to prevent the endothelial dysfunction that occurs in mice subjected to long-term low dietary nitrate and nitrite (Kina-Tanada et al., 2017) or aging (Rammos et al., 2015).

There are several studies that have explored whether such findings in mice translate to humans. With twice daily $\mathrm{NaNO}_{2}$ (80 or $160 \mathrm{mg}$ total daily for 10 weeks) in older adults, there was a trend toward improved FMD (DeVan et al., 2016). However, conflicting results have been published for supplementation with inorganic nitrate in healthy persons with normal baseline endothelial function. Some studies have shown a positive effect of dietary nitrate (Bondonno et al., 2012; Heiss et al., 2012; Rammos et al., 2014), whereas others did not (Bahra et al., 2012). In addition, in healthy volunteers in which a transient endothelial dysfunction is induced by a brief exposure to an ischemic insult in the forearm, prior ( 3 hour) acute nitrate supplementation in the form of beetroot juice or $\mathrm{KNO}_{3}$ capsules prevented this dysfunction (Webb et al., 2008b; Kapil et al., 2010). In patients with pre-existing endothelial dysfunction, a somewhat mixed picture has developed. In scenarios in which endothelial function is impaired, and this impairment is associated with risk factors for CVD, chronic oral nitrate supplementation improves FMD, i.e., in patients with hypertension and hypercholesterolemia (Kapil et al., 2015; Velmurugan et al., 2016). However, FMD was not improved after chronic supplementation in patients with diabetes and after acute supplementation in patients with peripheral arterial disease (PAD) (Kenjale et al., 2011; Gilchrist et al., 2013).

5. Arterial Stiffness. Central, large-artery stiffening caused by aging-related arteriosclerosis is an important independent predictive marker of $\mathrm{CV}$ risk (Vlachopoulos et al., 2010b), with the gold-standard measurement of this phenomenon being aortic pulse wave velocity (PWV) (Laurent et al., 2006). The evidence indicates that in those with stiffened central arteries, a rapid reflection of incident pressure waves leads to greater augmentation of central SBP (Safar, 2010), which is more predictive of CV events than brachial SBP (Vlachopoulos et al., 2010a). It has been demonstrated that increased arterial stiffness precedes incident hypertension in large, prospective cohorts (Kaess et al., 2012; Zheng et al., 2015). Moreover, the importance of stiffening in driving hypertension comes from observations that large-artery stiffening alone explains age-related increases in $\mathrm{BP}$ and failure of normal renal and baroreflex-mediated regulatory mechanisms to prevent this (Pettersen et al., 2014).

Studies in healthy volunteers have shown that acute inhibition of eNOS activity increases measures of elastic artery stiffness in vivo (Wilkinson et al., 2002; Schmitt et al., 2005; Bellien et al., 2010). Hence, increasing bioavailable $\cdot \mathrm{NO}$, via increment of systemic nitrite, should decrease PWV. In this respect, nitrite supplementation in aged rodents $\left(0.8 \mathrm{mmol} / / \mathrm{NaNO}_{2}\right.$ in drinking water for 3 weeks) and adults (1.2 or $2.4 \mathrm{mmol}$ $\mathrm{NaNO}_{2}$ orally for 10 weeks) reduced PWV (Sindler et al., 
2011; Fleenor et al., 2012; DeVan et al., 2016). Infusion of $\mathrm{NaNO}_{2}(8.7 \mu \mathrm{mol} / \mathrm{min}$ i.v. $)$ for 60 minutes into the brachial artery resulted in significant, large reductions in central SBP (Omar et al., 2015), with no change in brachial SBP, similar to the effects of oral nitrite dosing (DeVan et al., 2016). In healthy subjects, acute ( $8 \mathrm{mmol}$ $\mathrm{KNO}_{3}$ ) or chronic [4 weeks of daily $150 \mu \mathrm{mol} / \mathrm{kg} \mathrm{NaNO}_{3}$ ( $\sim 10 \mathrm{mmol}$ nitrate for a $70-\mathrm{kg}$ subject)] inorganic nitrate supplementation reduced PWV (Bahra et al., 2012; Rammos et al., 2014), with elevation of plasma nitrite and cGMP levels, confirming the production of bioactive -NO (Bahra et al., 2012).

In patients with hypertension, acute $(3.3 \mathrm{mmol} \mathrm{ni}-$ trate as beetroot juice) or chronic (daily $6.4 \mathrm{mmol}$ nitrate as beetroot juice for 4 weeks) inorganic nitrate supplementation also resulted in significant reductions in PWV (Ghosh et al., 2013; Kapil et al., 2015). This result intimate, therefore, that benefits accrued from nitrate supplementation observed in hypertensive cohorts are not only due to reductions of elevated arterial tone but likely also reflect modulation of elastic distensibility of the arterial tree by nitrite ${ }^{-}$-derived NO. More recently, despite reduction of central BP after 6 months of dietary nitrate supplementation in patients with or at risk of diabetes, there was no effect on PWV (Mills et al., 2017). Hutchinson-Gilford progeria syndrome is a rare genetic disease associated with multiple hallmarks of accelerated aging, including arterial stiffness and premature CVD despite a relative lack of traditional CV risk factors, leading to an average age of death $<15$ years old (Hennekam, 2006). Mutant LMNA (the gene encoding lamin $\mathrm{A}$ that is defective in the syndrome) mice supplemented with $\mathrm{NaNO}_{2}(500 \mathrm{mg} / \mathrm{l}$ in drinking water $)$ had improved aortic stiffness parameters and remodeling, suggesting a potential therapeutic approach in this orphan disease (Del Campo et al., 2019).

Further studies are now needed to determine the relative contributions of the reduction of distending BP in the aorta and other elastic arteries, and specific direct effects on arterial destiffening in mediating the effects of nitrite-derived NO.

6. Cerebral Blood Flow. The cerebral vasculature is a vascular bed in which the potential effects of the noncanonical pathway have been particularly assessed. In part, this is due to the fact that $\mathrm{NO}$ is known to regulate cerebral blood flow (Buchanan and Phillis, 1993) and critically regulates neurovascular coupling of neural activity to blood flow (Attwell et al., 2010). Since elevation of systemic nitrite concentration delivers $\cdot \mathrm{NO}$ and improves blood flow in the peripheral circulation, whether similar effects can be seen within the cerebral circulation, which is normally tightly autoregulated for flow in health, is particularly intriguing.

Nitrite infusion ( $1 \mu \mathrm{mol} / \mathrm{kg}$ per minute) in rats has been shown to reverse L-NAME-induced cerebral vasoconstriction and the consequent reduction in cerebral blood flow (Rifkind et al., 2007). Raising systemic levels of nitrite via acute dietary inorganic nitrate supplementation in older adults is also associated with improved blood flow to the frontal cortex, which is implicated in cognitive function and may be particularly vulnerable during aging (Presley et al., 2011), and reduces cerebral vascular resistance in the middle cerebral artery (Bond et al., 2013). The effect of inorganic nitrate supplementation on cognitive function has also been studied, although results are equivocal, with some smaller studies showing neutral results (Kelly et al., 2013; Bondonno et al., 2014; Thompson et al., 2014), and one study demonstrating improvement on some tasks that activate the frontal cortex in young adults (Wightman et al., 2015).

Recently, there has been some controversial work suggesting that migraneurs express an oral microbiome that is likely to lead to increased generation of $\cdot \mathrm{NO}$, which might contribute to the cerebral vasodilatation that is thought to underlie headaches in this setting (Gonzalez et al., 2016). The authors used analyses of the 16S rRNA Illumina sequencing of a cohort of migraneurs and nonmigraneurs from The American Gut Microbiome Project, matching to known genomes for their analyses. The authors made predictions regarding the expression of nitrate, nitrite, and -NO-reducing genes and suggested that there were higher levels of bacteria expressing these genes in the migraneurs (Gonzalez et al., 2016). However, the authors did not actually measure these genes, and unfortunately, detail regarding the individuals from whom the samples were collected was not made available. Further studies are needed to determine the importance, or not, of such a pathway in migraine.

Subarachnoid hemorrhage (SAH) is associated with significant morbidity and mortality related to delayed cerebral vasospasm that has been linked to diminished -NO levels (Pluta et al., 2001; Sadamitsu et al., 2001). Infusion of $\mathrm{NaNO}_{2}$, whether at the time of experimental $\mathrm{SAH}$ formation or delayed by 7 days, was associated with reduced arteriographic vasospasm in primates (Pluta et al., 2005; Fathi et al., 2011), suggesting nitrite could be a useful adjunct to existing therapies, and a small pilot study has recruited six patients for a 7-day nitrite infusion after a diagnosis of SAH with vasospasm, although results have not been published to date (clinicaltrials.gov NCT02176837). Interestingly, electroencephalographic responses to intravenous nitrite infusion $\left(\mathrm{NaNO}_{2} 10 \mu \mathrm{g} / \mathrm{kg}\right.$ per minute for 1 hour) predicted the occurrence of delayed cerebral ischemia, suggesting such a test could be used to prognosticate and stratify treatment (Garry et al., 2016).

\section{B. Nitrite and Nitrate in Exercise and Muscle Biology}

The intramyocyte and muscle $\mathrm{pH}$ and microvascular $\mathrm{O}_{2}$ tension decline in the contracting skeletal muscles (Richardson et al., 1995; Ferguson et al., 2015; Tanaka et al., 2016). Since it is well established that nitrite 
reduction is potentiated in an acidic and hypoxic environment (Modin et al., 2001; Castello et al., 2006), there has been considerable interest in the possibility that this anion might offer a novel approach to deliver -NO to enhance skeletal muscle function. $\mathrm{NO}$ has been demonstrated to influence a number of physiologic processes that are relevant to skeletal muscle function, including metabolism, perfusion, and contractility (Stamler and Meissner, 2001; Suhr et al., 2013). In support of the view that nitrite reduction is likely to occur within the exercised muscle are the findings published now some time ago demonstrating the negative difference in the arterial-venous plasma nitrite concentration across the contracting skeletal muscle bed (Abadeh et al., 1992). The potential benefits of the noncanonical pathway in improving muscle function have now been extensively investigated in different cohorts of individuals, in terms of exercise capacity, from the severely exercise tolerance impaired to the highly trained elite endurance athlete.

1. Nitrate and Exercise Performance on Moderately Trained Athletes. The first study to observe benefits of dietary nitrate ingestion on exercise was a randomized, double blind, placebo-controlled crossover study involving nine well trained healthy men of $\sim 28$ years (Larsen et al., 2007). In this study, the subjects consumed $0.1 \mathrm{mmol} / \mathrm{kg}$ per day of $\mathrm{NaNO}_{3}$ or a $\mathrm{NaCl}$ placebo for 3 days before completing a continuous incremental cycle ergometer test. Nitrate supplementation caused a significant decrease in maximal oxygen consumption $\left(\mathrm{VO}_{2 \max }\right)$ at submaximal work rates, with a mean reduction in $\mathrm{VO}_{2 \max }$ of $5 \%$. This reduction was surprisingly associated with significant improvements in muscle efficiency, from $19.7 \% \pm 1.6 \%$ to $21.1 \% \pm 1.3 \%$ (calculated as the work output per unit energy expended), and occurred without changes in blood (lactate), intimating that there was no increase in energy production. In addition, there were no differences in heart rate, ventilation, or respiratory exchange ratio between nitrate and placebo for any of the submaximal work rates (corresponding to $45 \%-80 \% \mathrm{VO}_{2 \max }$ ). These results were particularly surprising since a basic principle of human exercise physiology is that the $\mathrm{O}_{2}$ cost of submaximal exercise at a given work rate is fixed, irrespective of other factors such as health, fitness status, and age and indifferent to known nutritional, physical, or pharmacological interventions (Suhr et al., 2013). From these observations, the authors suggested that endurance exercise performance is a function of $\mathrm{VO}_{2 \max }$, the fractional utilization of $\mathrm{VO}_{2 \max }$, and exercise efficiency and that if all other factors are constant, an improvement in muscle efficiency would be expected to enable a greater work output for the same energy cost. This, in turn, translates into improved exercise performance (Larsen et al., 2007). These seminal findings caught the imagination of the sports and exercise world and led to a surge of interest to assess whether inorganic nitrate may be useful in terms of placing the body in an optimal condition to use $\mathrm{O}_{2}$ most efficiently to gain advantage in numerous forms of exercise, particularly for the elite endurance athlete.

The first independent study to corroborate the work of the Karolinska group came from Jones and coworkers in the UK (Bailey et al., 2009). This group took advantage of the recent discovery at that time that beetroot juice could be used as a simple and effective nitrate delivery method (Webb et al., 2008b). As per the study of Webb and colleagues, they gave $500 \mathrm{ml}$ of beetroot juice (containing $11.2 \pm 0.6 \mathrm{mmol} / \mathrm{l}$ nitrate) in a placebocontrolled crossover study of eight men (aged 19-38 years) in which black currant cordial (containing negligible nitrate) was used as the placebo for six consecutive days. The study was described as double blind; however, it is likely that the differences in the two liquids was evident to all. In this study the volunteers, as in the 2007 study of Larsen et al., completed a series of "step" moderate-intensity and severe-intensity exercise tests on the last 3 days (Bailey et al., 2009). As expected, plasma nitrate concentration was significantly elevated compared with placebo (beetroot juice: $273 \pm 44 \mathrm{nmol} / \mathrm{l}$ vs. placebo: $140 \pm 50 \mathrm{nmol} / \mathrm{l})$, and this was associated with statistically significant decreases in SBP, demonstrating efficacy of the intervention. However, the key observation documented was that, in agreement with the Karolinska group, dietary nitrate reduced the " $\mathrm{O}_{2}$ cost" of cycling at a fixed submaximal work rate. The authors show that muscle fractional $\mathrm{O}_{2}$ extraction during modest exercise and gain in pulmonary $\mathrm{O}_{2}$ uptake after onset of moderate exercise were reduced by $19 \%$. However, in addition to this benefit, the authors found that during severe exercise, the $\mathrm{O}_{2}$ uptake "slow component" was reduced. This slow component is thought to represent a progressive loss of muscle efficiency as high-intensity exercise continues (Jones et al., 2011). The peak oxygen uptake $\left(\mathrm{VO}_{2}\right)$ attained during high-intensity exercise was not different between treatments, but attainment of the peak $\mathrm{VO}_{2}$ was delayed with nitrate treatment, resulting in a longer time to exhaustion. These observations were repeated by the group in another study, which used a different form of exercise (i.e., knee extensors) (Bailey et al., 2010) and was again reproduced by Larsen et al. (2010) using combined arm and leg cranking as the form of exercise. Interestingly, in this study, the group found that the peak $\mathrm{VO}_{2}$ was reduced with dietary nitrate (Larsen et al., 2010) during maximal exercise using a large active muscle mass and that it was associated with a trend toward increased time to exhaustion. The authors suggested that this implied involvement of two separate mechanisms in the benefits of inorganic nitrate: one that reduces $\mathrm{VO}_{2 \max }$ and another that improves the energetic function of the working muscles.

Although these early observations have fueled interest in assessing the mechanisms and whether the 
effects can be sustained in the long term, there has been some controversy regarding effective dose. Using a similar exercise test of submaximal cycle ergometry, $\mathrm{VO}_{2 \max }$ was shown to be reduced (by $\sim 3 \%-5 \%$ ) after the acute ingestion of $0.033 \mathrm{~mol} / \mathrm{kg}$ nitrate, equating to $\sim 2.5 \mathrm{mmol}$ nitrate in a $70-\mathrm{kg}$ individual (Larsen et al., 2010), 5.2 (Vanhatalo et al., 2010), 6 (Wylie et al., 2016), and $16.8 \mathrm{mmol}$ nitrate (Wylie et al., 2013), but conversely not after the acute ingestion of 3 (Wylie et al., 2016), 4.2 (Wylie et al., 2013) and $\sim 8 \mathrm{mmol}$ nitrate (Betteridge et al., 2016) with no effect upon exercise tolerance (Vanhatalo et al., 2010; Wylie et al., 2013). However, in the study of Wylie and colleagues, increasing the dose substantially $(8.4$ and $16.8 \mathrm{mmol})$ did result in significant improvements (Wylie et al., 2013). These results seem to suggest that the acute ingestion of nitrate from 2.5 to $6 \mathrm{mmol}$ of nitrate may be sufficient to enhance exercise economy during submaximal cycling but that higher doses are required to demonstrate any improvement in exercise tolerance.

Importantly, these effects on cycling economy after short-term nitrate supplementation have been shown to be maintained when dosing is extended over 15 days (although not at 5 days in this study) (Vanhatalo et al., 2010) or $6 \mathrm{mmol} /$ day for 28 days (Wylie et al., 2016). These findings indicate that, as with the effects upon $\mathrm{BP}$, there is no development of tolerance as occurs with organic nitrates (Münzel et al., 2005). It is also worth noting that there are dissenting studies in which, despite elevation in plasma nitrite concentration after supplementation with nitrate in both recreationally active and moderately trained endurance athletes, no improvement in cycling exercise economy or performance was evidenced (Breese et al., 2013; Kelly et al., 2014).

Similar improvements in exercise economy and tolerance after nitrate supplementation have been shown during running (Lansley et al., 2011b; Murphy et al., 2012; Porcelli et al., 2015), knee extension (Bailey et al., 2009), walking (Lansley et al., 2011b), desert marching (Kuennen et al., 2015), kayaking (Muggeridge et al., 2013; Peeling et al., 2015), and rowing (Bond et al., 2012; Hoon et al., 2014). However, whether improved exercise tolerance (i.e., time to exhaustion in a constant work rate task) in turn then translates into an associated improvement in exercise performance (i.e., a set distance or amount of work is completed in a shorter time frame) is controversial. In one study, no such benefit is seen with acute administration of nitrate (Cermak et al., 2012b), but chronic (up to 6 days) nitrate supplementation did enhance cycling performance (Cermak et al., 2012a) in moderately trained endurance, suggesting that chronic nitrate supplementation may have more possibilities as an ergogenic aid than acute nitrate ingestion.

a. Mechanisms for enhanced exercise performance after nitrate supplementation. A number of possible mechanisms have been proposed to underlie the lower $\mathrm{O}_{2}$ cost of exercise. Bailey et al. (2010), using ${ }^{31} \mathrm{P}$-magnetic resonance spectroscopy, demonstrated a blunting of increases of ADP and inorganic phosphate $(\mathrm{Pi})$ concentration and sparing of intramuscular phosphocreatine concentration $(\mathrm{PCr})$ with nitrate treatment. These effects were apparent without increased contribution of anaerobic glycolysis to energy turnover, excluding the possibility that nitrate or nitrite had resulted in an inhibition of respiration (Brown and Cooper, 1994; Cleeter et al., 1994). The authors suggested that by reducing the ATP cost of force production, this facilitated a sparing of the finite $\mathrm{PCr}$ stores and a reduction in the $\mathrm{O}_{2}$ cost of exercise, resulting in an improved tolerance of intense exercise. The authors suggested that this effect likely relates to the activity of $\mathrm{NO}$ on the sarcoplasmic reticulum calcium ATPase or the actin-myosin ATPase (Ishii et al., 1998; Viner et al., 2000; Evangelista et al., 2010) and reason that a reduced ATP cost would blunt the changes in intramuscular substrates and metabolites that stimulate mitochondrial respiration (e.g., PCr, ADP, Pi) (Mahler, 1985; Meyer, 1989). Intriguingly, the depletion of muscle $\mathrm{PCr}$ and the buildup of $\mathrm{Pi}$ and ADP have been associated with the development of muscle fatigue during high-intensity exercise (Allen et al., 2008).

Other suggestions have been that nitrate supplementation improves muscle oxygenation and, therefore, mitochondrial efficiency (therefore lowering $\mathrm{VO}_{2}$ ) and muscle oxygenation (therefore sparing muscle $\mathrm{PCr}$ ) (Wilson, 1994). Indeed, assessment of muscle biopsies postexercise and nitrate treatment shows a reduction in the expression of adenine nucleotide translocase (which is a protein involved in mitochondrial proton conduction) associated with a $19 \%$ improvement in the mitochondrial phosphate/oxygen ratio (which is a ratio of the amount of $\mathrm{O}_{2}$ consumed per ATP produced). This observation suggests that nitrate impacts upon leakage of protons across the inner mitochondrial membrane. The authors speculate that since $\cdot \mathrm{NO}$ has been shown to inhibit cytochrome $\mathrm{C}$ oxidase (Brown and Cooper, 1994; Cleeter et al., 1994) in the setting of hypoxia, nitrite reduction is facilitated, delivering increased $\cdot \mathrm{NO}$, which results in the effects seen. Interestingly, acute supplementation of nitrite to isolated mitochondria in vitro did not affect phosphate/oxygen ratio, suggesting that several days of persistently elevated nitrite levels are needed for the induction of changes in the expression of mitochondrial proteins (i.e., adenine nucleotide translocase) and accords with observations suggesting improved benefits with dietary nitrate and prolonged daily ingestion.

There is also some suggestion that the mitochondriaindependent effects of nitrate/nitrite relate to changes in muscle $\mathrm{Ca}^{2+}$ handling and, hence, contractile function. In mice fed $\mathrm{NaNO}_{3}(1 \mathrm{mmol} / \mathrm{l}$ in the drinking water $)$ for 7 days, intracellular $\mathrm{Ca}^{2+}$ levels were increased and 
were associated with enhanced contractions in fasttwitch muscle fibers, but not slow twitch, at stimulation frequencies from 20 to $150 \mathrm{~Hz}$ (Hernandez et al., 2012). Expression analyses demonstrated that within the fasttwitch muscle cells, there was an increase in both calsequestin 1 and dihydropyridine receptor expression that resulted in enhanced $\mathrm{Ca}^{2+}$ store and, thus, availability of $\mathrm{Ca}^{2+}$ upon store release, thus causing a faster rate of force development and increased contractile force, particularly at low-frequency stimulation; although the exact molecular pathway responsible for this change in expression was not determined. The authors suggested, therefore, that improved performance with inorganic nitrate/nitrite, at least in part, related to increased muscle function during normal movement independent of changes in mitochondrial function (Hernandez et al., 2012).

Another potential contributory mechanism for improved muscle performance is the possibility that dietary nitrate increases blood flow, particularly considering the prominent vasodilator properties of nitrite, as discussed earlier. Indeed, in rats, dietary nitrate (in the form of beetroot juice fed to rats for 5 days) (Ferguson et al., 2013a) lowered exercising (treadmill) BP in tandem with lower blood lactate concentrations and substantial increases in hindlimb muscle blood flow. Using microspheres injected into the rats during the exercise, the authors were able to discriminate exactly which muscles were experiencing elevated blood flow and demonstrated that this occurred only in the exercising muscles and particularly in the type II muscle fibers [invoked in moderate to severe exercise intensity (Henneman et al., 1965)], thus providing improved $\mathrm{O}_{2}$ delivery where and when it was most needed. In a subsequent study, this view was supported by observations reporting much slower falls in microvascular $\mathrm{O}_{2}$ pressure after the onset of electrically evoked contractions of the spinotrapezius muscle of rats fed beetroot juice compared with those fed water (Ferguson et al., 2013b), implying increased muscle $\mathrm{O}_{2}$ delivery and, thus, a resistance to muscle fatigue, particularly of type II muscle fibers. These findings have been tested in humans. Breese et al. (2013) measured the effects of 4-6 days of nitrate supplementation on $\mathrm{VO}_{2}$ and muscle deoxyHb [which would reflect the balance between muscle $\mathrm{O}_{2}$ utilization and muscle $\mathrm{O}_{2}$ delivery kinetics (Koga et al., 2012)]. Nine healthy, physically active subjects were assigned in a randomized, double blind, crossover design to receive nitrate-containing beetroot juice ( $140 \mathrm{ml} /$ day, containing $\sim 8 \mathrm{mmol}$ nitrate) or nitrate-deplete juice ( $140 \mathrm{ml} /$ day) for 6 days. On days 4,5 , and 6 of the supplementation periods, subjects completed a double-step exercise protocol that included transitions from unloaded to moderate-intensity exercise (in which predominately type I muscle fibers are recruited), followed immediately by moderate- to severe-intensity exercise (in which the additional force production would be predominately gained through the recruitment of type II muscle fibers). The study found that nitrate supplementation accelerated the $\mathrm{VO}_{2}$ and muscle deoxyHb kinetics in the moderate- to severe-intensity work rate increment but not the low- to moderate-intensity work rate increment (Breese et al., 2013).

2. Nitrate and Exercise Performance in Patient Populations. The above evidence supports the view that during the hypoxemia created by exercise in which type II muscle fibers are recruited to drive muscle contraction, inorganic nitrate/nitrite acts to improve function. Thus, in individuals with a greater proportion of type II muscle (Hernandez et al., 2012; Ferguson et al., 2013a; Kelly et al., 2014), such as that found in patients with metabolic, respiratory, and CVD (Schaufelberger et al., 1995; Gosker et al., 2000; Mador and Bozkanat, 2001; Raguso et al., 2004; Askew et al., 2005; Oberbach et al., 2006), inorganic nitrate/nitrite may be therapeutically useful. Indeed, several studies have now shown improved exercise capacity in patients with chronic obstructive pulmonary disease (COPD) (Berry et al., 2015; Kerley et al., 2015; Leong et al., 2015; Shepherd et al., 2015b), PAD (Kenjale et al., 2011) and heart failure (HF) (Coggan et al., 2015; Zamani et al., 2015; Eggebeen et al., 2016). However, healthy older adults (Kelly et al., 2013) or patients with type II diabetes did not benefit from dietary nitrate intervention (Shepherd et al., 2015a). These studies are discussed more fully below. Finally, in addition to improving exercise performance, there is also preliminary evidence to suggest that nitrate supplementation can aid recovery postexercise (Clifford et al., 2016).

There are now numerous studies that have explored the potential advantage that inorganic nitrate might provide to endurance athletes. The evidence to date is mixed, with some reports identifying small but competitively important benefits, and others showing no effect (see Table 3). This discord has in part been attributed to the fact that in well trained endurance athletes, physiologic remodeling of the skeletal muscle occurs during chronic endurance training. Moreover, this remodeling is associated with an increase in NOS expression in both skeletal muscle [neuronal NOS (McConell et al., 2007)] and the vasculature supplying the muscles [eNOS (Green et al., 2004)], and also to an increase in the content of $\mathrm{Ca}^{2+}$-handling proteins in type II muscle (Kinnunen and Manttari, 2012) to promote both a lower percentage of type II skeletal muscle (Wilson et al., 2012) and lower mitochondrial UCP3 content (Fernstrom et al., 2004), which is an important determinant of exercise efficiency (Mogensen et al., 2006). Hence, the differing vascular physiology and skeletal muscle of well trained endurance athletes compared with lesser trained athletes may explain a diminished advantage of nitrate supplementation in well trained endurance athletes. 
Since there is a greater proportion of type II muscle used during high-intensity exercise (Krustrup et al., 2004), several research groups have focused on the possibility that this form of exercise may preferentially benefit from nitrate supplementation. Again, there are studies demonstrating benefit, whereas others show no advantage (see Table 4). This apparent discord may be due to the enormous heterogeneity in the studies with respect to the exercise modality, training status of the athletes/participants, the nitrate supplementation protocol, and/or the intermittent nature of the exercise regimes. On balance, however, it does seem that nitrate supplementation has ergogenic potential for athletes participating in sports in which speed, power, and repeated sprint ability are important determinants of success.

3. Cardiac Muscle Function and Heart Failure. Dysfunction of the classic pathways that underlie $\mathrm{NO}$ production are thought to play a major role in the pathogenesis of both HF with reduced ejection fraction (HFrEF, commonly referred to as systolic HF) and preserved ejection fraction ( $\mathrm{HFpEF}$, commonly referred to as diastolic HF) (Drexler, 1999; Cai and Harrison, 2000; van Heerebeek et al., 2012). Left ventricular ejection fraction (LVEF) for humans with $\mathrm{HFrEF}$ is typically $<40 \%$, HFpEF LVEF $>50 \%$, with an intermediate group of $\mathrm{HF}$ with mildly reduced ejection fraction for those with LVEF 40\%-49\% (Ponikowski et al., 2016). Patients are high risk for $\mathrm{HF}$ as the cause of their symptoms with elevated NT-pro-brain natriuretic peptide (NT-proBNP) (sinus rhythm $>1000 \mathrm{pg} / \mathrm{ml}$ and atrial fibrillation $>1600 \mathrm{pg} / \mathrm{ml}$ ) and brain natriuretic peptide (BNP) (sinus rhythm $>300 \mathrm{pg} / \mathrm{ml}$ and atrial fibrillation $>500 \mathrm{pg} / \mathrm{ml}$ ) levels, although lower levels remain compatible with the diagnosis depending on the acuity of the clinical setting (Ponikowski et al., 2016). Standard prognostic therapy in HF with angiotensinconverting enzyme inhibitors, angiotensin receptor blockers, statins, and the novel $\beta$-adrenoceptor antagonists all increase $\cdot \mathrm{NO}$ bioavailability through reduced oxidative stress and increased NOS activity (Omar et al., 2016). Although the organic nitrates provide an efficacious treatment option in the setting of acute $\mathrm{HF}$ and have shown some benefit in chronic HF (Cohn et al., 1986; Taylor et al., 2004), they have proven difficult to use as a long-term option because of the rapid development of tolerance, reflex tachycardia, and the induction of endothelial dysfunction (Münzel et al., 2011, 2013). As the global prevalence of HF increases, with the associated high levels of morbidity and mortality (Meta-analysis Global Group in Chronic Heart Failure (MAGGIC), 2012; Ponikowski et al., 2016), it has become increasingly important to identify and exploit novel methods by which to treat the HF syndrome. The role of inorganic nitrite and nitrate to restore diminished $\cdot \mathrm{NO}$ is one such possibility (Paulus and Tschöpe, 2013). a. $N O$ as an inotrope. -NO has both positive (Sarkar et al., 2000; Paolocci et al., 2003) and negative (Sandirasegarane and Diamond, 1999) inotropic effects in the failing heart, with many observations suggesting that these effects are cGMP-dependent (e.g., Balligand et al., 1993; Kojda et al., 1996), but there is also clear evidence of independence of GC-1 and cGMP signaling (Sarkar et al., 2000) and stimulation of $\beta$-adrenoceptors (Paolocci et al., 2003). These GC-1-independent effects have largely been attributed to the formation of nitroxyl anion and recruitment of ATP-sensitive $\mathrm{K}^{+}\left(\mathrm{K}_{\mathrm{ATP}}\right)$ channels and/or possibly the neuropeptide calcitonin gene-related peptide (Paolocci et al., 2001a,b; Zhu et al., 2015). There is also a growing body of evidence implicating $S$-nitrosation as the pathway for $\cdot \mathrm{NO}$-mediated cardiac effects. In particular, with respect to cardiac hypertrophy, studies with mice show a dependence of $\beta$-adrenoceptor signaling upon $\cdot \mathrm{NO}$ generation that is thought to trigger consequent $S$-nitrosation of key cardiac proteins, including phospholamban and troponin $\mathrm{C}$, to regulate cardiac function accordingly (Irie et al., 2015). Interestingly, there is growing support for the view that $S$-nitrosation, rather than being the protein modification responsible for the effects of $\cdot \mathrm{NO}$, represents a transient chemical step on the path to protein oxidation and disulfide bond formation and that the oxidation of proteins underlies changes in protein function in the setting of nitrosative stress (Wolhuter et al., 2018).

However, many studies have shown the importance of -NO-mediated GC-1 signaling using phosphodiesterase (PDE)-V inhibition to enhance cGMP availability. In a pressure-overload-induced model of $\mathrm{HF}$ using thoracic aortic constriction (TAC), C57BL6J mice received 6 weeks of treatment with $100 \mathrm{mg} / \mathrm{kg}$ per day of sildenafil in soft diet (vs. placebo). Sildenafil prevented further cardiac chamber dilatation, dysfunction, fibrosis, and molecular remodeling, all with beneficial increased myocardial PKG activity (Nagayama et al., 2009). This was coupled with in vitro evidence of improved cardiac muscle contractility, relaxation, and enhanced calcium handling. A further study demonstrated the beneficial effects of PDE-V inhibition using vardenafil in a rabbit model of $I / R$ injury via -NO-dependent opening of the mitochondrial $\mathrm{K}_{\mathrm{ATP}}$ channel (Salloum et al., 2006), as well as with sildenafil, albeit over a shorter time frame (Salloum et al., 2003). Finally, there is also evidence of the -NO-mediated protective effect of sildenafil in doxorubicin-induced cardiotoxicity secondary to generation of ROS formation in cardiac mitochondria and ROS-induced cardiomyocyte apoptosis (Fisher et al., 2005). Cardiotoxicity as a result of anticancer treatment is an increasingly recognized clinical area of major unmet need (Bloom et al., 2016; Zamorano et al., 2016). In their study, Fisher et al. (2005) demonstrated this protective effect in the male ICR strain of mice, in which sildenafil attenuated the 
TABLE 3

Clinical studies assessing the effect of nitrate supplementation upon exercise economy and/or endurance performance

\begin{tabular}{lcc}
\hline Reference & \multicolumn{1}{c}{ Cohort } & \multicolumn{1}{c}{ Intervention } \\
\hline Wilkerson & Eight well trained male & Nitrate-replete $(\sim 6 \mathrm{mmol}$ \\
et al., 2012 & cyclists & nitrate $)$ or -deplete \\
& & beetroot juice as placebo
\end{tabular}

MacLeod

et al., 2015

11 trained male cyclists

Nitrate-replete or -deplete beetroot juice as placebo

Peacock et al., 2012

10 male junior cross-country skiers

Boorsma

et al., 2014

Eight male $1500 \mathrm{~m}$ elite distance runners

Bescos

et al., 2012

Christensen et al., 2013

10 highly trained cyclists

Porcelli

et al., 2015

21 subjects (mean age, $22.7 \pm$ $1.8 \mathrm{yr}$ ) with different aerobic fitness level

Muggeridge

Eight male kayakers et al., 2013

Peeling et al., 2015

Male $(n=6)$ athletes (Study A) and international-level female $(n=5)$ athletes (Study B)

Study A: a 70-ml beetroot juice shot containing $\sim 4.8 \mathrm{mmol}$ of nitrate or placebo

Study B: two 70-ml beetroot juice shots containing $\sim 9.6 \mathrm{mmol}$ of nitrate or placebo
Nitrate-replete or -deplete beetroot juice as placebo

$210 \mathrm{ml}$ of nitrate-replete

(19.5 mmol) or -deplete

beetroot juice as placebo

Sodium nitrate $(10 \mathrm{mg} / \mathrm{kg})$ or sodium chloride $(10 \mathrm{mg} / \mathrm{kg})$ placebo

$0.5 \mathrm{l}$ nitrate-replete beetroot juice or $0.5 \mathrm{l}$ black currant juice as a placebo

Supplementation with either $0.5 \mathrm{l} /$ day of nitrate (5.5 mmol)-containing water or nitrate-free water as placebo

$70 \mathrm{ml}$ of nitrate-replete (5 mmol) concentrated beetroot juice or tomato juice as placebo

Nitrate-replete or -deplete beetroot juice as placebo
Randomized, single blind, crossover study

Measurements performed on two laboratory-based 50-mile time trial $2.5 \mathrm{~h}$ after consuming juice intervention

Randomized, double blind study

Measurements $2 \mathrm{~h}$ after consuming $70 \mathrm{ml}$ of intervention and prior to a 15-min self-selected cycling warmup, then a fixed 15 min of steadystate exercise at $50 \%$ maximum power output, and a $10-\mathrm{km}$ time trial in either normoxic or hypoxic (altitude) conditions

Two trials both randomized, double blind

Measurements $2.5 \mathrm{~h}$ prior to two 5 -min submaximal tests on a treadmill at $10 \mathrm{~km} / \mathrm{h}(\approx 55 \%$ of $\left.\mathrm{VO}_{2} \mathrm{max}\right)$ and $14 \mathrm{~km} / \mathrm{h}(\approx 75 \%$ of $\mathrm{VO}_{2} \mathrm{max}$ ), followed by a $5-\mathrm{km}$ running time trial

Randomized, double blind, crossover study

Volunteers supplemented for 8 days with $>1$ wk between interventions. On days 1 (acute) and 8 (chronic), subjects completed a submaximal treadmill run and 1500-m time trial.

Randomized, double blind, crossover study.

Measurements after a 40-min cycle ergometer distance-trial test after two 3-day periods of dietary intervention

Randomized, double blind, crossover study

Measurements of $\mathrm{VO}_{2}$ kinetics $(3 \times$ $6 \mathrm{~min}$ at $298 \pm 28 \mathrm{~W}$ ), endurance (120-min preload followed by a 400-kcal time trial), and repeated sprint capacity $(6 \times 20$-s sprints, recovery $100 \mathrm{~s}$ ) during two 6 -day dietary intervention intervals

Crossover, double blind, placebocontrolled study 6-day treatment. Participants performed an incremental running test until exhaustion and four repetitions of 6-min submaximal (approximately $80 \%$ of gas-exchange threshold) constant load exercise on a motorized treadmill. Moreover, subjects performed a $3-\mathrm{km}$ running time trial on the field.

Participants completed four performance trials of $15 \mathrm{~min}$ of paddling at $60 \%$ of maximum work rate, five 10-s all-out sprints, and a

$1-\mathrm{km}$ time trial. The second and third trials were preceded by supplementation $3 \mathrm{~h}$ prior to measurements

Study A: participants completed three laboratory-based sessions on a kayak ergometer of $7 \times 4$-min step test, two 4-min maximal effort performance trials. At $2.5 \mathrm{~h}$ prior to the warm-up of each test, the athletes received intervention.

Study B: participants completed two field-based 500-m time trials, separated by 4 days. At $2 \mathrm{~h}$ prior to each test, athletes received intervention.
Nitrate supplementation did not improve 50-mile time trial performance in well trained cyclists.

Nitrate supplementation did not lower the $\mathrm{O}_{2}$ cost of steady-state exercise or improve exercise performance in normoxia or hypoxia in a small sample of well trained male cyclists.

Nitrate supplementation did not reduce $\mathrm{O}_{2}$ cost of submaximal exercise or enhance endurance exercise performance in highly trained crosscountry skiers.

Acute and chronic nitrate supplementation did not reduce running $\mathrm{VO}_{2}$ or improve time trial performance.

Sodium nitrate supplementation did not improve trial performance in endurance athletes.

Nitrate supplementation did not affect $\mathrm{VO}_{2}$ kinetics and performance in elite cyclists.

Individual aerobic fitness level influenced ergogenic benefits induced by nitrate.

Nitrate supplementation had no effect on repeated supramaximal sprint or 1-km time trial kayaking performance.

In national-level male and international-level female kayak athletes, nitrate supplementation improved exercise economy in tasks predominantly reliant on the aerobic energy system and time trial performance, respectively. 
TABLE 3-Continued

\begin{tabular}{|c|c|c|c|c|}
\hline Reference & Cohort & Intervention & Design & Outcome \\
\hline $\begin{array}{l}\text { Hoon et al., } \\
2014\end{array}$ & 10 highly trained male rowers & $\begin{array}{l}\text { Nitrate-replete or -deplete } \\
\text { beetroot juice as placebo } \\
\text { Nitrate-replete juice } \\
\text { administered as a single } \\
\text { shot containing } 4.2 \mathrm{mmol} \text { or } \\
\text { a double shot containing } \\
8.4 \text { mmol nitrate }\end{array}$ & $\begin{array}{l}\text { Placebo-controlled, double blind, } \\
\text { crossover study } \\
\text { Intervention was consumed } 2 \mathrm{~h} \text { prior } \\
\text { to undertaking a } 2000-\mathrm{m} \text { rowing- } \\
\text { ergometer test. }\end{array}$ & $\begin{array}{l}\text { Compared with placebo, a } \\
\text { high ( } 8.4 \text { mmol nitrate) but } \\
\text { not moderate ( } 4.2 \text { mmol } \\
\text { nitrate) dose improved } \\
\text { rowing performance. }\end{array}$ \\
\hline $\begin{array}{l}\text { Bond et al., } \\
2012\end{array}$ & $\begin{array}{l}14 \text { well trained junior male } \\
\text { rowers }\end{array}$ & $\begin{array}{l}\text { Beetroot juice made from raw } \\
\text { vegetables delivering } 5.5 \text {. } \\
\text { mmol/day of nitrate for } \\
6 \text { days } \\
\text { A commercially available } \\
\text { black currant juice with } \\
\text { negligible nitrate content } \\
\text { was used as placebo }\end{array}$ & $\begin{array}{l}\text { Randomized, double blind, crossover } \\
\text { study } \\
\text { After supplementation, rowers } \\
\text { completed six maximal 500-m } \\
\text { ergometer. A 7-day washout period } \\
\text { followed repeat of the trial. Blood } \\
\text { pressure, oxygen saturation, } \\
\text { maximum heart rate, urine, and } \\
\text { lactates were measured. }\end{array}$ & $\begin{array}{l}\text { Nitrate supplementation } \\
\text { improved maximal rowing- } \\
\text { ergometer repetitions. }\end{array}$ \\
\hline
\end{tabular}

toxic effects of doxorubicin, with loss of that protection after treatment with the NOS inhibitors L-NAME and 5-hydroxydecanoate.

b. Cardiac hypertrophy and $\cdot N O$. Cardiac hypertrophy in response to increased afterload (e.g., systemic hypertension) is initially an adaptive response to increase wall stress. Subsequently, this develops into a maladaptive response with progressive left ventricular (LV) dilatation and reduction of ejection fraction. Left ventricular hypertrophy is an important risk factor for developing HFrEF, HFpEF, and atrial fibrillation, as well as for sudden cardiac death in patients (Katholi and Couri, 2011). The importance of ' NO in LV remodeling has been demonstrated in several experimental works - for instance, in transgenic mice with cardiomyocyterestricted overexpression of eNOS (NOS3-TG) versus WT littermates after myocardial infarction (MI) by left anterior descending artery ligation (Janssens et al., 2004). Pre-MI, a 30-fold increase in cardiac eNOS expression led to attenuation of the inotropic response to $\beta$-adrenoceptor agonist isoproterenol. Although infarct size was similar in both groups, NOS3-TG mice had significantly less cardiac dilatation and dysfunction (by LV end systolic diameter and fractional shortening), and enhanced contractile performance and ventricular relaxation (by rate of change of pressure $(\mathrm{dP} / \mathrm{dt})_{\max }$ and $\left.\mathrm{dP} / \mathrm{dt}_{\min }\right)$. There was no protective effect of enhanced eNOS expression on either remote cardiac fibrosis or survival.

ZSF1-HFpEF (leptin-resistant, obese, hypertensive Zucker diabetic fatty/spontaneously hypertensive HF F1 hybrid) rats develop a HFpEF phenotype after 20 weeks, with elevated LV filling pressures, preserved LVEF, increased lung weight with pulmonary congestion, and increased myocardial stiffness (Hamdani et al., 2013). Importantly, there was evidence to suggest reduced $\cdot \mathrm{NO}$ bioavailability (by 3-nitrotyrosine expression) in the $\mathrm{HFpEF}$ mice, with a significant reduction in PKG activity and cGMP concentration, confirming abnormalities in canonical -NO/GC-1/cGMP/PKG signaling (Hamdani et al., 2013).

This lack of bioavailable $\cdot \mathrm{NO}$ and subsequent GC-1 signaling (Paulus and Tschöpe, 2013) has important effects and not only correlates with the level of diastolic dysfunction (Tschöpe et al., 2005) but also plays a key role in the reduced systemic vasodilator response underlying impaired exercise capacity in patients with HFpEF (Borlaug et al., 2010; Edelmann et al., 2011; Haykowsky et al., 2012).

c. Positive inotropic and antihypertrophic effects of nitrite and nitrate. Subsequently, studies have shown that nitrite and nitrate treatment also produces a profile of activity reminiscent of $\cdot \mathrm{NO}$. Pellegrino et al. (2009) used the Langendorff rat heart model to demonstrate that even at low concentrations, $\mathrm{NaNO}_{2}(1 \mathrm{nmol} / \mathrm{l})$ significantly improves contractility, with reductions in $L V$ pressure and improved relaxation. These effects were shown to be NO-mediated and to act via the -NO/cGMP/PKG pathway, but independent of NOS activity. The positive inotropic activity of inorganic nitrite is broadly expressed across a range of species, as demonstrated by the same group in fish, amphibian, and mammalian hearts, in which exogenously applied nitrite improved the Frank-Starling response, with increases in stroke volume, stroke work, LV pressure, and $\mathrm{LV}$ relaxation ( $\left.\mathrm{LV} \mathrm{dP} / \mathrm{dt}_{\max }\right)$ (Angelone et al., 2012). Using male Wistar rats, Ashmore et al. (2014) demonstrated similar benefits with dietary nitrate $(0.7 \mathrm{mmol} / \mathrm{l}$ vs. equimolar $\mathrm{NaCl}$ ) treatment, which prevented hypoxiainduced mitochondrial dysfunction and reduced oxidative stress, while increasing available circulating $\cdot \mathrm{NO}$ through increased tissue L-arginine and reduced suppression of cardiac arginase expression. Similarly, in a mouse model of doxorubicin-induced cardiac dysfunction, provision of $\mathrm{NaNO}_{3}(1 \mathrm{~g} / \mathrm{l}$, equivalent to $12 \mathrm{mmol} / \mathrm{l})$ for 7 days prior to administration of doxorubicin improved both LV systolic, end-diastolic pressures, and ejection fraction (Zhu et al., 2011). These positive effects of $\mathrm{NO}$ and the evidence indicating deficiencies of $\mathrm{NO}$ in the HF setting have spurred researchers on to determine whether the noncanonical pathway for -NO delivery may be useful for improving outcome in this setting.

d. Preclinical studies: cardiac dysfunction, nitrite, and nitrate. In WT rats given L-NAME to induce 
TABLE 4

Clinical studies assessing nitrate supplementation on exercise performance during high-intensity exercise

\begin{tabular}{|c|c|c|c|c|c|}
\hline Reference & Cohort & Intervention & Design & Results & Outcome \\
\hline $\begin{array}{l}\text { Wylie et al., } \\
2013\end{array}$ & $\begin{array}{l}14 \text { male } \\
\text { recreational } \\
\text { team-sport } \\
\text { players }\end{array}$ & $\begin{array}{l}\text { Nitrate-replete or } \\
\text {-deplete beetroot } \\
\text { juice as placebo } \\
(490 \mathrm{ml})\end{array}$ & $\begin{array}{l}\text { Double blind, randomized, } \\
\text { crossover study with juice } \\
\text { delivered over } \sim 30 \mathrm{~h} \\
\text { preceding the completion of } \\
\text { a Yo-Yo intermittent } \\
\text { recovery level } 1 \text { test }\end{array}$ & $\begin{array}{l}\text { Performance in the Yo-Yo IR1 was } \\
4.2 \% \text { greater with nitrate } \\
\text { compared with the placebo. }\end{array}$ & $\begin{array}{l}\text { Acute nitrate supplementation } \\
\text { improved performance during } \\
\text { intense intermittent exercise } \\
\text { in team sports players. }\end{array}$ \\
\hline $\begin{array}{l}\text { Thompson } \\
\text { et al., } 2014\end{array}$ & $\begin{array}{l}16 \text { male team- } \\
\text { sport } \\
\text { players }\end{array}$ & $\begin{array}{l}\text { Intervention of } \\
\text { nitrate-replete } \\
\text { (140 ml/day; } \\
12.8 \mathrm{mmol}^{-} \text {of } \\
\text { nitrate })^{-o r} \\
\text { deplete beetroot } \\
\text { juice as placebo } \\
\text { (140 ml/day; } \\
0.08 \mathrm{mmol} \text { nitrate })\end{array}$ & $\begin{array}{l}\text { Double blind, randomized, } \\
\text { crossover study. On day } \\
7 \text { of supplementation, } \\
\text { subjects completed tests } \\
\text { on a cycle ergometer } \\
\text { during which cognitive } \\
\text { tasks were } \\
\text { simultaneously } \\
\text { performed. }\end{array}$ & $\begin{array}{l}\text { Total work done during the sprints was } \\
\text { greater with nitrate treatment }(123 \pm \\
19 \mathrm{~kJ}) \text { compared with the placebo } \\
(119 \pm 17 \mathrm{~kJ} ; P<0.05) \text {. Reaction time } \\
\text { of response to the cognitive tasks was } \\
\text { also improved. There was no } \\
\text { difference in response accuracy. }\end{array}$ & $\begin{array}{l}\text { Nitrate supplementation } \\
\text { enhanced repeated sprint } \\
\text { performance and } \\
\text { attenuated the decline in } \\
\text { cognitive function (and } \\
\text { specifically reaction time) } \\
\text { that may occur during } \\
\text { prolonged intermittent } \\
\text { exercise. }\end{array}$ \\
\hline \multirow[t]{2}{*}{$\begin{array}{l}\text { Aucouturier } \\
\text { et al., } 2015\end{array}$} & $\begin{array}{l}12 \text { male } \\
\text { subjects }\end{array}$ & $\begin{array}{l}\text { Intervention of } \\
\text { beetroot juice, } \\
500 \mathrm{ml} \text { with } \\
680 \mathrm{mg} / \mathrm{l} \text { of nitrate }\end{array}$ & $\begin{array}{l}\text { Randomized crossover } \\
\text { design single blinded to } \\
\text { the subjects with a 3-day } \\
\text { supplementation }\end{array}$ & $\begin{array}{l}\text { The number of repetitions completed } \\
\text { before reaching volitional } \\
\text { exhaustion was significantly } \\
\text { higher in the nitrate group than in } \\
\text { the placebo }(26.1 \pm 10.7 \text { vs. } 21.8 \pm \\
8.0 \text { respectively, } P<0.05) \text {. In } \\
\text { contrast during exercise performed } \\
\text { at intensity below the peak oxygen } \\
\text { uptake }\left(\mathrm{VO}_{2} \text { peak), oxygen uptake }\right. \\
\left(\mathrm{VO}_{2}\right) \text { was unaffected. }\end{array}$ & $\begin{array}{l}\text { Nitrate supplementation } \\
\text { enhanced tolerance to } \\
\text { exercise at supramaximal } \\
\text { intensity, with increased } \\
\text { microvascular total RBC } \\
\text { concentration in the } \\
\text { working muscle, in the } \\
\text { absence of effect on } \\
\text { contractile function and } \\
\text { resting hemodynamic }\end{array}$ \\
\hline & & $\begin{array}{l}\text { Placebo of apple-black } \\
\text { currant juice with } \\
\text { nitrate } \\
\text { content }<5 \mathrm{mg} / 1\end{array}$ & & $\begin{array}{l}\text { AUC for microvascular total } \\
\text { hemoglobin (AUC-THb) in the } \\
\text { vastus lateralis muscle assessed } \\
\text { by near infrared spectroscopy } \\
\text { during exercise was increased with } \\
\text { nitrate. }\end{array}$ & parameters. \\
\hline $\begin{array}{l}\text { Muggeridge } \\
\text { et al., } 2013\end{array}$ & $\begin{array}{l}\text { Eight male } \\
\text { kayakers }\end{array}$ & $\begin{array}{l}\text { Intervention of } 70 \mathrm{ml} \\
\text { nitrate-replete } \\
(5 \mathrm{mmol}) \\
\text { concentrated } \\
\text { beetroot juice or } \\
\text { tomato juice as } \\
\text { placebo }\end{array}$ & $\begin{array}{l}\text { Randomized crossover } \\
\text { study measuring work } \\
\text { rate during performance } \\
\text { trials composed of } 15 \text { min } \\
\text { of paddling at } 60 \% \text { of } \\
\text { maximum work rate, five } \\
10 \text {-s all-out sprints, and a } \\
1 \text {-km time trial. The } \\
\text { second and third trials } \\
\text { were preceded by } \\
\text { ingestion of intervention } \\
3 \text { h before exercise. }\end{array}$ & $\begin{array}{l}\mathrm{VO}_{2} \text { during steady-state exercise was } \\
\text { lower in the nitrate-treated than } \\
\text { in the PL treated with no } \\
\text { differences in either peak or time } \\
\text { trial performance. }\end{array}$ & $\begin{array}{l}\text { Nitrate supplementation had } \\
\text { no effect on performance. }\end{array}$ \\
\hline $\begin{array}{l}\text { Martin } \\
\text { et al., } 2014\end{array}$ & $\begin{array}{l}\text { Team-sport } \\
\text { athletes } \\
\text { (9 male, age } \\
22.3 \pm \\
2.1 \mathrm{yr} ; \\
7 \text { female, } \\
\text { age } 20.7 \pm \\
1.3 \mathrm{yr})\end{array}$ & $\begin{array}{l}\text { Intervention of } 70 \mathrm{ml} \\
\text { of nitrate-replete } \\
(0.3 \mathrm{~g} \text { nitrate }) \\
\text { concentrated } \\
\text { beetroot juice or } \\
\text { nitrate-deplete } \\
\text { beetroot juice as } \\
\text { placebo }\end{array}$ & $\begin{array}{l}\text { Double blind, randomized, } \\
\text { crossover study with } \\
\text { participants consuming } \\
\text { interventions } 2 \mathrm{~h} \text { prior to } \\
\text { tests }\end{array}$ & $\begin{array}{l}\text { There was no difference in overall } \\
\text { mean power output or the mean } \\
\text { power output for each individual } \\
\text { sprint test. }\end{array}$ & $\begin{array}{l}\text { Nitrate supplementation did } \\
\text { not improve performance. }\end{array}$ \\
\hline $\begin{array}{l}\text { Wylie et al., } \\
2016\end{array}$ & $\begin{array}{l}34 \text { healthy } \\
\text { subjects }\end{array}$ & $\begin{array}{l}\text { Intervention of } \\
\text { nitrate-replete ( } 3 \text { or } \\
6 \text { mmol nitrate/day) } \\
\text { concentrated } \\
\text { beetroot juice or } \\
\text { nitrate-deplete } \\
(0.08 \text { mmol } \\
\text { nitrate/day) } \\
\text { beetroot juice as } \\
\text { placebo }\end{array}$ & $\begin{array}{l}\text { Randomized } \\
\text { counterbalanced design. } \\
\text { Two moderate-intensity } \\
\text { step exercise tests } 2 \mathrm{~h} \\
\text { after the first ingestion } \\
\text { and after } 7,28, \text { and } \\
30 \text { days of } \\
\text { supplementation, } \\
\text { subjects completed. }\end{array}$ & $\begin{array}{l}\text { Compared with pre-treatment } \\
\text { baseline, } 6 \text { mmol nitrate reduced } \\
\text { the steady-state } \mathrm{VO}_{2} \text { during } \\
\text { moderate-intensity exercise by } 3 \% \text { at } \\
2 \mathrm{~h}(P=0.06), 7 \text { days and at } 28- \\
30 \text { days (both } P<0.05) \text { but was } \\
\text { unaffected by } 3 \text { mmol nitrate at all } \\
\text { measurement points. }\end{array}$ & $\begin{array}{l}\text { Up to } \sim 4 \text { wk supplementation } \\
\text { with nitrate at } 6 \text { but not } \\
3 \text { mmol reduced } \\
\text { submaximal exercise } \mathrm{VO}_{2} .\end{array}$ \\
\hline $\begin{array}{l}\text { Bescos } \\
\text { et al., } 2012\end{array}$ & $\begin{array}{l}13 \text { well trained } \\
\text { endurance } \\
\text { athletes }\end{array}$ & $\begin{array}{l}\text { Intervention of } \\
\text { NaNO } \\
\text { body mass } \\
\text { body } / \mathrm{kg} \text { of } \\
\text { Placebo: sodium } \\
\text { chloride, } 10 \mathrm{mg} / \mathrm{kg} \\
\text { of body mass }\end{array}$ & $\begin{array}{l}\text { Randomized, double blind, } \\
\text { crossover study with a } \\
40 \text { min cycle ergometer } \\
\text { distance-trial test after } \\
\text { two } 3 \text { day periods of } \\
\text { dietary supplementation }\end{array}$ & $\begin{array}{l}\text { There were no differences in either } \\
\text { the mean distance or mean power } \\
\text { output between treatments. }\end{array}$ & $\begin{array}{l}\text { Nitrate supplementation did } \\
\text { not improve a 40-min } \\
\text { distance-trial performance. }\end{array}$ \\
\hline \multirow[t]{2}{*}{$\begin{array}{l}\text { Coggan } \\
\text { et al., } 2015\end{array}$} & \multirow[t]{2}{*}{$\begin{array}{l}\text { Healthy men } \\
\text { and women } \\
(n=12 ; \\
\text { age }=22- \\
50 \mathrm{yr})\end{array}$} & \multirow[t]{2}{*}{$\begin{array}{l}\text { Nitrate-replete } \\
\quad(140 \mathrm{ml}, 11.2 \mathrm{mmol}) \\
\text { or -deplete beetroot } \\
\text { juice as placebo }\end{array}$} & $\begin{array}{l}\text { Double blind, placebo- } \\
\text { controlled, randomized } \\
\text { trial }\end{array}$ & $\begin{array}{l}\text { Nitrate treatment increased breath } \\
\text { NO by } 61 \% \text {. This was accompanied } \\
\text { by a } 4 \%(P<0.01 \text {; effect size }= \\
0.74) \text { increase in peak knee } \\
\text { extensor power at the highest } \\
\text { angular velocity tested (i.e., } 6.28 \\
\mathrm{rad} / \mathrm{s}) \text {. }\end{array}$ & \multirow[t]{2}{*}{$\begin{array}{l}\text { Acute nitrate } \\
\text { supplementation increased } \\
\text { whole-body NO production } \\
\text { and muscle speed and } \\
\text { power in healthy men and } \\
\text { women. }\end{array}$} \\
\hline & & & $\begin{array}{l}\text { Assessments at } 2 \mathrm{~h} \text { after } \\
\text { intervention }\end{array}$ & $\begin{array}{l}\text { Calculated maximal knee extensor } \\
\text { power was greater after dietary } \\
\text { nitrate. }\end{array}$ & \\
\hline
\end{tabular}


TABLE 4-Continued

\begin{tabular}{|c|c|c|c|c|c|}
\hline Reference & Cohort & Intervention & Design & Results & Outcome \\
\hline $\begin{array}{l}\text { Sandbakk } \\
\text { et al., } 2015\end{array}$ & $\begin{array}{l}\text { Nine male } \\
\text { elite cross- } \\
\text { country } \\
\text { skiers [age } \\
18 \pm 0 \mathrm{y} \\
\mathrm{VO}_{2} \mathrm{max} \\
69.3 \pm \\
5.8 \mathrm{ml} \\
\min (-1) \\
\mathrm{kg}(-1)]\end{array}$ & $\begin{array}{l}\text { Combined } \\
\text { supplementation } \\
\text { with } 6 \mathrm{~g} \text { L-arginine } \\
\text { and } 614 \mathrm{mg} \text { nitrate } \\
\text { against } 614 \mathrm{mg} \\
\text { nitrate alone and } \\
\text { placebo }\end{array}$ & $\begin{array}{l}\text { Randomized, crossover, } \\
\text { double blind study with } \\
48 \text { h pretreatment }\end{array}$ & $\begin{array}{l}\text { There were no differences in } \\
\text { physiologic responses during } \\
\text { submaximal running or in } 5-\mathrm{km} \\
\text { performance between treatments. }\end{array}$ & $\begin{array}{l}\text { There were no effects of } \\
\text { nitrate supplementation on } \\
\text { exercise economy or } \\
\text { endurance running } \\
\text { performance in endurance- } \\
\text { trained cross-country skiers. }\end{array}$ \\
\hline $\begin{array}{l}\text { Haider and } \\
\text { Folland, } \\
2014\end{array}$ & $\begin{array}{l}19 \text { healthy } \\
\text { untrained } \\
\text { men }(21 \pm \\
3 \mathrm{yr})\end{array}$ & $\begin{array}{l}\text { Nitrate-replete } \\
\text { (9.7 mmol/day) or } \\
\text {-deplete beetroot } \\
\text { juice as placebo }\end{array}$ & $\begin{array}{l}\text { Double blind, randomized, } \\
\text { crossover study, with } \\
\text { intervention given for } \\
\text { seven consecutive days. } \\
\text { After the last } \\
\text { supplementation dose, } \\
\text { force was recorded while } \\
\text { participants completed a } \\
\text { series of voluntary } \\
\text { involuntary (electrically } \\
\text { evoked) unilateral } \\
\text { isometric contractions of } \\
\text { the knee extensors. }\end{array}$ & $\begin{array}{l}\text { Nitrate enhanced peak force } \\
\text { response to low-frequency electrical } \\
\text { stimulation. Explosive force } \\
\text { production during the first } 50 \mathrm{~ms} \text { of } \\
\text { evoked maximal twitch and octet } \\
\text { contractions (eight electrical impulses } \\
\text { at } 300 \mathrm{~Hz} \text { ) was } 3 \%-15 \% \text { greater after } \\
\text { nitrate compared with placebo. } \\
\text { Maximum voluntary force was } \\
\text { unchanged nitrate. }\end{array}$ & $\begin{array}{l}\text { Nitrate supplementation } \\
\text { enhanced the contractile } \\
\text { properties of human } \\
\text { skeletal muscle. }\end{array}$ \\
\hline $\begin{array}{l}\text { Rimer et al., } \\
2016\end{array}$ & $\begin{array}{r}13 \text { trained } \\
\text { athletes }\end{array}$ & $\begin{array}{l}\text { Nitrate-replete } \\
\quad(\sim 11.2 \mathrm{mmol} \\
\text { nitrate }) \text { or -deplete } \\
\text { beetroot juice as } \\
\text { placebo } \\
(0.004 \mathrm{mmol})\end{array}$ & $\begin{array}{l}\text { Double blind crossover } \\
\text { study, with maximal } \\
\text { inertial-load cycling } \\
\text { trials ( } 3 \text { to } 4 \text { s) } \\
\text { immediately before and } \\
\text { after consuming } \\
\text { intervention. } \\
\text { Participants also } \\
\text { performed maximal } \\
\text { isokinetic cycling }(30 \mathrm{~s}) \text { to } \\
\text { assess performance } \\
\text { differences after } \\
\text { supplementation. }\end{array}$ & $\begin{array}{l}\text { PMAX was increased after nitrate } \\
\text { treatment. RP Mopt was increased } \\
\text { with nitrate treatment. }\end{array}$ & $\begin{array}{l}\text { Acute nitrate } \\
\text { supplementation enhanced } \\
\text { maximal muscle power in } \\
\text { trained athletes. }\end{array}$ \\
\hline $\begin{array}{l}\text { Lane et al., } \\
2014\end{array}$ & $\begin{array}{l}12 \text { male and } \\
12 \text { female } \\
\text { competitive } \\
\text { cyclists }\end{array}$ & $\begin{array}{l}\text { Trials were } \\
\text { undertaken with a } \\
\text { caffeinated gum } \\
\text { ( } 3 \mathrm{mg} / \mathrm{kg} \text { body } \\
\text { mass, } 40 \mathrm{~min} \text { prior } \\
\text { to the TT), } \\
\text { concentrated } \\
\text { beetroot juice } \\
\text { supplementation } \\
\text { ( } 8.4 \text { mmol of nitrate, } \\
2 \text { h prior to the TT), } \\
\text { caffeine plus beetroot } \\
\text { juice, or a control. }\end{array}$ & $\begin{array}{l}\text { Cyclists each completed } \\
\text { four experimental trials } \\
\text { in a double blind random } \\
\text { Latin square design. }\end{array}$ & $\begin{array}{l}\text { There was no effect of nitrate } \\
\text { supplementation when used or } \\
\text { when combined with caffeine. }\end{array}$ & $\begin{array}{l}\text { Nitrate supplementation was } \\
\text { not ergogenic under the } \\
\text { conditions of this study. }\end{array}$ \\
\hline $\begin{array}{l}\text { Lansley } \\
\text { et al., } 2011\end{array}$ & $\begin{array}{l}\text { Nine club- } \\
\text { level } \\
\text { competitive } \\
\text { male cyclists }\end{array}$ & $\begin{array}{l}\text { Nitrate-replete }(\mathrm{BR}) \\
\text { or -deplete beetroot } \\
\text { juice }(\mathrm{PL}) \\
\text { BR containing } \\
\sim 6.2 \mathrm{mmol} \text { of nitrate } \\
\text { PL containing } \\
\sim 0.0047 \mathrm{mmol} \text { of } \\
\text { nitrate }\end{array}$ & $\begin{array}{l}\text { Randomized, double blind, } \\
\text { crossover study with } \\
\text { intervention delivered } 2.5 \mathrm{~h} \\
\text { before the completion of a } 4- \\
\text { and a } 16.1-\mathrm{km} \text { time trial }\end{array}$ & $\begin{array}{l}\mathrm{VO}_{2} \text { during time trial were not } \\
\text { different between groups but nitrate } \\
\text { treatment significantly increased } \\
\text { mean PO during the } 4 \text {-and } 16.1-\mathrm{km} \\
\text { time trials. }\end{array}$ & $\begin{array}{l}\text { Acute nitrate } \\
\text { supplementation improved } \\
\text { cycling economy. }\end{array}$ \\
\hline $\begin{array}{l}\text { Flueck } \\
\text { et al., } 2016\end{array}$ & $\begin{array}{l}12 \text { healthy, } \\
\text { well trained } \\
\text { men }\end{array}$ & $\begin{array}{l}\text { Dosages were } 3,6, \\
\text { and } 12 \mathrm{mmol} \\
\text { nitrate as } \\
\text { concentrated } \\
\text { beetroot juice or } \\
\text { sodium nitrate } \\
\text { dissolved in water } \\
\text { vs. water placebo. }\end{array}$ & $\begin{array}{l}\text { Placebo-controlled, single } \\
\text { blind, crossover, } \\
\text { randomized study } \\
\text { Measurements } 3 \mathrm{~h} \text { after } \\
\text { ingestion. Participants } \\
\text { cycled for } 5 \text { min at } \\
\text { moderate intensity and a } \\
\text { further } 8 \text { min at severe } \\
\text { intensity. End-exercise } \mathrm{O}_{2} \\
\text { consumption at moderate } \\
\text { intensity. }\end{array}$ & $\begin{array}{l}\text { At severe-intensity exercise, end- } \\
\text { exercise oxygen consumption was } \\
\sim 4 \% \text { lower in the } 6 \mathrm{mmol} \text { nitrate } \\
\text { juice group compared with the } \\
6 \text { mmol salt ingestion or placebo. }\end{array}$ & $\begin{array}{l}\text { Nitrate supplementation with } \\
\text { juice reduced } \mathrm{O}_{2} \\
\text { consumption to a greater } \\
\text { extent compared with } \\
\text { nitrate salt } \\
\text { supplementation. }\end{array}$ \\
\hline
\end{tabular}

BR, beetroot juice; IR1, intermittent recovery test level 1; PL, placebo; RBC, red blood cell; TT, time-trial.

hypertension leading to cardiac enlargement and fibrosis, supplementation in drinking water with $\mathrm{NaNO}_{2}$ $(100 \mathrm{mg} / \mathrm{l})$ attenuated cardiac enlargement and fibrosis to a similar degree as captopril $(100 \mathrm{mg} / \mathrm{l})$, an angiotensinconverting enzyme inhibitor and first-line treatment of hypertension and HF (Sonoda et al., 2017). In a murine model of pressure overload by TAC, inducing hypertrophy and subsequent $\mathrm{HF}, \mathrm{NaNO}_{2}(50 \mathrm{mg} / \mathrm{l}, \sim 9-12 \mathrm{mg} / \mathrm{kg}$ per day in drinking water) versus vehicle for 9 weeks significantly reduced BNP levels, cardiac hypertrophy, and pulmonary edema at 9 weeks (Bhushan et al., 2014). Furthermore, nitrite pretreatment significantly 
prevented $\mathrm{LV}$ dilatation in both systole and diastole, as well as attenuating LV dysfunction (as measured by LVEF) at 9 weeks. These findings were replicated in a reversal model more representative of the clinical scenario in which patients might present, in which nitrite treatment was commenced 3 weeks after TAC.

More recently, the view that perhaps dietary nitrate might improve outcome by improving mitochondrial function has been tested in healthy rats. Interestingly, $\mathrm{NaNO}_{3}$ in the drinking water $(1 \mathrm{~g} / \mathrm{l})$ for 7 days resulted in elevation of circulating nitrate concentrations with reduction in both SBP and LV end diastolic volumes but absolutely no change in mitochondrial bioenergetics, suggesting that at least in healthy animals the effects of nitrate were not due to improved mitochondrial efficiency or oxidative capacity as has been suggested in other studies. However, what the authors did show was that nitrate treatment was associated with an increase in mitochondrial $\mathrm{H}_{2} \mathrm{O}_{2}$ emissions in $\mathrm{LV}$ homogenates without any change in redox state (Monaco et al., 2018).

The ability of nitrite and nitrate to enhance skeletal muscle performance is discussed elsewhere in this review. However, there is increasing evidence for a specific role of this particular characteristic of the anions in patients with HF (Coggan and Peterson, 2016). A recent study in rats that develop HF after induction of MI by coronary artery ligation (Ferguson et al., 2016) has demonstrated the benefits of dietary nitrate treatment. At 21 days after coronary artery occlusion, rats were randomized to 5 days of nitrate-rich ( $1 \mathrm{mmol} / \mathrm{kg}$ per day nitrate) versus nitrate-deplete beetroot juice and underwent investigations of skeletal muscle blood flow and vascular conductance. Blood flow and vascular conductance at rest were $22 \%$ and $20 \%$ higher, respectively, and significantly greater during exercise in the nitrate-fed rats.

Perhaps one of the key aspects of the nitrate-nitrite-NO pathway that has led to so much interest in its therapeutic utility has been the fact that one can easily and safely test its potential in the clinical setting through dietary administration. HF is no exception, with very rapid translation to the clinical setting after these early preclinical observations.

e. Clinical translation. In the first-in-human study by Ormerod et al. (2015), 25 patients with HFrEF established on best-tolerated HF therapy, undergoing elective right heart catheter during the workup for cardiac transplantation, were subjected to an infusion of $\mathrm{NaNO}_{2}$ for 5 minutes at $10 \mu \mathrm{g} / \mathrm{kg}$ per minute (group 1, $n=8$ ) and $50 \mu \mathrm{g} / \mathrm{kg}$ per minute (group 2, $n=17$ ), and a Swann-Ganz catheter used to measure cardiac and pulmonary hemodynamic parameters. Only the latter dose caused significant increases in plasma nitrite levels, but this rise was associated with a drop in SBP of $4 \mathrm{~mm} \mathrm{Hg}$ over the course of the infusion, as well as decreases in pulmonary and systemic vascular resistance. With this higher dose of nitrite, a significant decrease in right atrial pressure $(40 \%)$ and increases in trans-septal gradient (3 mm Hg), cardiac output (13\%), and stroke volume (14\%) were evident. In addition, in a subgroup analysis of patients with high pulmonary capillary wedge pressure $(>15 \mathrm{~mm} \mathrm{Hg})$, stroke volume was increased by $20 \%$, whereas in those with wedge pressures below $15 \mathrm{~mm} \mathrm{Hg}$, no change was observed. This study therefore demonstrated therapeutic potential for stable patients with HFrEF with clinically marked disease, suggesting that the worse the symptoms, the greater the potential benefit (Ormerod et al., 2015).

A number of small studies have been undertaken investigating the role of dietary nitrate in patients with or at risk of HF. Type 2 diabetes mellitus is a strong risk factor for both HFrEF and HFpEF (Cavender et al., 2015). In patients with or at risk of developing type 2 diabetes mellitus, 6 months of dietary nitrate supplementation $(4.5 \mathrm{mmol} /$ day $)$ was associated with a reduction of $L V$ volumes assessed by standard transthoracic echocardiography, but not in other parameters of improved cardiac performance, or with $\mathrm{BP}$ reduction in comparison with placebo (Faconti et al., 2019). This disappointing result may reflect issues with coexisting drug therapy (i.e., metformin) or microbial bioactivation of nitrate (Cabreiro et al., 2013; Forslund et al., 2015; Sun et al., 2018), as similar neutral results have been seen in other studies with dietary nitrate and diabetes (Gilchrist et al., 2013).

Hirai et al. (2017) in a double blind, randomized, placebo-controlled crossover study in 13 patients with LVEF $\leq 40 \%$, supplemented with $12.9 \mathrm{mmol}$ daily of dietary nitrate for 9 days, investigated the impact of treatment upon time to exercise intolerance. Ten patients completed low- and high-intensity cardiopulmonary exercise testing with noninvasive measures of central hemodynamics, arterial BP, pulmonary oxygen uptake, quadriceps muscle oxygenation, and serum lactate. Over the short period of intervention, they demonstrate that the enterosalivary circuit is intact, with significantly higher plasma nitrite concentrations after intervention versus placebo $(240 \pm 48$ vs. $56 \pm$ $8 \mathrm{nmol} / \mathrm{l}$, respectively). However, they were not able to demonstrate significant benefit in their primary outcome of time to exercise intolerance ( $495 \pm 53$ vs. $489 \pm$ $58 \mathrm{~s}, P>0.05)$ or in their other quoted measures over the short period of intervention. In contrast, in a separate randomized, placebo-controlled, double blind crossover study of nine patients with HFrEF (LVEF $28 \% \pm 11 \%$, NYHA II/III) assessing the potential of an $11.2 \mathrm{mmol}$ dose of dietary nitrate as beetroot juice (Coggan et al., 2015), significant improvements in muscle power using isokinetic dynamometry compared with placebo in both peak knee extensor power and calculated maximal velocity of knee extension were evidenced. 
Interestingly, these effects were made 2 hours after treatment, and although circulating nitrate levels were increased at this time point, nitrite concentrations were not.

This apparent dissonance between the effects of a single acute dose and daily dosing over several days was assessed in a single study in patients with HFpEF. Twenty older (69 \pm 7 years) hypertensive patients with $\mathrm{HFpEF}$ received a once-daily dose of $6.1 \mathrm{mmol}$ nitrate as beetroot juice (vs. nitrate-deplete placebo juice) in a phase II randomized double blind crossover study over 7 days (Eggebeen et al., 2016). The first dose of juice had no impact on submaximal exercise capacity $\sim 1.5$ hours after ingestion; however, over 1 week of intervention, there was a $24 \%$ increase in the time to volitional exhaustion compared with placebo. There was a further benefit of a significant reduction in SBP, at rest and during unloaded exercise, with a trend at volitional exhaustion. This is in line with previous findings using approximately double the dose, with $12.9 \mathrm{mmol}$ dietary nitrate, with improvements in exercise duration, work done, and peak $\mathrm{VO}_{2}$ in addition to increased cardiac output and a fall in systemic vascular resistance (Zamani et al., 2015), and concurs with two recent pilot studies in patients with hypertension and $\mathrm{HFpEF}$ in which time to volitional exhaustion was again increased after dietary nitrate supplementation (Shaltout et al., 2017). Shaltout et al. (2017) report the results of their pilot studies in older patients with hypertension and older patients with $\mathrm{HFpEF}$, in which no additional benefit of dietary nitrate ( 8 and $6.1 \mathrm{mmol}$ ) above and beyond exercise training compared with placebo was evident. However, within-group comparisons in terms of peak $\mathrm{O}_{2}$ consumption, reductions in SBP, and improved arterial compliance were observed. In this study, the authors suggest that escalating doses of dietary nitrate might confer additional benefit, but these studies also suggest enhanced benefits of prolonged over acute dosing in patients with HF similar to observations in healthy volunteer studies (Vanhatalo et al., 2010; Hoon et al., 2013). More recently, a multicenter, placebo-controlled, cross-over, randomized trial has investigated the effects of nebulised sodium nitrite (1.2 mmol nitrite thrice daily for 4 weeks in 105 patients) in patients with HFpEF (Borlaug et al. 2018). Despite significant resting BP reduction with inhaled nitrite (difference in MAP $\sim 5 \mathrm{mmHg}$ ) suggesting sufficient nitrite dosing/elevation to cause a hemodynamic effect (there were no direct measures of plasma nitrite concentrations), there was no effect on $\mathrm{VO}_{2 \mathrm{MAX}}$ (primary outcome there) or other important secondary outcomes measures used in HF trials (daily activity levels, symptom and functional class scores, NTproBNP levels, echocardiographic indices of diastolic dysfunction) (Borlaug et al., 2018). The reasons for the discrepancy between this and previous studies is not immediately clear but may relate to the half-life of nitrite and the dose/ route used.
Despite the variable results noted to date, the general excitement regarding such a simple intervention for this patient cohort is reflected by the fact that there are a number of further studies registered across the globe that continue to investigate the potential therapeutic role of inorganic nitrate/nitrite (summarized in Table 5). The outcome of these studies is eagerly awaited.

\section{Nitrite and Nitrate in Inflammation}

-NO is a potent anti-inflammatory mediator. Perhaps the primary characteristic that underlies this particular feature of $\mathrm{NO}$ bioactivity is that it potently inhibits leukocyte recruitment (Kubes et al., 1991), a key feature of inflammatory responses (Kolaczkowska and Kubes, 2013). The mechanism of this action of $\mathrm{NO}$ has been attributed primarily to the canonical pathway, i.e., GC-1 activation, to elevate cGMP levels, which then results in a suppression in expression of the adhesion molecule CD62P (P-selectin), which plays a key role in the first step, rolling, of the leukocyte recruitment process (Ahluwalia et al., 2004). Despite this, relatively few studies have investigated whether nitrate/nitritederived $\mathrm{NO}$ has the potential to reduce inflammatory responses in humans. In contrast, there are now several studies in mouse models demonstrating important antiinflammatory effects of the anions.

Bryan and his coworkers were the first to explore this particular phenomenon in a mouse model of hypercholesterolemia-induced microvascular inflammation. In this study, healthy C57BL6 mice were fed a high-cholesterol diet for 3 weeks, increasing cholesterol levels from $\sim 70 \mathrm{mg} / \mathrm{dl}$ in controls to $\sim 115 \mathrm{mg} / \mathrm{dl}$, elevating circulating leukocyte numbers from 4.8 to $6.8 \times 10^{6}$ cells $/ \mathrm{ml}$, and resulting in a 4 -fold increase in leukocytes adhering to the venular endothelium and an $\sim 70$-fold increase in emigrated cells measured by intravital microscopy in the cremaster tissue (Stokes et al., 2009). In mice treated concomitantly with 50 or $150 \mathrm{mg} / \mathrm{l} \mathrm{NaNO} \mathrm{N}_{2}$ in the drinking water, a similar reduction in both leukocyte adhesion and emigration was demonstrated. The authors suggested that this effect upon leukocyte recruitment related to an improvement in endothelial function due to elevations in tetrahydrobiopterin levels and, in this way, improves endothelium-derived $\cdot \mathrm{NO}$ activity rather than acting as a delivery method of $\cdot \mathrm{NO}$ per se.

Similar effects have been observed in another study, in which leukocyte recruitment was induced by an acute (90-minute) superfusion of the cremaster muscle with the neutrophil-specific chemokine (C-X-C motif) ligand 2 (CXCL2) (Macrophage Inflammatory Protein 2). This resulted in elevations of leukocyte adhesion and emigration, which were attenuated by a bolus of $\mathrm{NaNO}_{2}$ $(1.3 \mathrm{mg} / \mathrm{kg})$ given intravenously 1 hour prior to CXCL2 superfusion (Jädert et al., 2012). This effect of nitrite upon leukocyte adherence was shown to be dependent 
upon the activation of GC-1 and elevation of cGMP since the guanylyl cyclase inhibitor, ODQ, administered simultaneously with $\mathrm{NaNO}_{2}$, significantly attenuated leukocyte adhesion but, curiously, had no effect on leukocyte emigration. The authors suggested that this differential effect was likely due to an important role for cGMP in leukocyte adhesion but not margination, although if adherence of leukocytes is attenuated, one would expect some knockon effect upon emigration since the former is a prerequisite for the latter. The authors also demonstrated that after 1 week of treatment with $\mathrm{NaNO}_{3}(10 \mathrm{mmol} / \mathrm{l})$ added to the drinking water, a similar reduction in baseline leukocyte rolling was evident, although adhesion or emigration were unaffected, and that leukocyte adhesion and emigration were also reduced in response to CXCL2 (Jädert et al., 2012).

It is now reasonably certain that systemic treatment with nitrite (predominantly $\mathrm{NaNO}_{2}$ ) results in a reduction of the numbers of proinflammatory leukocyte at sites of inflammation. This has been demonstrated in a wide array of distinct animal models in several different species, including in dextran sodium sulfate-induced colonic inflammation as a model of colitis in rats (Ohtake et al., 2010; Jädert et al., 2013); a mouse model of postoperative ileus, a frequent outcome after abdominal surgery (Cosyns et al., 2015); chlorine gas exposure as a model of environmental toxicity and potential chemical warfare in mice, rats, and rabbits (Samal et al., 2012; Honavar et al., 2014, 2017); elastaseinduced pulmonary emphysema in a mouse model (Sonoda et al., 2018); and lung transplantation in rats (Sugimoto et al., 2012). In all of these models, reduced inflammatory responses correlate with reduced numbers of cells, and in many instances, this relates specifically to reduced numbers of neutrophils (Ohtake et al., 2010; Samal et al., 2012; Sugimoto et al., 2012; Cosyns et al., 2015).

This activity of nitrite against neutrophil recruitment has also been demonstrated with dietary nitrate. In a mouse model of atherosclerosis, the $\mathrm{ApoE} \mathrm{KO}$ mouse, fed $15 \mathrm{mmol} / / \mathrm{KNO}_{3}$ in the drinking water for 12 weeks, exhibited reduced leukocyte rolling and adhesion measured using intravital microscopy (Khambata et al., 2017). In addition, after only 2 weeks of dietary nitrate, neutrophil recruitment into the peritoneum in response to zymosan or tumor necrosis factor alpha $(\mathrm{TNF} \alpha)$ in the C57BL6 or littermate ApoE KO mice were also attenuated. Jädert et al. $(2012,2013)$ demonstrated similar effects of dietary nitrate $\left(10 \mathrm{mmol} / 1 \mathrm{NaNO}_{3}\right.$ for up to 7 days in the drinking water) against both Dextran sulfate sodium and nonsteroidal antiinflammatory drug (NSAID)-induced colitis.

The studies above demonstrate a clear impact of nitrite or nitrate treatment on neutrophil recruitment and activation; however, this effect has been suggested to be responsible for the associated reductions in monocyte/macrophage recruitment. In ApoE
KO mice fed a high-fat Western diet with $15 \mathrm{mmol} / \mathrm{l}$ $\mathrm{KNO}_{3}$ for 12 weeks, although plaque size was not altered, macrophage accumulation within the atherosclerotic plaque was significantly attenuated (Khambata et al., 2017). A similar outcome was evident with nitrite treatment and lung grafting (Sugimoto et al., 2012).

A possible mechanism for these antileukocyte effects of nitrate and nitrite is the selective inhibition of key adhesion molecules involved in the leukocyte recruitment process that enable the passage of the leukocyte from the centerline of blood flow to the endothelium and then across the blood vessel wall. As mentioned above, there is good evidence that $\mathrm{NO}$ targets $\mathrm{CD} 62 \mathrm{P}$ on endothelial cells to attenuate leukocyte rolling. In a rat model of NSAID-induced inflammation of the small intestine, endothelial CD62P expression was profoundly suppressed by treatment of rats prior with $\mathrm{NaNO}_{3}(10 \mathrm{mmol} / \mathrm{l})$ in the drinking waterinterestingly, an effect that was lost when the rats were pretreated with chlorhexidine mouthwash to suppress the oral nitrate reductase microbiome (Jädert et al., 2012). Further support for such an effect comes from the reported sensitivity of the anti-inflammatory effects of nitrate or nitrite to agents that scavenge $\cdot \mathrm{NO}$ [2-(4-carboxyphenyl)-4,4,5,5-tetramethylimidazoline-1oxyl-3-oxide (C-PTIO)] or block rises in cGMP through inhibition of GC-1 activity, namely by ODQ treatment (Sugimoto et al., 2012; Cosyns et al., 2015), since it is known that cGMP mediates $\cdot$ NO-induced suppression of CD62P expression (Ahluwalia et al., 2004).

However, there are a number of observations demonstrating that other endothelial adhesion molecules and key molecules expressed on the leukocytes themselves may also be targets for nitrite-derived $\cdot \mathrm{NO}$. In $\mathrm{TNF} \alpha$ treated human dermal microvascular endothelial cells, $\mathrm{NaNO}_{2}(1-100 \mu \mathrm{mol} / \mathrm{l})$ caused a concentration-dependent attenuation of intercellular adhesion molecule-1 (ICAM-1) expression, which is a ligand for several $\beta_{2}$-integrins (Jädert et al., 2012). Our own studies in ApoE mice have shown that treatment with $\mathrm{KNO}_{3}$ in the water (15 and $45 \mathrm{mmol} / \mathrm{l}$ ) causes a selective reduction in $\mathrm{TNF} \alpha$ induced neutrophil CD11b expression (an $\alpha$-integrin, a component of CD11b/CD18, also known as macrophage-1 antigen), with no effects observed on either CD62L (L-selectin) or CD162 (P-selectin glycoprotein ligand-1) expression (Khambata et al., 2017). Unfortunately, in this study, the potential impact upon endothelial CD62P expression was not assessed.

There is also some indication that treatment with these anions likely impacts upon mediator generation at the site of inflammation. Several of the above studies demonstrate reduced cytokine expression after treatment with the anions, particularly with respect to interleukin (IL)-1, IL-6, and TNF $\alpha$ (Ohtake et al., 2010; Sugimoto et al., 2012; Cosyns et al., 2015; Justice et al., 2015; Kautza et al., 2015). The exact 


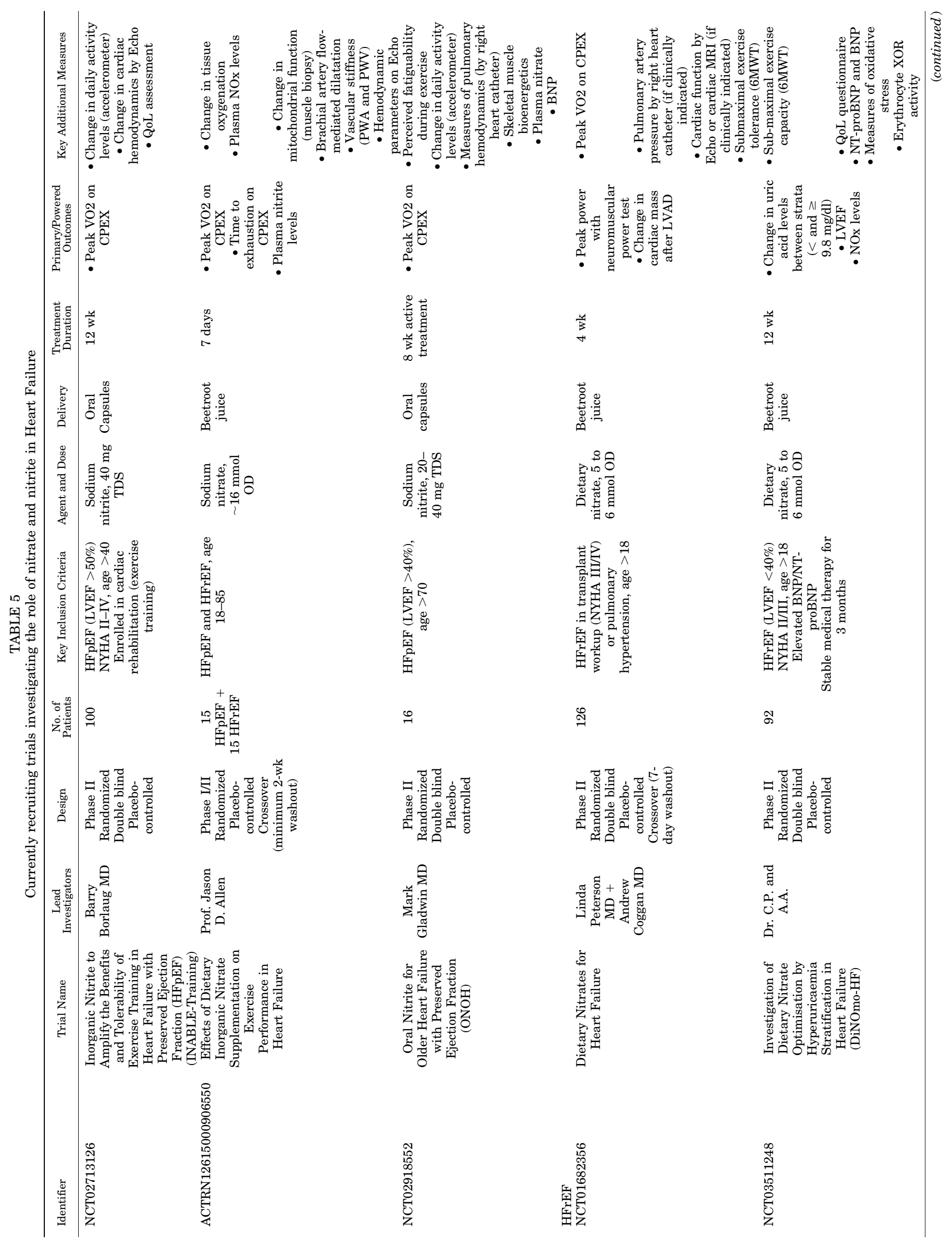

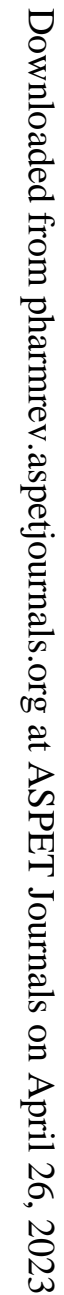




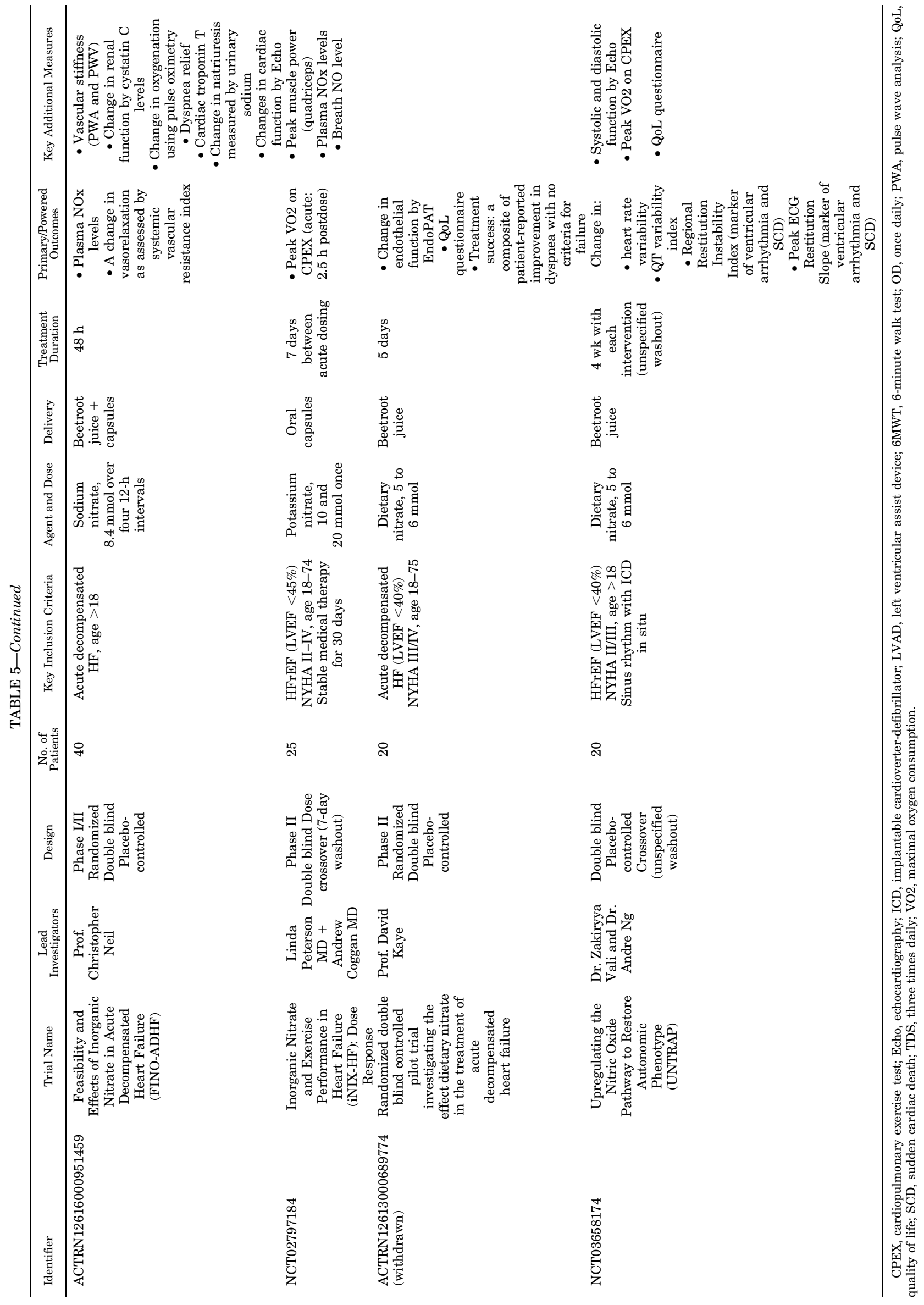


mechanisms of this effect are uncertain but may relate to $\mathrm{NO}$-induced suppression of nuclear factor kappa B expression and thus block of transcription of these cytokines (Sugimoto et al., 2012; Jädert et al., 2013). In addition, there has been some attention to the possibility that attenuation of leukocyte recruitment might relate to suppression of local chemokine generation and, again, there is some evidence to support this contention, including reduced circulating neutrophil chemokine levels (CXCL1 and CXCL2) and reduced monocyte chemokine ( $\mathrm{C}-\mathrm{C}$ motif) ligand 2 (CCL2) in ApoE $\mathrm{KO}$ mice fed dietary nitrate (Khambata et al., 2017). However, others have found no change in the levels of these cytokines in other inflammatory scenarios, including chlorine toxicity in lungs (Honavar et al., 2014), or in the inflammatory setting of aging. In the latter, the Karolinska group demonstrated no impact upon CCL2 and a number of key inflammatory cytokines after 17 months of treatment with $\mathrm{NaNO}_{3}(1 \mathrm{mmol} / \mathrm{l})$ in their drinking water (Hezel et al., 2015).

Finally, there is some evidence to suggest that, in addition to suppressing proinflammatory pathways, the nitrate/nitrite anions may also induce anti-inflammatory pathways. Interestingly, levels of mRNA for IL-10 levels, an anti-inflammatory cytokine, were increased within the plaque region in ApoE $\mathrm{KO}$ mice fed dietary $\mathrm{KNO}_{3}$ compared with KCl-treated controls (Khambata et al., 2017). In addition, in TNF $\alpha$-induced peritonitis, 2 weeks of pretreatment with $15 \mathrm{mmol} / \mathrm{l} \mathrm{KNO}_{3}$ resulted in elevated IL-10 peritoneal levels at 4 hours (Khambata et al., 2017). However, again, there is data contradicting these observations. In the extended studies of aging and chronic treatment with dietary nitrate for 17 months, circulating IL-10 levels were reduced (Hezel et al., 2015).

In sum, there is strong evidence that inorganic nitrate and nitrite treatment reduces the inflammatory response in a variety of preclinical inflammatory disease models. Whether these effects translate to humans and in the clinical setting has not yet been extensively tested prospectively. In two studies, the effect of dietary nitrate supplementation on proinflammatory monocyte-platelet aggregates has been assessed. In both, an acute supplementation study in healthy older volunteers $(n=12$, $13 \mathrm{mmol}$ nitrate) and our own work in a medium-term study in patients with hypercholesterolemia $(n=67$, $6 \mathrm{mmol}$ nitrate/day for 6 weeks), a reduction in proinflammatory monocyte-platelet aggregates was observed that was not apparent after placebo (Velmurugan et al., 2016; Raubenheimer et al., 2017). Furthermore, acute dietary nitrate supplementation was associated with a modest reduction in the activation state of circulating neutrophils (measured by CD11b expression) 3 hours postsupplementation, a time when nitrite levels peak post-dietary nitrate supplementation (see earlier) (Raubenheimer et al., 2017). Two further studies in healthy volunteers are underway specifically to look at whether dietary nitrate is able to abrogate both the inflammatory process and the resulting vascular dysfunction associated with this, utilizing two different acute experimental models of inflammation, and the results are eagerly awaited (clinical trials NCT: NCT03183830, NCT02715635).

1. Thrombosis. Platelets are critically important in the formation of clinically relevant thrombosis (Davì and Patrono, 2007) and are exquisitely sensitive to local generation of 'NO (Azuma et al., 1986), so much so that in the early days of ' $\mathrm{NO}$ biology, this response was used as a bioassay for $\mathrm{NO}$ production (Radomski et al., 1990). -NO has numerous effects on platelet biology, including reduction in adhesion, aggregation, recruitment, and formation of platelet-leukocyte aggregates (Radomski et al., 1987, 1990; Freedman et al., 1997; Chung et al., 2004). Accordingly, a deficiency of $\mathrm{NO}$ is associated with a state of platelet activation in relation to the actions above (Cadwgan and Benjamin, 1993; Stagliano et al., 1997; Freedman et al., 1998, 1999; Gkaliagkousi et al., 2009), and organic nitrovasodilators are known to have modest effects on platelet function (Hampton et al., 1967; Schafer et al., 1980).

Platelet inhibition by $\cdot \mathrm{NO}$ is mediated by GC-1/cGMP/PKG canonical signaling (Massberg et al., 1999), and this PKG activation, in turn, through phosphorylation of specific targets, leads to attenuation of platelet reactivity by triggering downstream inhibition of P-selectin expression (Murohara et al., 1995), phosphorylation of the thromboxane receptor (Wang et al., 1998), and VASP (Massberg et al., 2004), which further inhibits glycoprotein IIb/IIIa. Whatever the specific molecular pathways involved, it is clear that $\mathrm{NO}$ influences all of the major components of platelet function, including $\mathrm{Ca}^{2+}$ mobilization, shape change, secretion, and both integrin activation and outside-in signaling and thus, in this way, plays a key role in ensuring a coordinated regulation of platelet activity (Naseem and Roberts, 2011; Makhoul et al., 2018). However, the exact cellular source and localization of $\mathrm{NO}$ generation that reduces platelet activity is more controversial. There is evidence that supports the endothelium (Moore et al., 2010); however, there are also several observations identifying the platelet itself as the site for NOS-derived $\cdot \mathrm{NO}$ (Radomski et al., 1990), particularly eNOS (Freedman et al., 1999; Webb et al., 2008a; Radziwon-Balicka et al., 2017), although others have failed to localize eNOS within platelets (Gambaryan et al., 2008; Gambaryan and Tsikas, 2015). Irrespective of localization, it is clear that basal $\mathrm{NO}$ generation plays a critical role in repressing platelet reactivity under normal conditions. Thus, in scenarios in which there is a deficiency of bioavailable $\cdot \mathrm{NO}$, restoration of $\cdot \mathrm{NO}$ levels, through $\cdot \mathrm{NO}$ delivery, should recover normal platelet function. Several research groups have assessed whether provision of inorganic nitrate and nitrite might achieve this outcome. 
Ex vivo incubation of platelet-rich plasma, collected from healthy volunteers with supraphysiologic nitrite concentrations $\left(60 \mu \mathrm{mol} / \mathrm{l} \mathrm{NaNO}_{2}\right)$ was shown many years ago to reduce aggregatory responses to a wide range of platelet stimuli (ADP, arachidonic acid, and collagen), whereas similar concentrations of $\mathrm{NaNO}_{3}$ had no effects (Schafer et al., 1980). This finding has been supported more recently, when physiologically relevant nitrite concentrations (no more than $1 \mu \mathrm{mol} / \mathrm{l}$ ) achieved through in vivo treatment with dietary inorganic nitrate (Webb et al., 2008b) resulted in a suppression of ex vivo-assessed platelet aggregation responses. However, further work has shown convincingly that ex vivo treatment with nitrite salts does not directly alter platelet reactivity at physiologic concentrations. Rather, the evidence suggests that to reveal the antiplatelet effects of nitrite, reactivity must be assessed in the whole blood environment wherein platelets remain in close contact with the circulating elements of the blood.

In platelet-rich plasma, $0.1 \mu \mathrm{mol} / / \mathrm{NaNO}_{2}$ inhibited stimulus-induced platelet aggregation only when in the presence of erythrocytes (Srihirun et al., 2012). Similar findings were separately published by Velmurugan et al. (2013), in which $\mathrm{KNO}_{2}(0.1-0.3 \mu \mathrm{mol} / \mathrm{l})$ caused concentration-dependent suppression of platelet aggregation only when incubated with whole blood and not when incubated with platelet-rich plasma alone. Interestingly, the antiplatelet effects of nitrite are enhanced by deoxygenation of erythrocytes and blocked by -NO scavenging (Srihirun et al., 2012), as well as being associated with elevations in cGMP (Velmurugan et al., 2013). These findings fit well with the view that nitrite reduction in blood is in part dependent upon the reductase activity of erythrocytic $\mathrm{Hb}$ and requires partial deoxygenation (Cosby et al., 2003).

As one would suspect, the elevation of cGMP in the platelet with nitrite treatment results in the antiplatelet effects typical of $\cdot \mathrm{NO}$-induced GC-1 activation and is associated with suppression not only of P-selectin expression (Akrawinthawong et al., 2014) but also gpIIb/IIIa expression, both key pathways regulating platelet activity and known to be influenced by $\cdot \mathrm{NO}$ (Murohara et al., 1995; Keh et al., 1996). Further studies with inhaled $\mathrm{NaNO}_{2}(40 \mathrm{mg})$ have also demonstrated increased platelet phospho-VASP, confirming NO/GC-1/cGMP/PKG signaling and diminution of stimulus-induced platelet aggregation (Parakaw et al., 2017). These results together suggest that nitrite reduction does not occur at the level of the platelet itself but rather occurs at the level of the erythrocyte and that the $\mathrm{NO}$ generated acts on the neighboring platelet to elevate cGMP, resulting in downstream inhibition of key platelet activating pathways.

Platelets themselves contain nitrite (Apostoli et al., 2014), the levels of which are substantially reduced by treatment with ascorbic acid ex vivo [a nonspecific reducing agent, as per previous evidence shown in erythrocytes (Sibmooh et al., 2008)], which also simultaneously results in inhibition of platelet aggregation that is associated with elevations in cGMP and phospho-VASP and effects that are enhanced by inhibition of PDE-V and inhibited if treated with ODQ or C-PTIO. However, in this paper, the authors also show nitrate in platelets, the levels of which likewise are decreased with ascorbate. This observation is curious, since ascorbate provides a one-electron reduction; however, for nitrate reduction, two electrons are needed. The authors also show that treatment with $\mathrm{NaNO}_{2}$ causes inhibition of platelet aggregation that is also enhanced by treatment with ascorbate or PDE-V inhibitors; and that is prevented by treatment with ODQ or C-PTIO. The authors propose a number of controversial explanations for their observations. Since coincubation with NOS inhibitors had no impact upon any of the responses and since the authors previously have failed to show eNOS expression in platelets, they reason that the source of the widely reported capacity of platelets to generate $\cdot \mathrm{NO}$ is in fact due to nitrite reduction and not NOS catalytic activity. Moreover, unlike several other publications, since the authors conducted all of their ex vivo experiments in the absence of erythrocytes, they suggest that the platelet itself has the capacity to reduce nitrite directly (Apostoli et al., 2014), although the exact nitrite reductase was not identified.

As mentioned briefly, the beneficial effect of nitrite upon platelet reactivity can be exposed after elevation of circulating nitrite levels through oral administration of inorganic nitrate. Oral supplementation of healthy volunteers with either $2-8 \mathrm{mmol} \mathrm{KNO}_{2}$ (Richardson et al., 2002; Velmurugan et al., 2013) or 3.1-22.5 mmol dietary nitrate (192-1395 mg nitrate as beetroot juice) (Webb et al., 2008b; Velmurugan et al., 2013) prior to venepuncture, followed by examination of ex vivo platelet aggregation, results in a modest reduction in the platelet aggregatory response to stimulatory agonists such as ADP and collagen, with associated increases in platelet cGMP and suppression of P-selectin expression (Velmurugan et al., 2013). The modulating effects of dietary nitrate supplementation are additionally seen in healthy older adults after acute nitrate supplementation (13 mmol nitrate, $n=12$ ) with reduction in platelet $\mathrm{P}$-selectin expression and clotting time in whole blood, relating to both intrinsic and extrinsic pathways in whole blood but not plasma coagulation tests post-dietary nitrate supplementation (Raubenheimer et al., 2017).

Interruption of the enterosalivary circulation by spitting negated the anti-platelet effects of dietary nitrate, reconfirming the requirement for bioactivation of nitrate to nitrite within the oral cavity (Webb et al., 2008b). Similar effects are seen in mice-whilst treating mice for 1 week with $\mathrm{NaNO}_{2}(0.1 \mathrm{~g} / \mathrm{l})$ or $\mathrm{NaNO}_{3}$ $(1 \mathrm{~g} / \mathrm{l})$ reduced ex vivo platelet aggregation and prolonged bleeding time, when mice were fed with a lowNOx diet, the opposite occurred, with enhanced 
platelet aggregation and shorter bleeding time (Park et al., 2013). Finally, this beneficial profile of activity of nitrite and nitrate upon platelets evidenced in these acute healthy volunteer and preclinical studies does translate into the patient setting. In patients with endothelial dysfunction and modest hypercholesterolemia, 6 weeks of a once-per-day dietary nitrate supplementation $(\sim 6 \mathrm{mmol})$ was associated with lower basal and stimulus-induced platelet $\mathrm{P}$-selectin expression and leukocyte-platelet aggregates (Velmurugan et al., 2016). Again, these studies show a modest but significant effect. Such a profile of activity, we argue, lends itself as an alternative approach in primary and secondary prevention. Perhaps one of the key difficulties associated with antiplatelet therapy in the secondary prevention setting is the negative side effect profile of bleeding complications. Similarly, it is these very same bleeding complications that have resulted in cessation of the use of aspirin as a primary prevention strategy. We speculate that with such a modest but important antiplatelet profile, dietary nitrate offers a relatively safe and easy-to-administer option.

2. Peripheral Arterial Disease. The positive effects of inorganic nitrate/nitrite against inflammation and platelet function, in addition to the benefits in terms of skeletal muscle function, suggest that in diseases with chronic tissue, ischemia such as PAD associated with impaired blood flow, enhanced inflammation, and platelet activation, inorganic nitrate may be of value. In addition, since $\mathrm{NO}$ has a positive impact upon angiogenesis (Papapetropoulos et al., 1997; Cooke and Losordo, 2002), effective $\cdot \mathrm{NO}$ delivery through inorganic nitrate/nitrite might offer a mechanism for therapeutic angiogenesis.

In a mouse hindlimb ischemia model, both chronic nitrite and nitrate therapy increase ischemic tissue blood flow with associated endothelial cell proliferation and angiogenesis (Kumar et al., 2008; Hendgen-Cotta et al., 2012). In addition, evidence in humans suggests that dietary nitrate supplementation is associated with mobilization of circulating angiogenic cells (Heiss et al., 2012), strongly supporting the suggestion that nitrate therapeutics may work in PAD. However, again there is controversy. Major optimism was generated by the first study in patients with PAD demonstrating benefit. After a 3-month supervised exercise program in patients with $\mathrm{PAD}$, significant improvements in exercise capacity were seen and correlated to increases in plasma nitrite concentration (Allen et al., 2010). But more importantly, acute dietary nitrate supplementation (18 mmol nitrate in beetroot) was associated with $\sim 20 \%$ improvement in claudication onset time and peak walk time (Kenjale et al., 2011). However, divergent results have been apparent with chronic administration. After 10 weeks of twice-daily supplementation with $\mathrm{NaNO}_{2}$ (40 or $80 \mathrm{mg}$ ) versus placebo in diabetic patients with $\mathrm{PAD}$, there was an improvement in endothelial function in these patients with nitrite treatment, but there was no effect on 6-minute walk time (Mohler et al., 2014). Conversely, 8 weeks of $\mathrm{NaNO}_{3}$ ( $8.5 \mathrm{mmol} /$ day nitrate) was associated with a $\sim 40 \mathrm{~m}$ improvement in the 6-minute walk test (Bock et al., 2018a), although there was only a trend for similar effect $(\sim 30 \mathrm{~m})$ after 12 weeks of $4.2 \mathrm{mmol}$ nitrate with a structured exercise program compared with exercise and placebo (Woessner et al., 2018). However, these effects may have been explained, despite randomization and blinding, by a slightly worse baseline in the nitratetreated group and thus greater apparent improvement. Further definitive studies are awaited, but at present, whether dietary nitrate might be useful for PAD is uncertain.

3. Atherosclerosis. There is a wealth of evidence demonstrating that vascular $\cdot \mathrm{NO}$ is critical in sustaining vascular patency and that a deficiency in bioavailable -NO is a pivotal phenomenon involved in triggering atherogenesis (Böger et al., 1997; Antoniades et al., 2007). As discussed above, we know that NO reduces leukocyte adhesion and transmigration, reduces low density lipoprotein cholesterol oxidation, and inhibits vascular smooth muscle proliferation [for review, see Moncada and Higgs (1993)]. Moreover, from studies using NOS inhibitors and eNOS KO mice, we know that eNOS is the primary source of the vascular $\cdot \mathrm{NO}$ that underlies protection against atherogenesis in health (Kauser et al., 2000; Kuhlencordt et al., 2001). Furthermore, the uncoupling of eNOS in the disease setting is thought to be responsible for the reduced bioavailable -NO and endothelial dysfunction, which is implicated in the atherosclerotic process (Libby, 2002; Napoli et al., 2006). As a result, numerous studies have sought to restore $\cdot \mathrm{NO}$ levels utilizing $\cdot \mathrm{NO}$ donors, particularly the organic nitrates, L-arginine (the substrate for conventional $\mathrm{NO}$ synthesis), or the essential cofactor for NOS, tetrahydrobiopterin. Many of these studies have shown positive outcomes, including improvements in vascular function, systemic inflammatory profile, and local inflammation at lesional sites and positive effects upon platelet reactivity (Clarkson et al., 1996; Theilmeier et al., 1997; Wolf et al., 1997). However, translation of these findings to the clinical setting has not gone as well as hoped (e.g., Nakamura et al., 1999; Blum et al., 2000; Cunnington et al., 2012). The reasons for these discordant findings are variously attributed to eNOS uncoupling for L-arginine (Förstermann and Sessa, 2012), tolerance and induction per se of vascular dysfunction with the organic nitrates (Münzel et al., 2013), and/or oxidation of tetrahydrobiopterin (Cunnington et al., 2012). Although all of these approaches are distinct, they all aim to provide $\cdot \mathrm{NO}$ delivery to the atherogenic blood vessel. The failure of translation of all of these approaches supports the contention that alternative, but more effective, strategies to improve bioavailable $\mathrm{NO}$ levels are warranted. It is this 
need that underlies the testing of inorganic nitrate and nitrite in atherosclerosis.

As mentioned earlier in the review, there have been some studies that have begun to assess the potential of nitrate/nitrite as an 'NO delivery method in atherosclerosis. Inorganic nitrite and nitrate supplementation has been shown to reduce leukocyte-endothelial cell interactions in hypercholesterolemia (Stokes et al., 2009), and a 6 -week, once-per-day dietary nitrate treatment in patients with hypercholesterolemia improved endothelial function together with some evidence (although the study was not powered for some of these indices) suggesting that this improved vascular function was associated with a reduced systemic inflammation and reduced platelet reactivity (Velmurugan et al., 2016).

These positive mechanistic findings have been followed up by testing of the impact of inorganic nitrate salt supplementation upon plaque formation and size in mouse models of atherosclerosis. The first study assessing this reported in 2016 and, disappointingly, was negative. In this study, low density lipoprotein cholesterol receptor $\mathrm{KO}$ mice were fed a Western diet for 14 weeks and treated concomitantly with $\mathrm{NaNO}_{3}$ $(1 \mathrm{~g} / \mathrm{l})$ or equimolar $\mathrm{NaCl}$ in drinking water. At the end of this treatment period, there were no differences between the two groups in plaque size, histologic plaque scores, and macrophage, collagen, and smooth muscle content. It is noteworthy, however, that although there have been numerous studies demonstrating efficacy of such a dosing schedule, in this study, nitrate supplementation was not associated with an increase in systemic nitrite levels, and there was no change in BP. These results suggest that, at least in these animals, this dosing regimen was insufficient to evoke modulation of the nitrate-nitrite-NO pathway (Marsch et al., 2016). This failure may underlie the absence of any effects seen.

Interestingly, in ApoE $\mathrm{KO}$ mice, supplementation with $15 \mathrm{mmol} / \mathrm{KNO}_{3}$ for 12 weeks was associated with increases in systemic and organ nitrite levels in comparison with mice treated with equimolar $\mathrm{KCl}$. This rise was associated with reduced leukocyte rolling and adherence, assessed using intravital microscopy of the cremaster microcirculation, reduced circulating neutrophil numbers and monocyte activation, and upregulation of IL-10-dependent anti-inflammatory pathways. This multitude of anti-inflammatory effects resulted in a reduction in the inflammatory load within the plaque, while having no effect upon plaque size (Khambata et al., 2017). Intriguingly, in this study, we showed that tissues of the ApoE KO expressed greater nitrite reductase activity assessed ex vivo and that this activity, at least in part, was driven by elevated XOR activity, observations fitting with studies in humans indicating that individuals with coronary artery disease have increased vascular XOR expression and activity (Spiekermann et al., 2003). In a separate study, low to moderate dosing with $\mathrm{KNO}_{3}$ ( 0.1 and $1 \mathrm{mmol} / \mathrm{kg}$ per day) but not high-dose ( $10 \mathrm{mmol} / \mathrm{kg}$ per day) supplementation for 10 weeks in ApoE KO mice was associated with increased collagen expression and reduced lipid deposition and also, similarly, no differences in plaque size (Bakker et al., 2016). These two latter studies support the contention that reduced inflammation within the atherosclerotic plaques coupled with increased smooth muscle and collagen content, although not influencing plaque size, likely provides a more stable plaque phenotype (Stefanadis et al., 2017).

Interestingly, and perhaps contradicting the above work, is evidence suggesting that nitrite has important activity limiting intimal hyperplasia. Rats pretreated with $\mathrm{NaNO}_{2}$ (administered intraperitoneally, orally, or nebulized) inhibited pathologic intimal hyperplasia, caused in response to vascular wall injury through insertion of a balloon and inflation in the carotid artery. Importantly, treatment of rats after injury (15 days later) also resulted in a statistically significant reduction in hyperplasia assessed at 28 days. In addition, the authors demonstrated that this beneficial effect of nitrite was attenuated if rats were pretreated allopurinol, implicating XOR as the nitrite reductase in this setting (Alef et al., 2011).

Although there does seem to be some contrast in pathways, the evidence does support the view that the nitrate-nitrite- $\mathrm{NO}$ pathway may offer opportunities for limiting atherosclerosis and that such an approach may have utility not only in terms of dietary lifestyle interventions that limit disease from occurring in the first place but also as an additional strategy that may prove useful in the secondary prevention setting.

\section{Nitrite and Nitrate in the Respiratory System}

In the respiratory system, $\mathrm{NO}$ can be produced under physiologic conditions by heterogenous cell types, including pulmonary vascular endothelial cells, immune cells, respiratory epithelial cells, and intrinsic respiratory nerves (Barnes and Belvisi, 1993). Exhaled $\mathrm{NO}$ can be detected in the range of 20-60 ppb, although it may be that the majority of this is derived from the upper respiratory tract and that the distal airways in the lung parenchyma are associated with much lower levels (1-6 ppb) (Dillon et al., 1996). The physiologic role of -NO in the respiratory system is complex to understand in any specific area given the many different sources of $\cdot \mathrm{NO}$. The activity of $\cdot \mathrm{NO}$ will naturally depend on other local factors, including levels of oxidant stress (in a highoxygen environment).

In early studies, nitrovasodilators were shown in isolated airway smooth muscle to activate the canonical GC-1/cGMP pathway to produce muscular relaxation (Gruetter et al., 1989). Furthermore, inhaled 'NO was found to have small effects on bronchodilation in 
patients with asthma and to prevent methacholineinduced bronchoconstriction in a concentration-dependent manner in rodents. (Dupuy et al., 1992; Högman et al., 1993). There is also a contribution to physiologic bronchial tone by inhibitory nitrergic signaling that counteracts the excitatory cholinergic pathway (Belvisi et al., 1992; Ward et al., 1993). Perhaps therapeutically more important than effects on bronchial tone, $\mathrm{NO}$ is a key signaling molecule regulating basal pulmonary vascular tone to counteract pulmonary hypoxic vasoconstriction (Crawley et al., 1990; Persson et al., 1990; Liu et al., 1991). In addition to its actions mediated via elevation of cGMP, there are some $\mathrm{NO}$ effects in the respiratory system that are largely independent of this pathway. In particular, high levels of 'NO that can be generated by iNOS may be antimicrobial and tumoricidal by DNA deamination and inhibiting DNA synthesis (Kwon et al., 1991; Wink et al., 1991). Given the wideranging actions of $\mathrm{NO}$ in the pulmonary system, it is not surprising that strategies to harness $\cdot \mathrm{NO}$ activity have been explored in various respiratory-related diseases.

1. Pulmonary Hypertension. Pulmonary arterial hypertension $(\mathrm{PAH})$ is a rare condition characterized by increased pulmonary vascular resistance and associated elevated pulmonary arterial pressure (PAP), leading to right HF. Patients with PAH experience significant dyspnea, fatigue, and accelerated mortality. Pathophysiological alterations in PAH include abnormal pulmonary vasoconstriction and endothelial dysfunction, smooth muscle cell proliferation, and adverse remodeling of the pulmonary circulation. It has been known for some time that defects in $\cdot \mathrm{NO}$-mediated vasodilatation is one of the hallmarks of disease (Adnot et al., 1991), and this has led to the exploration of drugs that target the NO-GC-1-cGMP pathway for the reduction of PAP.

Inhaled NO (iNO), by virtue of its scavenging in the circulation by $\mathrm{Hb}$, results in selective delivery of $\cdot \mathrm{NO}$ to the pulmonary circulation without the potential adverse effects of systemic NO delivery, such as systemic arterial hypotension. Inhaled $\mathrm{NO}$ was demonstrated to be a selective pulmonary vasodilator more than 30 years ago (Frostell et al., 1991; Pepke-Zaba et al., 1991), but the need for continuous nebulization restricts its utility in ambulant patients with PAH. This limitation has, however, been overcome by taking the strategy of using selective inhibitors of cGMP breakdown by blocking the activity of PDE-V, thus augmenting the pulmonary vasodilatory effects of endogenously produced $\cdot \mathrm{NO}$. This approach is associated with clear improvements in patient-related and hemodynamic outcomes (Palmieri et al., 2004; Galiè et al., 2005, 2009; Pepke-Zaba et al., 2008) and is now commonly used clinically for this indication. Since it is widely accepted that there is a reduction in $\mathrm{NO}$ bioavailability in $\mathrm{PAH}$ ( $\mathrm{Hu}$ et al., 2010), there has been considerable focus on bypassing this step of the pathway through generation of direct activators/stimulators of GC-1. Riociguat is the first in class of these drugs to have received widespread marketing authorization for $\mathrm{PAH}$ after the positive results of the PATENT studies, demonstrating improvements in the 6-minute walking test (the most commonly used intermediate endpoint) and dyspnea scores in patients with PAH (Ghofrani et al., 2013).

Given the recent evidence of the ability of nitratenitrite-- $\mathrm{NO}$ reduction to produce bioactive $\cdot \mathrm{NO}$ and the fact that this pathway appears to be augmented in hypoxia, this knowledge has spurred interest in whether inorganic nitrite and nitrate could ameliorate pulmonary hypertension. Recent preclinical studies have explored the utility of this pathway in pulmonary hypertension. In ovine models of PAH induced by hypoxia, thromboxane, and hemolysis, both iNO and inhaled $\mathrm{NaNO}_{2}$ reduced pulmonary vasoconstriction and ameliorated PAP. An important distinction between the two treatment forms was that nitrite therapy was associated with less systemic hypotensive effects (Hunter et al., 2004; Blood et al., 2011). The effects of inhaled nitrite were kinetically slower than those for iNO and associated with less rebound vasoconstriction on termination of intervention (Hunter et al., 2004). Similarly, in both monocrotaline and hypoxia-induced $\mathrm{PAH}$ in rats, repeated inhaled nitrite application prevents but also reverses established effects of PAH on PAP, vascular smooth muscle proliferation, and right ventricular function (Zuckerbraun et al., 2010). Assessment of nitrite reductase ex vivo suggested that this effect was largely XOR-mediated, and in vivo, the effects of nitrite were abrogated by both XOR inhibition and dietary tungsten replacement of molybdenum in XOR (Zuckerbraun et al., 2010).

The potential beneficial effects of elevation of systemic levels of nitrite have been explored by both injection of inorganic nitrite and through dietary nitrate (via the enterosalivary circulation) and nitrite provision in drinking water. Acute intravenous and chronic intraperitoneal inorganic nitrite application are associated with improvements in PAP and right ventricular hypertrophy in monocrotaline- and hypoxia-induced PAH in rats (Casey et al., 2009; Pankey et al., 2012). However, for effective translation to human therapeutics, a more convenient form of systemic nitrite elevation would be desirable. In mice exposed to 3 weeks of hypoxia to induce typical pathologic changes of $\mathrm{PAH}$, both dietary nitrite $(0.6 \mathrm{mmol} / \mathrm{l})$ and nitrate $(45 \mathrm{mmol} / \mathrm{l})$ supplementation via drinking water reversed elevation of right ventricular pressure and hypertrophy. Dietary nitrate supplementation was also effective in a pathologically distinct model of PAH induced using bleomycin (Baliga et al., 2012) and monocrotaline (Tawa et al., 2019). Further work utilizing eNOS KO mice and XOR inhibitors suggested that both enzyme systems were important for the beneficial effects of elevated nitrite levels in these models, with evidence also implicating $\mathrm{NO}$ - 
mediated activation of GC-1-cGMP pathways (Baliga et al., 2012).

Whether local or systemic elevation of nitrite will translate to effective treatments in human disease is currently unknown. Earlier clinical studies in healthy volunteers given i.v. $\mathrm{NaNO}_{2}(1 \mu \mathrm{mol} / \mathrm{min})$ suggested acute improvements in hypoxia (12\%)-induced pulmonary artery pressures (measured by transthoracic echocardiography) (Ingram et al., 2010). Furthermore, a series of dose-ranging phase I pharmacokinetic studies of inhaled $\mathrm{NaNO}_{2}$ in healthy persons have suggested suitable safety parameters supporting a thrice daily maximal tolerated dose of $90 \mathrm{mg}$ of $\mathrm{NaNO}_{2}$ (Rix et al., 2015) to allow further exploration of inhaled nitrite in patients with $\mathrm{PAH}$. In patients with $\mathrm{PAH}$ due to $\mathrm{HFpEF}$ and chronic lung disease, acute inhaled nitrite lowered PAP, pulmonary capillary wedge pressures, and pulmonary vascular resistance (Simon et al., 2016). Recently, a report in five patients with echocardiographic evidence of PAH associated with $\beta$-thalassemia has suggested that acute inhaled nitrite rapidly decreases PAP, and this reverts shortly after inhalation terminates (Yingchoncharoen et al., 2018). In a pilot crossover study in 15 patients with $\mathrm{PAH}$, randomized to two 7-day treatment periods ( $16 \mathrm{mmol} /$ day nitrate vs. placebo), ingestion of a fixed dose of dietary nitrate was associated with increases in exhaled $\mathrm{NO}$ and plasma and salivary NOx and was not associated with any adverse systemic hemodynamic changes. There were no significant changes in pulmonary hemodynamic parameters assessed by echocardiography or cardiopulmonary exercise testing, or of function tests, such as the 6-minute walk test, although there were trends for improvements in right ventricular function and peak power per liter oxygen consumed, particularly in those patients in whom plasma nitrite flux was $>30 \%$ postnitrate ingestion (Henrohn et al., 2018). Although these data are encouraging, it remains for larger, adequately powered trials to determine whether inorganic nitrate supplementation has benefit in $\mathrm{PAH}$, with or without other drugs that modulate the NO-GC-1-cGMP system.

2. Chronic Obstructive Pulmonary Disease. COPD describes a progressive respiratory disease affecting the airways and lung parenchyma, resulting in irreversible airway obstruction. Patients with COPD describe dyspnea and reduced exercise tolerance due to a combination of ventilatory/gas-exchange impairment leading to hypoxia and skeletal muscle deconditioning. Exercise and pharmacological management improve the exercise capacity and physical function of patients with COPD (Barnes et al., 2015).

Given the effects of inorganic nitrate supplementation, via elevation of systemic nitrite levels, on various measures of exercise capacity in healthy persons described above and hypoxia-related augmentation of the nitrite-derived $\cdot \mathrm{NO}$ production, the utility of inorganic nitrate supplementation in COPD has been studied.
Two separate studies have shown that acute supplementation of dietary nitrate (7.6-12.9 mmol nitrate) improves $75 \%$ submaximal exercise time by 30 seconds and incremental shuttle walk test by $40 \mathrm{~m}$ compared with placebo (Berry et al., 2015; Kerley et al., 2015); in contrast, however, further studies using $13.5 \mathrm{mmol}$ nitrate daily for 2.5 days (Shepherd et al., 2015b) or $20 \mathrm{mmol}$ nitrate for 6 days (Friis et al., 2017) showed no benefit on the $\mathrm{O}_{2}$ cost of exercise or 6-minute walk test (Shepherd et al., 2015b; Friis et al., 2017). Importantly, in these studies, plasma nitrite levels were increased, and $\mathrm{BP}$ was robustly reduced, suggesting that both the chemical and functional effects of the nitrate-nitrite-NO pathway are present in patients with COPD. The difference between the responses in the two sets of studies is uncertain but may relate to differences in dosing schedules and warrants further investigation. Further evaluation of dietary nitrate supplementation $(6.5 \mathrm{mmol} /$ day nitrate for 8 days $)$ in patients with COPD showed no improvement in gas diffusion or peak exercise capacity, despite robust increases in exhaled $\mathrm{NO}$, but was associated with statistically significant (but small in magnitude) improvements in respiratory-focused quality of life (St. George's Respiratory Questionnaire) scores (Behnia et al., 2018). Similar to the position with PAH, large adequately powered studies are awaited to definitively explore the therapeutic potential of inorganic nitrate in COPD.

3. Sleep-Disordered Breathing. Obstructive sleep apnea syndrome (OSA) is the most common form of sleep-disordered breathing problem and results from recurrent occlusion of the upper airway during sleep. Numerous epidemiologic studies have implicated OSA as a causative, independent factor for CVD (Arzt et al., 2005; Yaggi et al., 2005; Somers et al., 2008). The pathophysiological links between OSA and CVD are not fully understood, but several mechanisms, such as elevated sympathetic drive, increased oxidative stress, and vascular inflammation resulting from repeated nocturnal hypoxia/reoxygenation cycles, have been suggested (Somers et al., 2008). Importantly, NO levels are diminished in OSA and are partially restored with the most common, effective form of therapy, continuous positive airway pressure (Ip et al., 2000; Schulz et al., 2000; Alonso-Fernández et al., 2009), suggesting that $\cdot \mathrm{NO}$ delivery in this setting may be of value.

The only study exploring the nitrate-nitrite-NO pathway in patients with OSA is restricted to a small $(n=3)$ 14-day, controlled crossover study. Nitrate supplementation (12.9 mmol nightly) was associated with increased plasma nitrate levels (nitrite was not measured) and with improvement in fatigue and visual attention scores, although no change in sleep quality or Epworth sleepiness scores, and changes in apnea/hypopnea index were not assessed. All patients had controlled BP levels on ambulatory monitoring at index, but there was a trend toward reduced nocturnal 
BP after nitrate supplementation (Kerley et al., 2016), providing confidence in the dosing schedule efficacy in this study.

Sleep-disordered breathing is also an occurrence in the acclimatization to hypobaric hypoxia at altitude. Given the reductions in $\mathrm{O}_{2}$ consumption associated with nitrate supplementation seen at sea level (see earlier), Patrician et al. (2018) investigated the acute effects of acute nocturnal dietary nitrate supplementation (10 mmol/day nitrate) in lowlanders after ascent to $3700-4900 \mathrm{~m}$, in comparison with a peri-sea level $(300 \mathrm{~m})$ on cardiorespiratory responses during sleep. Acute dietary nitrate supplementation had no effect on various measures of sleep-disordered breathing. Similar longer-term studies in lowland volunteers ascending to high altitude $(4600 \mathrm{~m})$ demonstrated that 7 days of dietary nitrate supplementation $(3.7 \mathrm{mmol}$ nitrate three times daily) had no effect on respiratory parameters, such as $\mathrm{O}_{2}$ saturation, or acute mountain sickness, despite robust increase in fractional exhaled -NO (Cumpstey et al., 2017).

Further studies are required to delineate the potential benefit of nitrite-derived $\mathrm{NO}$ in patients with sleepdisordered breathing, not only on the respiratory abnormalities but also on the elevated CV risk profile that such patients exhibit.

4. Toxic Lung Injury. Chlorine gas has been implicated in mass casualties due to accidental or deliberate exposure in civilian and military settings. The pathophysiology of chlorine gas-related lung injury includes pulmonary and systemic increased oxidative and nitrosative stress and hypoxemia, with persistence of airway remodeling and airway hyperreactivity over time (White and Martin, 2010). Since nitrite-derived 'NO has beneficial effects in I/R lung injury (Sugimoto et al., 2012; Okamoto et al., 2013), this has spurred interest as to whether it may be beneficial in other forms of lung injury. Rats exposed to $400 \mathrm{ppm}$ chlorine gas for 30 minutes were given $\mathrm{NaNO}_{2}(1 \mathrm{mg} / \mathrm{g}$, i.p.) repeatedly for up to 6 hours and then euthanized. Treatment with nitrite was associated with reduced bronchoalveolar lavage protein levels and reduced epithelial cell apoptosis (Yadav et al., 2011), with some evidence that intramuscular delivery was more effective than intraperitoneal delivery (Samal et al., 2012), which is more translatable to the management of mass casualty disaster scenarios by first responders. In an adaptation of this methodology, in rats exposed to a higher exposure of chlorine (600 ppm for 30 minutes) that induces $80 \%$ fatality, a single intramuscular injection of nitrite $(10 \mathrm{mg} / \mathrm{kg}) 30-60$ minutes postexposure reduced mortality to $50 \%$.

These findings have been repeated in a nonrodent model using New Zealand white rabbits. Chlorine gas (600 ppm, 45 minutes) is 35\% lethal after 18 hours and is associated with airway protein and neutrophil accumulation. Nitrite ( 1 or $10 \mathrm{mg} / \mathrm{kg}$, via i.m. injection) administered 30 minutes post-chlorine gas exposure prevented death in all rabbits, and this was associated with attenuated indices of acute lung injury (Honavar et al., 2017). Further mechanistic evaluation revealed that neutrophil depletion reduced the lethality of chlorine exposure but also abrogated any further improvement by nitrite, suggesting a neutrophil-dependent mechanism for nitrite-derived protection in this model (Honavar et al., 2014).

Taken together, these data provide further rationale for developing nitrite as a postexposure treatment to ameliorate chlorine gas exposure-related lung injury, although the pathway for further development of this approach is awaited given the complexities of trying to perform a clinical trial in this area.

\section{E. Nitrite and Nitrate in the GI System}

In normal GI tract physiology, 'NO modulates smooth muscle tone, thereby regulating intestinal peristalsis and gastric emptying, and maintains GI mucosa through regulation of acid and gastric mucus secretion and maintenance of mucosal blood flow (Salzman, 1995). Additionally, $\mathrm{NO}$ has roles in controlling pathogen growth (Fang, 1997), and from the first demonstrations of nitrite-derived $\mathrm{NO}$ production, the antimicrobial effects of this pathway particularly relevant to the gut were explored. Nitrite-derived NO controls both pathogenic fungal and bacterial growth in culture (Benjamin et al., 1994; Dykhuizen et al., 1996, 1998) through bactericidal activity (Björne et al., 2006).

In addition to antimicrobial activity, intragastric $\cdot \mathrm{NO}$ production, through acidification of nitrite, has local gastroprotective effects, increasing gastric mucosal blood flow and mucus thickness (Björne et al., 2004; Petersson et al., 2007). This pathway is thought to underlie NO-mediated reductions of gut injury from both NSAID and stress-induced ulcer formation (Miyoshi et al., 2003; Jansson et al., 2007). In inflammatory bowel disease, a common finding is disruption of the protective mucosal barrier and diminished mucus layer. In an experimental dextran sodium sulfate model of colitis, both peritreatment and post-treatment with inorganic nitrite $(1 \mathrm{mmol} / \mathrm{l}$ in drinking water for 7 days) improved mucus thickness, disease activity score, and histologic scores and restored goblet cell abundance (Jädert et al., 2013). Further studies in cultured human colonic epithelial cells demonstrate that nitrite application $(100 \mu \mathrm{M})$ improved wound closure after an incision into the cultured monolayer (Jädert et al., 2013), demonstrating that in addition to improvements in blood flow, nitrite treatment accelerates healing of wounds.

More recently, pretreatment with intravenous nitrite $(48 \mathrm{nmol})$ before intestinal manipulation that induces a model of postoperative ileus showed an improvement in intestinal transit and restored intestinal contractility within 24 hour (Cosyns et al., 2015). This effect was 
attributed to reductions in inflammatory cytokines and ROS and was dependent also upon elevations of cGMP (Cosyns et al., 2015). This approach is being assessed in a randomized clinical trial of pretreatment of 1 week with dietary nitrate prior to planned colorectal surgery $(n=30$, NCT03772444). In contrast, a recent report using an acute supraphysiological dose of $\mathrm{NaNO}_{2}$ $(20,40,60$, and $75 \mathrm{mg} / \mathrm{kg}$ b.wt.) in rats demonstrated dose-dependent increase in abnormal structure and significant morphologic damage in the intestine in animals examined 24 hours postdose (Ansari et al., 2017), although the relevance of these acute doses to human gut physiology is unclear, and previous reports in rats using similar doses have not shown the same effect (Roediger et al., 1986).

Whether nitrite- or nitrate-based therapeutic interventions are pursued in additional clinical studies for GI disorders is not clear at the present time, and manual search of publicly available clinical trial databases did not discover additional planned studies at this time.

\section{F. Nitrite and Nitrate in Metabolic Diseases}

With increasing prevalence worldwide of obesity (Hruby and $\mathrm{Hu}, 2015$ ), there has been a dramatic increase in the numbers of patients suffering from insulin resistance syndromes such as type II diabetes mellitus (Kharroubi and Darwish, 2015) and the related metabolic syndrome (Sorrentino, 2005), a clustering of cardiometabolic risk factors that are associated with increased risk of diabetes and CVD (Eckel et al., 2005). eNOS deficiency in animal models (Duplain et al., 2001; Cook et al., 2003) or long-term treatment with eNOS inhibitors leads to features of metabolic syndrome and diabetes, such as weight gain, insulin resistance, and dyslipidemia (Balon et al., 1999), a profile that is replicated in humans with eNOS polymorphisms (Monti et al., 2003; Fernandez et al., 2004). These data suggest that manipulating 'NO levels may have therapeutic utility in diabetes and metabolic disorders. Importantly, in C57BL6 mice on long-term (up to 18 months) dietary restriction of nitrite and nitrate, these abnormalities (increased visceral adiposity, dyslipidemia, glucose intolerance, insulin resistance) are replicated (Kina-Tanada et al., 2017). These results suggest not only that reduction in NO signaling is important irrespective of the source but also that augmenting bioactive NO through the nitrate-nitrite-NO pathway may be a useful therapeutic strategy.

Furthermore, intriguing epidemiologic data could also support this view: green leafy vegetable consumption (rich in dietary nitrate) is associated with reduced risk of developing type 2 diabetes (Carter et al., 2010), and habitual use of mouthwash [potentially interfering with enterosalivary conversion of nitrate to nitrite (c.f. effects on BP (Kapil et al., 2013)] is associated with progression of dysglycemia in overweight adults (Joshipura et al., 2017).

Several preclinical studies have explored elevating systemic nitrite levels in models of diabetes or metabolic syndrome, using both nitrite and nitrate. In adenosine $\mathrm{A}_{2 \mathrm{~B}}$-deficient mice (a model of metabolic syndrome on chow diet), acute nitrate loading $(0.1 \mathrm{mmol} / \mathrm{kg}$ i.p.) was associated with improvement in insulin resistance (homeostatic model assessment of insulin resistance) and glucose clearance (Peleli et al., 2015). These acute effects are also established in longer-term experiments. In another model of metabolic syndrome (eNOS deficiency), mice supplemented for 8-10 weeks with $\mathrm{NaNO}_{3}$ at a dose expected to recapitulate normal endogenous nitrate production from oxidative $\mathrm{NO}$ metabolism ( $1 \mathrm{mmol} / \mathrm{l}$ in drinking water) had reductions in visceral fat and weight and improvements in glucose homeostasis (Carlström et al., 2010). Similar results have been seen with nitrite supplementation in genetic models of diabetes. Nitrite supplementation of drinking water (50 mg/l nitrite) to $\mathrm{db} / \mathrm{db}$ mice, $\mathrm{KKA}(\mathrm{y})$ mice, and obese ZSF mice (Jiang et al., 2014; Ohtake et al., 2015; Lai et al., 2016) or $100 \mathrm{mg} / \mathrm{kg}$ nitrite via miniosmotic pump in ob ${ }^{\text {lep }}$ mice (Singamsetty et al., 2015) was associated with improvements in glucose tolerance and insulin sensitivity across all models.

Similar results have been seen for drug-induced models of diabetes using streptozotocin using nitrate supplementation $(100 \mathrm{mg} / \mathrm{l})$ for up to 2 months, resulting in improved glucose tolerance and insulin sensitivity (Khalifi et al., 2015; Gheibi et al., 2017). Lastly, in dietary models of metabolic syndrome using highfructose diets (with or without high-fat diets), both dietary nitrate (by gavage, $60 \mathrm{mg} / \mathrm{kg}$ ) (Li et al., 2016b) or nitrate salts (by gavage, $150 \mathrm{mg} / \mathrm{kg}$ ) (Essawy et al., 2014) were similarly associated with improvements in glucose tolerance and insulin sensitivity.

The mechanisms of such benefits via elevation of nitrite may be linked to: increased glucose transporter type 4 translocation in skeletal muscle (Jiang et al., 2014; Ohtake et al., 2015); by nitrite-related sirtuin 3-AMP-activated protein kinase (AMPK) activation, which shares a common effect with metformin (Lai et al., 2016); from improved pancreatic blood flow and $\beta$-cell stimulation for insulin release (Nyström et al., 2012; Gheibi et al., 2017); or from browning of white adipose tissue (Roberts et al., 2015) that may have antimetabolic effects.

Taken together, these results are similar across genetic, dietary, and drug-induced models of dysglycemia - nitrite or nitrate supplementation is associated with improvements in glucose tolerance and insulin sensitivity and suggest an exciting possibility that nitrite- or nitratebased therapeutics could be added to the armamentarium for type 2 diabetes and/or metabolic syndrome. Unfortunately, there has been scant translation of these effects in human studies to date. In patients with type 2 diabetes given $7.5 \mathrm{mmol}$ of dietary nitrate daily for 
2 weeks, despite significant elevations in systemic nitrite levels, there was no change in insulin sensitivity using the hyperinsulinemic euglycemic clamp method or improvements in BP or FMD (Gilchrist et al., 2013) that have been seen in numerous other patient groups (Rammos et al., 2014; Kapil et al., 2015; Velmurugan et al., 2016). Furthermore, in healthy persons, acute dietary nitrate supplementation with $11.9 \mathrm{mmol}$ nitrate did not change plasma glucose, C-peptide levels, or incretin levels and did not change hepatic blood flow, measured using magnetic resonance imaging (MRI) (Shepherd et al., 2016). The explanations for the lack of effect in type II diabetes is puzzling, but it might be that sirtuin 3-AMPK activation by metformin renders further nitrite stimulation of this pathway (Lai et al., 2016) redundant or that glycated $\mathrm{Hb}$ has altered nitrite reductase activity (James et al., 2004), meaning that despite elevated nitrite levels, bioactive $\mathrm{NO}$ is not produced. There is also growing evidence that the biologic activity of metformin is dependent upon the metabolism of the microbiome. Although the focus of studies has revolved around the gut, it is possible that the bioactivation of nitrate is impaired by the impact of metformin on the oral microbiome community (Cabreiro et al., 2013; Forslund et al., 2015; Sun et al., 2018).

An additional avenue of therapeutic utility in this area may be in the context of the complications of hyperglycemia, namely painful diabetic peripheral neuropathy. The first study to suggest possible benefit was conducted in patients with $\mathrm{PAD}(n=55$ total, $\sim 2 / 3$ type 2 diabetes) randomized to 40 or $80 \mathrm{mg}$ twice daily of sodium nitrite (or matching placebo) for 10 weeks followed by a further week of double-dosing - at the end of the study, there was a significant improvement in the pain domain of the physical component of the RAND 36 quality of life questionnaire despite no overall improvement in quality of life, although this was only apparent for the lower dose studied ( $40 \mathrm{mg}$ twice daily of nitrite) (Mohler et al., 2014). This paper was recently followed by a pilot study using a novel sustained-release formulation of sodium nitrite in patients with a diagnosis of diabetic peripheral neuropathy of $>3$ month's duration and significant pain using a numeric pain scale $(n=$ 24 total). Patients were similar, randomized to either $40 \mathrm{mg}$ twice daily, $80 \mathrm{mg}$ twice daily, or matched placebo. In this study, there were three questionnairebased assessments of pain as an unpowered secondary endpoint, with a suggestion of improvement with nitrite dosing for one of three pain scores used, although the study was underpowered to produce meaningful effect sizes or statistical confidence (Soin et al., 2018). Further studies are to be planned with larger $n$ numbers.

\section{G. Nitrite and Nitrate in I/R Injury}

1. Cytoprotection. There is a significant body of evidence demonstrating that nitrite operates as a major storage form of $\mathrm{NO}$ in blood and tissues (Bryan et al.,
2005) that can be reduced readily to $\mathrm{NO}$ to initiate cytoprotective signaling during pathologic states, particularly during I/R injury (van Faassen et al., 2009; Calvert and Lefer, 2010). The mechanisms by which this process occurs have been extensively studied, with increasing evidence suggestive of changes in mitochondrial function and anti-inflammatory, antiplatelet, and vasodilatory effects.

2. Potential Mechanisms for Nitrite-Induced Reduction in I/R Injury. A number of distinct molecular pathways have been proposed to underlie the reduction of nitrite in the setting of $I / R$ injury. There is strong evidence demonstrating that the benefits of nitrite in I/R injury are due, at least in part, to its conversion to -NO. Several studies have shown that nitrite-induced protection is blocked by the $\mathrm{NO}$ scavenger C-PTIO (Webb et al., 2004; Jung et al., 2006; Tripatara et al., 2007). This effect is also independent of NOS activity, as cytoprotection induced by nitrite is not prevented by NOS inhibition (Webb et al., 2004; Lu et al., 2005) or affected in eNOS KO models (Duranski et al., 2005; Milsom et al., 2010). We now also understand that nitrite reduction during $I / R$ is not just a phenomenon precipitated by acidic disproportionation, as suggested by Zweier et al. (1995), who identified nitrite-derived -NO generation in the ischemic heart in their seminal findings in 1995. Over the past decade, a number of different nitrite reductases have been implicated in nitrite-derived $\mathrm{NO}$ formation during I/R injury, with the role of each catalytic pathway identified being influenced both by the site/organ of injury and the severity of hypoxia. Much of the research focused on identifying the key nitrite reductase involved in the I/R injury setting has been conducted within the heart, where it appears that the two key nitrite reductases are $\mathrm{XOR}$ and $\mathrm{Mb}$.

XOR has been implicated in the reduction of nitrite to -NO in the myocardium in both animal and human heart tissue, with the first studies being conducted in the isolated rat heart and atrial appendage collected from patients undergoing cardiac surgery, respectively. In tissue supernatants, nitrite-derived $\cdot \mathrm{NO}$ generation was profoundly attenuated (50\%) after incubation with the XOR inhibitor allopurinol (Webb et al., 2004), observations that have been replicated by others (Baker et al., 2007; Li et al., 2008). Similarly, XOR has been implicated as the nitrite reductase in other organs, including when delivered topically in renal I/R injury in vivo in both rat and mouse models (Tripatara et al., 2007; Milsom et al., 2010). XOR also contributes to nitrite bioactivation in other hypoxic settings, including pulmonary hypertension (Baliga et al., 2012) and vascular remodeling after balloon injury (Alef et al., 2011), thus identifying a widespread function of XOR as a key nitrite reductase in hypoxic environments. This profile of activity is not unexpected, since studies with purified bovine enzyme demonstrate increasing XOR-dependent nitrite 
reduction with reducing $\mathrm{O}_{2}$ tension ( $\mathrm{Li}$ et al., 2001). This bioactivity, as mentioned earlier, occurs at the molybdenum site of the enzyme and is a reaction facilitated by at least three different reducing substrates, including xanthine, NADH, and aldehydes (Khambata et al., 2015). Perhaps of particular note in this respect is NADH, the levels of which rise in ischemic environments (Sahlin, 1983), possibly suggesting why XOR-dependent nitrite reduction predominates in such reduced $\mathrm{O}_{2}$ tension environments and plays a much lesser role under physiologic conditions (Dejam et al., 2007).

$\mathrm{Mb}$ represents the other key nitrite reductase implicated in the bioactivation of nitrite during I/R injury and, again, particularly in the heart (Rassaf et al., 2007; Shiva et al., 2007a). Mb must be partially deoxygenated to act as a nitrite reductase, only occurring when $\mathrm{O}_{2}$ levels fall below the $p_{50}$ of $\mathrm{Mb}$, as for $\mathrm{Hb}$ (Cosby et al., 2003; Crawford et al., 2006). Studies in the heart suggest that $60 \%-70 \%$ of nitrite-derived $\cdot \mathrm{NO}$ is due to deoxyMb-dependent conversion, with the balance due to XOR activity (Rassaf et al., 2007; Shiva et al., 2007a). Accordingly, nitrite reduction was abolished in the Mb KO mouse (Hendgen-Cotta et al., 2008), and the beneficial effects of nitrite after coronary artery occlusion were lost, including improved postischemic LV developed pressure. These studies suggest that $\mathrm{Mb}$ plays an important role in nitrite-induced regulation of cardiac energetics and oxygen utilization under conditions of hypoxia. To date, whether $\mathrm{Mb}$ is also critical in nitrite reduction in the human heart has not been elucidated.

3. Potential Mechanisms for Nitrite-Induced Cytoprotection in $I / R$ Injury. The activity of nitrite in $I / R$ injury has been attributed to both direct and $\mathrm{NO}$ dependent actions as a consequence of chemical modifications of both cellular proteins or lipids, mitigating the injury occurring at reperfusion. Potential molecular mechanisms for cytoprotection of the former include the direct $S$-nitrosation of critical regulatory thiols on proteins such as caspase-3, a pivotal protein of the apoptotic pathway, leading to its inactivation and preventing apoptotic cell death (Maejima et al., 2005), or the L-type calcium channel, which results in reduced cytosolic $\mathrm{Ca}^{2+}$ and subsequent I/R injury (Sun et al., 2006). There are several functional consequences of these chemical interactions that underlie the benefits of nitrite, with the key ones summarized below.

a. Improved mitochondrial function. $\cdot \mathrm{NO}$, through the activation of GC-1 and ultimately the production of cGMP, is known to be a key regulator of mitochondrial function as well as a stimulator of mitochondrial biogenesis (Clementi and Nisoli, 2005; Nisoli et al., 2005). It is thus unsurprising that the mitochondrion has emerged as a major subcellular target of nitrite, with evidence demonstrating the specific targeting of key proteins within the mitochondria organelle [for review, see Murillo et al. (2011)]. Studies have convincingly shown that nitrite directly inhibits complex 1 of the electron transport chain, causing a consequent decrease in ROS generation, a decrease in $\mathrm{Ca}^{2+}$ influx, and a reduction in cytochrome c release (Shiva et al., 2007b) after I/R injury in both the heart and liver (Gladwin et al., 2005). This inhibition of complex I may also in turn prevent opening of the mitochondrial permeability transition pore (Fontaine et al., 1998; Nadtochiy et al., 2007), leading to an improved mitochondrial tolerance to $\mathrm{Ca}^{2+}$ overload (Nadtochiy et al., 2007). Nitrite-induced elevations of $\mathrm{NO}$ activating cGMP, in turn, also activate PKG, resulting in stabilization of mitochondrial big conductance $\mathrm{K}$ (Frankenreiter et al., 2017) and $\mathrm{K}_{\mathrm{ATP}}$ channels (Sasaki et al., 2000), which is associated with decreased mitochondrial $\mathrm{Ca}^{2+}$ accumulation, and prevention of mitochondrial permeability transition pore opening (Takuma et al., 2001; Brown and Borutaite, 2002), properties that are likewise exhibited by $\mathrm{NO}$ (Brookes et al., 2000; Heusch et al., 2008). A significant component of the action of nitrite has also been attributed to the reversible inhibition of cytochrome $c$ oxidase (complex IV of the electron transport chain). -NO binds to this enzyme, in competition with $\mathrm{O}_{2}$, resulting in a reversible inhibition of $\mathrm{O}_{2}$ consumption (Poderoso et al., 1998). This effect in turn has consequences for the preservation of high-energy phosphate stores during $\mathrm{I} / \mathrm{R}$ injury, and this effect in particular may play a role in the phenomenon in the heart of "hibernation," in which the metabolic activity of the heart is temporarily shut down during ischemia to preserve high-energy phosphate reserves (HendgenCotta et al., 2008; Murillo et al., 2011).

As mentioned, there is also some suggestion that the effects of nitrite are in part mediated by direct actions of the anion and not 'NO (Mo et al., 2012; Kamga Pride et al., 2014). Mo and colleagues, using a rat model of carotid injury, showed that nitrite treatment reduced the hyperproliferative smooth muscle cell response to mechanical injury. The authors suggested that this action was due to upregulation of peroxisome proliferatoractivated receptor- $\gamma$ coactivator-1 (the master regulator of mitochondrial biogenesis) and, thus, accordingly, an increase in the number of mitochondria in the injured artery. In cultured rat aortic smooth muscle cells, the authors showed that the nitrite-induced increase in mitochondrial number was unlikely to account for the beneficial effect profile, despite small increases in cGMP. The authors further demonstrated that nitrite augmented adenylate kinase activity, leading to phosphorylation of AMPK, the consequent downstream activation of sirtuin1 and deacetylation of peroxisome proliferator-activated receptor- $\gamma$ coactivator-1. More importantly, all of these changes occurred independently of cGMP (Mo et al., 2012). Kamga Pride et al. (2014) showed in cultured rat H9c2 cardiomyocytes subjected to hypoxia and reoxygenation that treatment with nitrite for only 30 minutes under normoxic conditions substantially reduced the cell 
death after an ensuing hypoxic episode initiated 1 hour after the treatment. Since the treatment was conducted in normoxia, the authors suggested that conversion of nitrite to $\mathrm{NO}$ was unlikely. Using purportedly selective inhibitors, the authors provided evidence of protein kinase A-mediated phosphorylation, and thus inhibition, of dynamin-related protein 1 , leading to enhanced mitochondrial fusion. Functionally, this augmented mitochondrial superoxide production, which oxidized and activated AMPK, and is an essential step in nitritemediated preconditioning.

$b$. Antiplatelet effects. The activation and consequent adhesion and aggregation of platelets is a critical event in the lead up to an acute MI (AMI) and other ischemic injury (Didisheim et al., 1974; Badimon et al., 2002; Gawaz, 2004; Vorchheimer and Becker, 2006). It is widely accepted that platelet activation is key in the formation of thrombosis that culminates in stroke, AMI, and other vascular events (Davì and Patrono, 2007). As well as the obvious physical implications of thrombus formation after an event, activated platelets release several mediators that participate in the damage caused by the second wave of injury, occurring as a consequence of reperfusion, but also to the long-term consequence of $\mathrm{I} / \mathrm{R}$ injury contributing to the increased risk for secondary events in such patients (Badimon et al., 2002). It is therefore unsurprising that strategies repressing platelet reactivity play a key role in the treatment of organ ischemia and $\mathrm{I} / \mathrm{R}$ injury as well as reducing risk for further events. It is accepted that $\cdot \mathrm{NO}$, in health, acts as an important repressor of platelet activation and adhesion to intact vascular endothelium (Radomski et al., 1987; Dangel et al., 2010) as well as platelet aggregation itself (Radomski et al., 1990), as discussed earlier, and thus, there has been considerable interest in identifying -NO-based strategies that might be useful in I/R injury. Since there is substantial evidence that nitrite in vivo modulates platelet function, it is possible that some of the benefits in the I/R setting are derived through actions on platelets. In particular, in our own trial, NITRITE-AMI, in which patients received an intracoronary dose of nitrite at the point of reperfusion after primary percutaneous coronary intervention (PCI), we demonstrated reductions in ex vivo assessments of platelet reactivity (aggregation and cell activation markers) acutely but also, interestingly, up to 6 months after the intervention. We speculated that the acute reduction of platelet reactivity likely contributed to the reduced microvascular obstruction that is thought to be pathogenic and a primary mechanism in worsening cardiac cell death postreperfusion, which has recently been highlighted as an important target for developing novel cardioprotection therapies in the AMI setting (Nazir et al., 2016; Niccoli et al., 2019).

c. Anti-inflammatory effects. A key phenomenon contributing to damage in I/R injury is inflammation, and since several observations recently have identified anti-inflammatory properties of nitrite, it has been suggested that this effect may be contributing to the beneficial actions of nitrite in the $I / R$ setting. The recruitment of leukocytes and their consequent proinflammatory effects plays a critical role in determining the magnitude of damage induced post I/R injury (Entman and Smith, 1994). Polymorphonuclear cells are the major leukocytes found in necrotic tissue immediately after ischemic injury, with neutrophils the early cellular mediators of local microvascular changes and parenchymal damage (Vinten-Johansen, 2004). Monocytes and macrophages infiltrate later and extend the early injury phase (Ysebaert et al., 2000). In addition, lymphocytes have been identified as contributing to the damage in the later stages in the response to I/R injury in a variety of organ systems (Linfert et al., 2009). Lymphocyte-related cytokines are upregulated in the postischemic heart (Squadrito et al., 1999), and leukocyte adhesion molecules and chemokines, such as P-selectin glycoprotein ligand-1, CD11/CD18, ICAM-1, CCL2 (Herskowitz et al., 1995; Birdsall et al., 1997), and lymphocyte adhesion, migration, and signaling (Loetscher et al., 1996) have been implicated in experimental myocardial I/R injury.

As mentioned, -NO exerts an array of anti-inflammatory effects, and many of these have been demonstrated in experimental models of I/R injury in various vascular beds (Kubes et al., 1991; Palazzo et al., 1998; Ahluwalia et al., 2004). Leukocyte recruitment is a multistep process constituting leukocyte tethering, rolling, adhesion, and ultimately emigration from the microvasculature (Petri et al., 2008), and 'NO has been shown to influence each of these steps through the damping/repression of interactions of the leukocyte with endothelial cells (Kubes et al., 1991). Specifically, there is evidence showing that -NO inhibits adhesion molecule expression and activation, including that of P-selectin, ICAM-1, vascular cell adhesion molecule-1, and CD11b (Gauthier et al., 1994; Lefer and Lefer, 1996; Leite et al., 2009). Accordingly, data in humans have emerged from a phase 2 study suggesting that nitrite, and presumably nitrite-derived -NO, exerts anti-inflammatory effects when given during primary PCI for AMI (Jones et al., 2015a). In these patients, we demonstrated important reductions in neutrophil numbers and activation post-primary PCI (Jones et al., 2017). In the placebo-treated patients, we observed increases in the total circulating neutrophil numbers and levels of high-sensitivity C-reactive protein postreperfusion, which then decreased over time. In contrast, in nitrite-treated patients, these changes were suppressed up to 6 months post-primary PCI $(P<0.01)$. These differences were also associated with reduced expression of neutrophil CD11b, plasma CXCL1, CXCL5, and CCL2 levels $(P<0.05)$. Importantly, there were no differences in the number of any other leukocyte population measured (monocytes and lymphocytes) or activation markers expressed by these cells between the 
treatment groups. In addition, these effects on inflammatory markers were associated with a reduction in both microvascular obstruction and infarct size, suggesting important effects of nitrite on neutrophil activation and recruitment (Jones et al., 2017). Further study is needed to examine these effects.

4. Nitrite as a Mediator of Remote Ischemic Preconditioning. In the early 1990s, Przyklenk et al. (1993) proposed the existence of signal transduction between the local site of remote ischemia and the myocardium. This link has been identified as underlying the efficacy of remote ischemic preconditioning (rIPC), although the exact nature of this endocrine communication has remained uncertain. In 2014, Rassaf and coworkers conducted a series of experiments suggesting that nitrite may be the elusive endocrine factor responsible for the effects of rIPC (Rassaf et al., 2014). Their studies demonstrated that plasma nitrite concentration increases during reactive hyperemia in the brachial artery of healthy volunteers as a consequence of shear-stress triggering eNOS activation (Rassaf et al., 2006). In mouse models of rIPC, the authors demonstrated a similar elevation in circulating nitrite levels and that the benefits of rIPC were blocked with C-PTIO and absent in eNOS KO mice. In the final experiment, the authors infused human plasma collected from individuals subjected to, or not, rIPC into isolated mouse heart Langendorff preparations. In these experiments, they demonstrated that nitrite accounted for the effects of rIPC, since treatment of the transferred plasma with acidified sulfanilamide eliminated the transfer of protection (Rassaf et al., 2014). Prior to this work, Elrod et al. (2008), who used a transgenic mouse with cardiac restricted overexpression of eNOS, also provided evidence in support of an endocrine action of nitrite. These mice are characterized by increased levels of nitrite and other $\mathrm{NO}$ metabolites in the circulation, resulting in subsequent transport and storage in organs throughout the body, including the liver. Elrod et al. (2008) demonstrated that this elevation of tissue nitrite provided protection against the damaging effects of a consequent hepatic I/R injury.

An important caveat of the above findings is that the levels of nitrite generated in these models are approximately 10 -fold lower than those typically shown to be cytoprotective in preclinical models of $\mathrm{I} / \mathrm{R}$ injury (Webb et al., 2004; Duranski et al., 2005). This discrepancy in efficacy implies potential differences in bioactivity/potency of endogenously derived versus exogenously delivered nitrite and is an issue that is worthy of further interrogation.

5. Translational Aspects.

a. I/R injury. The cytoprotective actions of nitrite have been reproduced in a variety of animal models by different investigators focusing on different target organs (Webb et al., 2004; Duranski et al., 2005; Pluta et al., 2005; Jung et al., 2006; Tripatara et al., 2007).
Our group provided the first evidence of the cytoprotective effects of nitrite (Webb et al., 2004). In this study, we demonstrated that administration of $\mathrm{NaNO}_{2}(10$ or $100 \mu \mathrm{mol} / \mathrm{l}$ ) either prior to or at reperfusion in the isolated rat Langendorff heart preparation improved both LV function and coronary perfusion pressure as well as decreasing infarct size after an I/R insult. Many others have confirmed these effects in the heart using not only in vitro (Baker et al., 2007; Hendgen-Cotta et al., 2008) but also in vivo preclinical rodent models of AMI (Duranski et al., 2005; Bryan et al., 2007). Duranski et al. (2005) administered sodium nitrite via an intraventricular injection $(2.4-1920 \mathrm{nmol}) 5$ minutes prior to reperfusion after 30 minutes of occlusion of the left main coronary artery occlusion in mice. This group observed a dose-dependent decrease in infarct size. The maximum benefit was provided with a dose of $48 \mathrm{nmol}$, although the higher dose of $1920 \mathrm{nmol}$ nitrite failed to exert any significant cardioprotective effect. Bryan et al. (2007) used the same model and demonstrated that dietary nitrite supplementation $(50 \mathrm{mg} / \mathrm{l})$ for 7 days prior to ischemia caused a $48 \%$ reduction in infarct size.

In addition to rodents, the functional benefits of nitrite have been reproduced in larger species. In a canine model induced by ligation of the left anterior descending coronary artery in vivo, intravenous administration of $\mathrm{NaNO}_{2}(0.2 \mu \mathrm{mol} / \mathrm{min}$ per kilogram for the first 20 minutes and then $0.17 \mu \mathrm{mol} / \mathrm{min}$ per kilogram for 40 minutes) for the last hour of a 2-hour period of ischemia reduced infarct size by $\sim 50 \%$ compared with control (Gonzalez et al., 2008). The authors also considered intravenous administration of nitrite during the last 5 minutes $(0.2 \mu \mathrm{mol} / \mathrm{min}$ per kilogram $)$ of the 2 -hour occlusion in a bid to identify an approach with greater chance of clinical translation and showed that, with this treatment, infarct size and apoptosis were reduced to a similar level as with treatment of 60 minutes prior to reperfusion. There is, however, some evidence contradicting the above findings. In the multicenter preclinical CAESAR cardioprotection initiative (Jones et al., 2015), a lack of efficacy of nitrite was observed (Lefer et al., 2014). However, this multicenter assessment used intravenous delivery of $\mathrm{NaNO}_{2}$ and not local intracoronary administration (with higher local concentrations), as in many of the studies described above, and still remains unpublished in full form, thereby making it impossible to comment on methodological differences.

Similar protective effects of nitrite have also been evidenced in other organs, including the liver (Duranski et al., 2005), brain (Pluta et al., 2005), and kidney (Tripatara et al., 2007). In a murine model of hepatic $\mathrm{I} / \mathrm{R}$, intraperitoneal treatment with $\mathrm{NaNO}_{2}(1.2-480 \mathrm{nmol})$ during the ischemic period caused dose-dependent cytoprotective effects that resulted in reductions in hepatocellular necrosis and apoptosis and reductions of serum elevations of liver transaminases (Duranski et al., 2005). In a rat model of cerebral I/R, 48 and $480 \mathrm{nmol}$ of nitrite, 
infused intravenously at the start of reperfusion, exerted dose-dependent neuroprotective effects, reduced cerebral infarct volume by $33 \%$ and $77 \%$, respectively, and promoted neurologic functional recovery (Jung et al., 2006). Similarly, topical administration of $\mathrm{NaNO}_{2}(0.12 \mathrm{nmol} / \mathrm{g})$ in a rat model of renal $\mathrm{I} / \mathrm{R}$ injury 1 minute prior to reperfusion significantly attenuated renal dysfunction, reperfusion injury, glomerular dysfunction, and tubular injury (Tripatara et al., 2007). It is noteworthy that, in this study, intravenous administration of the same dose of $\mathrm{NaNO}_{2}$ at the same time point (1 minute before reperfusion) did not improve renal dysfunction or reperfusion injury (Tripatara et al., 2007). In all of these studies, the beneficial effects were shown to be due to the activity of $\cdot \mathrm{NO}$ and were most often specifically associated with the local application into or on the organ of interest.

Given this robust preclinical data regarding the cytoprotective effects of nitrite therapy, it is logical to consider the clinical translation of nitrite-based therapies for I/R injury. Clinical situations in which this may be important include the settings of AMI, cardiac surgery, angiogenesis, cardiac arrest, organ transplantation, and cerebrovascular accidents. This rapidly evolving field is summarized in the following sections.

b. Humans models of $I / R$ injury: transient endothelial dysfunction. A number of studies conducted in healthy volunteers demonstrate that elevations in the levels of circulating nitrite levels (achieved through administration of a high dietary nitrate load) lead to a number of beneficial effects, including prevention of transient endothelial dysfunction in a model of $\mathrm{I} / \mathrm{R}$ injury in the forearm (Webb et al., 2008b; Kapil et al., 2010). In this study it was shown that $I / R$ injury significantly reduced FMD (by $\sim 60 \%$ ) of the brachial artery, a phenomenon that was prevented in the volunteers after ingestion of a dietary nitrate load (Webb et al., 2008b). Similar beneficial effects have been demonstrated with $\mathrm{NaNO}_{2}$ infused at a dose of $1.5 \mu \mathrm{mol} / \mathrm{min}$ for 20 minutes prior to $I / R$ injury in the forearm of healthy volunteers. In this study, the authors demonstrated that peak FMD decreased by $43 \%$ after I/R when subjects received saline $(6.8 \% \pm 0.7 \%$ vs. $3.9 \% \pm 0.7 \%, P<0.01)$; however, nitrite treatment prior to ischemia prevented this decrease $(5.9 \% \pm 0.7 \%$ vs. $5.2 \% \pm 0.5 \%, P=$ N.S. $)$. However, the protective effects of nitrite were abolished when the nitrite infusion was initiated during the ischemic event (Ingram et al., 2013).

c. Organ-specific $I / R$ injury.

$i$. Myocardial $I / R$ Injury. In adults with inducible myocardial ischemia, intravenous infusion of $\mathrm{NaNO}_{2}$ improved functional cardiac responses during dobutamine stress echocardiography. In this small study (Ingram et al., 2013), 10 patients with inducible myocardial ischemia were randomized to either low-dose $\mathrm{NaNO}_{2}(1.5 \mu \mathrm{mol} / \mathrm{min}$ for 20 minutes $)$ or placebo in a double blind fashion. Long-axis myocardial function was quantified by peak systolic velocity (Versus) and strain rate (SR) responses. Comparing saline and nitrite infusions, Versus and SR at peak dobutamine increased in regions exhibiting ischemia (Versus from $9.5 \pm 0.5$ to $12.4 \pm 0.6 \mathrm{~cm} / \mathrm{s}$, SR from $-2.0 \pm 0.2$ to $-2.8 \pm$ 0.3 second $^{-1}$ ), whereas they did not change in normally functioning regions (Versus from $12.6 \pm 0.4$ to $12.6 \pm$ $0.6 \mathrm{~cm} / \mathrm{s}$, SR from $-2.6 \pm 0.3$ to $-2.3 \pm 0.1$ second $^{-1}$ ) $(P<0.001)$. With nitrite treatment, Versus improved only in those areas of the myocardium that were poorly functioning $(+122 \%, P<0.001)$, implying that the effects of this low-dose $\mathrm{NaNO}_{2}$ occurred primarily in regions of ischemic myocardium, with no effect in normoxic regions (Ingram et al., 2013).

Recently, two phase II studies have been conducted investigating the effects of nitrite therapy for AMI. There were many similarities between the studies, including that both enrolled patients undergoing primary PCI for ST-elevated MI. However, a key difference between the studies was that the $\mathrm{NaNO}_{2}$ was delivered via different routes, i.e., intravenous and intracoronary. The first of these studies, by Siddiqi et al. (2014), was based on the intravenous administration protocol employed to good effect by Gonzalez et al. (2008) in dogs. Siddiqi and colleagues recruited a total of 229 patients presenting with AMI who were randomized to receive either an intravenous infusion of $70 \mu \mathrm{mol}$ $\mathrm{NaNO}_{2}(n=118)$ or matching placebo $(n=111)$ over 5 minutes immediately before primary PCI (Siddiqi et al., 2014). In this study, a prerequisite for inclusion was that patients must have been categorized as with thrombolysis in myocardial infarction (TIMI) $\leq 1$ flow in the infarct-related artery at the time of reperfusion. The dose was chosen assuming a mean body weight of $70 \mathrm{~kg}$, corresponding to $1 \mu \mathrm{mol} / \mathrm{kg}$. Sadly, the primary endpoint of MI size (assessed at 6-8 days by cardiac MRI) did not differ between the groups. After adjustment for the area at risk for infarct, diabetes, or the recruitment center (patients were recruited at four different centers), there was still no difference between the groups. A number of secondary outcome measures also showed no signal, including plasma troponin I or creatine kinase area under the curve (72-hour), LV volumes or LVEF measured at 6-8 days, and infarct size at 6 months. This study would suggest that despite the promising preclinical data, the intravenous route of nitrite administration does not decrease infarct size after primary PCI for AMI (Siddiqi et al., 2014).

The second study was conducted by our own group (Jones et al., 2015) and examined the effects of intracoronary nitrite given prior to balloon inflation in patients with ST-elevated MI undergoing primary PCI. Eighty patients in total were randomized to receive intracoronary $10 \mathrm{ml} \mathrm{NaNO}(1.8 \mu \mathrm{mol})$ or $\mathrm{NaCl}$ (placebo) through an over-the-wire balloon positioned distal to the occlusion in the culprit coronary artery prior to balloon inflation. In this study, there were no reported adverse effects of nitrite associated with a 
significant increase in circulating nitrite that was evident 30 minutes after $\mathrm{NaNO}_{2}$ administration. Again, similarly to the above trial, the primary outcome of creatine kinase release $(P=0.92)$ was not different between the groups, as neither was troponin $\mathrm{T}(P=$ $0.85)$, or cardiac MRI-assessed infarct size $(P=0.254)$ in the whole patient cohort. However, in contrast, there was an improvement in myocardial salvage index $(P=0.05)$ and reduction in major adverse cardiac events (defined as all-cause mortality, hospitalization for $\mathrm{HF}, \mathrm{MI}$, or target vessel revascularization) at 1 year $(2.6 \%$ vs. $15.8 \% ; P=0.04)$ in the nitrite group. Additionally, in a 66-patient subgroup with TIMI $\leq 1$ flow, there was a $20 \%$ reduction in serum creatine kinase $(P=0.030)$, a $19 \%$ reduction in cardiac MRI-determined infarct size $(P=0.034)$, a $48 \%$ reduction in microvascular obstruction $(P=$ $0.015)$, and a $30 \%$ increase in myocardial salvage index $(P=0.002)$ with nitrite therapy. This would suggest that in patients with TIMI $\leq 1$ flow at time of primary PCI, intracoronary nitrite may have benefit as an adjunctive therapy (Jones et al., 2015).

The reason for the discrepancy between the two studies is not clear; however, a number of potential factors could have played a role, including patient selection, doses of nitrite, and/or mode of administration. In terms of the dose, there is a large body of preclinical evidence indicating that nitrite is cytoprotective against I/R injury only when given at concentrations $(2.5-10 \mu \mathrm{mol})$ that far exceed physiologic $(0.2-0.5 \mu \mathrm{mol} / \mathrm{l})$ levels of circulating nitrite. In the study by Siddiqi and colleagues, circulating nitrite with their intervention only reached $1.4 \mu \mathrm{mol} / \mathrm{l}$, a concentration that is lower than that reported in dogs, in which the same dosing regimen led to circulating levels of $5 \mu \mathrm{mol} / \mathrm{l}$ (Gonzalez et al., 2008). However, the levels achieved were 7.8 -fold higher than in the placebo group and consistent with levels achieved in a previous murine periconditioning study demonstrating at least some molecular effect of nitrite in mice at such concentrations (Duranski et al., 2005). Indeed, raising circulating levels of nitrite to those shown effective in most preclinical studies is likely to be associated with adverse effects, such as hypotension and methemoglobinemia, as demonstrated in healthy volunteers (Pluta et al., 2011). It is this possibility that underlies the advantage of intracoronary nitrite administration in which this route provides high local concentrations $(2.5-10 \mu \mathrm{M})$ within the myocardium only, thus minimizing potential systemic side effects that may occur with systemic nitrite administration. In the study delivering intracoronary nitrite, although levels of systemic nitrite were elevated in the study patients, indicating a degree of systemic absorption, levels achieved were approximately $0.5 \mu \mathrm{mol} / \mathrm{l}$, at the upper level of physiologic levels, which would be in keeping with the low rates of side effects seen in the study.
The question of what is the optimal route (intravenous vs. intracoronary) for nitrite therapy is an important issue to address for future studies. The two routes have been compared directly in the kidney; in this study, the local administration of nitrite was effective at reducing infarct size, whereas the same dose given via the intravenous route was not, indicating a superiority of local administration (Tripatara et al., 2007). In contrast, the intravenous route was effective in myocardial I/R injury in dogs (Gonzalez et al., 2008), although as noted above, the intracoronary route does have several advantages. Additionally, if agents are to be delivered at reperfusion, i.e., after angiography to ensure TIMI flow $\leq 1$, the intracoronary route does not delay reperfusion. This is compared with intravenous administration, which may result in a delay in reperfusion while administered and might require the establishment of very high circulating levels to achieve sufficient levels of nitrite. Together, these observations suggest that nitrite may have use in the treatment of acute ST-elevated MI in which nitrite could be delivered locally (intracoronary) before balloon inflation at the time of primary PCI; further studies in this area are needed.

ii. Cardiopulmonary Surgery. The injury that occurs as a consequence of ischemia and reperfusion during cardiac surgery, such as CABG, is distinctly different from that occurring during spontaneous AMI. In this setting, ischemia is induced artificially by aortic cross-clamping, and myocardial preservation strategies are employed throughout this ischemic period. Once surgery has been completed, the clamp is released, and the heart is then suddenly and globally reperfused with anticoagulated blood. This critical process, although necessary, does result in the immunologic priming of leukocytes due to exposure to the cardiopulmonary bypass circuit, but it is also characterized by a very high partial pressure of $\mathrm{O}_{2}$. Together, this restoration of the circuit delivers a substantial I/R stress. To date, assessing the role of nitrite in cardioprotection post-CABG has not been done. There is currently one clinical trial ongoing to investigate this (clinical trial NCT01098409); however, the start date for this study was 6 years ago, and few updates have occurred, suggesting that recruitment may be difficult. There has, however, been some reporting from a similar study from the same institution in patients. In this study, patients undergoing $\mathrm{CABG}$ were subjected to either placebo (saline) or $\mathrm{NaNO}_{2}$ treatment $(10 \mu \mathrm{g} / \mathrm{kg}$ per minute) either 30 minutes or 24 hours before surgery. In preischemia LV biopsies, $10 \mu \mathrm{g} / \mathrm{kg}$ per minute nitrite administration 24 hours or 30 minutes before CABG surgery was associated with statistically significant increases in the expression of both total eNOS and phosphorylated eNOS at position Ser 1177, an effect similarly evident in $L V$ biopsies taken at reperfusion. These results 
intimate that some of the benefits of nitrite may relate to improved eNOS signaling (Bailey et al., 2014).

iii. Skeletal Muscle I/R Injury (Crush Syndrome). Skeletal muscle crush syndrome occurs after prolonged physical compression of limb muscles (after events such as earthquakes, road traffic accidents, etc.), followed by the reperfusion that accompanies decompression of the limbs. It is associated with significant morbidity and mortality, and the current standard of care is i.v. crystalloid fluid therapy. Using a rat model of crush syndrome, muscle nitrite levels were shown to be reduced by crush injury, suggesting some eNOS dysfunction (Murata et al., 2012). Both bolus (200$500 \mu \mathrm{mol} / \mathrm{kg}$ ) and continuous infusions for 3 hours (200$500 \mu \mathrm{mol} / \mathrm{kg}$ ) of $\mathrm{NaNO}_{2}$ reduced lethality of the model (Murata et al., 2012, 2017), with improvements in both local skeletal muscle and distant (lung, kidney) indices of damage (Murata et al., 2017), suggesting a possible therapeutic option for this catastrophic condition.

$i v$. Transplantation. Since I/R injury is thought to play a major role in graft failure in liver and lung transplantation (Calvert and Lefer, 2010), there has been interest in assessing the efficacy of nitrite in this. In preclinical studies assessing hepatic $I / R$ injury in mice, nitrite (1.2-480 nmol) has been shown to exert profound dose-dependent protective effects on cellular necrosis and apoptosis, with protective effects observed at near-physiologic nitrite concentrations (Duranski et al., 2005). Nitrite-mediated protection of the liver was dependent on $\cdot \mathrm{NO}$ generation and independent of eNOS and hemoxygenase-1 enzyme activities (Duranski et al., 2005). In a preclinical murine model of liver transplantation, nitrite supplementation attenuated the release of liver enzymes, with the protective effects being even greater with longer cold preservation times. Separately, a reduction in apoptosis with preserved tissue morphology was evident with histologic analysis, and liver graft acute function post-transplantation was improved ( $\mathrm{Li}$ et al., 2012). Despite this promising preclinical data for nitrite therapy, translation into clinical studies has been slow, and so far there are no published studies of nitrite in human organ transplantation. Interestingly, iNO has proven beneficial in both transplantation of the lung (Yerebakan et al., 2009) and of the liver (Lang et al., 2007). Yerebakan et al. (2009) evaluated the effects of treatment with iNO (starting dose $40 \mathrm{ppm}$ ) in nine patients (six female, three male; mean age $42.9 \pm$ $15.8)$ requiring lung transplantation. Significant reductions in mean PAP (36.8 \pm 15.8 to $22 \pm 6.8$ at $6-8$ and $22.8 \pm 7.96 \mathrm{~mm} \mathrm{Hg}$ at $12-14$ hours) were evident with -NO treatment in all patients except one, with improvements in overall respiratory function. In patients undergoing orthotopic liver transplantation, Lang et al. (2007) demonstrated that treatment with inhaled $\mathrm{NO}$ doubled plasma nitrite levels and that this was associated with improved liver function and reduced injury (i.e., transaminases and coagulation studies) compared with the control group. Importantly, these positive effects were associated with hard outcomes for these patients, with reduced hospital length of stay by 1.24 days $(P=$ 0.034). Reperfusion resulted in increased apoptosis [indicated by terminal deoxynucleotidyl transferasemediated digoxigenin-deoxyuridine triphosphate nickend labeling staining (TUNEL)] in both the placebo and iNO groups; however, the magnitude of increased TUNEL staining was significantly attenuated $(\sim 75 \%)$ with NO treatment. Although the authors stated that not all effects of iNO may be mediated by nitrite, they suggested that those benefits related to I/R injury were likely due to the actions of nitrite. Currently, there are ongoing clinical trials assessing nitrite therapy in lung transplant recipients (NCT01715883).

v. Global Ischemia (Cardiac Arrest). Cardiac arrest results in significant mortality after initial resuscitation due in most cases to I/R-induced brain injury and, to a lesser degree, myocardial dysfunction (Nichol et al., 2008; Wachelder et al., 2009). Experimental models have suggested a protective role of intravenous nitrite or iNO both on neurologic and cardiac function after cardiac arrest (Dezfulian et al., 2009, 2012; Minamishima et al., 2011). Nitrite therapy after murine cardiac arrest improved 22-hour survival through improvements in myocardial contractility (Dezfulian et al., 2009). These improvements accompanied transient mitochondrial inhibition, which reduced oxidative injury to the heart; however, late brain injury related to cardiac arrest was still apparent and resulted in high rates of mortality. Further studies performed in a rat model of cardiac arrest with prolonged survival (7 days) have subsequently been performed (Dezfulian et al., 2012). In this study, cardiac arrest resulted in hippocampal CA1 delayed neuronal death, which has been well characterized in human cardiac arrest survivors (Horn and Schlote, 1992). Nitrite therapy resulted in increases in hippocampal nitrite and $S$-nitrosothiol levels, but not cGMP, shortly after therapy, with associated significant $(75 \%)$ increases in CA1 neuron survival. Based on this promising data, one pilot clinical study has been performed, which has demonstrated the feasibility and safety of low-dose nitrite infusion in cardiac arrest survivors but has, to date, not reported any improvement in outcome (Dezfulian et al., 2012). In the initial phase of this study, four patients who suffered cardiac arrest (within 12 hours) and were successfully resuscitated and survived to intensive care unit admission have been randomized in a double blind manner-3:1 ratio to $\mathrm{NaNO}_{2}$ (1 $\mathrm{mg}$ in $100 \mathrm{ml}$ normal saline) or $100 \mathrm{ml}$ saline placebo infused i.v. over 5 minutes. This initial dose of $1 \mathrm{mg}$ nitrite represents $0.2 \mu \mathrm{g} / \mathrm{kg}$ (based on $70 \mathrm{~kg}$ b.wt.). Nitrite infusion at this dose did not appear to cause significant hypotension or tachycardia, and mean metHB levels were $0.74 \% \pm 0.14 \%$ over time, with the highest recorded level of $1.1 \%$. Nitrite infusion 
increased plasma and blood levels in three of four patients (one received placebo), but the degree of increase was in all cases less than 5 -fold from the patient's baseline. Further data from the same study have now been published in 11 patients (seven nitrite/four placebo) receiving $1(n=3)$ or $9.6 \mathrm{mg}(n=4) \mathrm{NaNO}_{2}$ after resuscitation from outof-hospital cardiac arrest. Only the higher dose was associated with significant elevation in plasma nitrite levels, and neither dose was associated with worsening hemodynamics, although no hard outcomes were reported, and the study finished without completing its planned third dose ( $14.5 \mathrm{mg} \mathrm{NaNO}$ ) and was only able to recruit 11 patients into the study out of $>450$ out-ofhospital cardiac arrests in the 5 years that the study was open and recruiting (Dezfulian et al., 2018).

Perhaps a more pertinent time frame to start potentially protective nitrite therapy is at the time of resuscitation by emergency services personnel rather than in hospital. In this regard, a pilot study of paramedic-initiated intravenous nitrite therapy (over 30 seconds) immediately after standard advanced cardiac life support interventions were conducted (defibrillation, intubation, epinephrine) was performed in 120 patients. The initial dose chosen was $25 \mathrm{mg}$ nitrite but after review of pharmacokinetic data midtrial, the dose was increased for subsequent patients to $60 \mathrm{mg}$ ( $25 \mathrm{mg}: n=59 ; 60 \mathrm{mg}: n=61)$ to achieve the desired post-bolus nitrite concentration in venous blood of 10-20 $\mu \mathrm{mol} / \mathrm{l}$, probably due to hypoxic consumption of nitrite in the arrested state. The control group was acquired from contemporaneous controls in the paramedic data base of all out-of-hospital cardiac arrests who had received standard of care and did not receive nitrite $(n=355)$ during the period the study was open. Interestingly, there was no difference in outcomes (return of spontaneous circulation, rearrest, use of epinephrine, BP, survival to discharge, neurologically favorable survival) between the low- or high-dose nitrite groups or between patients receiving nitrite compared with control patients (Kim et al., 2018). A larger $(n=1500)$ randomized placebo-controlled trial is underway comparing two doses of nitrite (45 or $60 \mathrm{mg}$ ) and placebo, which should provide a definitive answer as to whether it is useful or not, with primary outcomes of survival to hospital admission and rearrest/epinephrine use prehospital (NCT03452917).

Although there is a multitude of preclinical and earlyphase clinical studies highlighting the diverse potential of nitrite-derived $\mathrm{NO}$ in human disease states, particularly in the CV system, almost 20 years of clinical studies have not yielded a positive phase III study in any condition, and neither inorganic nitrate nor nitrite is an established, guideline-recommended treatment as of yet. However, with the large number of adequately powered and mechanistically sound studies ongoing, it is likely that the medical community will have definitive answers as to the true therapeutic utility of these approaches within the next few years.

\section{Concerns Regarding Nitrite- and Nitrate-Based Therapeutics}

Over the past 30 years, there have been many attempts to manipulate the L-arginine: $\mathrm{NO}$ pathway through provision of substrate or cofactors to the NOS system (Zhang et al., 2011) to facilitate greater $\cdot \mathrm{NO}$ production. The discovery of authentic NO production from nitrite reduction (Benjamin et al., 1994; Lundberg et al., 1994; Zweier et al., 1995) has provided a further avenue within which to explore NO-based therapeutics.

\section{A. Epidemiologic Links to Possible Benefits of Dietary Nitrate}

Vegetables are a rich source of nitrate, with high amounts of nitrate found particularly in green leafy vegetables, which account for up to $85 \%$ of nitrate intake (Hord et al., 2009). Vegetarianism has long been associated with lower BP (Donaldson, 1926; Sacks et al., 1974; Armstrong et al., 1977, 1979; Ophir et al., 1983), and small-scale controlled clinical trials have demonstrated that increasing fruit and vegetable intakes are associated with lower BP (Rouse et al., 1983; Margetts et al., 1986; Appel et al., 1997). Epidemiologic studies have found consistent patterns demonstrating reduction in $\mathrm{BP}(\mathrm{Li}$ et al., 2016a), CVD (Joshipura et al., 1999, 2001; Bhupathiraju et al., 2013; Hu et al., 2014; Gan et al., 2015), and CV and non-CV death (Hung et al., 2004; Miller et al., 2017) associated with increased daily vegetable intake.

The precise constituent and mechanism of cardioprotection related to vegetable intake is elusive. There are many proposed vegetable constituents that could be responsible for beneficial $\mathrm{CV}$ effects, including soluble fiber, potassium, and antioxidants. Although there are issues with using epidemiologic data to try to identify micronutrient intake because of issues such as dietary recall (Naska et al., 2017) and, in the context of dietary nitrate, seasonal nitrate variation in vegetables (https:// www.food.gov.uk/research/research-projects/nitratemonitoring-in-spinach-and-lettuce-surveillance-programme), further analyses of such data have suggested green leafy vegetables, which are the largest source of dietary nitrate (Hord et al., 2009), appear to confer the greatest cardioprotective effects (Joshipura et al., 1999, 2001). Such data have led to the proposal that dietary nitrate is responsible for the beneficial effects of vegetable-rich diets (Lundberg et al., 2006; Webb et al., 2008b; Ralt, 2009), given the recent discoveries of reductive pathways that can take nitrate in humans to $\mathrm{NO}$ via nitrite as an intermediate (Lundberg et al., 2008).

Putting questions of therapeutic efficacy in human outcome trials aside given the lack of currently published data, there have been additional concerns raised about the safety of such approaches. Nitrate content of drinking water in Europe and the US is regulated and kept at $<50 \mathrm{mg} / \mathrm{l}$. There is an ADI recommendation for 
dietary nitrate as well, set at $3.7 \mathrm{mg} / \mathrm{kg}$ daily, which equates to $\sim 4 \mathrm{mmol}$ nitrate daily for an average $70-\mathrm{kg}$ person (European Food Safety Authority, 2008). However, as can be seen in particular from the section on BP and nitrate, most of the clinical studies that have beneficial effects have used acute or chronic dosing that is far above this recommended level. Fruit and vegetable-rich diets that have beneficial effects on CVD (Joshipura et al., 1999, 2001; Hung et al., 2004) and BP, such as the DASH diet (Appel et al., 1997), contain large amounts of nitrate naturally, perhaps up to $10-20 \mathrm{mmol}$ daily (Hord et al., 2009), far in excess of the recommended ADI above. Despite this, concerns relating to nitrite- and nitrate-based therapeutics continue largely based on two main areas: metHB and carcinogenesis.

\section{B. Methemoglobinemia}

Infants have very low nitrite levels, as their oral microbiome takes time to develop the right ecology for effective oral nitrate reduction (Jones et al., 2015b), but they are susceptible to preformed nitrite. Initial concerns regarding the etiological role of nitrate and methemoglobinemia were first reported in the early 1900s in children treated with bismuth subnitrate (Beck, 1909). It was recognized by these early clinician-scientists that many people could tolerate very large doses of inorganic nitrate with no ill effects, but that children, and those with intestinal infections, were particularly prone to methemoglobinemia (Beck, 1909). It was discovered that nitrate was metabolized to nitrite and that the problems of methemoglobinemia after nitrate ingestion were synonymous with that of nitrite ingestion, as first described by Gamgee (1868). As described earlier, nitrite reacts with oxyHb to form metHB, which is incapable of $\mathrm{O}_{2}$ transport (Doyle et al., 1981), and the young are particularly susceptible to the ill effects (Roe, 1933) because of preponderant fetal $\mathrm{Hb}$ and immature metHB reductase system (Gupta et al., 1999; Greer and Shannon, 2005).

In relation to this, post-World War II well-water surveys in rural American districts with reported cases of infant methemoglobinemia (Comly, 1945; Walton, 1951) led to the establishment of regulatory frameworks to control the nitrate level in such water at levels $<50 \mathrm{mg} / \mathrm{l}$ that are still in place (U.S. Public Health Service, 1962). Contemporary analysis of dietary nitrate consumption has re-evaluated this historical data and makes it less likely to be a significant concern (Fewtrell, 2004). The early reports of infantile methemoglobinemia were commonly in children that were unwell with presumed bacterial gastroenteritis (Cornblath and Hartmann, 1948), and therefore, the possibility of high systemic nitrite levels from intestinal bacterial conversion of nitrate to nitrite in vivo or in contaminated water supply has been suggested for apparent cases of nitrate-induced infantile methemoglobinemia (Hanukoglu and Danon, 1996; Avery, 1999). Indeed, recent data show no consistent association between drinking water nitrate levels and either the risk of developing clinical methemoglobinemia or blood metHB levels themselves (Ward et al., 2005).

Importantly, in oral dietary nitrate intervention studies, especially with beetroot juice with nitrate concentrations far higher than those set as safety limits for drinking water described above, there is only a modest rise in plasma nitrite levels (commonly $<1 \mu \mathrm{mol} / \mathrm{l}$, within the physiologic realm) and chronic supplementation with dietary nitrate that leads to long-term systemic nitrite elevation is not associated with elevation of metHB measured by co-oximetry (Kapil et al., 2015; Velmurugan et al., 2016). In adults, there is no report of vegetable intake causing clinically relevant methemoglobinemia, and cases in children are largely thought to be related to preformed nitrite accumulation due to bacterial contamination and preingestion nitrate-to-nitrite conversion (Chan, 2011).

Furthermore, systemic application of nitrite in mechanistic studies has achieved much higher levels of nitrite without significant elevation of metHB. Intra-arterial infusion of $\mathrm{NaNO}_{2}$ into the human forearm achieved systemic nitrite levels of $16 \mu \mathrm{mol} / \mathrm{l}$ (Cosby et al., 2003), far higher than that needed to achieve clinically meaningful reductions in BP (Ghosh et al., 2013; Kapil et al., 2015). In this study, metHB levels were pegged at $\sim 1 \%$ (Cosby et al., 2003). A more detailed pharmacokinetic study aimed at establishing dose-limiting toxicity of intravenous sodium nitrite as a therapeutic agent has been conducted. Infusions of sodium nitrite for 3-9 hours at $\sim 7 \mu \mathrm{mol} / \mathrm{kg}$ per hour produced large symptomatic reductions in $\mathrm{BP}$ associated to plasma nitrite levels of 1-5 $\mu \mathrm{mol} / \mathrm{l}$, which caused clinically insignificant, asymptomatic elevation of metHB to only $2 \%-5 \%$ (Pluta et al., 2011), well below the levels that are associated with symptomatic dyspnea (Ash-Bernal et al., 2004).

\section{Carcinogenesis}

The potential for carcinogenesis has long been a concern in relation to nitrite and nitrate biology. Indeed, almost all of the works in the 1970s and 1980s looking at oral nitrate reduction were done for the purpose of exploring possible contributions to carcinogenesis via $N$-nitrosamines (Harada et al., 1974; Tannenbaum et al., 1974, 1976; Ishiwata et al., 1975a,b,c,d; Ishiwata, 1976a,b; Spiegelhalder et al., 1976; Eisenbrand et al., 1980; Tannenbaum and Correa, 1985), and more recently, concerns have been re-expressed relating to cancers in the upper GI tract (Iijima et al., 2003).

It is more than 60 years since the first appreciation that $N$-nitrosamines were carcinogenic. Six months of feeding rats with dimethylnitrosamine $(50 \mathrm{ppm})$ produces large, necrotic hepatocellular carcinoma (Magee and Barnes, 1956), and long-term supplementation in rats of other related $N$-nitrosamines causes malignant tumors of other major organ systems, including esophagus, stomach, liver, and kidney as well (Magee and Barnes, 1967). These effects are not limited to rats but have been 
found in $\sim 40$ other species in which $N$-nitrosamines are directly carcinogenic (Bogovski and Bogovski, 1981).

The relevance of $N$-nitrosamines to nitrite and nitrate biology is apparent on understanding that they can be formed in vitro by incubating gastric juice, nitrite, and secondary amines (Sen et al., 1969) and in vivo in humans after dietary ingestion of nitrite-containing foods (Fine et al., 1977). Endogenous nitrosation reactions can occur from swallowed nitrite, either from dietary sources or from oral nitrate reduction that can be protonated to nitrous acid, which can further yield the powerful nitrosating agent dinitrogen trioxide, which in turn can nitrosate secondary and tertiary amines via the addition of nitronium cation, eventually forming $N$-nitrosamines (Leaf et al., 1989; Tricker, 1997). Ascorbate (vitamin C) and other food-based micronutrients such as polyphenols and tocopherol (vitamin E) inhibit this formation (Bartsch and Frank, 1996), suggesting that any putative risk relating to dietary nitrite/nitrate ingestion may be potentially mitigated in persons consuming whole vegetables as a source rather than through water or nitrite-containing meat.

The US National Toxicology Program produced a technical report studying 2-year drinking water supplementation studies of high levels of nitrite $(\sim 16-65 \mathrm{mmol} / \mathrm{l})$ in rodents and concluded that there was no evidence of carcinogenesis (National Toxicology Program, 2001). In contrast, the International Agency for Research on Cancer evaluated the effects of both nitrate and nitrate on human carcinogenesis and reported (International Agency for Research on Cancer, 2010) the following:

- inadequate evidence linking dietary and water sources of nitrate to cancer overall,

- limited evidence linking dietary nitrite to stomach cancer risk,

- inverse risk of dietary nitrate and stomach cancer, and

- nitrite and nitrate under conditions resulting in endogenous nitrosation are probably carcinogenic.

In addition, additional expert reports have been prepared that contend there is no effect. For example, the WHO Expert Committee on Food Additives concluded that there was no evidence that nitrate was carcinogenic to humans (Speijers and van den Brandt, 2003). In subsequent large cohorts, fruit and vegetablerich diets that exceed the $\mathrm{ADI}$ severalfold are not associated with any increase in cancer or mortality (Hung et al., 2004) and may indeed offer protection against cancer (World Cancer Research Fund/American Institute for Cancer Research, 2007; Boffetta et al., 2010). Epidemiologic work in this is area is naturally hamstrung by the methods for data collection in such works. Exposure estimates for dietary nitrite and nitrate across different populations are problematic because of the lack of widely applicable dietary databases that include the nitrate and nitrite content of common foods.

Furthermore, there are agricultural issues that alter nitrate content found naturally in batches of plants. Plants accumulate nitrate through the roots and use it for novel synthesis of amino acids and proteins (Vogtmann and Biedermann, 1985). If the plant does not use the nitrate immediately, it is stored in vacuoles, and it remains in the vacuoles if the plants are supplied with more nitrate than they can use and therefore will be stored more readily in vegetables with a low rate of photosynthesis (Martinoia et al., 2007). Hence, vegetables harvested in winter have higher nitrate content than those harvested in the summer (https://www.food.gov.uk/research/researchprojects/nitrate-monitoring-in-spinach-and-lettucesurveillance-programme). Further variability comes from the amount of nitrate in irrigation water, potential use of nitrogen-containing fertilizers, and postharvest storage (Blom-Zandstra, 1989). This produces a problem when trying to estimate dietary nitrate intake using databases of mean nitrate content for epidemiologic purposes. These also produce a problem when trying to consider dietary nitrate as a therapeutic, though the use of inorganic nitrate salts in capsule or tablet form (Zand et al., 2011), although excluding the protective effects of coexistent micronutrients, or concentrated, fixed-dose dietary nitrate supplements, could avoid this (Muggeridge et al., 2014).

A recent National Heart, Lung, and Blood Institute working group reviewed all these epidemiologic data and made some recommendations for future research, including the addition of location-specific information relating to nitrate content of foodstuffs; use of urine and plasma nitrate measures as an index of exposure; addition of drinking water exposure to dietary databases and questionnaires; and a focus on subpopulations at risk of carcinogenesis, such as smokers or those taking supplements (Ahluwalia et al., 2016).

\section{Pharmacokinetic Considerations considering Nitrite and Nitrate as $\cdot N O$-Therapeutics}

Inorganic nitrate can be thought of as a prodrug for bioactive nitrite, as it is largely thought to be inert in mammalian systems unchanged. In almost all disease areas studied in preclinical and clinical studies to date, the effect of systemic nitrite elevation through nitrite or nitrate supplementation (the latter requiring the enterosalivary conversion to nitrite involving oral microbiota) are synonymous.

There are possible pharmacokinetic advantages to oral dosing with nitrate over nitrite, however. Nitrate has a much longer half-life in human plasma ( $\sim 6$ hours) (van Velzen et al., 2008) compared with oral or intravenous nitrite application (Dejam et al., 2007; Hunault et al., 2009) and, therefore, is appropriate for dosing with a once-daily regimen. With chronic oral nitrate dosing, there is sustained nitrite elevation at trough 24 hours postdosing (Kapil et al., 2015; Ahluwalia 
et al., 2016) while nitrite is typically given two to three times daily (Mohler et al., 2014; DeVan et al., 2016). Adherence is improved in chronic medical conditions, such as systemic and pulmonary hypertension, that could be targeted by nitrite/nitrate therapeutics by once-daily compared with multiple-times-daily posology (Waxman et al., 2013; Vrijens et al., 2017). There is the additional benefit that dietary nitrate supplementation is applicable on a public health scale through campaigns to increase vegetable intake (https:// www.nhs.uk/live-well/eat-well/why-5-a-day) and is potentially low-cost and therefore applicable to constrained emerging health economies.

\section{Conclusions}

Until recently, the prevailing view of mammalian $\cdot \mathrm{NO}$ biology included the production of $\cdot \mathrm{NO}$ uniquely from the five-electron oxidation of the amino acid L-arginine by NOS (Stuehr, 1999). However, recent evidence has proved the existence of an alternative or noncanonical pathway that utilizes the sequential reduction of nitrate to nitrite, and thence $\mathrm{NO}$, and involves a fundamental, symbiotic role for hitherto bystander oral microbiota (Lundberg et al., 2008). This alternative pathway for $\cdot \mathrm{NO}$ generation is more active in hypoxia and acidosis, a situation in which the classic L-arginine pathway is dysfunctional and therefore provides a backup system for $\mathrm{NO}$ generation by re-cycling the oxidative products of NO metabolism, with important contributions from the diet as well. This reveals that nitrite and nitrate are no longer end products of $\cdot \mathrm{NO}$ metabolism but exist in a balanced 'NO cycle (Reutov and Sorokina, 1998; Reutov, 2002).

Given the protean roles that have been discovered for -NO in physiology and pathophysiology, it is not surprising that there has been a wide-ranging exploration of the potential roles of this new biology. Translational studies, predominantly in the realm of cardiorespiratory disease, have demonstrated beneficial effects with systemic or local elevation of nitrite levels, whether achieved directly or after nitrate supplementation and oral reduction of nitrate to nitrite. The next few years will see the publication of important outcome studies in patient populations in need of additional therapeutics and will determine whether this early evidence translates into truly beneficial outcomes and useful therapeutic medicines.

Or, as said almost 80 years ago by Stieglitz and Palmer (1937):

"Because of the rapid disappearance of nitrite from blood and the relative constancy of the level found in freshly drawn blood, one may tentatively assume that there is a constant production and destruction of the nitrite going on in the body.

The source of the nitrite of the blood may be from administration by any route, absorption of nitrites from the bacterial reduction of food or drug nitrates in the lower portion of the bowel or absorption of nitrates and a subsequent reduction in the blood stream itself or a reduction of nitrates in the tissues. Any of these sources may be foci of a more or less constant production of nitrite...

Nitrite... has profound effects in very small amounts on a great many functions of the body directly by its action of relaxing smooth muscle, especially arteriolar muscle, and indirectly by its effects on the blood flow in secretory organs.

The exact physiologic significance of the blood nitrite is uncertain, but it may be that normally it aids in maintaining those functions which are stimulated by the administration of therapeutic doses. Clinical application of nitrite analysis of the blood may reveal some correlation between a disturbed nitrite metabolism and abnormalities of the arterial tension."

\section{Authorship Contributions}

Wrote or contributed to the writing of the manuscript: Kapil, Khambata, Jones, Rathod, Primus, Massimo, Fukuto, Ahluwalia.

\section{References}

Aamand R, Dalsgaard T, Jensen FB, Simonsen U, Roepstorff A, and Fago A (2009) Generation of nitric oxide from nitrite by carbonic anhydrase: a possible link between metabolic activity and vasodilation. Am J Physiol Heart Circ Physiol 297: H2068-H2074.

Abadeh S, Case PC, and Harrison R (1992) Demonstration of xanthine oxidase in human heart. Biochem Soc Trans 20:346S.

Abadeh S, Case PC, and Harrison R (1993) Purification of xanthine oxidase from human heart. Biochem Soc Trans 21:99S

Adachi T, Fukushima T, Usami Y, and Hirano K (1993) Binding of human xanthine oxidase to sulphated glycosaminoglycans on the endothelial-cell surface. Biochem $J$ 289:523-527.

Adnot S, Raffestin B, Eddahibi S, Braquet P, and Chabrier PE (1991) Loss of endothelium-dependent relaxant activity in the pulmonary circulation of rats exposed to chronic hypoxia. J Clin Invest 87:155-162.

Ahluwalia A, Foster P, Scotland RS, McLean PG, Mathur A, Perretti M, Moncada S, and Hobbs AJ (2004) Antiinflammatory activity of soluble guanylate cyclase: cGMP-dependent down-regulation of P-selectin expression and leukocyte recruitment. Proc Natl Acad Sci USA 101:1386-1391.

Ahluwalia A, Gladwin M, Coleman GD, Hord N, Howard G, Kim-Shapiro DB, Lajous M, Larsen FJ, Lefer DJ, McClure LA, et al. (2016) Dietary nitrate and the epidemiology of cardiovascular disease: report from a national heart, lung, and blood institute workshop. J Am Heart Assoc 5:e003402.

Akrawinthawong K, Park JW, Piknova B, Sibmooh N, Fucharoen S, and Schechter AN (2014) A flow cytometric analysis of the inhibition of platelet reactivity due to nitrite reduction by deoxygenated erythrocytes. PLoS One 9:e92435.

Alef MJ, Vallabhaneni R, Carchman E, Morris SM Jr, Shiva S, Wang Y, Kelley EE Tarpey MM, Gladwin MT, Tzeng E, et al. (2011) Nitrite-generated NO circumvents dysregulated arginine/NOS signaling to protect against intimal hyperplasia in Sprague-Dawley rats. J Clin Invest 121:1646-1656.

Alexander SPH, Fabbro D, Kelly E, Mathie A, Peters JA, Veale EL, Armstrong JF, Faccenda E, Harding SD, Pawson AJ, et al.; CGTP Collaborators (2019) The concise guide to pharmacology 2019/20: catalytic receptors. $\mathrm{Br} J$ Pharmacol 176: S247-S296.

Allen DG, Lamb GD, and Westerblad H (2008) Skeletal muscle fatigue: cellular mechanisms. Physiol Rev 88:287-332.

Allen JD, Stabler T, Kenjale A, Ham KL, Robbins JL, Duscha BD, Dobrosielski DA, and Annex BH (2010) Plasma nitrite flux predicts exercise performance in peripheral arterial disease after 3months of exercise training. Free Radic Biol Med 49:1138-1144.

Alonso-Fernández A, García-Río F, Arias MA, Hernanz A, de la Peña M, Piérola J, Barceló A, López-Collazo E, and Agustí A (2009) Effects of CPAP on oxidative stress and nitrate efficiency in sleep apnoea: a randomised trial. Thorax 64: 581-586.

Amaral JH, Ferreira GC, Pinheiro LC, Montenegro MF, and Tanus-Santos JE (2015) Consistent antioxidant and antihypertensive effects of oral sodium nitrite in DOCA-salt hypertension. Redox Biol 5:340-346.

Amdahl MB, Sparacino-Watkins CE, Corti P, Gladwin MT, and Tejero J (2017) Efficient reduction of vertebrate cytoglobins by the cytochrome $\mathrm{b}_{5} /$ cytochrome $\mathrm{b}_{5}$ reductase/NADH system. Biochemistry 56:3993-4004.

Andring JT, Lomelino CL, Tu C, Silverman DN, McKenna R, and Swenson ER (2018) Carbonic anhydrase II does not exhibit nitrite reductase or nitrous anhydrase activity. Free Radic Biol Med 117:1-5. 
Angelone T, Gattuso A, Imbrogno S, Mazza R, and Tota B (2012) Nitrite is a positive modulator of the Frank-Starling response in the vertebrate heart. Am J Physiol Regul Integr Comp Physiol 302:R1271-R1281.

Ansari FA, Ali SN, Arif H, Khan AA, and Mahmood R (2017) Acute oral dose of sodium nitrite induces redox imbalance, DNA damage, metabolic and histological changes in rat intestine. PLoS One 12:e0175196.

Antoniades C, Shirodaria C, Crabtree M, Rinze R, Alp N, Cunnington C, Diesch J, Tousoulis D, Stefanadis C, Leeson P, et al. (2007) Altered plasma versus vascular biopterins in human atherosclerosis reveal relationships between endothelial nitric oxide synthase coupling, endothelial function, and inflammation. Circulation 116 2851-2859.

Apostoli GL, Solomon A, Smallwood MJ, Winyard PG, and Emerson M (2014) Role of inorganic nitrate and nitrite in driving nitric oxide-cGMP-mediated inhibition of platelet aggregation in vitro and in vivo. J Thromb Haemost 12 1880-1889.

Appel LJ, Moore TJ, Obarzanek E, Vollmer WM, Svetkey LP, Sacks FM, Bray GA, Vogt TM, Cutler JA, Windhauser MM, et al.; DASH Collaborative Research Group (1997) A clinical trial of the effects of dietary patterns on blood pressure. $N$ Engl $J$ Med 336:1117-1124

Armstrong B, Clarke H, Martin C, Ward W, Norman N, and Masarei J (1979) Urinary sodium and blood pressure in vegetarians. Am J Clin Nutr 32:2472-2476.

Armstrong B, van Merwyk AJ, and Coates H (1977) Blood pressure in seventh-day adventist vegetarians. Am J Epidemiol 105:444-449.

Arzt M, Young T, Finn L, Skatrud JB, and Bradley TD (2005) Association of sleepdisordered breathing and the occurrence of stroke. Am J Respir Crit Care Med 172: $1447-1451$

Ash-Bernal R, Wise R, and Wright SM (2004) Acquired methemoglobinemia: a retrospective series of 138 cases at 2 teaching hospitals. Medicine (Baltimore) 83 $265-273$

Ashmore T, Fernandez BO, Branco-Price C, West JA, Cowburn AS, Heather LC, Griffin JL, Johnson RS, Feelisch M, and Murray AJ (2014) Dietary nitrate increases arginine availability and protects mitochondrial complex I and energetics in the hypoxic rat heart. $J$ Physiol 592:4715-4731.

Ashor AW, Jajja A, Sutyarjoko A, Brandt K, Qadir O, Lara J, and Siervo M (2015) Effects of beetroot juice supplementation on microvascular blood flow in older overweight and obese subjects: a pilot randomised controlled study. J Hum Hypertens 29:511-513.

Ashor AW, Lara J, and Siervo M (2017) Medium-term effects of dietary nitrate supplementation on systolic and diastolic blood pressure in adults: a systematic review and meta-analysis. J Hypertens 35:1353-1359.

Ashworth A, Mitchell K, Blackwell JR, Vanhatalo A, and Jones AM (2015) Highnitrate vegetable diet increases plasma nitrate and nitrite concentrations and reduces blood pressure in healthy women. Public Health Nutr 18:2669-2678.

Askew CD, Green S, Walker PJ, Kerr GK, Green AA, Williams AD, and Febbraio MA (2005) Skeletal muscle phenotype is associated with exercise tolerance in patients with peripheral arterial disease. J Vasc Surg 41:802-807.

Attwell D, Buchan AM, Charpak S, Lauritzen M, Macvicar BA, and Newman EA (2010) Glial and neuronal control of brain blood flow. Nature 468:232-243.

Aucouturier J, Boissiere J, Pawlak-Chaouch M, Cuvelier G, and Gamelin FX (2015) Effect of dietary nitrate supplementation on tolerance to supramaximal intensity intermittent exercise. Nitric Oxide 49:16-25.

Avery AA (1999) Infantile methemoglobinemia: reexamining the role of drinking water nitrates. Environ Health Perspect 107:583-586.

Azuma H, Ishikawa M, and Sekizaki S (1986) Endothelium-dependent inhibition of platelet aggregation. $\mathrm{Br} J$ Pharmacol 88:411-415.

Badimon L, Badimon JJ, Vilahur G, Segalés E, and Llorente V (2002) Pathogenesis of the acute coronary syndromes and therapeutic implications. Pathophysiol Haemost Thromb 32:225-231.

Bahra M, Kapil V, Pearl V, Ghosh S, and Ahluwalia A (2012) Inorganic nitrate ingestion improves vascular compliance but does not alter flow-mediated dilatation in healthy volunteers. Nitric Oxide 26:197-202.

Bailey DM, Rasmussen P, Overgaard M, Evans KA, Bohm AM, Seifert T, Brassard P, Zaar M, Nielsen HB, Raven PB, et al. (2017) Nitrite and s-nitrosohemoglobin exchange across the human cerebral and femoral circulation: relationship to basal and exercise blood flow responses to hypoxia. Circulation 135:166-176.

Bailey JC, Feelisch M, Horowitz JD, Frenneaux MP, and Madhani M (2014) Pharmacology and therapeutic role of inorganic nitrite and nitrate in vasodilatation. Pharmacol Ther 144:303-320.

Bailey SJ, Fulford J, Vanhatalo A, Winyard PG, Blackwell JR, DiMenna FJ, Wilkerson DP, Benjamin N, and Jones AM (2010) Dietary nitrate supplementation enhances muscle contractile efficiency during knee-extensor exercise in humans. $J$ Appl Physiol (1985) 109:135-148.

Bailey SJ, Winyard P, Vanhatalo A, Blackwell JR, Dimenna FJ, Wilkerson DP, Tarr $\mathrm{J}$, Benjamin N, and Jones AM (2009) Dietary nitrate supplementation reduces the $\mathrm{O}_{2}$ cost of low-intensity exercise and enhances tolerance to high-intensity exercise in humans. J Appl Physiol (1985) 107:1144-1155.

Baker JE, Su J, Fu X, Hsu A, Gross GJ, Tweddell JS, and Hogg N (2007) Nitrite confers protection against myocardial infarction: role of xanthine oxidoreductase, NADPH oxidase and K(ATP) channels. J Mol Cell Cardiol 43:437-444.

Bakker JR, Bondonno NP, Gaspari TA, Kemp-Harper BK, McCashney AJ, Hodgson JM, Croft KD, and Ward NC (2016) Low dose dietary nitrate improves endothelial dysfunction and plaque stability in the $\mathrm{ApoE}^{-/-}$mouse fed a high fat diet. Free Radic Biol Med 99:189-198.

Baliga RS, Milsom AB, Ghosh SM, Trinder SL, Macallister RJ, Ahluwalia A and Hobbs AJ (2012) Dietary nitrate ameliorates pulmonary hypertension: cytoprotective role for endothelial nitric oxide synthase and xanthine oxidoreductase. Circulation 125:2922-2932.

Balligand JL, Kelly RA, Marsden PA, Smith TW, and Michel T (1993) Control of cardiac muscle cell function by an endogenous nitric oxide signaling system. Proc Natl Acad Sci USA 90:347-351.
Balon TW, Jasman AP, and Young JC (1999) Effects of chronic N(omega)-nitro-Larginine methyl ester administration on glucose tolerance and skeletal muscle glucose transport in the rat. Nitric Oxide 3:312-320.

Barnes PJ and Belvisi MG (1993) Nitric oxide and lung disease. Thorax 48 1034-1043.

Barnes PJ, Burney PG, Silverman EK, Celli BR, Vestbo J, Wedzicha JA, and Wouters EF (2015) Chronic obstructive pulmonary disease. Nat Rev Dis Primers 1:15076.

Bartholomew B and Hill MJ (1984) The pharmacology of dietary nitrate and the origin of urinary nitrate. Food Chem Toxicol 22:789-795.

Bartsch H and Frank N (1996) Blocking the endogenous formation of N-nitroso compounds and related carcinogens. IARC Sci Publ:189-201.

Basu S, Grubina R, Huang J, Conradie J, Huang Z, Jeffers A, Jiang A, He X, Azarov I Seibert $\mathrm{R}$, et al. (2007) Catalytic generation of $\mathrm{N}_{2} \mathrm{O}_{3}$ by the concerted nitrite reductase and anhydrase activity of hemoglobin. Nat Chem Biol 3:785-794

Batchelor AM, Bartus K, Reynell C, Constantinou S, Halvey EJ, Held KF, Dostmann WR, Vernon J, and Garthwaite J (2010) Exquisite sensitivity to subsecond, picomolar nitric oxide transients conferred on cells by guanylyl cyclase-coupled receptors. Proc Natl Acad Sci USA 107:22060-22065.

Beck EG (1909) Toxic effects from bismuth subnitrate with reports of cases to date. JAMA LII:14-18.

Behnia M, Wheatley CM, Avolio A, and Johnson BD (2018) Influence of dietary nitrate supplementation on lung function and exercise gas exchange in COPD patients. Nitric Oxide 76:53-61.

Beier S, Classen HG, Loeffler K, Schumacher E, and Thöni H (1995) Antihypertensive effect of oral nitrite uptake in the spontaneously hypertensive rat. Arzneimittelforschung 45:258-261.

Bellien J, Favre J, Iacob M, Gao J, Thuillez C, Richard V, and Joannidès R (2010) Arterial stiffness is regulated by nitric oxide and endothelium-derived hyperpolarizing factor during changes in blood flow in humans. Hypertension $\mathbf{5 5}$ 674-680.

Belvisi MG, Stretton CD, Yacoub M, and Barnes PJ (1992) Nitric oxide is the endogenous neurotransmitter of bronchodilator nerves in humans. Eur J Pharmacol 210:221-222.

Benjamin N, O’Driscoll F, Dougall H, Duncan C, Smith L, Golden M, and McKenzie H (1994) Stomach NO synthesis. Nature 368:502.

Bernheim F and Dixon M (1928) The reduction of nitrates in animal tissues. Biochem $J$ 22:125-134.

Berry CE and Hare JM (2004) Xantine oxidoreductase and cardiovascular disease: molecular mechanisms and pathophysiological implications. $J$ Physiol 555: $589-606$.

Berry MJ, Justus NW, Hauser JI, Case AH, Helms CC, Basu S, Rogers Z, Lewis MT, and Miller GD (2015) Dietary nitrate supplementation improves exercise performance and decreases blood pressure in COPD patients. Nitric Oxide 48:22-30.

Bescos R, Ferrer-Roca V, Galilea PA, Roig A, Drobnic F, Sureda A, Martorell M, Cordova A, Tur JA, and Pons A (2012) Sodium nitrate supplementation does not enhance performance of endurance athletes. Med Sci Sports Exerc 44:2400-2409.

Betteridge S, Bescos R, Martorell M, Pons A, Garnham AP, Stathis CC, and McConell GK (2016) No effect of acute beetroot juice ingestion on oxygen consumption, glucose kinetics, or skeletal muscle metabolism during submaximal exercise in males. $J$ Appl Physiol (1985) 120:391-398.

Bhupathiraju SN, Wedick NM, Pan A, Manson JE, Rexrode KM, Willett WC, Rimm $\mathrm{EB}$, and $\mathrm{Hu} \mathrm{FB}$ (2013) Quantity and variety in fruit and vegetable intake and risk of coronary heart disease. Am J Clin Nutr 98:1514-1523.

Bhushan S, Kondo K, Polhemus DJ, Otsuka H, Nicholson CK, Tao Y-X, Huang H, Georgiopoulou VV, Murohara T, Calvert JW, et al. (2014) Nitrite therapy improves left ventricular function during heart failure via restoration of nitric oxidemediated cytoprotective signaling. Circ Res 114:1281-1291.

Birdsall HH, Green DM, Trial J, Youker KA, Burns AR, MacKay CR, LaRosa GJ, Hawkins HK, Smith CW, Michael LH, et al. (1997) Complement C5a, TGF-beta 1, and MCP-1, in sequence, induce migration of monocytes into ischemic canine myocardium within the first one to five hours after reperfusion. Circulation 95: 684-692.

Björne H, Petersson J, Phillipson M, Weitzberg E, Holm L, and Lundberg JO (2004) Nitrite in saliva increases gastric mucosal blood flow and mucus thickness [published correction appears in $J$ Clin Invest (2004) 113:490]. J Clin Invest 113 $106-114$

Björne H, Weitzberg E, and Lundberg JO (2006) Intragastric generation of antimicrobial nitrogen oxides from saliva--physiological and therapeutic considerations. Free Radic Biol Med 41:1404-1412.

Blekkenhorst LC, Lewis JR, Prince RL, Devine A, Bondonno NP, Bondonno CP, Wood LG, Puddey IB, Ward NC, Croft KD, et al. (2018) Nitrate-rich vegetables do not lower blood pressure in individuals with mildly elevated blood pressure: a 4-wk randomized controlled crossover trial. Am J Clin Nutr 107:894-908.

Blom-Zandstra M (1989) Nitrate accumulation in vegetables and its relationship to quality. Ann Appl Biol 115:553-561.

Blood AB, Schroeder HJ, Terry MH, Merrill-Henry J, Bragg SL, Vrancken K, Liu T, Herring JL, Sowers LC, Wilson SM, et al. (2011) Inhaled nitrite reverses hemolysis-induced pulmonary vasoconstriction in newborn lambs without blood participation. Circulation 123:605-612.

Bloom MW, Hamo CE, Cardinale D, Ky B, Nohria A, Baer L, Skopicki H, Lenihan DJ, Gheorghiade M, Lyon AR, et al. (2016) Cancer therapy-related cardiac dysfunction and heart failure: part 1: definitions, pathophysiology, risk factors, and imaging. Circ Heart Fail 9:e002661.

Blough NV and Zafiriou OC (1985) Reaction of superoxide with nitric oxide to form peroxonitrite in alkaline aqueous solution. Inorg Chem 24:3502-3504.

Blum A, Hathaway L, Mincemoyer R, Schenke WH, Kirby M, Csako G, Waclawiw MA, Panza JA, and Cannon RO III (2000) Oral L-arginine in patients with coronary artery disease on medical management. Circulation 101:2160-2164.

Bock JM, Treichler DP, Norton SL, Ueda K, Hughes WE, and Casey DP (2018a) Inorganic nitrate supplementation enhances functional capacity and lower-limb 
microvascular reactivity in patients with peripheral artery disease. Nitric Oxide 80:45-51.

Bock JM, Ueda K, Schneider AC, Hughes WE, Limberg JK, Bryan NS, and Casey DP (2018b) Inorganic nitrate supplementation attenuates peripheral chemoreflex sensitivity but does not improve cardiovagal baroreflex sensitivity in older adults. Am J Physiol Heart Circ Physiol 314:H45-H51.

Boffetta P, Couto E, Wichmann J, Ferrari P, Trichopoulos D, Bueno-de-Mesquita HB, van Duijnhoven FJ, Büchner FL, Key T, Boeing H, et al. (2010) Fruit and vegetable intake and overall cancer risk in the European Prospective Investigation into Cancer and Nutrition (EPIC). J Natl Cancer Inst 102:529-537.

Böger RH, Bode-Böger SM, Brandes RP, Phivthong-ngam L, Böhme M, Nafe R, Mügge A, and Frölich JC (1997) Dietary L-arginine reduces the progression of atherosclerosis in cholesterol-fed rabbits: comparison with lovastatin. Circulation 96:1282-1290.

Bogovski P and Bogovski S (1981) Animal species in which N-nitroso compounds induce cancer. Int $J$ Cancer 27:471-474.

Bond H, Morton L, and Braakhuis AJ (2012) Dietary nitrate supplementation improves rowing performance in well-trained rowers. Int J Sport Nutr Exerc Metab 22:251-256.

Bond V Jr, Curry BH, Adams RG, Asadi MS, Millis RM, and Haddad GE (2013) Effects of dietary nitrates on systemic and cerebrovascular hemodynamics. Cardiol Res Pract 2013:435629.

Bond V Jr, Curry BH, Adams RG, Millis RM, and Haddad GE (2014) Cardiorespiratory function associated with dietary nitrate supplementation. Appl Physiol Nutr Metab 39:168-172.

Bondonno CP, Downey LA, Croft KD, Scholey A, Stough C, Yang X, Considine MJ, Ward NC, Puddey IB, Swinny E, et al. (2014a) The acute effect of flavonoid-rich apples and nitrate-rich spinach on cognitive performance and mood in healthy men and women. Food Funct 5:849-858.

Bondonno CP, Liu AH, Croft KD, Considine MJ, Puddey IB, Woodman RJ, and Hodgson JM (2015a) Antibacterial mouthwash blunts oral nitrate reduction and increases blood pressure in treated hypertensive men and women. Am J Hypertens 28:572-575.

Bondonno CP, Liu AH, Croft KD, Ward NC, Shinde S, Moodley Y, Lundberg JO, Puddey IB, Woodman RJ, and Hodgson JM (2015b) Absence of an effect of high nitrate intake from beetroot juice on blood pressure in treated hypertensive individuals: a randomized controlled trial. Am J Clin Nutr 102:368-375.

Bondonno CP, Liu AH, Croft KD, Ward NC, Yang X, Considine MJ, Puddey IB, Woodman RJ, and Hodgson JM (2014b) Short-term effects of nitrate-rich green leafy vegetables on blood pressure and arterial stiffness in individuals with highnormal blood pressure. Free Radic Biol Med 77:353-362.

Bondonno CP, Yang X, Croft KD, Considine MJ, Ward NC, Rich L, Puddey IB Swinny E, Mubarak A, and Hodgson JM (2012) Flavonoid-rich apples and nitrate-rich spinach augment nitric oxide status and improve endothelial function in healthy men and women: a randomized controlled trial. Free Radic Biol Med 52:95-102.

Bonner FT and Hughes MN (1988) The aqueous solution chemistry of nitrogen in low positive oxidation states. Comments Inorg Chem 7:215-234.

Boorsma RK, Whitfield J, and Spriet LL (2014) Beetroot juice supplementation does not improve performance of elite 1500-m runners. Med Sci Sports Exerc 46: 2326-2334.

Borlaug BA, Olson TP, Lam CS, Flood KS, Lerman A, Johnson BD, and Redfield MM (2010) Global cardiovascular reserve dysfunction in heart failure with preserved ejection fraction. $J$ Am Coll Cardiol 56:845-854.

Borlaug BA, Anstrom KJ, Lewis GD, Shah SJ, Levine JA, Koepp GA, Givertz MM Felker GM, LeWinter MM, Mann DL, et al. (2018) Effect of inorganic nitrite vs placebo on exercise capacity among patients with heart failure with preserved ejection fraction: The INDIE-HFpEF Randomized Clinical Trial. JAMA $\mathbf{3 2 0}$ 1764-1773.

Botden IP, Batenburg WW, de Vries R, Langendonk JG, Sijbrands EJ, and Danser $\mathrm{AH}$ (2012) Nitrite- and nitroxyl-induced relaxation in porcine coronary (micro-) arteries: underlying mechanisms and role as endothelium-derived hyperpolarizing factor(s). Pharmacol Res 66:409-418.

Bourdillon N, Fan JL, Uva B, Müller H, Meyer P, and Kayser B (2015) Effect of oral nitrate supplementation on pulmonary hemodynamics during exercise and time trial performance in normoxia and hypoxia: a randomized controlled trial. Front Physiol 6:288.

Brandes RP, Kim D, Schmitz-Winnenthal FH, Amidi M, Gödecke A, Mülsch A and Busse R (2000) Increased nitrovasodilator sensitivity in endothelial nitric oxide synthase knockout mice: role of soluble guanylyl cyclase. Hypertension $\mathbf{3 5}$ 231-236

Breese BC, McNarry MA, Marwood S, Blackwell JR, Bailey SJ, and Jones AM (2013) Beetroot juice supplementation speeds $\mathrm{O} 2$ uptake kinetics and improves exercise tolerance during severe-intensity exercise initiated from an elevated metabolic rate. Am J Physiol Regul Integr Comp Physiol 305:R1441-R1450.

Brookes PS, Salinas EP, Darley-Usmar K, Eiserich JP, Freeman BA, Darley-Usmar VM, and Anderson PG (2000) Concentration-dependent effects of nitric oxide on mitochondrial permeability transition and cytochrome c release. J Biol Chem 275 : 20474-20479.

Brooks J (1937) The action of nitrite on haemoglobin in the absence of oxygen. Proc $R$ Soc Lond B Biol Sci 123:368-382.

Brown GC and Cooper CE (1994) Nanomolar concentrations of nitric oxide reversibly inhibit synaptosomal respiration by competing with oxygen at cytochrome oxidase. FEBS Lett 356:295-298.

Brown GC and Borutaite V (2002) Nitric oxide inhibition of mitochondrial respiration and its role in cell death. Free Radic Biol Med 33:1440-1450.

Broxterman RM, La Salle DT, Zhao J, Reese VR, Richardson RS, and Trinity JD (2019) Influence of dietary inorganic nitrate on blood pressure and vascular function in hypertension: prospective implications for adjunctive treatment. $J$ Appl Physiol (1985) 127:1085-1094.
Brunner H, Cockcroft JR, Deanfield J, Donald A, Ferrannini E, Halcox J, Kiowski W, Lüscher TF, Mancia G, Natali A, et al. Working Group on Endothelins and Endothelial Factors of the European Society of Hypertension (2005) Endothelial function and dysfunction. Part II: Association with cardiovascular risk factors and diseases. A statement by the Working Group on Endothelins and Endothelial Factors of the European Society of Hypertension. J Hypertens 23:233-246.

Bryan NS, Fernandez BO, Bauer SM, Garcia-Saura MF, Milsom AB, Rassaf T, Maloney RE, Bharti A, Rodriguez J, and Feelisch M (2005) Nitrite is a signaling molecule and regulator of gene expression in mammalian tissues. Nat Chem Biol 1 290-297.

Bryan NS, Calvert JW, Elrod JW, Gundewar S, Ji SY, and Lefer DJ (2007) Dietary nitrite supplementation protects against myocardial ischemia-reperfusion injury. Proc Natl Acad Sci USA 104:19144-19149.

Buchanan JE and Phillis JW (1993) The role of nitric oxide in the regulation of cerebral blood flow. Brain Res 610:248-255.

Burleigh M, Liddle L, Muggeridge DJ, Monaghan C, Sculthorpe N, Butcher J, Henriquez F, and Easton C (2019) Dietary nitrate supplementation alters the oral microbiome but does not improve the vascular responses to an acute nitrate dose. Nitric Oxide 89:54-63.

Burleigh MC, Liddle L, Monaghan C, Muggeridge DJ, Sculthorpe N, Butcher JP, Henriquez FL, Allen JD, and Easton C (2018) Salivary nitrite production is elevated in individuals with a higher abundance of oral nitrate-reducing bacteria. Free Radic Biol Med 120:80-88.

Burmester T, Weich B, Reinhardt S, and Hankeln T (2000) A vertebrate globin expressed in the brain. Nature 407:520-523.

Butler A and Moffett J (2005) A treatment for cardiovascular dysfunction in a Dunhaung medical manuscript, in Medieval Chinese Medicine: The Dunhuang Medical Manuscripts (Lo EY and Cullen C eds) pp 363-368, RoutledgeCurzon, London.

Butler AR and Feelisch M (2008) Therapeutic uses of inorganic nitrite and nitrate: from the past to the future. Circulation 117:2151-2159.

Butler AR and Ridd JH (2004) Formation of nitric oxide from nitrous acid in ischemic tissue and skin. Nitric Oxide 10:20-24.

Cabreiro F, Au C, Leung KY, Vergara-Irigaray N, Cochemé HM, Noori T, Weinkove D, Schuster E, Greene ND, and Gems D (2013) Metformin retards aging in C. elegans by altering microbial folate and methionine metabolism. Cell 153:228-239.

Cadwgan TM and Benjamin N (1993) Evidence for altered platelet nitric oxide synthesis in essential hypertension. J Hypertens 11:417-420.

Cai $\mathrm{H}$ and Harrison DG (2000) Endothelial dysfunction in cardiovascular diseases: the role of oxidant stress. Circ Res 87:840-844.

Calvert JW and Lefer DJ (2010) Clinical translation of nitrite therapy for cardiovascular diseases. Nitric Oxide 22:91-97.

Carlström M, Larsen FJ, Nyström T, Hezel M, Borniquel S, Weitzberg E, and Lundberg JO (2010) Dietary inorganic nitrate reverses features of metabolic syndrome in endothelial nitric oxide synthase-deficient mice. Proc Natl Acad Sci USA 107: 17716-17720.

Carlström M, Liu M, Yang T, Zollbrecht C, Huang L, Peleli M, Borniquel S, Kishikawa H, Hezel M, Persson AE, et al. (2015) Cross-talk between nitrate-nitrite-no and no synthase pathways in control of vascular no homeostasis. Antioxid Redox Signal 23:295-306.

Carlström M, Persson AE, Larsson E, Hezel M, Scheffer PG, Teerlink T, Weitzberg E, and Lundberg JO (2011) Dietary nitrate attenuates oxidative stress, prevents cardiac and renal injuries, and reduces blood pressure in salt-induced hypertension. Cardiovasc Res 89:574-585.

Carter P, Gray LJ, Troughton J, Khunti K, and Davies MJ (2010) Fruit and vegetable intake and incidence of type 2 diabetes mellitus: systematic review and metaanalysis. BMJ 341:c4229.

Casey DB, Badejo AMJ Jr, Dhaliwal JS, Murthy SN, Hyman AL, Nossaman BD, and Kadowitz PJ (2009) Pulmonary vasodilator responses to sodium nitrite are mediated by an allopurinol-sensitive mechanism in the rat. Am J Physiol Heart Circ Physiol 296:H524-H533.

Castello PR, David PS, McClure T, Crook Z, and Poyton RO (2006) Mitochondria cytochrome oxidase produces nitric oxide under hypoxic conditions: implications for oxygen sensing and hypoxic signaling in eukaryotes. Cell Metab 3:277-287.

Cavender MA, Steg PG, Smith SC Jr, Eagle K, Ohman EM, Goto S, Kuder J, Im K Wilson PW, and Bhatt DL REACH Registry Investigators (2015) Impact of diabetes mellitus on hospitalization for heart failure, cardiovascular events, and death: outcomes at 4 years from the reduction of atherothrombosis for continued health (reach) registry. Circulation 132:923-931.

Cermak NM, Gibala MJ, and van Loon LJ (2012a) Nitrate supplementation's improvement of $10-\mathrm{km}$ time-trial performance in trained cyclists. Int J Sport Nutr Exerc Metab 22:64-71.

Cermak NM, Res P, Stinkens R, Lundberg JO, Gibala MJ, and van Loon LJC (2012b) No improvement in endurance performance after a single dose of beetroot juice. Int J Sport Nutr Exerc Metab 22:470-478.

Chan TY (2011) Vegetable-borne nitrate and nitrite and the risk of methaemoglobinaemia. Toxicol Lett 200:107-108.

Chilvers C, Inskip H, Caygill C, Bartholomew B, Fraser P, and Hill M (1984) A survey of dietary nitrate in well-water users. Int $J$ Epidemiol 13:324-331.

Choi H-M, Kim B-H, Nho H, Kim K-A, Park J, Chang M-J, and Kim J-G (2016) Dietary nitrate supplementation attenuates blood pressure in young prehypertensive men during exercise. $J$ Ment Health 12:25-33.

Christensen PM, Nyberg M, and Bangsbo J (2013) Influence of nitrate supplementation on vo(2) kinetics and endurance of elite cyclists. Scand J Med Sci Sports 23: e21-31.

Chung AWY, Radomski A, Alonso-Escolano D, Jurasz P, Stewart MW, Malinski T, and Radomski MW (2004) Platelet-leukocyte agoregation induced by PAR agonists: regulation by nitric oxide and matrix metalloproteinases. $\mathrm{Br} J$ Pharmacol 143: $845-855$. 
Clarkson P, Adams MR, Powe AJ, Donald AE, McCredie R, Robinson J, McCarthy SN, Keech A, Celermajer DS, and Deanfield JE (1996) Oral L-arginine improves endothelium-dependent dilation in hypercholesterolemic young adults. $J$ Clin Invest 97:1989-1994.

Classen HG, Stein-Hammer C, and Thöni H (1990) Hypothesis: the effect of oral nitrite on blood pressure in the spontaneously hypertensive rat. Does dietary nitrate mitigate hypertension after conversion to nitrite? J Am Coll Nutr 9:500-502

Cleeter MW, Cooper JM, Darley-Usmar VM, Moncada S, and Schapira AH (1994) Reversible inhibition of cytochrome c oxidase, the terminal enzyme of the mitochondrial respiratory chain, by nitric oxide. Implications for neurodegenerative diseases. FEBS Lett 345:50-54.

Clementi E and Nisoli E (2005) Nitric oxide and mitochondrial biogenesis: a key to long-term regulation of cellular metabolism. Comp Biochem Physiol A Mol Integr Physiol 142:102-110.

Clifford T, Bell O, West DJ, Howatson G, and Stevenson EJ (2016) The effects of beetroot juice supplementation on indices of muscle damage following eccentric exercise. Eur J Appl Physiol 116:353-362.

Coggan AR, Leibowitz JL, Spearie CA, Kadkhodayan A, Thomas DP, Ramamurthy S, Mahmood K, Park S, Waller S, Farmer M, et al. (2015) Acute dietary nitrate intake improves muscle contractile function in patients with heart failure: a double-blind, placebo-controlled, randomized trial. Circ Heart Fail 8:914-920.

Coggan AR and Peterson LR (2016) Dietary nitrate and skeletal muscle contractile function in heart failure. Curr Heart Fail Rep 13:158-165.

Cohn JN, Archibald DG, Ziesche S, Franciosa JA, Harston WE, Tristani FE, Dunkman WB, Jacobs W, Francis GS, Flohr KH, et al. (1986) Effect of vasodilator therapy on mortality in chronic congestive heart failure. Results of a Veterans Administration Cooperative Study. N Engl J Med 314:1547-1552.

Coles LT and Clifton PM (2012) Effect of beetroot juice on lowering blood pressure in free-living, disease-free adults: a randomized, placebo-controlled trial. Nutr $J$ 11:106

Comly HH (1945) Cyanosis in infants caused by nitrates in well water. JAMA 129: $112-116$

Cook S, Hugli O, Egli M, Vollenweider P, Burcelin R, Nicod P, Thorens B, and Scherrer U (2003) Clustering of cardiovascular risk factors mimicking the human metabolic syndrome $\mathrm{X}$ in eNOS null mice. Swiss Med Wkly 133:360-363.

Cooke JP and Losordo DW (2002) Nitric oxide and angiogenesis. Circulation 105: 2133-2135.

Cornblath M and Hartmann AF (1948) Methemoglobinemia in young infants. $J$ Pediatr 33:421-425.

Cosby K, Partovi KS, Crawford JH, Patel RP, Reiter CD, Martyr S, Yang BK, Waclawiw MA, Zalos G, Xu X, et al. (2003) Nitrite reduction to nitric oxide by deoxyhemoglobin vasodilates the human circulation. Nat Med 9:1498-1505.

Cosyns SMR, Shiva S, and Lefebvre RA (2015) Protective effect of exogenous nitrite in postoperative ileus. $\mathrm{Br}$ J Pharmacol 172:4864-4874.

Crawford JH, Isbell TS, Huang Z, Shiva S, Chacko BK, Schechter AN, Darley-Usmar VM, Kerby JD, Lang JDJ Jr, Kraus D, et al. (2006) Hypoxia, red blood cells, and nitrite regulate NO-dependent hypoxic vasodilation. Blood 107:566-574.

Crawley DE, Liu SF, Evans TW, and Barnes PJ (1990) Inhibitory role of endothelium-derived relaxing factor in rat and human pulmonary arteries. $\mathrm{Br} J$ Pharmacol 101:166-170.

Cumpstey AF, Hennis PJ, Gilbert-Kawai ET, Fernandez BO, Poudevigne M, Cobb A, Meale P, Mitchell K, Moyses H, Pöhnl H, et al.; Xtreme Alps Research Group (2017) Effects of dietary nitrate on respiratory physiology at high altitude - Results from the Xtreme Alps study. Nitric Oxide 71:57-68.

Cunnington C, Van Assche T, Shirodaria C, Kylintireas I, Lindsay AC, Lee JM, Antoniades C, Margaritis M, Lee R, Cerrato R, et al. (2012) Systemic and vascular oxidation limits the efficacy of oral tetrahydrobiopterin treatment in patients with coronary artery disease. Circulation 125:1356-1366.

Damacena-Angelis C, Oliveira-Paula GH, Pinheiro LC, Crevelin EJ, Portella RL, Moraes LAB, and Tanus-Santos JE (2017) Nitrate decreases xanthine oxidoreductasemediated nitrite reductase activity and attenuates vascular and blood pressure responses to nitrite. Redox Biol 12:291-299.

Dangel O, Mergia E, Karlisch K, Groneberg D, Koesling D, and Friebe A (2010) Nitric oxide-sensitive guanylyl cyclase is the only nitric oxide receptor mediating platelet inhibition. J Thromb Haemost 8:1343-1352.

Davì G and Patrono C (2007) Platelet activation and atherothrombosis. N Engl J Med 357:2482-2494.

Dawes C (1972) Circadian rhythms in human salivary flow rate and composition. $J$ Physiol 220:529-545.

Dejam A, Hunter CJ, Pelletier MM, Hsu LL, Machado RF, Shiva S, Power GG, Kelm M, Gladwin MT, and Schechter AN (2005) Erythrocytes are the major in travascular storage sites of nitrite in human blood. Blood 106:734-739.

Dejam A, Hunter CJ, Tremonti C, Pluta RM, Hon YY, Grimes G, Partovi K, Pelletier MM, Oldfield EH, Cannon RO III, et al. (2007) Nitrite infusion in humans and nonhuman primates: endocrine effects, pharmacokinetics, and tolerance formation. Circulation 116:1821-1831.

Del Campo L, Sánchez-López A, Salaices M, von Kleeck RA, Expósito E, GonzálezGómez C, Cussó L, Guzmán-Martínez G, Ruiz-Cabello J, Desco M, et al. (2019) Vascular smooth muscle cell-specific progerin expression in a mouse model of Hutchinson-Gilford progeria syndrome promotes arterial stiffness: therapeutic effect of dietary nitrite. Aging Cell 18:e12936.

DeVan AE, Johnson LC, Brooks FA, Evans TD, Justice JN, Cruickshank-Quinn C Reisdorph N, Bryan NS, McQueen MB, Santos-Parker JR, et al. (2016) Effects of sodium nitrite supplementation on vascular function and related small metabolite signatures in middle-aged and older adults. J Appl Physiol (1985) 120:416-425.

Dewhirst FE, Chen T, Izard J, Paster BJ, Tanner AC, Yu WH, Lakshmanan A and Wade WG (2010) The human oral microbiome. J Bacteriol 192:5002-5017.

Dezfulian C, Alekseyenko A, Dave KR, Raval AP, Do R, Kim F, and Perez-Pinzon MA (2012) Nitrite therapy is neuroprotective and safe in cardiac arrest survivors. Nitric Oxide 26:241-250.
Dezfulian C, Olsufka M, Fly D, Scruggs S, Do R, Maynard C, Nichol G, and Kim F (2018) Hemodynamic effects of IV sodium nitrite in hospitalized comatose survivors of out of hospital cardiac arrest. Resuscitation 122:106-112.

Dezfulian C, Shiva S, Alekseyenko A, Pendyal A, Beiser DG, Munasinghe JP, Anderson SA, Chesley CF, Vanden Hoek TL, and Gladwin MT (2009) Nitrite therapy after cardiac arrest reduces reactive oxygen species generation, improves cardiac and neurological function, and enhances survival via reversible inhibition of mitochondrial complex I. Circulation 120:897-905.

Didisheim P, Kazmier FJ, and Fuster V (1974) Platelet inhibition in the management of thrombosis. Thromb Diath Haemorrh 32:21-34.

Dillon WC, Hampl V, Shultz PJ, Rubins JB, and Archer SL (1996) Origins of breath nitric oxide in humans. Chest 110:930-938.

Doel JJ, Benjamin N, Hector MP, Rogers M, and Allaker RP (2005) Evaluation of bacterial nitrate reduction in the human oral cavity. Eur J Oral Sci 113:14-19.

Donaldson AN (1926) The relation of protein foods to hypertension. Cal West Med 24: $328-331$.

Dougall HT, Smith L, Duncan C, and Benjamin N (1995) The effect of amoxycillin on salivary nitrite concentrations: an important mechanism of adverse reactions? $\mathrm{Br} J$ Clin Pharmacol 39:460-462.

Doyle MP, Pickering RA, DeWeert TM, Hoekstra JW, and Pater D (1981) Kinetics and mechanism of the oxidation of human deoxyhemoglobin by nitrites. $J$ Biol Chem 256:12393-12398.

Drexler H (1999) Nitric oxide synthases in the failing human heart: a doubled-edged sword? Circulation 99:2972-2975.

Duncan C, Dougall H, Johnston P, Green S, Brogan R, Leifert C, Smith L, Golden M, and Benjamin N (1995) Chemical generation of nitric oxide in the mouth from the enterosalivary circulation of dietary nitrate. Nat Med 1:546-551.

Duplain H, Burcelin R, Sartori C, Cook S, Egli M, Lepori M, Vollenweider P, Pedrazzini T, Nicod P, Thorens B, et al. (2001) Insulin resistance, hyperlipidemia, and hypertension in mice lacking endothelial nitric oxide synthase. Circulation 104:342-345

Dupuy PM, Shore SA, Drazen JM, Frostell C, Hill WA, and Zapol WM (1992) Bronchodilator action of inhaled nitric oxide in guinea pigs. J Clin Invest 90: $421-428$

Duranski MR, Greer JJ, Dejam A, Jaganmohan S, Hogg N, Langston W, Patel RP, Yet SF, Wang X, Kevil CG, et al. (2005) Cytoprotective effects of nitrite during in vivo ischemia-reperfusion of the heart and liver. J Clin Invest 115:1232-1240.

Dykhuizen RS, Fraser A, McKenzie H, Golden M, Leifert C, and Benjamin N (1998) Helicobacter pylori is killed by nitrite under acidic conditions. Gut 42:334-337.

Dykhuizen RS, Frazer R, Duncan C, Smith CC, Golden M, Benjamin N, and Leifert C (1996) Antimicrobial effect of acidified nitrite on gut pathogens: importance of dietary nitrate in host defense. Antimicrob Agents Chemother 40:1422-1425.

Eckel RH, Grundy SM, and Zimmet PZ (2005) The metabolic syndrome. Lancet 365 : 1415-1428.

Edelmann F, Gelbrich G, Düngen HD, Fröhling S, Wachter R, Stahrenberg R, Binder L, Töpper A, Lashki DJ, Schwarz S, et al. (2011) Exercise training improves exercise capacity and diastolic function in patients with heart failure with preserved ejection fraction: results of the Ex-DHF (Exercise training in Diastolic Heart Failure) pilot study. J Am Coll Cardiol 58:1780-1791.

Eggebeen J, Kim-Shapiro DB, Haykowsky M, Morgan TM, Basu S, Brubaker P, Rejeski J, and Kitzman DW (2016) One week of daily dosing with beetroot juice improves submaximal endurance and blood pressure in older patients with heart failure and preserved ejection fraction. JACC Heart Fail 4:428-437.

Eich RF, Li T, Lemon DD, Doherty DH, Curry SR, Aitken JF, Mathews AJ, Johnson KA, Smith RD, Phillips GN Jr, et al. (1996) Mechanism of NO-induced oxidation of myoglobin and hemoglobin. Biochemistry 35:6976-6983.

Eisenbrand G, Spiegelhalder B, and Preussmann R (1980) Nitrate and nitrite in saliva. Oncology 37:227-231.

Elrod JW, Calvert JW, Gundewar S, Bryan NS, and Lefer DJ (2008) Nitric oxide promotes distant organ protection: evidence for an endocrine role of nitric oxide. Proc Natl Acad Sci USA 105:11430-11435.

Entman ML and Smith CW (1994) Postreperfusion inflammation: a model for reaction to injury in cardiovascular disease. Cardiovasc Res 28:1301-1311.

Erez A, Nagamani SC, Shchelochkov OA, Premkumar MH, Campeau PM, Chen Y, Garg HK, Li L, Mian A, Bertin TK, et al. (2011) Requirement of argininosuccinate lyase for systemic nitric oxide production. Nat Med 17:1619-1626.

Essawy SS, Abdel-Sater KA, and Elbaz AA (2014) Comparing the effects of inorganic nitrate and allopurinol in renovascular complications of metabolic syndrome in rats: role of nitric oxide and uric acid. Arch Med Sci 10:537-545.

European Centre for Ecotoxicology and Toxicology of Chemicals (1988) Technica report 27. Nitrate and Drinking Water, European Centre for Ecotoxicology and Toxicology of Chemicals, Brussels, Belgium.

European Food Safety Authority (2008) Opinion of the scientific panel on contaminants in the food chain on a request from the european commission to perform a scientific risk assessment on nitrate in vegetables. EFSA J 689:1-79.

Evangelista AM, Rao VS, Filo AR, Marozkina NV, Doctor A, Jones DR, Gaston B, and Guilford WH (2010) Direct regulation of striated muscle myosins by nitric oxide and endogenous nitrosothiols. PLoS One 5:e11209.

Faconti L, Mills CE, Govoni V, Gu H, Morant S, Jiang B, Cruickshank JK, and Webb AJ (2019) Cardiac effects of 6 months' dietary nitrate and spironolactone in patients with hypertension and with/at risk of type 2 diabetes, in the factorial design, double-blind, randomized controlled VaSera trial. $\mathrm{Br} J$ Clin Pharmacol 85 $169-180$.

Fang FC (1997) Perspectives series: host/pathogen interactions. Mechanisms of nitric oxide-related antimicrobial activity. J Clin Invest 99:2818-2825.

Fathi AR, Pluta RM, Bakhtian KD, Qi M, and Lonser RR (2011) Reversal of cerebral vasospasm via intravenous sodium nitrite after subarachnoid hemorrhage in primates. J Neurosurg 115:1213-1220. 
Feelisch M and Noack EA (1987) Correlation between nitric oxide formation during degradation of organic nitrates and activation of guanylate cyclase. Eur $J$ Pharmacol 139:19-30.

Ferguson SK, Hirai DM, Copp SW, Holdsworth CT, Allen JD, Jones AM, Musch TI, and Poole DC (2013a) Impact of dietary nitrate supplementation via beetroot juice on exercising muscle vascular control in rats. $J$ Physiol 591:547-557.

Ferguson SK, Hirai DM, Copp SW, Holdsworth CT, Allen JD, Jones AM, Musch TI and Poole DC (2013b) Effects of nitrate supplementation via beetroot juice on contracting rat skeletal muscle microvascular oxygen pressure dynamics. Respir Physiol Neurobiol 187:250-255.

Ferguson SK, Holdsworth CT, Colburn TD, Wright JL, Craig JC, Fees A, Jones AM Allen JD, Musch TI, and Poole DC (2016) Dietary nitrate supplementation: impact on skeletal muscle vascular control in exercising rats with chronic heart failure. J Appl Physiol (1985) 121:661-669.

Ferguson SK, Holdsworth CT, Wright JL, Fees AJ, Allen JD, Jones AM, Musch TI, and Poole DC (2015) Microvascular oxygen pressures in muscles comprised of different fiber types: impact of dietary nitrate supplementation. Nitric Oxide 48 $38-43$.

Fernandez ML, Ruiz R, Gonzalez MA, Ramirez-Lorca R, Couto C, Ramos A Gutierrez-Tous R, Rivera JM, Ruiz A, Real LM, et al. (2004) Association of NOS3 gene with metabolic syndrome in hypertensive patients. Thromb Haemost 92:413-418.

Fernström M, Tonkonogi M, and Sahlin K (2004) Effects of acute and chronic en durance exercise on mitochondrial uncoupling in human skeletal muscle. J Physiol 554:755-763.

Fewtrell L (2004) Drinking-water nitrate, methemoglobinemia, and global burden of disease: a discussion. Environ Health Perspect 112:1371-1374.

Finan A, Keenan P, Donovan FO, Mayne P, and Murphy J (1998) Methaemoglobinaemia associated with sodium nitrite in three siblings. BMJ 317:1138-1139.

Fine DH, Ross R, Rounbehler DP, Silvergleid A, and Song L (1977) Formation in vivo of volatile $\mathrm{N}$-nitrosamines in man after ingestion of cooked bacon and spinach Nature 265:753-755.

Fisher PW, Salloum F, Das A, Hyder H, and Kukreja RC (2005) Phosphodiesterase-5 inhibition with sildenafil attenuates cardiomyocyte apoptosis and left ventricular dysfunction in a chronic model of doxorubicin cardiotoxicity. Circulation 111: $1601-1610$

Fleenor BS, Sindler AL, Eng JS, Nair DP, Dodson RB, and Seals DR (2012) Sodium nitrite de-stiffening of large elastic arteries with aging: role of normalization of advanced glycation end-products. Exp Gerontol 47:588-594.

Flitney FW, Pritchard RJ, Kennovin GD, Bisland SK, Hirst DG, and Fricker SP (2011) Antitumor actions of ruthenium(III)-based nitric oxide scavengers and nitric oxide synthase inhibitors. Mol Cancer Ther 10:1571-1580.

Flueck JL, Bogdanova A, Mettler S, and Perret C (2016) Is beetroot juice more effective than sodium nitrate? The effects of equimolar nitrate dosages of nitrate-rich beetroot juice and sodium nitrate on oxygen consumption during exercise. Appl Physiol Nutr Metab 41:421-429.

Fontaine E, Eriksson O, Ichas F, and Bernardi P (1998) Regulation of the permeability transition pore in skeletal muscle mitochondria. Modulation by electron flow through the respiratory chain complex i. J Biol Chem 273:12662-12668.

Fordel E, Geuens E, Dewilde S, Rottiers P, Carmeliet P, Grooten J, and Moens L (2004) Cytoglobin expression is upregulated in all tissues upon hypoxia: an in vitro and in vivo study by quantitative real-time PCR. Biochem Biophys Res Commun 319:342-348.

Forslund K, Hildebrand F, Nielsen T, Falony G, Le Chatelier E, Sunagawa S, Prifti E, Vieira-Silva S, Gudmundsdottir V, Pedersen HK, et al.; MetaHIT consortium (2015) Disentangling type 2 diabetes and metformin treatment signatures in the human gut microbiota. Nature 528:262-266.

Förstermann U and Sessa WC (2012) Nitric oxide synthases: regulation and function. Eur Heart $J$ 33:829-837, 837a-837d.

Frankenreiter S, Bednarczyk P, Kniess A, Bork NI, Straubinger J, Koprowski P, Wrzosek A, Mohr E, Logan A, Murphy MP, et al. (2017) cGMP-elevating compounds and ischemic conditioning provide cardioprotection against ischemia and reperfusion injury via cardiomyocyte-specific BK channels. Circulation 136 $2337-2355$.

Freedman JE, Loscalzo J, Barnard MR, Alpert C, Keaney JF, and Michelson AD (1997) Nitric oxide released from activated platelets inhibits platelet recruitment. $J$ Clin Invest 100:350-356.

Freedman JE, Sauter R, Battinelli EM, Ault K, Knowles C, Huang PL, and Loscalzo J (1999) Deficient platelet-derived nitric oxide and enhanced hemostasis in mice lacking the NOSIII gene. Circ Res 84:1416-1421.

Freedman JE, Ting B, Hankin B, Loscalzo J, Keaney JF Jr, and Vita JA (1998) Impaired platelet production of nitric oxide predicts presence of acute coronary syndromes. Circulation 98:1481-1486.

Frick A (1924) Medical treatment of peptic ulcer without alkalis. JAMA 82:595-599.

Friis AL, Steenholt CB, Løkke A, and Hansen M (2017) Dietary beetroot juice - effects on physical performance in COPD patients: a randomized controlled crossover trial. Int J Chron Obstruct Pulmon Dis 12:1765-1773.

Frostell C, Fratacci MD, Wain JC, Jones R, and Zapol WM (1991) Inhaled nitric oxide. A selective pulmonary vasodilator reversing hypoxic pulmonary vasoconstriction. Circulation 83:2038-2047.

Fukuto JM, Cho JY, and Switzer CH (2000) The Chemical Properties of Nitric Oxide and Related Nitrogen Oxides, in Nitric Oxide: Biology and Pathobiology (Ignarro L ed) pp 23-40, Academic Press, London.

Furchgott RF and Bhadrakom S (1953) Reactions of strips of rabbit aorta to epinephrine, isopropylarterenol, sodium nitrite and other drugs. J Pharmacol Exp Ther 108:129-143.

Galiè N, Brundage BH, Ghofrani HA, Oudiz RJ, Simonneau G, Safdar Z, Shapiro S, White RJ, Chan M, Beardsworth A, et al.; Pulmonary Arterial Hypertension and Response to Tadalafil (PHIRST) Study Group (2009) Tadalafil therapy for pulmonary arterial hypertension [published correction appears in Circulation (2011) 124:e279]. Circulation 119:2894-2903.
Galiè N, Ghofrani HA, Torbicki A, Barst RJ, Rubin LJ, Badesch D, Fleming T, Parpia T, Burgess G, Branzi A, et al.; Sildenafil Use in Pulmonary Arterial Hypertension (SUPER) Study Group (2005) Sildenafil citrate therapy for pulmonary arterial hypertension. N Engl J Med 353:2148-2157.

Gambaryan S, Kobsar A, Hartmann S, Birschmann I, Kuhlencordt PJ, Müller-Ester W, Lohmann SM, and Walter U (2008) NO-synthase-/NO-independent regulation of human and murine platelet soluble guanylyl cyclase activity. J Thromb Haemost 6:1376-1384

Gambaryan S and Tsikas D (2015) A review and discussion of platelet nitric oxide and nitric oxide synthase: do blood platelets produce nitric oxide from L-arginine or nitrite? Amino Acids 47:1779-1793.

Gamgee A (1868) Researches on the blood - on the action of nitrites on blood. Philos Trans $R$ Soc Lond 158:589-625.

Gan Y, Tong X, Li L, Cao S, Yin X, Gao C, Herath C, Li W, Jin Z, Chen Y, et al. (2015) Consumption of fruit and vegetable and risk of coronary heart disease: a metaanalysis of prospective cohort studies. Int $J$ Cardiol 183:129-137.

Gao X, Yang T, Liu M, Peleli M, Zollbrecht C, Weitzberg E, Lundberg JO, Persson $\mathrm{AE}$, and Carlström M (2015) NADPH oxidase in the renal microvasculature is a primary target for blood pressure-lowering effects by inorganic nitrate and nitrite. Hypertension 65:161-170.

Garry PS, Rowland MJ, Ezra M, Herigstad M, Hayen A, Sleigh JW, Westbrook J, Warnaby CE, and Pattinson KT (2016) Electroencephalographic response to sodium nitrite may predict delayed cerebral ischemia after severe subarachnoid hemorrhage. Crit Care Med 44:e1067-e1073.

Gauthier TW, Davenpeck KL, and Lefer AM (1994) Nitric oxide attenuates leukocyteendothelial interaction via P-selectin in splanchnic ischemia-reperfusion. Am J Physiol 267:G562-G568.

Gautier C, van Faassen E, Mikula I, Martasek P, and Slama-Schwok A (2006) Endothelial nitric oxide synthase reduces nitrite anions to NO under anoxia. Biochem Biophys Res Commun 341:816-821.

Gawaz M (2004) Role of platelets in coronary thrombosis and reperfusion of ischemic myocardium. Cardiovasc Res 61:498-511.

Gheibi S, Bakhtiarzadeh F, Jeddi S, Farrokhfall K, Zardooz H, and Ghasemi A (2017) Nitrite increases glucose-stimulated insulin secretion and islet insulin content in obese type 2 diabetic male rats. Nitric Oxide 64:39-51.

Ghofrani HA, Galiè N, Grimminger F, Grünig E, Humbert M, Jing ZC, Keogh AM, Langleben D, Kilama MO, Fritsch A, et al.; PATENT-1 Study Group (2013) Riociguat for the treatment of pulmonary arterial hypertension. $N$ Engl J Med 369: $330-340$

Ghosh SM, Kapil V, Fuentes-Calvo I, Bubb KJ, Pearl V, Milsom AB, Khambata R, Maleki-Toyserkani S, Yousuf M, Benjamin N, et al. (2013) Enhanced vasodilator activity of nitrite in hypertension: critical role for erythrocytic xanthine oxidoreductase and translational potential. Hypertension 61:1091-1102.

Gilchrist M, Winyard PG, Aizawa K, Anning C, Shore A, and Benjamin N (2013) Effect of dietary nitrate on blood pressure, endothelial function, and insulin sensitivity in type 2 diabetes. Free Radic Biol Med 60:89-97.

Gilchrist M, Winyard PG, Fulford J, Anning C, Shore AC, and Benjamin N (2014) Dietary nitrate supplementation improves reaction time in type 2 diabetes: development and application of a novel nitrate-depleted beetroot juice placebo. Nitric Oxide 40:67-74.

Gkaliagkousi E, Douma S, Zamboulis C, and Ferro A (2009) Nitric oxide dysfunction in vascular endothelium and platelets: role in essential hypertension. J Hypertens 27:2310-2320

Gladwin MT, Schechter AN, Kim-Shapiro DB, Patel RP, Hogg N, Shiva S, Cannon RO III, Kelm M, Wink DA, Espey MG, et al. (2005) The emerging biology of the nitrite anion. Nat Chem Biol 1:308-314.

Gladwin MT, Shelhamer JH, Schechter AN, Pease-Fye ME, Waclawiw MA, Panza JA, Ognibene FP, and Cannon RO III (2000) Role of circulating nitrite and S-nitrosohemoglobin in the regulation of regional blood flow in humans. Proc Nat Acad Sci USA 97:11482-11487.

Goaz PW and Biswell HA (1961) Nitrate reduction in whole saliva. J Dent Res 40 355-365.

Godfrey M and Majid DS (1998) Renal handling of circulating nitrates in anesthetized dogs. Am J Physiol 275:F68-F73.

Gonzalez A, Hyde E, Sangwan N, Gilbert JA, Viirre E, and Knight R (2016) Migraines are correlated with higher levels of nitrate-, nitrite-, and nitric oxide-reducing oral microbes in the american gut project cohort. mSystems $\mathbf{1}$ e00105-e00116

Gonzalez FM, Shiva S, Vincent PS, Ringwood LA, Hsu LY, Hon YY, Aletras AH, Cannon RO III, Gladwin MT, and Arai AE (2008) Nitrite anion provides potent cytoprotective and antiapoptotic effects as adjunctive therapy to reperfusion for acute myocardial infarction. Circulation 117:2986-2994.

Gosker HR, Wouters EF, van der Vusse GJ, and Schols AM (2000) Skeletal muscle dysfunction in chronic obstructive pulmonary disease and chronic heart failure: underlying mechanisms and therapy perspectives. Am J Clin Nutr 71:1033-1047.

Govoni M, Jansson EA, Weitzberg E, and Lundberg JO (2008) The increase in plasma nitrite after a dietary nitrate load is markedly attenuated by an antibacterial mouthwash. Nitric Oxide 19:333-337.

Grau M, Hendgen-Cotta UB, Brouzos P, Drexhage C, Rassaf T, Lauer T, Dejam A Kelm M, and Kleinbongard P (2007) Recent methodological advances in the analysis of nitrite in the human circulation: nitrite as a biochemical parameter of the L-arginine/NO pathway. J Chromatogr B Analyt Technol Biomed Life Sci 851: $106-123$.

Green DJ, Maiorana A, O'Driscoll G, and Taylor R (2004) Effect of exercise training on endothelium-derived nitric oxide function in humans. J Physiol 561:1-25.

Green LC, Ruiz de Luzuriaga K, Wagner DA, Rand W, Istfan N, Young VR, and Tannenbaum SR (1981) Nitrate biosynthesis in man. Proc Natl Acad Sci USA 78:7764-7768 
Greenway FL, Predmore BL, Flanagan DR, Giordano T, Qiu Y, Brandon A, Lefer DJ, Patel RP, and Kevil CG (2012) Single-dose pharmacokinetics of different oral sodium nitrite formulations in diabetes patients. Diabetes Technol Ther 14:552-560. Greer FR and Shannon M; American Academy of Pediatrics Committee on Nutrition; American Academy of Pediatrics Committee on Environmental Health (2005) Infant methemoglobinemia: the role of dietary nitrate in food and water. Pediatrics 116:784-786.

Grubina R, Huang Z, Shiva S, Joshi MS, Azarov I, Basu S, Ringwood LA, Jiang A, Hogg N, Kim-Shapiro DB, et al. (2007) Concerted nitric oxide formation and release from the simultaneous reactions of nitrite with deoxy- and oxyhemoglobin. J Biol Chem 282:12916-12927.

Gruetter CA, Childers CE, Bosserman MK, Lemke SM, Ball JG, and Valentovic MA (1989) Comparison of relaxation induced by glyceryl trinitrate, isosorbide dinitrate, and sodium nitroprusside in bovine airways. Am Rev Respir Dis 139:1192-1197.

Gruetter CA, Kadowitz PJ, and Ignarro LJ (1981) Methylene blue inhibits coronary arterial relaxation and guanylate cyclase activation by nitroglycerin, sodium nitrite, and amyl nitrite. Can J Physiol Pharmacol 59:150-156.

Guimarães DD, Cruz JC, Carvalho-Galvão A, Zhuge Z, Marques SM, Naves LM, Persson AEG, Weitzberg E, Lundberg JO, Balarini CM, et al. (2019) Dietary nitrate reduces blood pressure in rats with angiotensin ii-induced hypertension via mechanisms that involve reduction of sympathetic hyperactivity. Hypertension $\mathbf{7 3}$ 839-848.

Gupta SK, Gupta RC, Seth AK, Gupta AB, Bassin JK, and Gupta A (1999) Adaptation of cytochrome-b5 reductase activity and methaemoglobinaemia in areas with a high nitrate concentration in drinking-water. Bull World Health Organ 77: $749-753$.

Haas M, Classen HG, Thöni H, Classen UG, and Drescher B (1999) Persistent antihypertensive effect of oral nitrite supplied up to one year via the drinking water in spontaneously hypertensive rats. Arzneimittelforschung 49:318-323.

Haider G and Folland JP (2014) Nitrate supplementation enhances the contractile properties of human skeletal muscle. Med Sci Sports Exerc 46:2234-2243.

Hajishengallis G, Darveau RP, and Curtis MA (2012) The keystone-pathogen hypothesis. Nat Rev Microbiol 10:717-725.

Hamdani N, Franssen C, Lourenço A, Falcão-Pires I, Fontoura D, Leite S, Plettig L López B, Ottenheijm CA, Becher PM, et al. (2013) Myocardial titin hypophosphorylation importantly contributes to heart failure with preserved ejection fraction in a rat metabolic risk model. Circ Heart Fail 6:1239-1249.

Hampton JR, Harrison MJ, Honour AJ, and Mitchell JR (1967) Platelet behaviour and drugs used in cardiovascular disease. Cardiovasc Res 1:101-107.

Han TH, Hyduke DR, Vaughn MW, Fukuto JM, and Liao JC (2002) Nitric oxide reaction with red blood cells and hemoglobin under heterogeneous conditions. Proc Natl Acad Sci USA 99:7763-7768.

Hanff E, Böhmer A, Zinke M, Gambaryan S, Schwarz A, Supuran CT, and Tsikas D (2016) Carbonic anhydrases are producers of S-nitrosothiols from inorganic nitrite and modulators of soluble guanylyl cyclase in human platelets. Amino Acids 48 $1695-1706$.

Hanukoglu A and Danon PN (1996) Endogenous methemoglobinemia associated with diarrheal disease in infancy. $J$ Pediatr Gastroenterol Nutr 23:1-7.

Harada M, Ishiwata H, Nakamura Y, Tanimura A, and Ishidate M (1974) Studies on in vivo formation of nitroso compounds. Food Hyg Safe Sci 15:206-207.

Havemeyer A, Bittner F, Wollers S, Mendel R, Kunze T, and Clement B (2006) Identification of the missing component in the mitochondrial benzamidoxime prodrug-converting system as a novel molybdenum enzyme. J Biol Chem 281: 34796-34802.

Hawksworth GM and Hill MJ (1971) Bacteria and the N-nitrosation of secondary amines. Br J Cancer 25:520-526.

Haykowsky MJ, Brubaker PH, Stewart KP, Morgan TM, Eggebeen J, and Kitzman DW (2012) Effect of endurance training on the determinants of peak exercise oxygen consumption in elderly patients with stable compensated heart failure and preserved ejection fraction. J Am Coll Cardiol 60:120-128.

Heiss C, Meyer C, Totzeck M, Hendgen-Cotta UB, Heinen Y, Luedike P, Keymel S, Ayoub N, Lundberg JO, Weitzberg E, et al. (2012) Dietary inorganic nitrate mobilizes circulating angiogenic cells. Free Radic Biol Med 52:1767-1772.

Hendgen-Cotta UB, Luedike P, Totzeck M, Kropp M, Schicho A, Stock P, Rammos C, Niessen M, Heiss C, Lundberg JO, et al. (2012) Dietary nitrate supplementation improves revascularization in chronic ischemia. Circulation 126:1983-1992.

Hendgen-Cotta UB, Merx MW, Shiva S, Schmitz J, Becher S, Klare JP, Steinhoff HJ, Goedecke A, Schrader J, Gladwin MT, et al. (2008) Nitrite reductase activity of myoglobin regulates respiration and cellular viability in myocardial ischemiareperfusion injury. Proc Natl Acad Sci USA 105:10256-10261.

Hennekam RC (2006) Hutchinson-Gilford progeria syndrome: review of the phenotype. Am J Med Genet A 140:2603-2624.

Henneman E, Somjen G, and Carpenter DO (1965) Excitability and inhibitability of motoneurons of different sizes. J Neurophysiol 28:599-620.

Henrohn D, Björkstrand K, Lundberg JO, Granstam SO, Baron T, Ingimarsdóttir IJ, Hedenström H, Malinovschi A, Wernroth ML, Jansson M, et al. (2018) Effects of oral supplementation with nitrate-rich beetroot juice in patients with pulmonary arterial hypertension-results from beet-pah, an exploratory randomized, doubleblind, placebo-controlled, crossover study. J Card Fail 24:640-653.

Hermann L (1865) Ueber die wirkungen des stickoxydulgases auf das blut. Arch Anat Physiol Lpz 469-481.

Hernández A, Schiffer TA, Ivarsson N, Cheng AJ, Bruton JD, Lundberg JO, Weitzberg E, and Westerblad H (2012) Dietary nitrate increases tetanic $[\mathrm{Ca} 2+] \mathrm{i}$ and contractile force in mouse fast-twitch muscle. J Physiol 590:3575-3583.

Herold S, Exner M, and Nauser T (2001) Kinetic and mechanistic studies of the NO* mediated oxidation of oxymyoglobin and oxyhemoglobin. Biochemistry 40 $3385-3395$

Herskowitz A, Choi S, Ansari AA, and Wesselingh S (1995) Cytokine mRNA expression in postischemic/reperfused myocardium. Am J Pathol 146:419-428.
Heusch G, Boengler K, and Schulz R (2008) Cardioprotection: nitric oxide, protein kinases, and mitochondria. Circulation 118:1915-1919.

Hezel MP, Liu M, Schiffer TA, Larsen FJ, Checa A, Wheelock CE, Carlström M Lundberg JO, and Weitzberg E (2015) Effects of long-term dietary nitrate supplementation in mice. Redox Biol 5:234-242.

Hirai DM, Zelt JT, Jones JH, Castanhas LG, Bentley RF, Earle W, Staples P, Tschakovsky ME, McCans J, O'Donnell DE, et al. (2017) Dietary nitrate supplementation and exercise tolerance in patients with heart failure with reduced ejection fraction. Am J Physiol Regul Integr Comp Physiol 312:R13-R22.

Högman M, Frostell CG, Hedenström H, and Hedenstierna G (1993) Inhalation of nitric oxide modulates adult human bronchial tone. Am Rev Respir Dis 148: 1474-1478.

Hobbs AJ and Stasch J-P (2010) Soluble guanylate cyclase: allosteric activation and redox regulation. In Nitric Oxide: Biology and Pathobiology, (Ed, Ignarro L) Academic Press, pp. 301-326.

Honavar J, Doran S, Oh J-Y, Steele C, Matalon S, and Patel RP (2014) Nitrite therapy improves survival postexposure to chlorine gas. Am J Physiol Lung Cell Mol Physiol 307:L888-L894.

Honavar J, Doran S, Ricart K, Matalon S, and Patel RP (2017) Nitrite therapy prevents chlorine gas toxicity in rabbits. Toxicol Lett 271:20-25.

Honikel KO (2008) The use and control of nitrate and nitrite for the processing of meat products. Meat Sci 78:68-76.

Hoon MW, Johnson NA, Chapman PG, and Burke LM (2013) The effect of nitrate supplementation on exercise performance in healthy individuals: a systematic review and meta-analysis. Int $J$ Sport Nutr Exerc Metab 23:522-532.

Hoon MW, Jones AM, Johnson NA, Blackwell JR, Broad EM, Lundy B, Rice AJ, and Burke LM (2014) The effect of variable doses of inorganic nitrate-rich beetroot juice on simulated 2,000-m rowing performance in trained athletes. Int $J$ Sports Physiol Perform 9:615-620.

Hopmann KH, Cardey B, Gladwin MT, Kim-Shapiro DB, and Ghosh A (2011) Hemoglobin as a nitrite anhydrase: modeling methemoglobin-mediated $\mathrm{N}_{2} \mathrm{O}_{3}$ formation. Chemistry 17:6348-6358.

Hord NG, Tang Y, and Bryan NS (2009) Food sources of nitrates and nitrites: the physiologic context for potential health benefits. Am J Clin Nutr 90:1-10.

Horn M and Schlote W (1992) Delayed neuronal death and delayed neuronal recovery in the human brain following global ischemia. Acta Neuropathol 85:79-87.

Houston M, Estevez A, Chumley P, Aslan M, Marklund S, Parks DA, and Freeman BA (1999) Binding of xanthine oxidase to vascular endothelium. Kinetic characterization and oxidative impairment of nitric oxide-dependent signaling. $J$ Biol Chem 274:4985-4994.

Hruby A and Hu FB (2015) The epidemiology of obesity: a big picture. Pharmacoeconomics 33:673-689.

Hu D, Huang J, Wang Y, Zhang D, and Qu Y (2014) Fruits and vegetables consumption and risk of stroke: a meta-analysis of prospective cohort studies. Stroke 45:1613-1619.

Hu W, Jin R, Zhang J, You T, Peng Z, Ge X, Bronson RT, Halperin JA, Loscalzo J, and Qin X (2010) The critical roles of platelet activation and reduced NO bioavailability in fatal pulmonary arterial hypertension in a murine hemolysis model. Blood 116:1613-1622.

Huang KT, Keszler A, Patel N, Patel RP, Gladwin MT, Kim-Shapiro DB, and Hogg N (2005a) The reaction between nitrite and deoxyhemoglobin. Reassessment of reaction kinetics and stoichiometry. J Biol Chem 280:31126-31131.

Huang L, Borniquel S, and Lundberg JO (2010) Enhanced xanthine oxidoreductase expression and tissue nitrate reduction in germ free mice. Nitric Oxide 22:191-195.

Huang Z, Shiva S, Kim-Shapiro DB, Patel RP, Ringwood LA, Irby CE, Huang KT, Ho C, Hogg N, Schechter AN, et al. (2005b) Enzymatic function of hemoglobin as a nitrite reductase that produces NO under allosteric control. $J$ Clin Invest 115: 2099-2107.

Hughes MN (2008) Chemistry of nitric oxide and related species. Methods Enzymol 436:3-19.

Hunault CC, van Velzen AG, Sips AJ, Schothorst RC, and Meulenbelt J (2009) Bioavailability of sodium nitrite from an aqueous solution in healthy adults. Toxicol Lett 190:48-53.

Hung HC, Joshipura KJ, Jiang R, Hu FB, Hunter D, Smith-Warner SA, Colditz GA, Rosner B, Spiegelman D, and Willett WC (2004) Fruit and vegetable intake and risk of major chronic disease. J Natl Cancer Inst 96:1577-1584.

Hunter CJ, Dejam A, Blood AB, Shields H, Kim-Shapiro DB, Machado RF, Tarekegn S, Mulla N, Hopper AO, Schechter AN, et al. (2004) Inhaled nebulized nitrite is a hypoxia-sensitive NO-dependent selective pulmonary vasodilator. Nat Med 10 $1122-1127$

Hustad GO, Cerveny JG, Trenk H, Deibel RH, Kautter DA, Fazio T, Johnston RW, and Kolari OE (1973) Effect of sodium nitrite and sodium nitrate on botulinal toxin production and nitrosamine formation in wieners. Appl Microbiol 26:22-26.

Hyde ER, Luk B, Cron S, Kusic L, McCue T, Bauch T, Kaplan H, Tribble G, Petrosino JF, and Bryan NS (2014) Characterization of the rat oral microbiome and the effects of dietary nitrate. Free Radic Biol Med 77:249-257.

Ignarro LJ, Fukuto JM, Griscavage JM, Rogers NE, and Byrns RE (1993) Oxidation of nitric oxide in aqueous solution to nitrite but not nitrate: comparison with enzymatically formed nitric oxide from L-arginine. Proc Natl Acad Sci USA 90 8103-8107.

Ignarro LJ and Gruetter CA (1980) Requirement of thiols for activation of coronary arterial guanylate cyclase by glyceryl trinitrate and sodium nitrite: possible involvement of S-nitrosothiols. Biochim Biophys Acta 631:221-231.

Iijima K, Grant J, McElroy K, Fyfe V, Preston T, and McColl KE (2003) Novel mechanism of nitrosative stress from dietary nitrate with relevance to gastrooesophageal junction cancers. Carcinogenesis 24:1951-1960.

Ingram TE, Fraser AG, Bleasdale RA, Ellins EA, Margulescu AD, Halcox JP and James PE (2013) Low-dose sodium nitrite attenuates myocardial ischemia and vascular ischemia-reperfusion injury in human models. $J$ Am Coll Cardiol 61: $2534-2541$ 
Ingram TE, Pinder AG, Bailey DM, Fraser AG, and James PE (2010) Low-dose sodium nitrite vasodilates hypoxic human pulmonary vasculature by a means that is not dependent on a simultaneous elevation in plasma nitrite. Am J Physiol Heart Circ Physiol 298:H331-H339.

Innocenti A, Zimmerman S, Ferry JG, Scozzafava A, and Supuran CT (2004) Carbonic anhydrase inhibitors. Inhibition of the zinc and cobalt $\gamma$-class enzyme from the archaeon Methanosarcina thermophila with anions. Bioorg Med Chem Lett 14: $3327-3331$

International Agency for Research on Cancer (2010) Ingested Nitrate and Nitrite, and Cyanobacterial Peptide Toxins, International Agency for Research on Cancer, Lyon, France.

Ip MS, Lam B, Chan LY, Zheng L, Tsang KW, Fung PC, and Lam WK (2000) Circulating nitric oxide is suppressed in obstructive sleep apnea and is reversed by nasal continuous positive airway pressure. Am J Respir Crit Care Med 162: 2166-2171.

Irie T, Sips PY, Kai S, Kida K, Ikeda K, Hirai S, Moazzami K, Jiramongkolchai P, Bloch DB, Doulias PT, et al. (2015) S-nitrosylation of calcium-handling proteins in cardiac adrenergic signaling and hypertrophy. Circ Res 117:793-803.

Ishii T, Sunami O, Saitoh N, Nishio H, Takeuchi T, and Hata F (1998) Inhibition of skeletal muscle sarcoplasmic reticulum $\mathrm{Ca} 2+$-ATPase by nitric oxide. FEBS Lett 440:218-222.

Ishiwata $\mathrm{H}$ (1976a) Studies on in vivo formation of nitroso compounds (vii). Food Hyg Safe Sci 17:369-373.

Ishiwata H (1976b) Studies on in vivo formation of nitroso compounds (viii). Food Hyg Safe Sci 17:423-427.

Ishiwata H, Boriboon P, Harada M, Tanimura A, and Ishidate M (1975a) Studies on in vivo formation of nitroso compounds (iv). Food Hyg Safe Sci 16:93-98.

Ishiwata $\mathrm{H}$, Boriboon P, Nakamura Y, Harada M, Tanimura A, and Ishidate M (1975b) Studies on in vivo formation of nitroso compounds (ii). Food Hyg Safe Sci 16:19-24.

Ishiwata H, Tanimura A, and Ishidate M (1975c) Studies on in vivo formation of nitroso compounds (v). Food Hyg Safe Sci 16:234-239.

Ishiwata H, Tanimura A, and Ishidate M (1975d) Studies on in vivo formation of nitroso compounds (iii). Food Hyg Safe Sci 16:89-92.

Jackson JK, Patterson AJ, MacDonald-Wicks LK, Oldmeadow C, and McEvoy MA (2018) The role of inorganic nitrate and nitrite in cardiovascular disease risk factors: a systematic review and meta-analysis of human evidence. Nutr Rev $\mathbf{7 6}$ 348-371.

Jädert C, Petersson J, Massena S, Ahl D, Grapensparr L, Holm L, Lundberg JO, and Phillipson M (2012) Decreased leukocyte recruitment by inorganic nitrate and nitrite in microvascular inflammation and NSAID-induced intestinal injury. Free Radic Biol Med 52:683-692.

Jädert C, Phillipson M, Holm L, Lundberg JO, and Borniquel S (2013) Preventive and therapeutic effects of nitrite supplementation in experimental inflammatory bowel disease. Redox Biol 2:73-81.

Jajja A, Sutyarjoko A, Lara J, Rennie K, Brandt K, Qadir O, and Siervo M (2014) Beetroot supplementation lowers daily systolic blood pressure in older, overweight subjects. Nutr Res 34:868-875.

James PE, Lang D, Tufnell-Barret T, Milsom AB, and Frenneaux MP (2004) Vasorelaxation by red blood cells and impairment in diabetes: reduced nitric oxide and oxygen delivery by glycated hemoglobin. Circ Res 94:976-983.

Janssens S, Pokreisz P, Schoonjans L, Pellens M, Vermeersch P, Tjwa M, Jans P, Scherrer-Crosbie M, Picard MH, Szelid Z, et al. (2004) Cardiomyocyte-specific overexpression of nitric oxide synthase 3 improves left ventricular performance and reduces compensatory hypertrophy after myocardial infarction. Circ Res $\mathbf{9 4}$ $1256-1262$.

Jansson EA, Huang L, Malkey R, Govoni M, Nihlén C, Olsson A, Stensdotter M, Petersson J, Holm L, Weitzberg E, et al. (2008) A mammalian functional nitrate reductase that regulates nitrite and nitric oxide homeostasis. Nat Chem Biol 4 411-417.

Jansson EA, Petersson J, Reinders C, Sobko T, Björne H, Phillipson M, Weitzberg E, Holm L, and Lundberg JO (2007) Protection from nonsteroidal anti-inflammatory drug (NSAID)-induced gastric ulcers by dietary nitrate. Free Radic Biol Med 42: $510-518$.

Jarasch ED, Bruder G, and Heid HW (1986) Significance of xanthine oxidase in capillary endothelial cells. Acta Physiol Scand Suppl 548:39-46.

Jarasch ED, Grund C, Bruder G, Heid HW, Keenan TW, and Franke WW (1981) Localization of xanthine oxidase in mammary-gland epithelium and capillary endothelium. Cell 25:67-82.

Jayaraman T, Tejero J, Chen BB, Blood AB, Frizzell S, Shapiro C, Tiso M, Hood BL, Wang X, Zhao X, et al. (2011) 14-3-3 binding and phosphorylation of neuroglobin during hypoxia modulate six-to-five heme pocket coordination and rate of nitrite reduction to nitric oxide. $J$ Biol Chem 286:42679-42689.

Jensen FB (2005) Nitrite transport into pig erythrocytes and its potential biological role. Acta Physiol Scand 184:243-251.

Jensen FB and Rohde S (2010) Comparative analysis of nitrite uptake and hemoglobinnitrite reactions in erythrocytes: sorting out uptake mechanisms and oxygenation dependencies. Am J Physiol Regul Integr Comp Physiol 298:R972-R982

Jiang H, Torregrossa AC, Potts A, Pierini D, Aranke M, Garg HK, and Bryan NS (2014) Dietary nitrite improves insulin signaling through GLUT4 translocation. Free Radic Biol Med 67:51-57.

Jockel-Schneider Y, Goßner SK, Petersen N, Stölzel P, Hägele F, Schweiggert RM, Haubitz I, Eigenthaler M, Carle R, and Schlagenhauf U (2016) Stimulation of the nitrate-nitrite-NO-metabolism by repeated lettuce juice consumption decreases gingival inflammation in periodontal recall patients: a randomized, double-blinded, placebo-controlled clinical trial. J Clin Periodontol 43:603-608.

Jones AM, Grassi B, Christensen PM, Krustrup P, Bangsbo J, and Poole DC (2011) Slow component of VO2 kinetics: mechanistic bases and practical applications. Med Sci Sports Exerc 43:2046-2062.
Jones DA, Khambata RS, Andiapen M, Rathod KS, Mathur A, and Ahluwalia A (2017) Intracoronary nitrite suppresses the inflammatory response following primary percutaneous coronary intervention. Heart 103:508-516.

Jones DA, Pellaton C, Velmurugan S, Rathod KS, Andiapen M, Antoniou S, van Eijl S, Webb AJ, Westwood MA, Parmar MK, et al. (2015a) Randomized phase 2 trial of intracoronary nitrite during acute myocardial infarction. Circ Res 116:437-447.

Jones JA, Hopper AO, Power GG, and Blood AB (2015b) Dietary intake and bioactivation of nitrite and nitrate in newborn infants. Pediatr Res 77:173-181.

Jones SP, Tang XL, Guo Y, Steenbergen C, Lefer DJ, Kukreja RC, Kong M, Li Q, Bhushan S, Zhu X, et al. (2015c) The NHLBI-sponsored Consortium for preclinicA assESsment of cARdioprotective therapies (CAESAR): a new paradigm for rigorous, accurate, and reproducible evaluation of putative infarct-sparing interventions in mice, rabbits, and pigs. Circ Res 116:572-586.

Jones T, Dunn EL, Macdonald JH, Kubis HP, McMahon N, and Sandoo A (2019) The effects of beetroot juice on blood pressure, microvascular function and large-vessel endothelial function: a randomized, double-blind, placebo-controlled pilot study in healthy older adults. Nutrients 11:E1792.

Jonvik KL, Nyakayiru J, Pinckaers PJ, Senden JM, van Loon LJ, and Verdijk LB (2016) Nitrate-rich vegetables increase plasma nitrate and nitrite concentrations and lower blood pressure in healthy adults. J Nutr 146:986-993.

Joris PJ and Mensink RP (2013) Beetroot juice improves in overweight and slightly obese men postprandial endothelial function after consumption of a mixed meal. Atherosclerosis 231:78-83.

Joshipura KJ, Ascherio A, Manson JE, Stampfer MJ, Rimm EB, Speizer FE, Hennekens $\mathrm{CH}$, Spiegelman D, and Willett WC (1999) Fruit and vegetable intake in relation to risk of ischemic stroke. JAMA 282:1233-1239.

Joshipura KJ, Hu FB, Manson JE, Stampfer MJ, Rimm EB, Speizer FE, Colditz G, Ascherio A, Rosner B, Spiegelman D, et al. (2001) The effect of fruit and vegetable intake on risk for coronary heart disease. Ann Intern Med 134:1106-1114.

Joshipura KJ, Muñoz-Torres FJ, Morou-Bermudez E, and Patel RP (2017) Overthe-counter mouthwash use and risk of pre-diabetes/diabetes. Nitric Oxide 71:14-20.

Jourd'heuil D, Jourd'heuil FL, Kutchukian PS, Musah RA, Wink DA, and Grisham MB (2001) Reaction of superoxide and nitric oxide with peroxynitrite. Implications for peroxynitrite-mediated oxidation reactions in vivo. $J$ Biol Chem 276 28799-28805.

Jovanovski E, Bosco L, Khan K, Au-Yeung F, Ho H, Zurbau A, Jenkins AL, and Vuksan V (2015) Effect of spinach, a high dietary nitrate source, on arterial stiffness and related hemodynamic measures: a randomized, controlled trial in healthy adults. Clin Nutr Res 4:160-167.

Jung KH, Chu K, Ko SY, Lee ST, Sinn DI, Park DK, Kim JM, Song EC, Kim M, and Roh JK (2006) Early intravenous infusion of sodium nitrite protects brain against in vivo ischemia-reperfusion injury. Stroke 37:2744-2750.

Justice JN, Gioscia-Ryan RA, Johnson LC, Battson ML, de Picciotto NE, Beck HJ, Jiang H, Sindler AL, Bryan NS, Enoka RM, et al. (2015) Sodium nitrite supplementation improves motor function and skeletal muscle inflammatory profile in old male mice. J Appl Physiol (1985) 118:163-169.

Kaess BM, Rong J, Larson MG, Hamburg NM, Vita JA, Levy D, Benjamin EJ, Vasan RS, and Mitchell GF (2012) Aortic stiffness, blood pressure progression, and incident hypertension. JAMA 308:875-881.

Kahn T, Bosch J, Levitt MF, and Goldstein MH (1975) Effect of sodium nitrate loading on electrolyte transport by the renal tubule. Am J Physiol 229:746-753.

Kamga Pride C, Mo L, Quesnelle K, Dagda RK, Murillo D, Geary L, Corey C, Portella R, Zharikov S, St Croix C, et al. (2014) Nitrite activates protein kinase A in normoxia to mediate mitochondrial fusion and tolerance to ischaemia/reperfusion. Cardiovasc Res 101:57-68

Kapil V, Haydar SM, Pearl V, Lundberg JO, Weitzberg E, and Ahluwalia A (2013) Physiological role for nitrate-reducing oral bacteria in blood pressure control. Free Radic Biol Med 55:93-100.

Kapil V, Khambata RS, Robertson A, Caulfield MJ, and Ahluwalia A (2015) Dietary nitrate provides sustained blood pressure lowering in hypertensive patients: a randomized, phase 2, double-blind, placebo-controlled study. Hypertension $\mathbf{6 5}$ $320-327$.

Kapil V, Milsom AB, Okorie M, Maleki-Toyserkani S, Akram F, Rehman F, Arghandawi S, Pearl V, Benjamin N, Loukogeorgakis S, et al. (2010) Inorganic nitrate supplementation lowers blood pressure in humans: role for nitrite-derived NO. Hypertension 56:274-281.

Kapil V, Rathod KS, Khambata RS, Bahra M, Velmurugan S, Purba A, S Watson D, Barnes MR, Wade WG, and Ahluwalia A (2018) Sex differences in the nitratenitrite-NO ${ }^{\bullet}$ pathway: role of oral nitrate-reducing bacteria. Free Radic Biol Med 126:113-121.

Katholi RE and Couri DM (2011) Left ventricular hypertrophy: major risk factor in patients with hypertension: update and practical clinical applications. Int $J$ Hypertens 2011:495349.

Kauser K, da Cunha V, Fitch R, Mallari C, and Rubanyi GM (2000) Role of endogenous nitric oxide in progression of atherosclerosis in apolipoprotein E-deficient mice. Am J Physiol Heart Circ Physiol 278:H1679-H1685.

Kautza B, Gomez H, Escobar D, Corey C, Ataya B, Luciano J, Botero AM, Gordon L, Brumfield J, Martinez S, et al. (2015) Inhaled, nebulized sodium nitrite protects in murine and porcine experimental models of hemorrhagic shock and resuscitation by limiting mitochondrial injury. Nitric Oxide 51:7-18.

Keh D, Gerlach M, Kürer I, Seiler S, Kerner T, Falke KJ, and Gerlach H (1996) The effects of nitric oxide (NO) on platelet membrane receptor expression during activation with human alpha-thrombin. Blood Coagul Fibrinolysis 7:615-624.

Kelly J, Fulford J, Vanhatalo A, Blackwell JR, French O, Bailey SJ, Gilchrist M, Winyard PG, and Jones AM (2013) Effects of short-term dietary nitrate supplementation on blood pressure, $\mathrm{O} 2$ uptake kinetics, and muscle and cognitive function in older adults. Am J Physiol Regul Integr Comp Physiol 304:R73-R83.

Kelly J, Vanhatalo A, Bailey SJ, Wylie LJ, Tucker C, List S, Winyard PG, and Jones AM (2014) Dietary nitrate supplementation: effects on plasma nitrite and 
pulmonary $\mathrm{O} 2$ uptake dynamics during exercise in hypoxia and normoxia. Am J Physiol Regul Integr Comp Physiol 307:R920-R930.

Kenjale AA, Ham KL, Stabler T, Robbins JL, Johnson JL, Vanbruggen M, Privette G, Yim E, Kraus WE, and Allen JD (2011) Dietary nitrate supplementation enhances exercise performance in peripheral arterial disease. J Appl Physiol (1985) 110: 1582-1591.

Kerley CP, Cahill K, Bolger K, McGowan A, Burke C, Faul J, and Cormican L (2015) Dietary nitrate supplementation in COPD: an acute, double-blind, randomized, placebo-controlled, crossover trial. Nitric Oxide 44:105-111.

Kerley CP, Dolan E, and Cormican L (2016) Dietary nitrate decreased blood pressure in obstructive sleep apnoea syndrome: a series of $\mathrm{N}$-of-1 trials. J Hypertens 34 $808-810$

Kerley CP, Dolan E, James PE, and Cormican L (2018) Dietary nitrate lowers ambulatory blood pressure in treated, uncontrolled hypertension: a 7-d, double-blind, randomised, placebo-controlled, cross-over trial Br J Nutr 119:658-663.

Khalifi S, Rahimipour A, Jeddi S, Ghanbari M, Kazerouni F, and Ghasemi A (2015) Dietary nitrate improves glucose tolerance and lipid profile in an animal model of hyperglycemia. Nitric Oxide 44:24-30.

Khambata RS, Ghosh SM, and Ahluwalia A (2015) "repurposing" of xanthine oxidoreductase as a nitrite reductase: a new paradigm for therapeutic targeting in hypertension. Antioxid Redox Signal 23:340-353.

Khambata RS, Ghosh SM, Rathod KS, Thevathasan T, Filomena F, Xiao Q, and Ahluwalia A (2017) Antiinflammatory actions of inorganic nitrate stabilize the atherosclerotic plaque. Proc Natl Acad Sci USA 114.E550-E559.

Khan AA, Wang Y, Sun Y, Mao XO, Xie L, Miles E, Graboski J, Chen S, Ellerby LM, Jin K, et al. (2006) Neuroglobin-overexpressing transgenic mice are resistant to cerebral and myocardial ischemia. Proc Natl Acad Sci USA 103:17944-17948.

Kharroubi AT and Darwish HM (2015) Diabetes mellitus: the epidemic of the century. World J Diabetes 6:850-867.

Kim F, Dezfulian C, Empey PE, Morrell M, Olsufka M, Scruggs S, Kudenchuk P, May S, Maynard C, Sayre MR, et al. (2018) Usefulness of intravenous sodium nitrite during resuscitation for the treatment of out-of-hospital cardiac arrest. Am $J$ Cardiol 122:554-559.

Kina-Tanada M, Sakanashi M, Tanimoto A, Kaname T, Matsuzaki T, Noguchi K, Uchida T, Nakasone J, Kozuka C, Ishida M, et al. (2017) Long-term dietary nitrite and nitrate deficiency causes the metabolic syndrome, endothelial dysfunction and cardiovascular death in mice. Diabetologia 60:1138-1151.

Kinnunen S and Mänttäri S (2012) Specific effects of endurance and sprint training on protein expression of calsequestrin and SERCA in mouse skeletal muscle. $J$ Muscle Res Cell Motil 33:123-130.

Kleinbongard P, Dejam A, Lauer T, Jax T, Kerber S, Gharini P, Balzer J, Zotz RB, Scharf RE, Willers R, et al. (2006) Plasma nitrite concentrations reflect the degree of endothelial dysfunction in humans. Free Radic Biol Med 40:295-302.

Kleinbongard P, Dejam A, Lauer T, Rassaf T, Schindler A, Picker O, Scheeren T, Gödecke A, Schrader J, Schulz R, et al. (2003) Plasma nitrite reflects constitutive nitric oxide synthase activity in mammals. Free Radic Biol Med 35:790-796.

Koga S, Kano Y, Barstow TJ, Ferreira LF, Ohmae E, Sudo M, and Poole DC (2012) Kinetics of muscle deoxygenation and microvascular po(2) during contractions in rat: comparison of optical spectroscopy and phosphorescence-quenching techniques. J Appl Physiol (1985) 112:26-32.

Kojda G, Kottenberg K, Nix P, Schlüter KD, Piper HM, and Noack E (1996) Low increase in cGMP induced by organic nitrates and nitrovasodilators improves contractile response of rat ventricular myocytes. Circ Res 78:91-101.

Kolaczkowska E and Kubes P (2013) Neutrophil recruitment and function in health and inflammation. Nat Rev Immunol 13:159-175.

Kortboyer JM, Colbers EPH, Vaessen HAMG, Groen K, Zeilmaker MJ, Slob W, Speiliers GJA, and Meulenbelt J (1994) A pilot-study to investigate nitrate and nitrite kinetics in healthy volunteers with normal and artificially increased gastric $\mathrm{pH}$ after sodium nitrate ingestion, in Proceedings of the International Workshop on Health Aspects of Nitrate and its Metabolites (particularly nitrite). pp 269-284, Council of Europe Press, Bilthoven, Netherlands.

Kozlov AV, Staniek K, and Nohl H (1999) Nitrite reductase activity is a novel function of mammalian mitochondria. FEBS Lett 454:127-130.

Krustrup P, Söderlund K, Mohr M, and Bangsbo J (2004) The slow component of oxygen uptake during intense, sub-maximal exercise in man is associated with additional fibre recruitment. Pflugers Arch 447:855-866.

Kubes P, Suzuki M, and Granger DN (1991) Nitric oxide: an endogenous modulator of leukocyte adhesion. Proc Natl Acad Sci USA 88:4651-4655

Kuennen M, Jansen L, Gillum T, Granados J, Castillo W, Nabiyar A, and Christmas K (2015) Dietary nitrate reduces the O2 cost of desert marching but elevates the rise in core temperature. Eur J Appl Physiol 115:2557-2569.

Kuhlencordt PJ, Gyurko R, Han F, Scherrer-Crosbie M, Aretz TH, Hajjar R, Picard $\mathrm{MH}$, and Huang PL (2001) Accelerated atherosclerosis, aortic aneurysm formation, and ischemic heart disease in apolipoprotein E/endothelial nitric oxide synthase double-knockout mice Circulation 104:448-454.

Kumar D, Branch BG, Pattillo CB, Hood J, Thoma S, Simpson S, Illum S, Arora N, Chidlow JH Jr, Langston W, et al. (2008) Chronic sodium nitrite therapy augments ischemia-induced angiogenesis and arteriogenesis. Proc Natl Acad Sci USA 105 $7540-7545$.

Kwon NS, Stuehr DJ, and Nathan CF (1991) Inhibition of tumor cell ribonucleotide reductase by macrophage-derived nitric oxide. J Exp Med 174:761-767.

Lagerlö F and Dawes C (1984) The volume of saliva in the mouth before and after swallowing. J Dent Res 63:618-621.

Lai Y-C, Tabima DM, Dube JJ, Hughan KS, Vanderpool RR, Goncharov DA, St Croix CM, Garcia-Ocaña A, Goncharova EA, Tofovic SP, et al. (2016) Sirt3-amp-activated protein kinase activation by nitrite and metformin improves hyperglycemia and normalizes pulmonary hypertension associated with heart failure with preserved ejection fraction. Circulation 133:717-731.

Lancaster JR Jr (1994) Simulation of the diffusion and reaction of endogenously produced nitric oxide. Proc Natl Acad Sci USA 91:8137-8141.
Lancaster JR Jr (1997) A tutorial on the diffusibility and reactivity of free nitric oxide. Nitric Oxide 1:18-30.

Lane SC, Hawley JA, Desbrow B, Jones AM, Blackwell JR, Ross ML, Zemski AJ, and Burke LM (2014) Single and combined effects of beetroot juice and caffeine supplementation on cycling time trial performance. Appl Physiol Nutr Metab $\mathbf{3 9}$ $1050-1057$.

Lang JD Jr, Teng X, Chumley P, Crawford JH, Isbell TS, Chacko BK, Liu Y, Jhala N, Crowe DR, Smith AB, et al. (2007) Inhaled NO accelerates restoration of liver function in adults following orthotopic liver transplantation. J Clin Invest 117: 2583-2591.

Lansley KE, Winyard PG, Bailey SJ, Vanhatalo A, Wilkerson DP, Blackwell JR Gilchrist M, Benjamin N, and Jones AM (2011a) Acute dietary nitrate supplementation improves cycling time trial performance. Med Sci Sports Exerc 43 $1125-1131$.

Lansley KE, Winyard PG, Fulford J, Vanhatalo A, Bailey SJ, Blackwell JR, DiMenna FJ, Gilchrist M, Benjamin N, and Jones AM (2011b) Dietary nitrate supplementation reduces the $\mathrm{O}_{2}$ cost of walking and running: a placebo-controlled study. $J$ Appl Physiol (1985) 110:591-600.

Larsen FJ, Ekblom B, Sahlin K, Lundberg JO, and Weitzberg E (2006) Effects of dietary nitrate on blood pressure in healthy volunteers. $N$ Engl J Med 355: 2792-2793.

Larsen FJ, Weitzberg E, Lundberg JO, and Ekblom B (2007) Effects of dietary nitrate on oxygen cost during exercise. Acta Physiol (Oxf) 191:59-66.

Larsen FJ, Weitzberg E, Lundberg JO, and Ekblom B (2010) Dietary nitrate reduces maximal oxygen consumption while maintaining work performance in maxima exercise. Free Radic Biol Med 48:342-347.

Lauer T, Preik M, Rassaf T, Strauer BE, Deussen A, Feelisch M, and Kelm M (2001) Plasma nitrite rather than nitrate reflects regional endothelial nitric oxide synthase activity but lacks intrinsic vasodilator action. Proc Natl Acad Sci USA 98 12814-12819.

Laurent S, Cockcroft J, Van Bortel L, Boutouyrie P, Giannattasio C, Hayoz D, Pannier B, Vlachopoulos C, Wilkinson I, and Struijker-Boudier H; European Network for Non-invasive Investigation of Large Arteries (2006) Expert consensus document on arterial stiffness: methodological issues and clinical applications. Eur Heart $J$ 27:2588-2605.

Law MR, Morris JK, and Wald NJ (2009) Use of blood pressure lowering drugs in the prevention of cardiovascular disease: meta-analysis of 147 randomised trials in the context of expectations from prospective epidemiological studies. BMJ 338:b1665

Law MR, Wald NJ, Morris JK, and Jordan RE (2003) Value of low-dose combination treatment with blood pressure lowering drugs: analysis of 354 randomised trials. $B M J$ 326:1427.

Leaf CD, Wishnok JS, and Tannenbaum SR (1989) Mechanisms of endogenous nitrosation Cancer Surv 8:323-334.

Lee JS, Stebbins CL, Jung E, Nho H, Kim JK, Chang MJ, and Choi HM (2015) Effects of chronic dietary nitrate supplementation on the hemodynamic response to dynamic exercise. Am J Physiol Regul Integr Comp Physiol 309:R459-R466.

Lefer AM and Lefer DJ (1996) The role of nitric oxide and cell adhesion molecules on the microcirculation in ischaemia-reperfusion. Cardiovasc Res 32:743-751.

Lefer D, Jones S, Steenbergen C, Kukreja R, Guo Y, Tang X-L, Li Q, Ockaili R, Salloum F, Kong M, et al. (2014) Sodium nitrite fails to limit myocardial infarct size: results from the CAESAR cardioprotection consortium. FASEB J 28:LB645.

Leite AC, Cunha FQ, Dal-Secco D, Fukada SY, Girão VC, and Rocha FA (2009) Effects of nitric oxide on neutrophil influx depends on the tissue: role of leukotriene B4 and adhesion molecules. Br J Pharmacol 156:818-825.

Leong $\mathrm{P}$, Basham JE, Yong T, Chazan A, Finlay $\mathrm{P}$, Barnes S, Bardin PG, and Campbell D (2015) A double blind randomized placebo control crossover trial on the effect of dietary nitrate supplementation on exercise tolerance in stable moderate chronic obstructive pulmonary disease. BMC Pulm Med 15:52.

Lewington S, Clarke R, Qizilbash N, Peto R, and Collins R; Prospective Studies Collaboration (2002) Age-specific relevance of usual blood pressure to vascular mortality: a meta-analysis of individual data for one million adults in 61 prospective studies [published correction appears in Lancet (2003) 361:1060]. Lancet 360:1903-1913.

Li B, Li F, Wang L, and Zhang D (2016a) Fruit and vegetables consumption and risk of hypertension: a meta-analysis. J Clin Hypertens (Greenwich) 18:468-476.

Li H, Cui H, Kundu TK, Alzawahra W, and Zweier JL (2008) Nitric oxide production from nitrite occurs primarily in tissues not in the blood: critical role of xanthine oxidase and aldehyde oxidase. J Biol Chem 283:17855-17863.

Li H, Duncan C, Townend J, Killham K, Smith LM, Johnston P, Dykhuizen R, Kelly D, Golden M, Benjamin N, et al. (1997) Nitrate-reducing bacteria on rat tongues. Appl Environ Microbiol 63:924-930.

Li H, Hemann C, Abdelghany TM, El-Mahdy MA, and Zweier JL (2012a) Characterization of the mechanism and magnitude of cytoglobin-mediated nitrite reduction and nitric oxide generation under anaerobic conditions. J Biol Chem 287: 36623-36633.

Li H, Kundu TK, and Zweier JL (2009) Characterization of the magnitude and mechanism of aldehyde oxidase-mediated nitric oxide production from nitrite. $J$ Biol Chem 284:33850-33858.

Li H, Samouilov A, Liu X, and Zweier JL (2001) Characterization of the magnitude and kinetics of xanthine oxidase-catalyzed nitrite reduction. Evaluation of its role in nitric oxide generation in anoxic tissues. J Biol Chem 276:24482-24489.

Li H, Samouilov A, Liu X, and Zweier JL (2003) Characterization of the magnitude and kinetics of xanthine oxidase-catalyzed nitrate reduction: evaluation of its role in nitrite and nitric oxide generation in anoxic tissues. Biochemistry 42:1150-1159. Li H, Samouilov A, Liu X, and Zweier JL (2004) Characterization of the effects of oxygen on xanthine oxidase-mediated nitric oxide formation. J Biol Chem 279: 16939-16946.

Li Q and Lancaster JR Jr (2012) A conspectus of cellular mechanisms of nitrosothiol formation from nitric oxide. For Immunopathol Dis Therap 3:183-191. 
Li T, Lu X, Sun Y, and Yang X (2016b) Effects of spinach nitrate on insulin resistance, endothelial dysfunction markers and inflammation in mice with high-fat and highfructose consumption. Food Nutr Res 60:32010.

Li W, Meng Z, Liu Y, Patel RP, and Lang JD (2012b) The hepatoprotective effect of sodium nitrite on cold ischemia-reperfusion injury. $J$ Transplant 2012:635179.

Liao JC, Hein TW, Vaughn MW, Huang KT, and Kuo L (1999) Intravascular flow decreases erythrocyte consumption of nitric oxide. Proc Natl Acad Sci USA 96: $8757-8761$

Libby P (2002) Inflammation in atherosclerosis. Nature 420:868-874.

Licht WR, Schultz DS, Fox JG, Tannenbaum SR, and Deen WM (1986) Mechanisms for nitrite loss from the stomach. Carcinogenesis 7:1681-1687.

Lim YJ, Foo TC, Yeung AWS, Tu X, Ma Y, Hawkins CL, Witting PK, Jameson GNL, Terentis AC, and Thomas SR (2019) Human indoleamine 2,3-dioxygenase 1 is an efficient mammalian nitrite reductase. Biochemistry 58:974-986.

Linder L, Kiowski W, Bühler FR, and Lüscher TF (1990) Indirect evidence for release of endothelium-derived relaxing factor in human forearm circulation in vivo. Blunted response in essential hypertension. Circulation 81:1762-1767.

Linder N, Rapola J, and Raivio KO (1999) Cellular expression of xanthine oxidoreductase protein in normal human tissues. Lab Invest 79:967-974.

Linfert D, Chowdhry T, and Rabb H (2009) Lymphocytes and ischemia-reperfusion injury. Transplant Rev (Orlando) 23:1-10.

Ling WC, Murugan DD, Lau YS, Vanhoutte PM, and Mustafa MR (2016) Sodium nitrite exerts an antihypertensive effect and improves endothelial function through activation of eNOS in the SHR. Sci Rep 6:33048.

Lipicky RJ (1994) Trough: peak ratio: the rationale behind the United States Food and Drug Administration recommendations. J Hypertens Suppl 12:S17-S18, discussion S18-S19.

Liu AH, Bondonno CP, Croft KD, Puddey IB, Woodman RJ, Rich L, Ward NC, Vita JA, and Hodgson JM (2013) Effects of a nitrate-rich meal on arterial stiffness and blood pressure in healthy volunteers. Nitric Oxide 35:123-130.

Liu C, Wajih N, Liu X, Basu S, Janes J, Marvel M, Keggi C, Helms CC, Lee AN, Belanger AM, et al. (2015) Mechanisms of human erythrocytic bioactivation of nitrite. J Biol Chem 290:1281-1294.

Liu SF, Crawley DE, Barnes PJ, and Evans TW (1991) Endothelium-derived relaxing factor inhibits hypoxic pulmonary vasoconstriction in rats. Am Rev Respir Dis 143:32-37.

Liu X, Miller MJ, Joshi MS, Sadowska-Krowicka H, Clark DA, and Lancaster JR Jr (1998) Diffusion-limited reaction of free nitric oxide with erythrocytes. J Biol Chem 273:18709-18713.

Loetscher P, Seitz M, Clark-Lewis I, Baggiolini M, and Moser B (1996) Activation of NK cells by CC chemokines. Chemotaxis, $\mathrm{Ca} 2+$ mobilization, and enzyme release. J Immunol 156:322-327.

Lu P, Liu F, Yao Z, Wang CY, Chen DD, Tian Y, Zhang JH, and Wu YH (2005) Nitrite-derived nitric oxide by xanthine oxidoreductase protects the liver against ischemia-reperfusion injury. Hepatobiliary Pancreat Dis Int 4:350-355.

Lundberg JO, Feelisch M, Björne H, Jansson EA, and Weitzberg E (2006) Cardioprotective effects of vegetables: is nitrate the answer? Nitric Oxide $\mathbf{1 5}$ 359-362.

Lundberg JO and Govoni M (2004) Inorganic nitrate is a possible source for systemic generation of nitric oxide. Free Radic Biol Med 37:395-400.

Lundberg JO, Weitzberg E, Cole JA, and Benjamin N (2004) Nitrate, bacteria and human health. Nat Rev Microbiol 2:593-602.

Lundberg JO, Weitzberg E, and Gladwin MT (2008) The nitrate-nitrite-nitric oxide pathway in physiology and therapeutics. Nat Rev Drug Discov 7:156-167.

Lundberg JO, Weitzberg E, Lundberg JM, and Alving K (1994) Intragastric nitric oxide production in humans: measurements in expelled air. Gut 35:1543-1546.

MacLeod KE, Nugent SF, Barr SI, Koehle MS, Sporer BC, and MacInnis MJ (2015) Acute beetroot juice supplementation does not improve cycling performance in normoxia or moderate hypoxia. Int J Sport Nutr Exerc Metab 25:359-366.

Mador MJ and Bozkanat E (2001) Skeletal muscle dysfunction in chronic obstructive pulmonary disease. Respir Res 2:216-224

Maejima Y, Adachi S, Morikawa K, Ito H, and Isobe M (2005) Nitric oxide inhibits myocardial apoptosis by preventing caspase-3 activity via S-nitrosylation. J Mol Cell Cardiol 38:163-174

Magee PN and Barnes JM (1956) The production of malignant primary hepatic tumours in the rat by feeding dimethylnitrosamine. Br J Cancer 10:114-122.

Magee PN and Barnes JM (1967) Carcinogenic nitroso compounds. Adv Cancer Res 10:163-246.

Maher AR, Milsom AB, Gunaruwan P, Abozguia K, Ahmed I, Weaver RA, Thomas P, Ashrafian H, Born GV, James PE, et al. (2008) Hypoxic modulation of exogenous nitrite-induced vasodilation in humans. Circulation 117:670-677.

Mahler M (1985) First-order kinetics of muscle oxygen consumption, and an equivalent proportionality between QO2 and phosphorylcreatine level. Implications for the control of respiration. J Gen Physiol 86:135-165.

Makhoul S, Walter E, Pagel O, Walter U, Sickmann A, Gambaryan S, Smolenski A, Zahedi RP, and Jurk K (2018) Effects of the NO/soluble guanylate cyclase/cGMP system on the functions of human platelets. Nitric Oxide 76:71-80.

Malinski T, Taha Z, Grunfeld S, Patton S, Kapturczak M, and Tomboulian P (1993) Diffusion of nitric oxide in the aorta wall monitored in situ by porphyrinic microsensors. Biochem Biophys Res Commun 193:1076-1082.

Margetts BM, Beilin LJ, Vandongen R, and Armstrong BK (1986) Vegetarian diet in mild hypertension: a randomised controlled trial. Br Med J (Clin Res Ed) 293: 1468-1471.

Marsch E, Theelen TL, Janssen BJ, Briede JJ, Haenen GR, Senden JM, van Loon LJ, Poeze M, Bierau J, Gijbels MJ, et al. (2016) The effect of prolonged dietary nitrate supplementation on atherosclerosis development. Atherosclerosis 245:212-221.

Marshall JM (1994) Peripheral chemoreceptors and cardiovascular regulation. Physiol Rev 74:543-594.

Martin K, Smee D, Thompson KG, and Rattray B (2014) No improvement of repeatedsprint performance with dietary nitrate. Int J Sports Physiol Perform 9:845-850.
Martinoia E, Maeshima M, and Neuhaus HE (2007) Vacuolar transporters and their essential role in plant metabolism. $J$ Exp Bot 58:83-102.

Maruyuma S, Murumatsu K, Shimizu S, and Maki S (1976) Reduction of nitrate with bacillus coagulans in human saliva. Food Hyg Safe Sci 17:19-26.

Massberg S, Grüner S, Konrad I, Garcia Arguinzonis MI, Eigenthaler M, Hemler K, Kersting J, Schulz C, Muller I, Besta F, et al. (2004) Enhanced in vivo platelet adhesion in vasodilator-stimulated phosphoprotein (VASP)-deficient mice. Blood 103: $136-142$

Massberg S, Sausbier M, Klatt P, Bauer M, Pfeifer A, Siess W, Fässler R, Ruth P, Krombach F and Hofmann F (1999) Increased adhesion and agregation of platelets lacking cyclic guanosine $3^{\prime}, 5^{\prime}$-monophosphate kinase I. J Exp Med 189:1255-1264.

Matthew E (1909) Vaso-dilators in high blood pressure. QJM 2:261-278.

May JM, Qu ZC, Xia L, and Cobb CE (2000) Nitrite uptake and metabolism and oxidant stress in human erythrocytes. Am J Physiol Cell Physiol 279: C1946-C1954.

McConell GK, Bradley SJ, Stephens TJ, Canny BJ, Kingwell BA, and Lee-Young RS (2007) Skeletal muscle nNOS mu protein content is increased by exercise training in humans. Am J Physiol Regul Integr Comp Physiol 293:R821-R828.

McDonagh ST, Wylie LJ, Winyard PG, Vanhatalo A, and Jones AM (2015) The effects of chronic nitrate supplementation and the use of strong and weak antibacterial agents on plasma nitrite concentration and exercise blood pressure. Int $J$ Sports Med 36:1177-1185.

McKnight GM, Smith LM, Drummond RS, Duncan CW, Golden M, and Benjamin N (1997) Chemical synthesis of nitric oxide in the stomach from dietary nitrate in humans. Gut 40:211-214.

Meredith PA (1994) New FDA guidelines on the treatment of hypertension: comparison of different therapeutic classes according to trough/peak blood pressure responses. Arch Mal Coeur Vaiss 87:1423-1429.

Meta-analysis Global Group in Chronic Heart Failure (MAGGIC) (2012) The survival of patients with heart failure with preserved or reduced left ventricular ejection fraction: an individual patient data meta-analysis. Eur Heart $J$ 33:1750-1757.

Meyer RA (1989) Linear dependence of muscle phosphocreatine kinetics on total creatine content. Am J Physiol 257:C1149-C1157.

Mikula I, Durocher S, Martasek P, Mutus B, and Slama-Schwok A (2009) Isoformspecific differences in the nitrite reductase activity of nitric oxide synthases under hypoxia. Biochem $J$ 418:673-682.

Millar TM, Stevens CR, Benjamin N, Eisenthal R, Harrison R, and Blake DR (1998) Xanthine oxidoreductase catalyses the reduction of nitrates and nitrite to nitric oxide under hypoxic conditions. FEBS Lett 427:225-228.

Miller V, Mente A, Dehghan M, Rangarajan S, Zhang X, Swaminathan S, Dagenais G, Gupta R, Mohan V, Lear S, et al.; Prospective Urban Rural Epidemiology (PURE) Study Investigators (2017) Fruit, vegetable, and legume intake, and cardiovascular disease and deaths in 18 countries (PURE): a prospective cohort study. Lancet 390:2037-2049.

Mills CE, Govoni V, Faconti L, Casagrande M-L, Morant SV, Webb AJ, and Cruickshank JK (2017) Reducing arterial stiffness independently of blood pressure: the vasera trial $J$ Am Coll Cardiol 70:1683-1684.

Milsom AB, Patel NS, Mazzon E, Tripatara P, Storey A, Mota-Filipe H, Sepodes B, Webb AJ, Cuzzocrea S, Hobbs AJ, et al. (2010) Role for endothelial nitric oxide synthase in nitrite-induced protection against renal ischemia-reperfusion injury in mice. Nitric Oxide 22:141-148.

Minamishima S, Kida K, Tokuda K, Wang H, Sips PY, Kosugi S, Mandeville JB, Buys ES, Brouckaert P, Liu PK, et al. (2011) Inhaled nitric oxide improves outcomes after successful cardiopulmonary resuscitation in mice. Circulation 124:1645-1653.

Mittal CK, Arnold WP, and Murad F (1978) Characterization of protein inhibitors of guanylate cyclase activation from rat heart and bovine lung. $J$ Biol Chem 253: 1266-1271.

Miyoshi M, Kasahara E, Park AM, Hiramoto K, Minamiyama Y, Takemura S, Sato EF, and Inoue M (2003) Dietary nitrate inhibits stress-induced gastric mucosal injury in the rat. Free Radic Res 37:85-90.

Mo L, Wang Y, Geary L, Corey C, Alef MJ, Beer-Stolz D, Zuckerbraun BS, and Shiva S (2012) Nitrite activates AMP kinase to stimulate mitochondrial biogenesis independent of soluble guanylate cyclase. Free Radic Biol Med 53:1440-1450.

Modarai B, Kapadia YK, Kerins M, and Terris J (2002) Methylene blue: a treatment for severe methaemoglobinaemia secondary to misuse of amyl nitrite. Emerg Med $J$ 19:270-271.

Modin A, Björne H, Herulf M, Alving K, Weitzberg E, and Lundberg JO (2001) Nitrite-derived nitric oxide: a possible mediator of 'acidic-metabolic' vasodilation. Acta Physiol Scand 171:9-16.

Mogensen M, Bagger M, Pedersen PK, Fernström M, and Sahlin K (2006) Cycling efficiency in humans is related to low UCP3 content and to type I fibres but not to mitochondrial efficiency. J Physiol 571:669-681.

Mohler ER III, Hiatt WR, Gornik HL, Kevil CG, Quyyumi A, Haynes WG, and Annex BH (2014) Sodium nitrite in patients with peripheral artery disease and diabetes mellitus: safety, walking distance and endothelial function. Vasc Med 19:9-17.

Monaco CMF, Miotto PM, Huber JS, van Loon LJC, Simpson JA, and Holloway GP (2018) Sodium nitrate supplementation alters mitochondrial $\mathrm{H}_{2} \mathrm{O}_{2}$ emission but does not improve mitochondrial oxidative metabolism in the heart of healthy rats. Am J Physiol Regul Integr Comp Physiol 315:R191-R204.

Moncada S and Higgs A (1993) The L-arginine-nitric oxide pathway. $N$ Engl J Med 329:2002-2012.

Moncada S and Higgs EA (2006) The discovery of nitric oxide and its role in vascular biology. Br J Pharmacol 147 (Suppl 1):S193-S201.

Moncada S, Palmer RM, and Higgs EA (1991) Nitric oxide: physiology, pathophysiology, and pharmacology. Pharmacol Rev 43:109-142.

Montenegro MF, Amaral JH, Pinheiro LC, Sakamoto EK, Ferreira GC, Reis RI, Marçal DM, Pereira RP, and Tanus-Santos JE (2011) Sodium nitrite downregulates 
vascular NADPH oxidase and exerts antihypertensive effects in hypertension. Free Radic Biol Med 51:144-152.

Montenegro MF, Pinheiro LC, Amaral JH, Ferreira GC, Portella RL, and TanusSantos JE (2014) Vascular xanthine oxidoreductase contributes to the antihypertensive effects of sodium nitrite in L-NAME hypertension. Naunyn Schmiedebergs Arch Pharmacol 387:591-598.

Montenegro MF, Pinheiro LC, Amaral JH, Marçal DM, Palei AC, Costa-Filho AJ, and Tanus-Santos JE (2012) Antihypertensive and antioxidant effects of a single daily dose of sodium nitrite in a model of renovascular hypertension. Naunyn Schmiedebergs Arch Pharmacol 385:509-517.

Montenegro MF, Sundqvist ML, Larsen FJ, Zhuge Z, Carlström M, Weitzberg E, and Lundberg JO (2017) Blood pressure-lowering effect of orally ingested nitrite is abolished by a proton pump inhibitor. Hypertension 69:23-31.

Monti LD, Barlassina C, Citterio L, Galluccio E, Berzuini C, Setola E, Valsecchi G, Lucotti P, Pozza G, Bernardinelli L, et al. (2003) Endothelial nitric oxide synthase polymorphisms are associated with type 2 diabetes and the insulin resistance syndrome. Diabetes 52:1270-1275.

Moore C, Tymvios C, and Emerson M (2010) Functional regulation of vascular and platelet activity during thrombosis by nitric oxide and endothelial nitric oxide synthase. Thromb Haemost 104:342-349.

Moreno-Vivián C, Cabello P, Martínez-Luque M, Blasco R, and Castillo F (1999) Prokaryotic nitrate reduction: molecular properties and functional distinction among bacterial nitrate reductases. J Bacteriol 181:6573-6584.

Moretti C, Zhuge Z, Zhang G, McCann Haworth S, Paulo LL, Guimaraes DD, Cruz JC, Montenegro MF, Cordero-Herrera I, Braga VA, et al. (2019) The obligatory role of host microbiota in bioactivation of dietary nitrate. Free Radic Biol Med $\mathbf{1 4 5}$ $342-348$.

Moriwaki Y, Yamamoto T, Suda M, Nasako Y, Takahashi S, Agbedana OE, Hada T, and Higashino K (1993) Purification and immunohistochemical tissue localization of human xanthine oxidase. Biochim Biophys Acta 1164:327-330.

Moriwaki Y, Yamamoto T, Takahashi S, Tsutsumi Z, and Hada T (2001) Widespread cellular distribution of aldehyde oxidase in human tissues found by immunohistochemistry staining. Histol Histopathol 16:745-753.

Moriwaki Y, Yamamoto T, Yamakita J, Takahashi S, and Higashino K (1998) Comparative localization of aldehyde oxidase and xanthine oxidoreductase activity in rat tissues. Histochem $J$ 30:69-74.

Muggeridge DJ, Howe CC, Spendiff O, Pedlar C, James PE, and Easton C (2013) The effects of a single dose of concentrated beetroot juice on performance in trained flatwater kayakers. Int $J$ Sport Nutr Exerc Metab 23:498-506.

Muggeridge DJ, Howe CCF, Spendiff O, Pedlar C, James PE, and Easton C (2014) A single dose of beetroot juice enhances cycling performance in simulated altitude. Med Sci Sports Exerc 46:143-150.

Münzel T, Daiber A, and Gori T (2011) Nitrate therapy: new aspects concerning molecular action and tolerance. Circulation 123:2132-2144.

Münzel T, Daiber A, and Gori T (2013) More answers to the still unresolved question of nitrate tolerance. Eur Heart $J$ 34:2666-2673.

Münzel T, Daiber A, and Mülsch A (2005) Explaining the phenomenon of nitrate tolerance. Circ Res 97:618-628.

Murata I, Miyake Y, Takahashi N, Suzuki R, Fujiwara T, Sato Y, Inoue Y, Kobayashi J, and Kanamoto I (2017) Low-dose sodium nitrite fluid resuscitation prevents lethality from crush syndrome by improving nitric oxide consumption and preventing myoglobin cytotoxicity in kidney in a rat model. Shock 48:112-118.

Murata I, Nozaki R, Ooi K, Ohtake K, Kimura S, Ueda H, Nakano G, Sonoda K, Inoue $\mathrm{Y}$, Uchida $\mathrm{H}$, et al. (2012) Nitrite reduces ischemia/reperfusion-induced muscle damage and improves survival rates in rat crush injury model. J Trauma Acute Care Surg 72:1548-1554.

Murillo D, Kamga C, Mo L, and Shiva S (2011) Nitrite as a mediator of ischemic preconditioning and cytoprotection. Nitric Oxide 25:70-80.

Murohara T, Parkinson SJ, Waldman SA, and Lefer AM (1995) Inhibition of nitric oxide biosynthesis promotes P-selectin expression in platelets. Role of protein kinase C. Arterioscler Thromb Vasc Biol 15:2068-2075.

Murphy M, Eliot K, Heuertz RM, and Weiss E (2012) Whole beetroot consumption acutely improves running performance. J Acad Nutr Diet 112:548-552.

Murumatsu K, Maruyuma S, and Nishizawa S (1979) Nitrate-reducing bacterial flora and its ability to reduce nitrate in human saliva. Food Hyg Safe Sci 20:106-114.

Nadtochiy SM, Burwell LS, and Brookes PS (2007) Cardioprotection and mitochondrial S-nitrosation: effects of S-nitroso-2-mercaptopropionyl glycine (SNO-MPG) in cardiac ischemia-reperfusion injury. J Mol Cell Cardiol 42:812-825.

Nagababu E, Ramasamy S, and Rifkind JM (2006) S-nitrosohemoglobin: a mechanism for its formation in conjunction with nitrite reduction by deoxyhemoglobin. Nitric Oxide 15:20-29.

Nagamani SC, Campeau PM, Shchelochkov OA, Premkumar MH, Guse K, BrunettiPierri N, Chen Y, Sun Q, Tang Y, Palmer D, et al. (2012) Nitric-oxide supplementation for treatment of long-term complications in argininosuccinic aciduria. Am J Hum Genet 90:836-846.

Nagayama T, Hsu S, Zhang M, Koitabashi N, Bedja D, Gabrielson KL, Takimoto E, and Kass DA (2009) Sildenafil stops progressive chamber, cellular, and molecular remodeling and improves calcium handling and function in hearts with preexisting advanced hypertrophy caused by pressure overload. J Am Coll Cardiol 53: $207-215$.

Nakamura Y, Moss AJ, Brown MW, Kinoshita M, and Kawai C; Multicenter Myocardial Ischemia Research Group (1999) Long-term nitrate use may be deleterious in ischemic heart disease: a study using the databases from two large-scale postinfarction studies. Am Heart J 138:577-585.

Napoli C, de Nigris F, Williams-Ignarro S, Pignalosa O, Sica V, and Ignarro LJ (2006) Nitric oxide and atherosclerosis: an update. Nitric Oxide 15:265-279.

Naseem KM and Roberts W (2011) Nitric oxide at a glance. Platelets 22:148-152.

Naska A, Lagiou A, and Lagiou P (2017) Dietary assessment methods in epidemiological research: current state of the art and future prospects. F1000 Res 6:926.
National Toxicology Program (2001) NTP Technical Report on Toxicology and Carciongenesis Studies of Sodium Nitrite in F344/N Rats and B6C3F1 Mice (Drinking Water Studies), National Institutes of Health, Durham, NC.

Nazir SA, McCann GP, Greenwood JP, Kunadian V, Khan JN, Mahmoud IZ, Blackman DJ, Been M, Abrams KR, Shipley L, et al. (2016) Strategies to attenuate micro-vascular obstruction during P-PCI: the randomized reperfusion facilitated by local adjunctive therapy in ST-elevation myocardial infarction trial. Eur Heart $J$ 37:1910-1919.

Niccoli G, Montone RA, Ibanez B, Thiele H, Crea F, Heusch G, Bulluck H, Hausenloy DJ, Berry C, Stiermaier T, et al. (2019) Optimized treatment of ST-elevation myocardial infarction. Circ Res 125:245-258.

Nichol G, Thomas E, Callaway CW, Hedges J, Powell JL, Aufderheide TP, Rea T, Lowe R, Brown T, Dreyer J, et al.; Resuscitation Outcomes Consortium Investigators (2008) Regional variation in out-of-hospital cardiac arrest incidence and outcome [published correction appears in JAMA (2008) 300:1763]. JAMA 300: $1423-1431$.

Nisoli E, Tonello C, Cardile A, Cozzi V, Bracale R, Tedesco L, Falcone S, Valerio A, Cantoni O, Clementi E, et al. (2005) Calorie restriction promotes mitochondrial biogenesis by inducing the expression of eNOS. Science 310:314-317.

Nohl H, Staniek K, Sobhian B, Bahrami S, Redl H, and Kozlov AV (2000) Mitochondria recycle nitrite back to the bioregulator nitric monoxide. Acta Biochim Pol 47:913-921.

Notay K, Incognito AV, and Millar PJ (2017) Acute beetroot juice supplementation on sympathetic nerve activity: a randomized, double-blind, placebo-controlled proofof-concept study. Am J Physiol Heart Circ Physiol 313:H59-H65.

Nyström T, Ortsäter H, Huang Z, Zhang F, Larsen FJ, Weitzberg E, Lundberg JO, and Sjöholm $\AA$ (2012) Inorganic nitrite stimulates pancreatic islet blood flow and insulin secretion. Free Radic Biol Med 53:1017-1023.

Oberbach A, Bossenz Y, Lehmann S, Niebauer J, Adams V, Paschke R, Schön MR Blüher M, and Punkt K (2006) Altered fiber distribution and fiber-specific glycolytic and oxidative enzyme activity in skeletal muscle of patients with type 2 diabetes. Diabetes Care 29:895-900.

O'Gallagher K, Khan F, Omar SA, Kalra S, Danson E, Cabaco AR, Martin K, Melikian N, Shah AM, and Webb AJ (2018) Inorganic nitrite selectively dilates epicardial coronary arteries. J Am Coll Cardiol 71:363-364.

Ohtake K, Koga M, Uchida H, Sonoda K, Ito J, Uchida M, Natsume H, and Kobayash $\mathrm{J}$ (2010) Oral nitrite ameliorates dextran sulfate sodium-induced acute experimental colitis in mice. Nitric Oxide 23:65-73.

Ohtake K, Nakano G, Ehara N, Sonoda K, Ito J, Uchida H, and Kobayashi J (2015) Dietary nitrite supplementation improves insulin resistance in type 2 diabetic KKA(y) mice. Nitric Oxide 44:31-38.

Okamoto T, Tang X, Janocha A, Farver CF, Gladwin MT, and McCurry KR (2013) Nebulized nitrite protects rat lung grafts from ischemia reperfusion injury. $J$ Thorac Cardiovasc Surg 145:1108-1116.e1.

Omar SA, Fok H, Tilgner KD, Nair A, Hunt J, Jiang B, Taylor P, Chowienczyk P, and Webb AJ (2015) Paradoxical normoxia-dependent selective actions of inorganic nitrite in human muscular conduit arteries and related selective actions on central blood pressures. Circulation 131:381-389, discussion 389.

Omar SA, Webb AJ, Lundberg JO, and Weitzberg E (2016) Therapeutic effects of inorganic nitrate and nitrite in cardiovascular and metabolic diseases. $J$ Intern Med 279:315-336.

Ophir O, Peer G, Gilad J, Blum M, and Aviram A (1983) Low blood pressure in vegetarians: the possible role of potassium. Am J Clin Nutr 37:755-762.

Ormerod JOM, Arif S, Mukadam M, Evans JDW, Beadle R, Fernandez BO, Bonser RS, Feelisch M, Madhani M, and Frenneaux MP (2015) Short-term intravenous sodium nitrite infusion improves cardiac and pulmonary hemodynamics in heart failure patients. Circ Heart Fail 8:565-571.

Packer PJ, Leach SA, Duncan SN, Thompson MH, and Hill MJ (1989) The effect of different sources of nitrate exposure on urinary nitrate recovery in humans and its relevance to the methods of estimating nitrate exposure in epidemiological studies. Carcinogenesis 10:1989-1996.

Palazzo AJ, Jones SP, Girod WG, Anderson DC, Granger DN, and Lefer DJ (1998) Myocardial ischemia-reperfusion injury in CD18- and ICAM-1-deficient mice. Am J Physiol 275:H2300-H2307.

Palmieri EA, Affuso F, Fazio S, and Lembo D (2004) Tadalafil in primary pulmonary arterial hypertension. Ann Intern Med 141:743-744.

Pankey EA, Badejo AM, Casey DB, Lasker GF, Riehl RA, Murthy SN, Nossaman BD, and Kadowitz PJ (2012) Effect of chronic sodium nitrite therapy on monocrotalineinduced pulmonary hypertension. Nitric Oxide 27:1-8.

Pannala AS, Mani AR, Spencer JP, Skinner V, Bruckdorfer KR, Moore KP, and RiceEvans CA (2003) The effect of dietary nitrate on salivary, plasma, and urinary nitrate metabolism in humans. Free Radic Biol Med 34:576-584.

Panza JA, Casino PR, Kilcoyne CM, and Quyyumi AA (1993) Role of endotheliumderived nitric oxide in the abnormal endothelium-dependent vascular relaxation of patients with essential hypertension. Circulation 87:1468-1474.

Paolocci N, Katori T, Champion HC, St John ME, Miranda KM, Fukuto JM, Wink DA, and Kass DA (2003) Positive inotropic and lusitropic effects of HNO/NO- in failing hearts: independence from beta-adrenergic signaling. Proc Natl Acad Sci USA 100:5537-5542.

Paolocci N, Pagliaro P, Isoda T, Saavedra FW, and Kass DA (2001a) Role of calciumsensitive $\mathrm{K}(+)$ channels and nitric oxide in in vivo coronary vasodilation from enhanced perfusion pulsatility. Circulation 103:119-124.

Paolocci N, Saavedra WF, Miranda KM, Martignani C, Isoda T, Hare JM, Espey MG, Fukuto JM, Feelisch M, Wink DA, et al. (2001b) Nitroxyl anion exerts redoxsensitive positive cardiac inotropy in vivo by calcitonin gene-related peptide signaling. Proc Natl Acad Sci USA 98:10463-10468.

Papapetropoulos A, García-Cardeña G, Madri JA, and Sessa WC (1997) Nitric oxide production contributes to the angiogenic properties of vascular endothelial growth factor in human endothelial cells. J Clin Invest 100:3131-3139.

Parakaw T, Suknuntha K, Vivithanaporn P, Schlagenhauf A, Topanurak S, Fucharoen S, Pattanapanyasat K, Schechter A, Sibmooh N, and Srihirun S (2017) 
Platelet inhibition and increased phosphorylated vasodilator-stimulated phosphoprotein following sodium nitrite inhalation. Nitric Oxide 66:10-16.

Park JW, Piknova B, Huang PL, Noguchi CT, and Schechter AN (2013) Effect of blood nitrite and nitrate levels on murine platelet function. PLoS One 8:e55699.

Patrician A, Engan H, Lundsten D, Grote L, Vigetun-Haughey H, and Schagatay E (2018) The effect of dietary nitrate on nocturnal sleep-disordered breathing and arterial oxygen desaturation at high altitude. High Alt Med Biol 19:21-27.

Paulus WJ and Tschöpe C (2013) A novel paradigm for heart failure with preserved ejection fraction: comorbidities drive myocardial dysfunction and remodeling through coronary microvascular endothelial inflammation. J Am Coll Cardiol 62:263-271.

Pawloski JR, Hess DT, and Stamler JS (2001) Export by red blood cells of nitric oxide bioactivity. Nature 409:622-626.

Peacock O, Tjonna AE, James P, Wisloff U, Welde B, Bohlke N, Smith A, Stokes K, Cook C, and Sandbakk O (2012) Dietary nitrate does not enhance running performance in elite cross-country skiers. Med Sci Sports Exerc 44:2213-2219.

Peeling P, Cox GR, Bullock N, and Burke LM (2015) Beetroot juice improves on-water $500 \mathrm{~m}$ time-trial performance, and laboratory-based paddling economy in nationa and international-level kayak athletes. Int J Sport Nutr Exerc Metab 25:278-284.

Peleli M, Hezel M, Zollbrecht C, Persson AE, Lundberg JO, Weitzberg E, Fredholm $\mathrm{BB}$, and Carlström M (2015) In adenosine A2B knockouts acute treatment with inorganic nitrate improves glucose disposal, oxidative stress, and AMPK signaling in the liver. Front Physiol 6:222.

Pellegrino D, Shiva S, Angelone T, Gladwin MT, and Tota B (2009) Nitrite exerts potent negative inotropy in the isolated heart via eNOS-independent nitric oxide generation and cGMP-PKG pathway activation. Biochim Biophys Acta 1787:818-827.

Pepke-Zaba J, Gilbert C, Collings L, and Brown MC (2008) Sildenafil improves health-related quality of life in patients with pulmonary arterial hypertension. Chest 133:183-189.

Pepke-Zaba J, Higenbottam TW, Dinh-Xuan AT, Stone D, and Wallwork J (1991) Inhaled nitric oxide as a cause of selective pulmonary vasodilatation in pulmonary hypertension. Lancet 338:1173-1174.

Persson MG, Gustafsson LE, Wiklund NP, Moncada S, and Hedqvist P (1990) Endogenous nitric oxide as a probable modulator of pulmonary circulation and hypoxic pressor response in vivo. Acta Physiol Scand 140:449-457.

Petersen MG, Dewilde S, and Fago A (2008) Reactions of ferrous neuroglobin and cytoglobin with nitrite under anaerobic conditions. J Inorg Biochem 102:1777-1782.

Petersson J, Carlström M, Schreiber O, Phillipson M, Christoffersson G, Jägare A Roos S, Jansson EA, Persson AE, Lundberg JO, et al. (2009) Gastroprotective and blood pressure lowering effects of dietary nitrate are abolished by an antiseptic mouthwash. Free Radic Biol Med 46:1068-1075.

Petersson J, Phillipson M, Jansson EA, Patzak A, Lundberg JO, and Holm L (2007) Dietary nitrate increases gastric mucosal blood flow and mucosal defense. Am J Physiol Gastrointest Liver Physiol 292:G718-G724.

Petri B, Phillipson M, and Kubes P (2008) The physiology of leukocyte recruitment: an in vivo perspective. J Immunol 180:6439-6446.

Pettersen KH, Bugenhagen SM, Nauman J, Beard DA, and Omholt SW (2014) Arterial stiffening provides sufficient explanation for primary hypertension. PLOS Comput Biol 10:e1003634.

Pierce JM and Nielsen MS (1989) Acute acquired methaemoglobinaemia after amyl nitrite poisoning. BMJ 298:1566

Pinheiro LC, Montenegro MF, Amaral JH, Ferreira GC, Oliveira AM, and TanusSantos JE (2012) Increase in gastric $\mathrm{pH}$ reduces hypotensive effect of oral sodium nitrite in rats. Free Radic Biol Med 53:701-709.

Pluta RM, Dejam A, Grimes G, Gladwin MT, and Oldfield EH (2005) Nitrite infusions to prevent delayed cerebral vasospasm in a primate model of subarachnoid hemorrhage. JAMA 293:1477-1484.

Pluta RM, Oldfield EH, Bakhtian KD, Fathi AR, Smith RK, Devroom HL, Nahavandi M, Woo S, Figg WD, and Lonser RR (2011) Safety and feasibility of long-term intravenous sodium nitrite infusion in healthy volunteers. PLoS One 6:e14504.

Pluta RM, Thompson BG, Afshar JK, Boock RJ, Iuliano B, and Oldfield EH (2001) Nitric oxide and vasospasm. Acta Neurochir Suppl (Wien) 77:67-72.

Poderoso JJ, Peralta JG, Lisdero CL, Carreras MC, Radisic M, Schöpfer F, Cadenas $\mathrm{E}$, and Boveris A (1998) Nitric oxide regulates oxygen uptake and hydrogen peroxide release by the isolated beating rat heart. Am J Physiol 274:C112-C119.

Ponikowski P, Voors AA, Anker SD, Bueno H, Cleland JGF, Coats AJS, Falk V, González-Juanatey JR, Harjola V-P, Jankowska EA, et al.; Authors/Task Force Members; Document Reviewers (2016) 2016 ESC Guidelines for the diagnosis and treatment of acute and chronic heart failure: the Task Force for the diagnosis and treatment of acute and chronic heart failure of the European Society of Cardiology (ESC). Developed with the special contribution of the Heart Failure Association (HFA) of the ESC. Eur J Heart Fail 18:891-975.

Porcelli S, Ramaglia M, Bellistri G, Pavei G, Pugliese L, Montorsi M, Rasica L, and Marzorati M (2015) Aerobic fitness affects the exercise performance responses to nitrate supplementation. Med Sci Sports Exerc 47:1643-1651.

Presley TD, Morgan AR, Bechtold E, Clodfelter W, Dove RW, Jennings JM, Kraft RA, King SB, Laurienti PJ, Rejeski WJ, et al. (2011) Acute effect of a high nitrate diet on brain perfusion in older adults. Nitric Oxide 24:34-42.

Przyklenk K, Bauer B, Ovize M, Kloner RA, and Whittaker P (1993) Regional ischemic 'preconditioning' protects remote virgin myocardium from subsequent sustained coronary occlusion. Circulation 87:893-899.

Qin L, Liu X, Sun Q, Fan Z, Xia D, Ding G, Ong HL, Adams D, Gahl WA, Zheng C, et al. (2012) Sialin (SLC17A5) functions as a nitrate transporter in the plasma membrane. Proc Natl Acad Sci USA 109:13434-13439.

Radi R, Rubbo H, Bush K, and Freeman BA (1997) Xanthine oxidase binding to glycosaminoglycans: kinetics and superoxide dismutase interactions of immobilized xanthine oxidase-heparin complexes. Arch Biochem Biophys 339:125-135.

Radomski MW, Palmer RM, and Moncada S (1987) Endogenous nitric oxide inhibits human platelet adhesion to vascular endothelium. Lancet 2:1057-1058.

Radomski MW, Palmer RM, and Moncada S (1990) An L-arginine/nitric oxide pathway present in human platelets regulates aggregation. Proc Natl Acad Sci USA 87:5193-5197.
Radziwon-Balicka A, Lesyk G, Back V, Fong T, Loredo-Calderon EL, Dong B, El-Sikhry H, El-Sherbeni AA, El-Kadi A, Ogg S, et al. (2017) Differential eNOS-signalling by platelet subpopulations regulates adhesion and aggregation. Cardiovasc Res 113:1719-1731.

Raguso CA, Guinot SL, Janssens JP, Kayser B, and Pichard C (2004) Chronic hypoxia: common traits between chronic obstructive pulmonary disease and altitude. Curr Opin Clin Nutr Metab Care 7:411-417.

Rahma M, Kimura S, Yoneyama H, Kosaka H, Nishiyama A, Fukui T, and Abe Y (2001) Effects of furosemide on the tubular reabsorption of nitrates in anesthetized dogs. Eur J Pharmacol 428:113-119.

Ralt D (2009) Does NO metabolism play a role in the effects of vegetables in health? Nitric oxide formation via the reduction of nitrites and nitrates. Med Hypotheses 73:794-796.

Rammos C, Hendgen-Cotta UB, Sobierajski J, Bernard A, Kelm M, and Rassaf T (2014) Dietary nitrate reverses vascular dysfunction in older adults with moderately increased cardiovascular risk. J Am Coll Cardiol 63:1584-1585.

Rammos C, Totzeck M, Deenen R, Köhrer K, Kelm M, Rassaf T, and Hendgen-Cotta UB (2015) Dietary nitrate is a modifier of vascular gene expression in old male mice. Oxid Med Cell Longev 2015:658264.

Rassaf T, Flögel U, Drexhage C, Hendgen-Cotta U, Kelm M, and Schrader J (2007) Nitrite reductase function of deoxymyoglobin: oxygen sensor and regulator of cardiac energetics and function. Circ Res 100:1749-1754.

Rassaf T, Heiss C, Hendgen-Cotta U, Balzer J, Matern S, Kleinbongard P, Lee A Lauer T, and Kelm M (2006) Plasma nitrite reserve and endothelial function in the human forearm circulation. Free Radic Biol Med 41:295-301.

Rassaf T, Totzeck M, Hendgen-Cotta UB, Shiva S, Heusch G, and Kelm M (2014) Circulating nitrite contributes to cardioprotection by remote ischemic preconditioning. Circ Res 114:1601-1610.

Raubenheimer K, Hickey D, Leveritt M, Fassett R, Ortiz de Zevallos Munoz J, Allen JD, Briskey D, Parker TJ, Kerr G, Peake JM, et al. (2017) Acute effects of nitraterich beetroot juice on blood pressure, hemostasis and vascular inflammation markers in healthy older adults: a randomized, placebo-controlled crossover study. Nutrients 9:E1270.

Reichert E and Mitchell SW (1880) On the physiological action of potassium nitrite. Am J Med Sci 80:158-180.

Reutov VP (2002) Nitric oxide cycle in mammals and the cyclicity principle. Biochemistry (Mosc) 67:293-311.

Reutov VP and Sorokina EG (1998) NO-synthase and nitrite-reductase components of nitric oxide cycle. Biochemistry (Mosc) 63:874-884.

Richardson G, Hicks SL, O’Byrne S, Frost MT, Moore K, Benjamin N, and McKnight GM (2002) The ingestion of inorganic nitrate increases gastric S-nitrosothiol levels and inhibits platelet function in humans. Nitric Oxide 7:24-29.

Richardson RS, Noyszewski EA, Kendrick KF, Leigh JS, and Wagner PD (1995) Myoglobin O2 desaturation during exercise. Evidence of limited O2 transport. $J$ Clin Invest 96:1916-1926.

Rifkind JM, Nagababu E, Barbiro-Michaely E, Ramasamy S, Pluta RM, and Mayevsky A (2007) Nitrite infusion increases cerebral blood flow and decreases mean arterial blood pressure in rats: a role for red cell NO. Nitric Oxide 16:448-456.

Rimer EG, Peterson LR, Coggan AR, and Martin JC (2016) Increase in maximal cycling power with acute dietary nitrate supplementation. Int $J$ Sports Physiol Perform 11:715-720.

Rix PJ, Vick A, Attkins NJ, Barker GE, Bott AW, Alcorn H Jr, Gladwin MT, Shiva S, Bradley S, Hussaini A, et al. (2015) Pharmacokinetics, pharmacodynamics, safety, and tolerability of nebulized sodium nitrite (AIR001) following repeat-dose inhalation in healthy subjects. Clin Pharmacokinet 54:261-272.

Roberts LD, Ashmore T, Kotwica AO, Murfitt SA, Fernandez BO, Feelisch M, Murray AJ, and Griffin JL (2015) Inorganic nitrate promotes the browning of white adipose tissue through the nitrate-nitrite-nitric oxide pathway. Diabetes 64:471-484.

Robinson JM and Lancaster JR Jr (2005) Hemoglobin-mediated, hypoxia-induced vasodilation via nitric oxide: mechanism(s) and physiologic versus pathophysiologic relevance. Am J Respir Cell Mol Biol 32:257-261.

Roe HE (1933) Methemoglobinemia following the administration of bismuth subnitrate: report of a fatal case. JAMA 101:352-354.

Roediger WE, Radcliffe BC, Deakin EJ, and Nance SH (1986) Specific metabolic effect of sodium nitrite on fat metabolism by mucosal cells of the colon. Dig Dis Sci 31:535-539. Rosenbaek JB, Pedersen EB, and Bech JN (2018) The effect of sodium nitrite infusion on renal function, brachial and central blood pressure during enzyme inhibition by allopurinol, enalapril or acetazolamide in healthy subjects: a randomized, doubleblinded, placebo-controlled, crossover study. BMC Nephrol 19:244.

Rouse IL, Beilin LJ, Armstrong BK, and Vandongen R (1983) Blood-pressure-lowering effect of a vegetarian diet: controlled trial in normotensive subjects. Lancet 1:5-10.

Rubbo H, Darley-Usmar V, and Freeman BA (1996) Nitric oxide regulation of tissue free radical injury. Chem Res Toxicol 9:809-820.

Sacks FM, Rosner B, and Kass EH (1974) Blood pressure in vegetarians. Am $J$ Epidemiol 100:390-398.

Sadamitsu D, Kuroda Y, Nagamitsu T, Tsuruta R, Inoue T, Ueda T, Nakashima K Ito H, and Maekawa T (2001) Cerebrospinal fluid and plasma concentrations of nitric oxide metabolites in postoperative patients with subarachnoid hemorrhage. Crit Care Med 29:77-79.

Safar ME (2010) Arterial aging--hemodynamic changes and therapeutic options. Nat Rev Cardiol 7:442-449.

Sahlin K (1983) NADH and NADPH in human skeletal muscle at rest and during ischaemia. Clin Physiol 3:477-485

Salen EB (1925) On the incidence and clinical significance of nitrites in the urine of humans. Acta Med Scand 63:369-424.

Salgado MT, Nagababu E, and Rifkind JM (2009) Quantification of intermediates formed during the reduction of nitrite by deoxyhemoglobin. J Biol Chem 284: 12710-12718. 
Salloum F, Yin C, Xi L, and Kukreja RC (2003) Sildenafil induces delayed preconditioning through inducible nitric oxide synthase-dependent pathway in mouse heart. Circ Res 92:595-597.

Salloum FN, Ockaili RA, Wittkamp M, Marwaha VR, and Kukreja RC (2006) Vardenafil: a novel type 5 phosphodiesterase inhibitor reduces myocardial infarct size following ischemia/reperfusion injury via opening of mitochondrial K(ATP) channels in rabbits. $J$ Mol Cell Cardiol 40:405-411.

Salzman AL (1995) Nitric oxide in the gut. New Horiz 3:33-45.

Samal AA, Honavar J, Brandon A, Bradley KM, Doran S, Liu Y, Dunaway C, Steele C, Postlethwait EM, Squadrito GL, et al. (2012) Administration of nitrite after chlorine gas exposure prevents lung injury: effect of administration modality. Free Radic Biol Med 53:1431-1439.

Samouilov A, Woldman YY, Zweier JL, and Khramtsov VV (2007) Magnetic resonance study of the transmembrane nitrite diffusion. Nitric Oxide 16:362-370.

Sandbakk SB, Sandbakk O, Peacock O, James P, Welde B, Stokes K, Bohlke N, and Tjonna AE (2015) Effects of acute supplementation of l-arginine and nitrate on endurance and sprint performance in elite athletes. Nitric Oxide 48:10-15.

Sandirasegarane L and Diamond J (1999) The nitric oxide donors, SNAP and DEA/NO, exert a negative inotropic effect in rat cardiomyocytes which is independent of cyclic GMP elevation. J Mol Cell Cardiol 31:799-808.

Santamaria P (2006) Nitrate in vegetables: toxicity, content, intake and ec regulation. J Sci Food Agric 86:10-17.

Sarkar D, Vallance P, Amirmansour C, and Harding SE (2000) Positive inotropic effects of NO donors in isolated guinea-pig and human cardiomyocytes independent of NO species and cyclic nucleotides. Cardiovasc Res 48:430-439.

Sasaki N, Sato T, Ohler A, O’Rourke B, and Marbán E (2000) Activation of mitochondrial ATP-dependent potassium channels by nitric oxide. Circulation 101:439-445.

Sasaki T, Kameoka F, Ichikawa T, and Matano K (1981) Nitrite-producing activity of the human mouth. Food Hyg Safe Sci 22:490-495.

Sasaki T and Matano K (1979) Formation of nitrite from nitrate at the dorsum linguae. Food Hyg Safe Sci 20:363-369.

Schafer AI, Alexander RW, and Handin RI (1980) Inhibition of platelet function by organic nitrate vasodilators. Blood 55:649-654.

Schaufelberger M, Eriksson BO, Grimby G, Held P, and Swedberg K (1995) Skeletal muscle fiber composition and capillarization in patients with chronic heart failure: relation to exercise capacity and central hemodynamics. J Card Fail 1:267-272.

Schmitt M, Avolio A, Qasem A, McEniery CM, Butlin M, Wilkinson IB, and Cockcroft JR (2005) Basal NO locally modulates human iliac artery function in vivo. Hypertension 46:227-231.

Schreiber F, Stief P, Gieseke A, Heisterkamp IM, Verstraete W, de Beer D, and Stoodley P (2010) Denitrification in human dental plaque. BMC Biol 8:24

Schuddeboom LJ (1993) Nitrates and Nitrites in Foodstuffs, Council of Europe Press, Brussels, Belgium

Schulz R, Schmidt D, Blum A, Lopes-Ribeiro X, Lücke C, Mayer K, Olschewski H, Seeger W, and Grimminger F (2000) Decreased plasma levels of nitric oxide derivatives in obstructive sleep apnoea: response to CPAP therapy. Thorax 55:1046-1051.

Segal SS and Duling BR (1986) Flow control among microvessels coordinated by intercellular conduction. Science 234:868-870.

Sen NP, Smith DC, and Schwinghamer L (1969) Formation of N-nitrosamines from secondary amines and nitrite in human and animal gastric juice. Food Cosmet Toxicol 7:301-307.

Shaltout HA, Eggebeen J, Marsh AP, Brubaker PH, Laurienti PJ, Burdette JH, Basu S, Morgan A, Dos Santos PC, Norris JL, et al. (2017) Effects of supervised exercise and dietary nitrate in older adults with controlled hypertension and/or heart failure with preserved ejection fraction. Nitric Oxide 69:78-90.

Shepherd AI, Gilchrist M, Winyard PG, Jones AM, Hallmann E, Kazimierczak R, Rembialkowska E, Benjamin N, Shore AC, and Wilkerson DP (2015a) Effects of dietary nitrate supplementation on the oxygen cost of exercise and walking performance in individuals with type 2 diabetes: a randomized, double-blind, placebocontrolled crossover trial. Free Radic Biol Med 86:200-208.

Shepherd AI, Wilkerson DP, Dobson L, Kelly J, Winyard PG, Jones AM, Benjamin N, Shore AC, and Gilchrist M (2015b) The effect of dietary nitrate supplementation on the oxygen cost of cycling, walking performance and resting blood pressure in individuals with chronic obstructive pulmonary disease: a double blind placebo controlled, randomised control trial. Nitric Oxide 48:31-37.

Shepherd AI, Wilkerson DP, Fulford J, Winyard PG, Benjamin N, Shore AC, and Gilchrist M (2016) Effect of nitrate supplementation on hepatic blood flow and glucose homeostasis: a double-blind, placebo-controlled, randomized control trial. Am J Physiol Gastrointest Liver Physiol 311:G356-G364.

Shingles R, Roh MH, and McCarty RE (1997) Direct measurement of nitrite transport across erythrocyte membrane vesicles using the fluorescent probe, 6-methoxyN-(3-sulfopropyl) quinolinium. J Bioenerg Biomembr 29:611-616.

Shiva S, Huang Z, Grubina R, Sun J, Ringwood LA, MacArthur PH, Xu X, Murphy E, Darley-Usmar VM, and Gladwin MT (2007a) Deoxymyoglobin is a nitrite reductase that generates nitric oxide and regulates mitochondrial respiration. Circ Res 100 $654-661$.

Shiva S, Sack MN, Greer JJ, Duranski M, Ringwood LA, Burwell L, Wang X, MacArthur $\mathrm{PH}$, Shoja A, Raghavachari N, et al. (2007b) Nitrite augments tolerance to ischemia/ reperfusion injury via the modulation of mitochondrial electron transfer. $J$ Exp Med 204:2089-2102.

Shiva S, Wang X, Ringwood LA, Xu X, Yuditskaya S, Annavajjhala V, Miyajima H, Hogg N, Harris ZL, and Gladwin MT (2006) Ceruloplasmin is a NO oxidase and nitrite synthase that determines endocrine NO homeostasis. Nat Chem Biol 2 : 486-493.

Sibmooh N, Piknova B, Rizzatti F, and Schechter AN (2008) Oxidation of ironnitrosyl-hemoglobin by dehydroascorbic acid releases nitric oxide to form nitrite in human erythrocytes. Biochemistry 47:2989-2996.

Siddiqi N, Neil C, Bruce M, MacLennan G, Cotton S, Papadopoulou S, Feelisch M, Bunce N, Lim PO, Hildick-Smith D, et al.; NIAMI investigators (2014) Intravenous sodium nitrite in acute ST-elevation myocardial infarction: a randomized controlled trial (NIAMI). Eur Heart $J$ 35:1255-1262.

Simon MA, Vanderpool RR, Nouraie M, Bachman TN, White PM, Sugahara M, Gorcsan J III, Parsley EL, and Gladwin MT (2016) Acute hemodynamic effects of inhaled sodium nitrite in pulmonary hypertension associated with heart failure with preserved ejection fraction. JCI Insight 1:e89620.

Sindler AL, Cox-York K, Reese L, Bryan NS, Seals DR, and Gentile CL (2015) Oral nitrite therapy improves vascular function in diabetic mice. Diab Vasc Dis Res 12:221-224.

Sindler AL, Fleenor BS, Calvert JW, Marshall KD, Zigler ML, Lefer DJ, and Seals DR (2011) Nitrite supplementation reverses vascular endothelial dysfunction and large elastic artery stiffness with aging. Aging Cell 10:429-437.

Singamsetty S, Watanabe Y, Guo L, Corey C, Wang Y, Tejero J, McVerry BJ, Gladwin MT, Shiva S, and O'Donnell CP (2015) Inorganic nitrite improves components of the metabolic syndrome independent of weight change in a murine model of obesity and insulin resistance. J Physiol 593:3135-3145.

Skold A, Cosco DL, and Klein R (2011) Methemoglobinemia: pathogenesis, diagnosis, and management. South Med J 104:757-761.

Sobko T, Marcus C, Govoni M, and Kamiya S (2010) Dietary nitrate in Japanese traditional foods lowers diastolic blood pressure in healthy volunteers. Nitric Oxide 22:136-140.

Soin A, Bock G, Giordano A, Patel C, and Drachman D (2018) A randomized, doubleblind study of the effects of a sustained release formulation of sodium nitrite (srnitrite) on patients with diabetic neuropathy. Pain Physician 21:179-190.

Somers VK, White DP, Amin R, Abraham WT, Costa F, Culebras A, Daniels S, Floras JS, Hunt CE, Olson LJ, et al. (2008) Sleep apnea and cardiovascular disease: an american heart association/american college of cardiology foundation scientific statement from the american heart association council for high blood pressure research professional education committee, council on clinical cardiology, stroke council, and council on cardiovascular nursing. J Am Coll Cardiol 52:686-717.

Sonoda K, Ohtake K, Tagiri M, Hirata M, Tamada H, Uchida H, Ito J, and Kobayashi $\mathrm{J}$ (2018) Dietary nitrite attenuates elastase-induced pulmonary emphysema in a mouse model. Biol Pharm Bull 41:1818-1823

Sonoda K, Ohtake K, Uchida H, Ito J, Uchida M, Natsume H, Tamada H, and Kobayashi J (2017) Dietary nitrite supplementation attenuates cardiac remodeling in 1-NAME-induced hypertensive rats. Nitric Oxide 67:1-9.

Sorrentino MJ (2005) Implications of the metabolic syndrome: the new epidemic. Am $J$ Cardiol 96:3E-7E

Sparacino-Watkins CE, Tejero J, Sun B, Gauthier MC, Thomas J, Ragireddy V, Merchant BA, Wang J, Azarov I, Basu P, et al. (2014) Nitrite reductase and nitricoxide synthase activity of the mitochondrial molybdopterin enzymes mARC1 and mARC2. J Biol Chem 289:10345-10358.

Speijers GJA and van den Brandt PA (2003) Nitrate (and Potential Endogenous Formation of N-nitroso Compounds), World Health Organisation, Geneva, Switzerland

Spicer CW (1977) Photochemical atmospheric pollutants derived from nitrogen oxides. Atmos Environ 11:1089-1095.

Spiegelhalder B, Eisenbrand G, and Preussmann R (1976) Influence of dietary nitrate on nitrite content of human saliva: possible relevance to in vivo formation of N-nitroso compounds. Food Cosmet Toxicol 14:545-548.

Spiekermann S, Landmesser U, Dikalov S, Bredt M, Gamez G, Tatge H, Reepschläger N, Hornig B, Drexler H, and Harrison DG (2003) Electron spin resonance characterization of vascular xanthine and $\mathrm{NAD}(\mathrm{P}) \mathrm{H}$ oxidase activity in patients with coronary artery disease: relation to endothelium-dependent vasodilation. Circulation 107:1383-1389.

Squadrito F, Altavilla D, Squadrito G, Saitta A, Campo GM, Arlotta M, Quartarone C, Ferlito M, and Caputi AP (1999) Cyclosporin-A reduces leukocyte accumulation and protects against myocardial ischaemia reperfusion injury in rats. Eur $J$ Pharmacol 364:159-168.

Srihirun S, Sriwantana T, Unchern S, Kittikool D, Noulsri E, Pattanapanyasat K, Fucharoen S, Piknova B, Schechter AN, and Sibmooh N (2012) Platelet inhibition by nitrite is dependent on erythrocytes and deoxygenation. PLoS One 7:e30380.

Stagliano NE, Zhao W, Prado R, Dewanjee MK, Ginsberg MD, and Dietrich WD (1997) The effect of nitric oxide synthase inhibition on acute platelet accumulation and hemodynamic depression in a rat model of thromboembolic stroke. J Cereb Blood Flow Metab 17:1182-1190.

Stamler JS, Jaraki O, Osborne J, Simon DI, Keaney J, Vita J, Singel D, Valeri CR and Loscalzo J (1992) Nitric oxide circulates in mammalian plasma primarily as an S-nitroso adduct of serum albumin. Proc Natl Acad Sci USA 89:7674-7677.

Stamler JS, Jia L, Eu JP, McMahon TJ, Demchenko IT, Bonaventura J, Gernert K, and Piantadosi CA (1997) Blood flow regulation by S-nitrosohemoglobin in the physiological oxygen gradient. Science 276:2034-2037.

Stamler JS and Meissner G (2001) Physiology of nitric oxide in skeletal muscle. Physiol Rev 81:209-237.

Stefanadis C, Antoniou CK, Tsiachris D, and Pietri P (2017) Coronary atherosclerotic vulnerable plaque: current perspectives. J Am Heart Assoc 6:e005543.

Stein LY and Klotz MG (2016) The nitrogen cycle. Curr Biol 26:R94-R98.

Stichtenoth DO, Gutzki FM, Tsikas D, Selve N, Bode-Böger SM, Böger RH, and Frölich JC (1994) Increased urinary nitrate excretion in rats with adjuvant arthritis. Ann Rheum Dis 53:547-549.

Stieglitz EJ (1927) Bismuth subnitrate in the therapy of hypertension. J Pharmacol Exp Ther 32:23-35.

Stieglitz EJ (1928) The pharmacodynamics and value of bismuth subnitrate in hypertension. J Pharmacol Exp Ther 34:407-423.

Stieglitz EJ (1930) Bismith subnitrate in the treatment of arterial hypertension. JAMA 95:842-846.

Stieglitz EJ (1932) Therapeutic results with bismuth subnitrate in hypertensive arterial disease. J Pharmacol Exp Ther 46:343-356.

Stieglitz EJ and Palmer AE (1934) A colorimetric method for the determination of nitrite in blood. J Pharmacol Exp Ther 51:398-410. 
Stieglitz EJ and Palmer AE (1936) Studies on the pharmacology of the nitrite efect of bismuth subnitrate. $J$ Pharmacol Exp Ther 56:216-222.

Stieglitz EJ and Palmer AE (1937) The blood nitrite. Arch Intern Med (Chic) 59:620-630

Stokes KY, Dugas TR, Tang Y, Garg H, Guidry E, and Bryan NS (2009) Dietary nitrite prevents hypercholesterolemic microvascular inflammation and reverses endothelial dysfunction. Am J Physiol Heart Circ Physiol 296:H1281-H1288.

Stuehr DJ (1999) Mammalian nitric oxide synthases. Biochim Biophys Acta 1411:217-230.

Sugamura K and Keaney JF Jr (2011) Reactive oxygen species in cardiovascular disease. Free Radic Biol Med 51:978-992.

Sugimoto R, Okamoto T, Nakao A, Zhan J, Wang Y, Kohmoto J, Tokita D, Farver CF, Tarpey MM, Billiar TR, et al. (2012) Nitrite reduces acute lung injury and improves survival in a rat lung transplantation model. Am J Transplant 12:2938-2948.

Suhr F, Gehlert S, Grau M, and Bloch W (2013) Skeletal muscle function during exercisefine-tuning of diverse subsystems by nitric oxide. Int $J$ Mol Sci 14:7109-7139.

Sun J, Picht E, Ginsburg KS, Bers DM, Steenbergen C, and Murphy E (2006) Hypercontractile female hearts exhibit increased S-nitrosylation of the L-type Ca2+ channel alpha1 subunit and reduced ischemia/reperfusion injury. Circ Res 98:403-411.

Sun L, Xie C, Wang G, Wu Y, Wu Q, Wang X, Liu J, Deng Y, Xia J, Chen B, et al. (2018) Gut microbiota and intestinal FXR mediate the clinical benefits of metformin. Nat Med 24:1919-1929.

Sun Y, Jin K, Peel A, Mao XO, Xie L, and Greenberg DA (2003) Neuroglobin protects the brain from experimental stroke in vivo. Proc Natl Acad Sci USA 100:3497-3500.

Sundqvist ML, Lundberg JO, and Weitzberg E (2016) Effects of antiseptic mouthwash on resting metabolic rate: a randomized, double-blind, crossover study. Nitric Oxide 61:38-44.

Takuma K, Phuagphong P, Lee E, Mori K, Baba A, and Matsuda T (2001) Anti-apoptotic effect of cGMP in cultured astrocytes: inhibition by cGMP-dependent protein kinase of mitochondrial permeable transition pore. J Biol Chem 276:48093-48099.

Tanaka Y, Poole DC, and Kano Y (2016) Ph homeostasis in contracting and recovering skeletal muscle: integrated function of the microcirculation with the interstitium and intramyocyte milieu. Curr Top Med Chem 16:2656-2663.

Tannenbaum SR and Correa P (1985) Nitrate and gastric cancer risks. Nature 317: $675-676$.

Tannenbaum SR, Sinskey AJ, Weisman M, and Bishop W (1974) Nitrite in human saliva. Its possible relationship to nitrosamine formation. J Natl Cancer Inst 53:79-84.

Tannenbaum SR, Weisman M, and Fett D (1976) The effect of nitrate intake on nitrite formation in human saliva. Food Cosmet Toxicol 14:549-552.

Tawa M, Yano Y, Yamanaka M, Sawano T, Iesaki K, Murata Y, Tanaka R, Nakagawa K, Ohkita M, and Matsumura Y (2019) Effects of beet juice supplementation on monocrotaline-induced pulmonary hypertension in rats. Am J Hypertens 32:216-222.

Taylor AL, Ziesche S, Yancy C, Carson P, D'Agostino R Jr, Ferdinand K, Taylor M, Adams K, Sabolinski M, Worcel M, et al. African-American Heart Failure Trial Investigators (2004) Combination of isosorbide dinitrate and hydralazine in blacks with heart failure. $N$ Engl J Med 351:2049-2057.

Tejero J, Sparacino-Watkins CE, Ragireddy V, Frizzell S, and Gladwin MT (2015) Exploring the mechanisms of the reductase activity of neuroglobin by site-directed mutagenesis of the heme distal pocket. Biochemistry 54:722-733.

Theilmeier G, Chan JR, Zalpour C, Anderson B, Wang BY, Wolf A, Tsao PS, and Cooke JP (1997) Adhesiveness of mononuclear cells in hypercholesterolemic humans is normalized by dietary L-arginine. Arterioscler Thromb Vasc Biol 17:3557-3564.

Thomas DD, Liu X, Kantrow SP, and Lancaster JR Jr (2001) The biological lifetime of nitric oxide: implications for the perivascular dynamics of $\mathrm{NO}$ and O2. Proc Natl Acad Sci USA 98:355-360.

Thompson KG, Turner L, Prichard J, Dodd F, Kennedy DO, Haskell C, Blackwell JR, and Jones AM (2014) Influence of dietary nitrate supplementation on physiological and cognitive responses to incremental cycle exercise. Respir Physiol Neurobiol 193: $11-20$

Tiso M, Tejero J, Basu S, Azarov I, Wang X, Simplaceanu V, Frizzell S, Jayaraman T, Geary L, Shapiro C, et al. (2011) Human neuroglobin functions as a redoxregulated nitrite reductase. J Biol Chem 286:18277-18289.

Totzeck M, Hendgen-Cotta UB, Luedike P, Berenbrink M, Klare JP, Steinhoff H-J, Semmler D, Shiva S, Williams D, Kipar A, et al. (2012) Nitrite regulates hypoxic vasodilation via myoglobin-dependent nitric oxide generation. Circulation 126 325-334.

Trevisi P, Casini L, Nisi I, Messori S, and Bosi P (2011) Effect of high oral doses of nitrate on salivary recirculation of nitrates and nitrites and on bacterial diversity in the saliva of young pigs. J Anim Physiol Anim Nutr (Berl) 95:206-213.

Tribble GD, Angelov N, Weltman R, Wang B-Y, Eswaran SV, Gay IC, Parthasarathy K, Dao DV, Richardson KN, Ismail NM, et al. (2019) Frequency of tongue cleaning impacts the human tongue microbiome composition and enterosalivary circulation of nitrate. Front Cell Infect Microbiol 9:39.

Tricker AR (1997) N-nitroso compounds and man: sources of exposure, endogenous formation and occurrence in body fluids. Eur J Cancer Prev 6:226-268.

Tripatara P, Patel NS, Webb A, Rathod K, Lecomte FM, Mazzon E, Cuzzocrea S, Yaqoob MM, Ahluwalia A, and Thiemermann C (2007) Nitrite-derived nitric oxide protects the rat kidney against ischemia/reperfusion injury in vivo: role for xanthine oxidoreductase. J Am Soc Nephrol 18:570-580.

Tschöpe C, Bock C-T, Kasner M, Noutsias M, Westermann D, Schwimmbeck P-L, Pauschinger M, Poller W-C, Kühl U, Kandolf R, et al. (2005) High prevalence of cardiac parvovirus B19 infection in patients with isolated left ventricular diastolic dysfunction. Circulation 111:879-886.

Tsuchiya K, Kanematsu Y, Yoshizumi M, Ohnishi H, Kirima K, Izawa Y, Shikishima M, Ishida T, Kondo S, Kagami S, et al. (2005) Nitrite is an alternative source of NO in vivo. Am J Physiol Heart Circ Physiol 288:H2163-H2170.

U.S. Public Health Service (1962) Public Health Service Drinking Water Standards, United States Government Printing Office, Washington D.C.

Vanderkooi JM, Wright WW, and Erecinska M (1994) Nitric oxide diffusion coefficients in solutions, proteins and membranes determined by phosphorescence. Biochim Biophys Acta 1207:249-254. van Faassen EE, Bahrami S, Feelisch M, Hogg N, Kelm M, Kim-Shapiro DB, Kozlov AV, Li H, Lundberg JO, Mason R, et al. (2009) Nitrite as regulator of hypoxic signaling in mammalian physiology. Med Res Rev 29:683-741.

Vanhatalo A, Bailey SJ, Blackwell JR, DiMenna FJ, Pavey TG, Wilkerson DP, Benjamin N, Winyard PG, and Jones AM (2010) Acute and chronic effects of dietary nitrate supplementation on blood pressure and the physiological responses to moderate-intensity and incremental exercise. Am J Physiol Regul Integr Comp Physiol 299:R1121-R1131.

Vanhatalo A, Blackwell JR, L'Heureux JE, Williams DW, Smith A, van der Giezen M, Winyard PG, Kelly J, and Jones AM (2018) Nitrate-responsive oral microbiome modulates nitric oxide homeostasis and blood pressure in humans. Free Radic Biol Med 124:21-30.

van Heerebeek L, Hamdani N, Falcão-Pires I, Leite-Moreira AF, Begieneman MPV, Bronzwaer JGF, van der Velden J, Stienen GJM, Laarman GJ, Somsen A, et al. (2012) Low myocardial protein kinase $\mathrm{G}$ activity in heart failure with preserved ejection fraction. Circulation 126:830-839.

Vanin AF, Bevers LM, Slama-Schwok A, and van Faassen EE (2007) Nitric oxide synthase reduces nitrite to NO under anoxia. Cell Mol Life Sci 64:96-103.

van Velzen AG, Sips AJ, Schothorst RC, Lambers AC, and Meulenbelt J (2008) The oral bioavailability of nitrate from nitrate-rich vegetables in humans. Toxicol Lett 181:177-181.

Vaughn MW, Huang KT, Kuo L, and Liao JC (2000) Erythrocytes possess an intrinsic barrier to nitric oxide consumption. J Biol Chem 275:2342-2348.

Vaughn MW, Kuo L, and Liao JC (1998) Estimation of nitric oxide production and reaction rates in tissue by use of a mathematical model. Am J Physiol 274: H2163-H2176.

Velmurugan S, Gan JM, Rathod KS, Khambata RS, Ghosh SM, Hartley A, Van Eijl S, Sagi-Kiss V, Chowdhury TA, Curtis M, et al. (2016) Dietary nitrate improves vascular function in patients with hypercholesterolemia: a randomized, doubleblind, placebo-controlled study. Am J Clin Nutr 103:25-38.

Velmurugan S, Kapil V, Ghosh SM, Davies S, McKnight A, Aboud Z, Khambata RS, Webb AJ, Poole A, and Ahluwalia A (2013) Antiplatelet effects of dietary nitrate in healthy volunteers: involvement of cGMP and influence of sex. Free Radic Biol Med 65:1521-1532.

Viner RI, Williams TD, and Schöneich C (2000) Nitric oxide-dependent modification of the sarcoplasmic reticulum Ca-ATPase: localization of cysteine target sites. Free Radic Biol Med 29:489-496.

Vinten-Johansen J (2004) Involvement of neutrophils in the pathogenesis of lethal myocardial reperfusion injury. Cardiovasc Res 61:481-497.

Vitturi DA, Teng X, Toledo JC, Matalon S, Lancaster JR Jr, and Patel RP (2009) Regulation of nitrite transport in red blood cells by hemoglobin oxygen fractional saturation. Am J Physiol Heart Circ Physiol 296:H1398-H1407.

Vlachopoulos C, Aznaouridis K, O'Rourke MF, Safar ME, Baou K, and Stefanadis C (2010a) Prediction of cardiovascular events and all-cause mortality with central haemodynamics: a systematic review and meta-analysis. Eur Heart $J$ 31:1865-1871.

Vlachopoulos C, Aznaouridis K, and Stefanadis C (2010b) Prediction of cardiovascular events and all-cause mortality with arterial stiffness: a systematic review and meta-analysis. J Am Coll Cardiol 55:1318-1327.

Vleeming W, van de Kuil A, te Biesebeek JD, Meulenbelt J, and Boink AB (1997) Effect of nitrite on blood pressure in anaesthetized and free-moving rats. Food Chem Toxicol 35:615-619.

Vogtmann H and Biedermann R (1985) The nitrate story--no end in sight. Nutr Health 3:217-239.

Vorchheimer DA and Becker R (2006) Platelets in atherothrombosis. Mayo Clin Proc 81:59-68.

Vrijens B, Antoniou S, Burnier M, de la Sierra A, and Volpe M (2017) Current situation of medication adherence in hypertension. Front Pharmacol 8:100.

Wachelder EM, Moulaert VR, van Heugten C, Verbunt JA, Bekkers SC, and Wade DT (2009) Life after survival: long-term daily functioning and quality of life after an out-of-hospital cardiac arrest. Resuscitation 80:517-522.

Wagner DA, Schultz DS, Deen WM, Young VR, and Tannenbaum SR (1983) Metabolic fate of an oral dose of $15^{\mathrm{N}}$-labeled nitrate in humans: effect of diet supplementation with ascorbic acid. Cancer Res 43:1921-1925.

Wagner DA, Young VR, Tannenbaum SR, Schultz DS, and Deen WM (1984) Mammalian nitrate biochemistry: metabolism and endogenous synthesis. IARC Sci Publ:247-253.

Wallace GB and Ringer AI (1909) The lowering of blood-pressure by the nitrite group. JAMA LIII:1629-1630.

Walton G (1951) Survey of literature relating to infant methemoglobinemia due to nitrate-contaminated water. Am J Public Health Nations Health 41:986-996.

Wang G-R, Zhu Y, Halushka PV, Lincoln TM, and Mendelsohn ME (1998) Mechanism of platelet inhibition by nitric oxide: in vivo phosphorylation of thromboxane receptor by cyclic GMP-dependent protein kinase. Proc Natl Acad Sci USA 95:4888-4893.

Wang J, Fischer K, Zhao X, Tejero J, Kelley EE, Wang L, Shiva S, Frizzell S, Zhang Y, Basu P, et al. (2010) Novel function of sulfite oxidase as a nitrite reductase that generates nitric oxide. Free Radic Biol Med 49 (Suppl):S122.

Wang J, Krizowski S, Fischer-Schrader K, Niks D, Tejero J, Sparacino-Watkins C, Wang L, Ragireddy V, Frizzell S, Kelley EE, et al. (2015) Sulfite oxidase catalyzes single-electron transfer at molybdenum domain to reduce nitrite to nitric oxide. Antioxid Redox Signal 23:283-294.

Ward FW, Coates ME, and Walker R (1985) Nitrate reduction in germfree rats. Prog Clin Biol Res 181:123-125.

Ward FW, Coates ME, and Walker R (1986) Nitrate reduction, gastro-intestinal $\mathrm{pH}$ and N-nitrosation in gnotobiotic and conventional rats. Food Chem Toxicol 24:17-22.

Ward JK, Belvisi MG, Fox AJ, Miura M, Tadjkarimi S, Yacoub MH, and Barnes PJ (1993) Modulation of cholinergic neural bronchoconstriction by endogenous nitric oxide and vasoactive intestinal peptide in human airways in vitro. J Clin Invest 92:736-742.

Ward MH, deKok TM, Levallois P, Brender J, Gulis G, Nolan BT, and VanDerslice J; International Society for Environmental Epidemiology (2005) Workgroup report: drinking-water nitrate and health--recent findings and research needs. Environ Health Perspect 113:1607-1614. 
Waxman A, Chen SY, Boulanger L, Watson JA, and Golden G (2013) Factors associated with adherence to phosphodiesterase type 5 inhibitors for the treatment of pulmonary arterial hypertension. $J$ Med Econ 16:298-306.

Webb A, Bond R, McLean P, Uppal R, Benjamin N, and Ahluwalia A (2004) Reduction of nitrite to nitric oxide during ischemia protects against myocardial ischemia-reperfusion damage. Proc Natl Acad Sci USA 101:13683-13688.

Webb AJ and Ahluwalia A (2010) Mechanisms of nitrite reduction in ischemia in the cardiovascular system, in Nitric Oxide: Biology and Pathobiology (Ignarro L ed) pp 555-586, Elsevier, Los Angeles, CA.

Webb AJ, Milsom AB, Rathod KS, Chu WL, Qureshi S, Lovell MJ, Lecomte FM, Perrett D, Raimondo C, Khoshbin E, et al. (2008a) Mechanisms underlying erythrocyte and endothelial nitrite reduction to nitric oxide in hypoxia: role for xanthine oxidoreductase and endothelial nitric oxide synthase. Circ Res 103:957-964.

Webb AJ, Patel N, Loukogeorgakis S, Okorie M, Aboud Z, Misra S, Rashid R, Miall P, Deanfield J, Benjamin N, et al. (2008b) Acute blood pressure lowering, vasoprotective, and antiplatelet properties of dietary nitrate via bioconversion to nitrite. Hypertension 51:784-790.

Weiss S, Wilkins RW, and Haynes FW (1937) The nature of circulatory collapse induced by sodium nitrite. J Clin Invest 16:73-84.

Wennmalm A, Benthin G, Edlund A, Jungersten L, Kieler-Jensen N, Lundin S, Westfelt UN, Petersson AS, and Waagstein F (1993) Metabolism and excretion of nitric oxide in humans. An experimental and clinical study. Circ Res 73:1121-1127.

White CW and Martin JG (2010) Chlorine gas inhalation: human clinical evidence of toxicity and experience in animal models. Proc Am Thorac Soc 7:257-263.

Wightman EL, Haskell-Ramsay CF, Thompson KG, Blackwell JR, Winyard PG, Forster J, Jones AM, and Kennedy DO (2015) Dietary nitrate modulates cerebral blood flow parameters and cognitive performance in humans: a double-blind, placebo-controlled, crossover investigation. Physiol Behav 149:149-158.

Wilkerson DP, Hayward GM, Bailey SJ, Vanhatalo A, Blackwell JR, and Jones AM (2012) Influence of acute dietary nitrate supplementation on 50 mile time trial performance in well-trained cyclists. Eur J Appl Physiol 112:4127-4134.

Wilkins RW, Haynes FW, and Weiss S (1937) The role of the venous system in circulatory collapse induced by sodium nitrite. J Clin Invest 16:85-91.

Wilkinson IB, Qasem A, McEniery CM, Webb DJ, Avolio AP, and Cockcroft JR (2002) Nitric oxide regulates local arterial distensibility in vivo. Circulation 105:213-217.

Wilson DF (1994) Factors affecting the rate and energetics of mitochondrial oxidative phosphorylation. Med Sci Sports Exerc 26:37-43.

Wilson JM, Loenneke JP, Jo E, Wilson GJ, Zourdos MC, and Kim JS (2012) The effects of endurance, strength, and power training on muscle fiber type shifting. $J$ Strength Cond Res 26:1724-1729.

Wink DA (2003) Ion implicated in blood pact. Nat Med 9:1460-1461.

Wink DA, Kasprzak KS, Maragos CM, Elespuru RK, Misra M, Dunams TM, Cebula TA, Koch WH, Andrews AW, Allen JS, et al. (1991) DNA deaminating ability and genotoxicity of nitric oxide and its progenitors. Science 254:1001-1003.

Witter JP, Balish E, and Gatley SJ (1979) Distribution of nitrogen-13 from labeled nitrate and nitrite in germfree and conventional-flora rats. Appl Environ Microbiol 38:870-878.

Woessner M, Smoliga JM, Tarzia B, Stabler T, Van Bruggen M, and Allen JD (2016) A stepwise reduction in plasma and salivary nitrite with increasing strengths of mouthwash following a dietary nitrate load. Nitric Oxide 54:1-7.

Woessner M, VanBruggen MD, Pieper CF, Sloane R, Kraus WE, Gow AJ, and Allen JD (2018) Beet the best? Circ Res 123:654-659.

Wolf A, Zalpour C, Theilmeier G, Wang BY, Ma A, Anderson B, Tsao PS, and Cooke JP (1997) Dietary L-arginine supplementation normalizes platelet aggregation in hypercholesterolemic humans. J Am Coll Cardiol 29:479-485.

Wolhuter K, Whitwell HJ, Switzer CH, Burgoyne JR, Timms JF, and Eaton P (2018) Evidence against stable protein s-nitrosylation as a widespread mechanism of posttranslational regulation. Mol Cell 69:438-450.e5.

World Cancer Research Fund/American Institute for Cancer Research (2007) Food, Nutrition, Physical Activity, and the Prevention of Cancer: a Global Perspective, American Institute for Cancer Research (AICR), Washington, DC.

World Health Organization (2011) Nitrate and Nitrite in Drinking-water: Background document for development of WHO Guidelines for Drinking-water Quality, World Health Organization Press, Geneva, Switzerland.

Wylie LJ, Kelly J, Bailey SJ, Blackwell JR, Skiba PF, Winyard PG, Jeukendrup AE Vanhatalo A, and Jones AM (2013) Beetroot juice and exercise: pharmacodynamic and dose-response relationships. J Appl Physiol (1985) 115:325-336.

Wylie LJ, Ortiz de Zevallos J, Isidore T, Nyman L, Vanhatalo A, Bailey SJ, and Jones AM (2016) Dose-dependent effects of dietary nitrate on the oxygen cost of moderate-intensity exercise: acute vs. chronic supplementation. Nitric Oxide 57:30-39.
Yadav AK, Doran SF, Samal AA, Sharma R, Vedagiri K, Postlethwait EM, Squadrito GL, Fanucchi MV, Roberts LJ II, Patel RP, et al. (2011) Mitigation of chlorine gas lung injury in rats by postexposure administration of sodium nitrite. Am J Physiol Lung Cell Mol Physiol 300:L362-L369.

Yaggi HK, Concato J, Kernan WN, Lichtman JH, Brass LM, and Mohsenin V (2005) Obstructive sleep apnea as a risk factor for stroke and death. $N$ Engl J Med 353: 2034-2041.

Yerebakan C, Ugurlucan M, Bayraktar S, Bethea BT, and Conte JV (2009) Effects of inhaled nitric oxide following lung transplantation. J Card Surg 24:269-274.

Yingchoncharoen T, Rakyhao T, Chuncharunee S, Sritara P, Pienvichit P, Paiboonsukwong K, Sathavorasmith P, Sirirat K, Sriwantana T, Srihirun S, et al (2018) Inhaled nebulized sodium nitrite decreases pulmonary artery pressure in $\beta$-thalassemia patients with pulmonary hypertension. Nitric Oxide 76:174-178.

Ysebaert DK, De Greef KE, Vercauteren SR, Ghielli M, Verpooten GA, Eyskens EJ, and De Broe ME (2000) Identification and kinetics of leukocytes after severe ischaemia/reperfusion renal injury. Nephrol Dial Transplant 15:1562-1574.

Zafeiridis A, Triantafyllou A, Papadopoulos S, Koletsos N, Touplikioti P, Zafeiridis AS, Gkaliagkousi E, Dipla K, and Douma S (2019) Dietary nitrate improves muscle microvascular reactivity and lowers blood pressure at rest and during isometric exercise in untreated hypertensives. Microcirculation 26:e12525.

Zamani P, Rawat D, Shiva-Kumar P, Geraci S, Bhuva R, Konda P, Doulias PT, Ischiropoulos H, Townsend RR, Margulies KB, et al. (2015) Effect of inorganic nitrate on exercise capacity in heart failure with preserved ejection fraction. Circulation 131:371-380, discussion 380 .

Zamorano JL, Lancellotti P, Rodriguez Muñoz D, Aboyans V, Asteggiano R, Galderisi M, Habib G, Lenihan DJ, Lip GYH, Lyon AR, et al.; ESC Scientific Document Group (2016) 2016 ESC Position Paper on cancer treatments and cardiovascular toxicity developed under the auspices of the ESC Committee for Practice Guidelines: the task force for cancer treatments and cardiovascular toxicity of the European Society of Cardiology (ESC) [published correction appears in Eur Heart $J$ (2018) 39:839]. Eur Heart $J$ 37:2768-2801.

Zand J, Lanza F, Garg HK, and Bryan NS (2011) All-natural nitrite and nitratecontaining dietary supplement promotes nitric oxide production and reduces triglycerides in humans. Nutr Res 31:262-269.

Zavodnik IB, Lapshina EA, Rekawiecka K, Zavodnik LB, Bartosz G, and Bryszewska M (1999) Membrane effects of nitrite-induced oxidation of human red blood cells. Biochim Biophys Acta 1421:306-316.

Zhang Y, Janssens SP, Wingler K, Schmidt HH, and Moens AL (2011) Modulating endothelial nitric oxide synthase: a new cardiovascular therapeutic strategy. Am $J$ Physiol Heart Circ Physiol 301:H634-H646.

Zhang Z, Naughton D, Winyard PG, Benjamin N, Blake DR, and Symons MC (1998) Generation of nitric oxide by a nitrite reductase activity of xanthine oxidase: a potential pathway for nitric oxide formation in the absence of nitric oxide synthase activity. Biochem Biophys Res Commun 249:767-772.

Zhao H, Xu X, Ujiie K, Star RA, and Muallem S (1994) Transport and interaction of nitrogen oxides and $\mathrm{NO}_{2}$ with $\mathrm{CO}_{2}-\mathrm{HCO}_{3}^{-}$transporters in pancreatic acini. Am J Physiol 267:C385-C393.

Zheng X, Jin C, Liu Y, Zhang J, Zhu Y, Kan S, Wu Y, Ruan C, Lin L, Yang X, et al. (2015) Arterial stiffness as a predictor of clinical hypertension. J Clin Hypertens (Greenwich) 17:582-591.

Zhu G, Groneberg D, Sikka G, Hori D, Ranek MJ, Nakamura T, Takimoto E, Paolocci N, Berkowitz DE, Friebe A, et al. (2015) Soluble guanylate cyclase is required for systemic vasodilation but not positive inotropy induced by nitroxyl in the mouse. Hypertension 65:385-392.

Zhu S-G, Kukreja RC, Das A, Chen Q, Lesnefsky EJ, and Xi L (2011) Dietary nitrate supplementation protects against doxorubicin-induced cardiomyopathy by improving mitochondrial function. J Am Coll Cardiol 57:2181-2189.

Zobell CE (1932) Factors influencing the reduction of nitrates and nitrites by bacteria in semisolid media. J Bacteriol 24:273-281.

Zuckerbraun BS, Shiva S, Ifedigbo E, Mathier MA, Mollen KP, Rao J, Bauer PM, Choi JJW, Curtis E, Choi AMK, et al. (2010) Nitrite potently inhibits hypoxic and inflammatory pulmonary arterial hypertension and smooth muscle proliferation via xanthine oxidoreductase-dependent nitric oxide generation. Circulation 121 98-109.

Zweier JL, Samouilov A, and Kuppusamy P (1999) Non-enzymatic nitric oxide synthesis in biological systems. Biochim Biophys Acta 1411:250-262.

Zweier JL, Wang P, Samouilov A, and Kuppusamy P (1995) Enzymeindependent formation of nitric oxide in biological tissues. Nat Med $\mathbf{1}$ 804-809. 